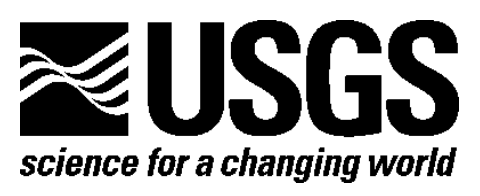

In cooperation with the U.S. Fish and Wildlife Service

\title{
Development of a Decision Support Tool for Water and Resource Management using Biotic, Abiotic, and Hydrological Assessments of Topock Marsh, Arizona
}

By Chris Holmquist-Johnson, Leanne Hanson, Joan Daniels, Colin Talbert, and Jeanette Haegele

Open-File Report 2016-1065

U.S. Department of the Interior

U.S. Geological Survey 


\section{U.S. Department of the Interior \\ SALLY JEWELL, Secretary}

\section{U.S. Geological Survey \\ Suzette M. Kimball, Director}

U.S. Geological Survey, Reston, Virginia: 2016

For more information on the USGS—-the Federal source for science about the Earth,

its natural and living resources, natural hazards, and the environment-visit

http://www.usgs.gov/ or call 1-888-ASK-USGS (1-888-275-8747).

For an overview of USGS information products, including maps, imagery, and publications, visit http://store.usgs.gov.

Any use of trade, firm, or product names is for descriptive purposes only and does not imply endorsement by the U.S. Government.

Although this information product, for the most part, is in the public domain, it also may contain copyrighted materials as noted in the text. Permission to reproduce copyrighted items must be secured from the copyright owner.

\section{Suggested citation:}

Holmquist-Johnson, Chris; Hanson, Leanne; Daniels, Joan; Talbert, Colin; and Haegele, Jeanette, 2016, Development of a decision support tool for water and resource management using biotic, abiotic, and hydrological assessments of Topock Marsh, Arizona: U.S. Geological Survey Open-File Report 2016-1065, 121 p., http://dx.doi.org/10.3133/ofr20161065. 


\section{Acknowledgments}

We would like to thank the U.S. Geological Survey (USGS) for their base support for this project, Doug Andersen, USGS, for his valuable advice throughout the project, and James Roberts, USGS, for his assistance in the editing of this document.

We would also like to thank the Bureau of Reclamation Technical Service Center (TSC) in Denver, Colorado, for their support in this project; the U.S. Fish and Wildlife Service (FWS)-Region 2, for funding the work reported herein, particularly Andrew Hautzinger for his continued support and patience; the Havasu National Wildlife Refuge (Havasu NWR) staff plus Mitch Thorson and Rob Randall, Arizona Fish and Wildlife Conservation Office (AZFWCO), and their respective staffs who helped us fulfill this task in so many ways; Janet Kirsch, Chris Pope, Chris Dodge, Barbara Raulston, and Joe Kahl, Bureau of Reclamation, Lower Colorado Region; Rick Wydoski and Eric Best, Reclamation, TSC; C. Doug Adams, Bureau of Land Management; and Gregg Cummins, Arizona Game and Fish Department, for sharing their data and knowledge; plus Joaquin Baca, FWS-Region 2, for his assistance in the editing of this document. A special thanks to volunteer Marge Penton for her invaluable assistance in the field as well as the Havasu NWR Student Conservation Association whose students provided assistance with numerous data collection efforts. Without everyone's involvement and assistance, this work could not have been performed. 


\section{Contents}

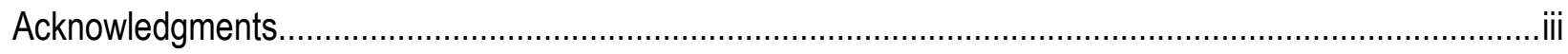

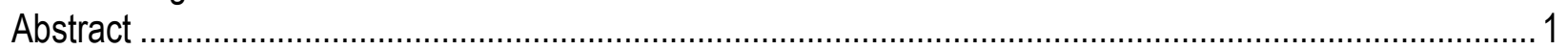

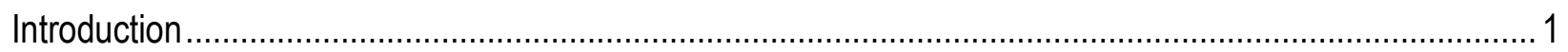

Tier 1-Water Quality and Aquatic Biota Assessment....................................................................

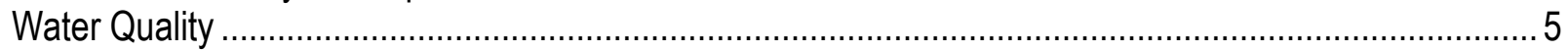

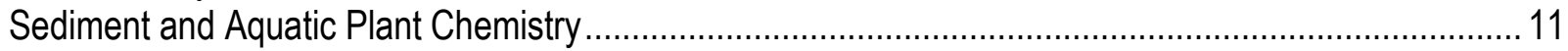

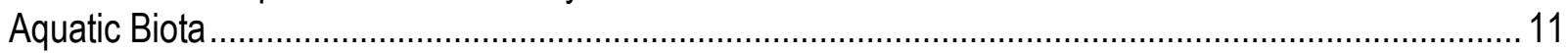

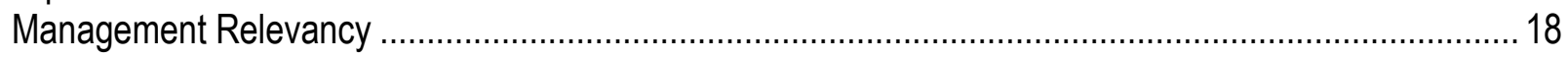

Tier 2-Emergent Vegetation Mapping and Assessment using Unmanned Aircraft and Remote Sensing

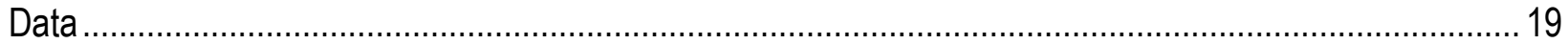

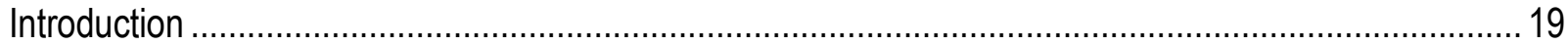

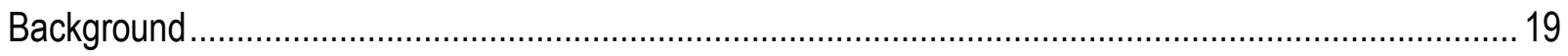

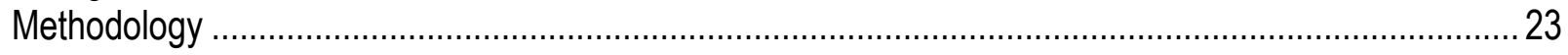

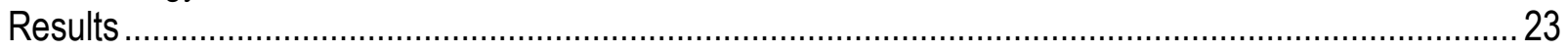

Tier 3-Hydrologic Model Development and Marsh Topography ........................................................2 25

Topock Marsh Hydrology and Management Requirements .............................................................2

Historical Inflows and Water Surface Elevations …………........................................................ 25

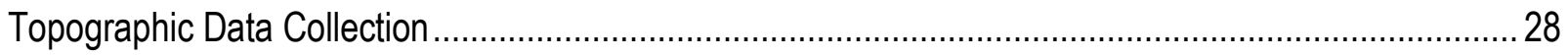

Digital Elevation Model of Topock Marsh ........................................................................................ 33

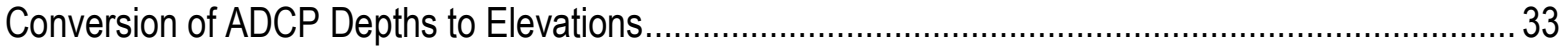

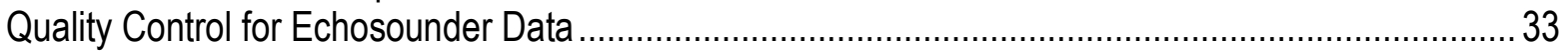

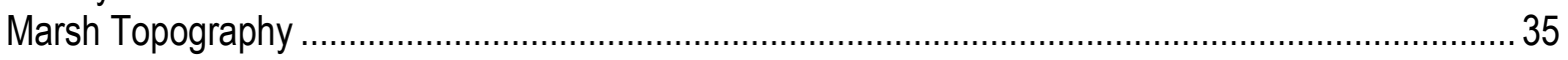

Tier 4-Development of Decision Support System for Water and Resource Management .......................... 38

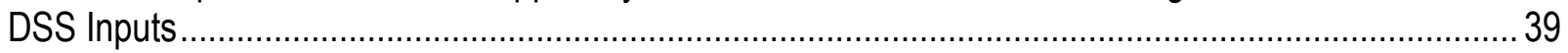

Tier 1 Water Quality and Aquatic Biota Assessment ………......................................................... 39

Marsh Hydrology and Associated Water Surface Elevation ........................................................... 41

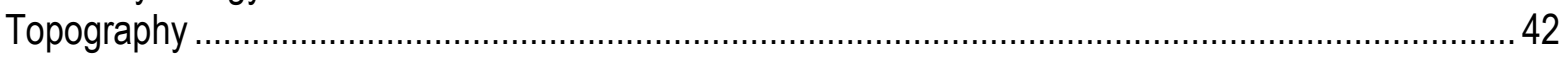

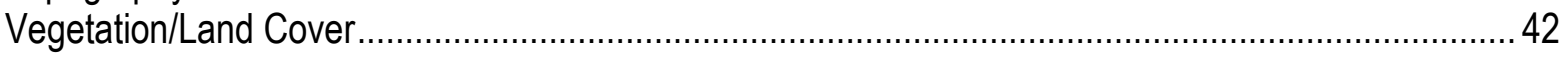

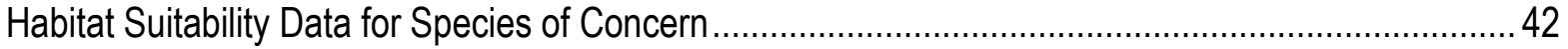

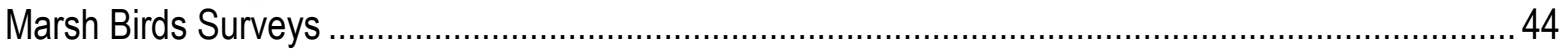

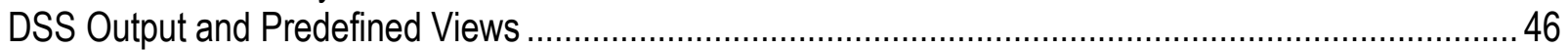

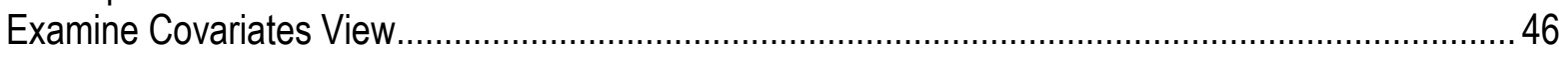

Habitat versus Water Surface Elevation (WSE) Curves .............................................................. 48

Edit Habitat Suitability .................................................................................................... 51

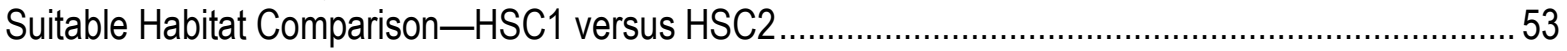

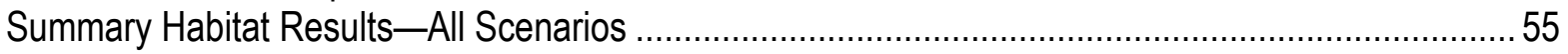

Water Storage and Inflow Requirements Comparison................................................................ 57

Example Application of DSS to Assess Habitat Effects Associated with Historical Water Management

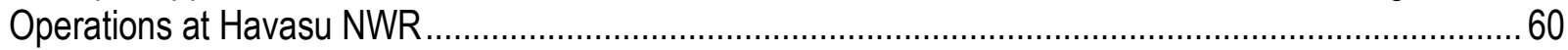

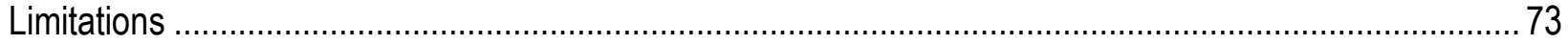

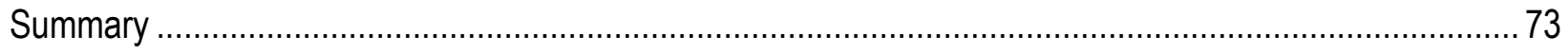


References Cited

Appendix 1. User's Manual for the Havasu NWR Decision Support System (DSS).

Appendix 2. Report by Colorado State University: Mapping Land Cover and Invasive Tamarisk in Havasu National Wildlife Refuge, AZ..

\section{Figures}

1. Location of 3 water irrigation canals (Inlet, Fire Break, and Farm Ditch) and 10 biotic and abiotic sampling stations (TP-0 through TP-9) within Topock Marsh, Arizona.

2. Topock Marsh, Arizona, inlet flows and water elevations at the South Dike from January 2009 through October 2014

3. Density and biovolume phytoplankton data from sampling stations in Topock Marsh, Arizona, during August and October 2011; February and March 2012; June, July, and October 2013; and February, April, and October 2014.

4. Density and biomass zooplankton data from sampling stations in Topock Marsh, Arizona, during August and October 2011; February and March 2012; June, July, and October 2013; and February, April, and October 2014.

5. Scatterplot of coverage values for the submerged aquatic vegetation in Topock Marsh, Arizona, during October 2011, 2013, and 2014 in relation to water depth and turbidity measurements for each observation point

6. Northern part of Topock Marsh, Arizona, showing gill net locations for the Arizona Game and Fish Department, 2010-15

7. Southern part of Topock Marsh, Arizona showing gill net locations for the Arizona Game and Fish Department, 2011-15

8. Raven RQ-11A small Unmanned Aircraft System .................................................................... 20

9. Project area map showing unmanned aircraft system flight operation boundary, Needles airport, Needles, California, and Topock, Arizona..............................................................................21

10. Topock Marsh, Arizona, land cover map displayed in the decision support system .......................24

11. Topock Marsh, Arizona, inlet flows from January 2005 through December 2014 ......................... 26

12. Topock Marsh, Arizona, water surface elevations (WSE) at the South Dike from January 2005 through December 2014

13. Topock Marsh, Arizona, water surface elevations for three historical hydrologic scenarios (wet,

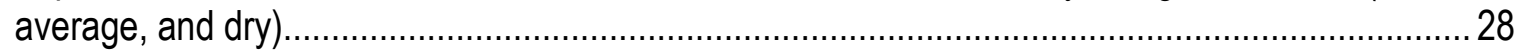

14. Global Positioning System survey control points established at Topock Marsh, Arizona, for the Havasu National Wildlife Refuge decision support system ..................................................... 29

15. Sample bathymetric data collected at Topock Marsh along various boat traces using Acoustic Doppler Current Profiler and boat-mounted real-time kinematic Global Positioning System .......... 31

16. Data sources for input to the digital elevation model describing the marsh topography at Topock Marsh.

17. Error distribution of Topock Marsh bed elevations derived from Acoustic Doppler Current Profiler data compared with those obtained by direct survey methods.....

18. Example of using breaklines to assist in proper triangulated irregular network generation from mass point data

19. Digital elevation model for Topock Marsh, Arizona, using 2014 survey data based on National Geodetic Vertical Datum 1929.

20. Havasu National Wild life Refuge decision support system framework 
21. Screenshot example of decision support system Tier 1 data tables and figures menu

22. Screenshot example of historical marsh water surface elevations for three hydrologic scenarios (wet, average, and dry).....

23. Screenshot example of hypothetical marsh water surface elevation scenarios associated with maximum available habitat for three focal species

24. Screenshot example of bird survey data from 2009 to 2014 for Yuma Ridgway's rail at Topock Marsh.

25. Screenshot example of covariates view within the decision support system showing historical comparison of marsh depth and distance to water on April 1 for the 2011_low and 2014_high marsh hydrologic scenarios

26. Screenshots of habitat versus marsh elevation for three focal species (Yuma Ridgway's rail, black rail, southwestern willow flycatcher) using the default HSC1 data and associated habitat calculated for each hydrologic scenario for Yuma Ridgway's rail HSC1 breeding/foraging

27. Screenshots of habitat versus marsh elevation for three focal species (Yuma Ridgway's rail, black rail, southwestern willow flycatcher) using hypothetical HSC2 data and associated habitat calculated for each hydrologic scenario for Yuma Ridgway's rail HSC2 breeding/foraging

28. Screenshot example of edit habitat suitability view with segment maps displaying available habitat for Yuma Ridgway's rail HSC2 breeding/foraging at water surface elevation equal to 455 feet.

29. Screenshot example of suitable habitat comparison HSC1 vs HSC2 for Yuma Ridgway's rail breeding/foraging for two hydrologic scenarios.

30. Screenshot example of summary habitat results for six species/lifestages for three historical and three hypothetical maximum habitat scenarios

31. Screenshot of historical water storage and inflow requirements for historical scenarios.................58

32. Screen shot of hypothetical maximum habitat scenario water storage and inflow requirements comparison

33. Screenshot of covariates view within the decision support system showing historical comparison of marsh depth and distance to water on June 1 for the 2011_low and 2014_high marsh hydrologic scenarios

34. Screenshot of habitat versus water surface elevation using the default HSC1 data and associated habitat calculated for 2011 and 2014 hydrologic scenario for Yuma Ridgway's rail HSC1 breeding/foraging

35. Screenshot of habitat versus water surface elevation using the hypothetical HSC2 data and associated habitat calculated for 2011 and 2014 hydrologic scenario for Yuma Ridgway's rail HSC2 breeding/foraging

36. Screenshot of example of Edit Habitat Suitability view and segment map displaying available habitat for Yuma Ridgway's rail HSC1 breeding/foraging at water surface elevation equals 454.7 feet.

37. Screenshot of example of Edit Habitat Suitability view and segment map displaying available habitat for Yuma Ridgway's rail HSC2 breeding/foraging at water surface elevation equals 454.7 feet.

38. Screenshot example of suitable habitat comparison HSC1 vs HSC2 for Yuma Ridgway's rail breeding/foraging for two hydrologic scenarios.

39. Screenshot example of summary habitat results for three focal species for three historical hydrologic scenarios 


\section{Tables}

1. Topock Marsh, Arizona, water chemistry July, September, and October 2011; February and March 2012; June, July, and October 2013; and February, April, and September/October 2014.....6

2. Summary of fish captured per net by Arizna Game and Fish Department using experimental gill nets each February from 2010 through 2015

3. Nine cover types identified in vegetation classification of Topock Marsh, Havasu National Wildlife Refuge, Arizona ...

4. Eleven species and three species groups included in the Havasu National Wildlife Refuge decision support system for Topock Marsh, Havasu National Wildlife Refuge, Arizona ....

5. Three focal species, lifestages, and habitat suitability criteria identified by project stakeholders for inclusion in the Havasu National Wildlife Refuge decision support system for Topock Marsh, Havasu National Wildlife Refuge, Arizona ....

6. Three focal species, lifestages, and hypothetical habitat suitability criteria identified by U.S. Geological Survey Fort Collins Science Center and Refuge staff for inclusion in the Havasu National Wild life Refuge decision support system for Topock Marsh, Havasu National Wildlife Refuge, Arizona. 


\section{Conversion Factors}

Inch/Pound to International System of Units

\begin{tabular}{|c|c|c|}
\hline Multiply & By & To obtain \\
\hline \multicolumn{3}{|c|}{ Length } \\
\hline inch (in.) & 2.54 & centimeter $(\mathrm{cm})$ \\
\hline foot (ft) & 0.3048 & meter $(\mathrm{m})$ \\
\hline mile (mi) & 1.609 & kilometer (km) \\
\hline mile, nautical (nmi) & 1.852 & kilometer $(\mathrm{km})$ \\
\hline \multicolumn{3}{|c|}{ Area } \\
\hline acre & 4,047 & square meter $\left(\mathrm{m}^{2}\right)$ \\
\hline square mile $\left(\mathrm{mi}^{2}\right)$ & 259.0 & hectare (ha) \\
\hline square mile $\left(\mathrm{mi}^{2}\right)$ & 2.590 & square kilometer $\left(\mathrm{km}^{2}\right)$ \\
\hline \multicolumn{3}{|c|}{ Volume } \\
\hline ounce, fluid (fl. oz) & 0.02957 & liter $(\mathrm{L})$ \\
\hline pint (pt) & 0.4732 & liter (L) \\
\hline quart (qt) & 0.9464 & liter $(\mathrm{L})$ \\
\hline gallon (gal) & 3.785 & liter (L) \\
\hline cubic foot $\left(\mathrm{ft}^{3}\right)$ & 0.02832 & cubic meter $\left(\mathrm{m}^{3}\right)$ \\
\hline acre-foot (acre-ft) & 1,233 & cubic meter $\left(\mathrm{m}^{3}\right)$ \\
\hline \multicolumn{3}{|c|}{ Flow rate } \\
\hline acre-foot per day (acre-ft/d) & 0.01427 & cubic meter per second $\left(\mathrm{m}^{3} / \mathrm{s}\right)$ \\
\hline acre-foot per year (acre-ft/yr) & 1,233 & cubic meter per year $\left(\mathrm{m}^{3} / \mathrm{yr}\right)$ \\
\hline cubic foot per second $\left(\mathrm{ft}^{3} / \mathrm{s}\right)$ & 0.02832 & cubic meter per second $\left(\mathrm{m}^{3} / \mathrm{s}\right)$ \\
\hline \multicolumn{3}{|c|}{ Mass } \\
\hline ounce, avoirdupois (oz) & 28.35 & $\operatorname{gram}(\mathrm{g})$ \\
\hline pound, avoirdupois (lb) & 0.4536 & kilogram (kg) \\
\hline
\end{tabular}

Temperature in degrees Celsius $\left({ }^{\circ} \mathrm{C}\right)$ may be converted to degrees Fahrenheit $\left({ }^{\circ} \mathrm{F}\right)$ as ${ }^{\circ} \mathrm{F}=\left(1.8 \times{ }^{\circ} \mathrm{C}\right)+32$.

Temperature in degrees Fahrenheit $\left({ }^{\circ} \mathrm{F}\right)$ may be converted to degrees Celsius $\left({ }^{\circ} \mathrm{C}\right)$ as ${ }^{\circ} \mathrm{C}=\left({ }^{\circ} \mathrm{F}-32\right) / 1.8$.

\section{Datum}

Vertical coordinate information is referenced to the National Geodetic Vertical Datum of 1929 (NGVD 29) using Geiod99.

Horizontal coordinate information is referenced to the North American Datum of 1983 (NAD 83).

Altitude, as used in this report, refers to distance above the vertical datum. 


\title{
Development of a Decision Support Tool for Water and Resource Management using Biotic, Abiotic, and Hydrological Assessments of Topock Marsh, Arizona
}

\author{
By Chris Holmquist-Johnson, Leanne Hanson, Joan Daniels, Colin Talbert, and Jeanette Haegele
}

\begin{abstract}
Topock Marsh is a large wetland adjacent to the Colorado River and the main feature of Havasu National Wildlife Refuge (Havasu NWR) in southern Arizona. In 2010, the U.S. Fish and Wildlife Service (FWS) and Bureau of Reclamation began a project to improve water management capabilities at Topock Marsh and protect habitats and species. Initial construction required a drawdown, which caused below-average inflows and water depths in 2010-11. U.S. Geological Survey Fort Collins Science Center (FORT) scientists collected an assemblage of biotic, abiotic, and hydrologic data from Topock Marsh during the drawdown and immediately after, thus obtaining valuable information needed by FWS.

Building upon that work, FORT developed a decision support system (DSS) to better understand ecosystem health and function of Topock Marsh under various hydrologic conditions. The DSS was developed using a spatially explicit geographic information system package of historical data, habitat indices, and analytical tools to synthesize outputs for hydrologic time periods. Deliverables include high-resolution orthorectified imagery of Topock Marsh; a DSS tool that can be used by Havasu NWR to compare habitat availability associated with three hydrologic scenarios (dry, average, wet years); and this final report which details study results. This project, therefore, has addressed critical FWS management questions by integrating ecologic and hydrologic information into a DSS framework. This DSS will assist refuge management to make better informed decisions about refuge operations and better understand the ecological results of those decisions by providing tools to identify the effects of water operations on species-specific habitat and ecological processes. While this approach was developed to help FWS use the best available science to determine more effective water management strategies at Havasu NWR, technologies used in this study could be applied elsewhere within the region.
\end{abstract}

\section{Introduction}

Topock Marsh is a 4,000-acre wetland adjacent to and east of the Colorado River near Needles, California, and the main feature of the Havasu National Wildlife Refuge (NWR), or the Refuge. The U.S. Fish and Wildlife Service (FWS), in cooperation with the Bureau of Reclamation (Reclamation), began construction of an Infrastructure Improvement Project in 2009 to allow more efficient water use and to help protect the habitats and species found within the Refuge. Part of this project was to build the new concrete-lined Fire Break Canal to deliver water directly from the Colorado River to the marsh approximately one-third of the distance south between the North Dike to the South Dike (fig. 1). During construction, normal water delivery from the Colorado River into Topock Marsh was restricted, 
resulting in unusually low water elevations in 2010-11, and thereafter, the Inlet Canal remained closed as the Fire Break Canal became fully functional in January 2012. The U.S. Geological Survey (USGS) Fort Collins Science Center (FORT) monitored the water quality and aquatic flora and fauna of Topock Marsh during the drawdown and immediately after, thus obtaining information on immediate effects of drawdown on the marsh. Stress from the drawdown, however, may have had delayed effects on aquatic resources and significant changes to the refuge water delivery infrastructure (canals and ditches) and operations. Water flow from each of the inlet canals graphed along the same time line as the marsh elevations measured at the South Dike is illustrated in figure 2.

The goal of this project was to build on previous FORT work by providing an assemblage of biotic, abiotic, and hydrologic data needed by FWS to better understand the health and function of Topock Marsh under various hydrologic conditions. With funding provided by the FWS Desert Landscape Conservation Cooperative (Desert LCC), FORT developed a decision support system (DSS) using a spatially explicit geographic information system (GIS) package of historical data, habitat indices, and analytical tools to synthesize outputs for varying hydrologic conditions. Phase 1 of the DSS approach will help FWS use the best available science to determine more effective water management strategies. The Havasu NWR DSS tool can be used by the refuge managers to compare habitat availability associated with three historical hydrologic scenarios (historical dry, average, wet years) along with additional proposed operations of interest. This project addresses FWS Desert LCC Priority Critical Management Questions 1 and 2

(https://lccnetwork.org/sites/default/files/Resources/DLCCCMQs.pdf) through the integration of ecological and hydrologic information into a DSS framework to assist refuge management to make better informed decisions about refuge operations and better understand results of those decisions ecologically. The Havasu NWR DSS will specifically provide tools to identify effects of water operations on ecological processes and species-specific habitats.

Results from this project address two significant Havasu NWR management issues. First, FWS needs to know the effects of the 2010-11 drawdown and subsequent changes in infrastructure and water operations described above on Topock Marsh aquatic resources. Second, FWS needs a DSS tool to help make science-based decisions on operating the current infrastructure system at Topock Marsh and to prepare the Havasu NWR Comprehensive Conservation Plan (CCP). Completion of the CCP will support Havasu NWR's future water management decisions to maintain quality wildlife habitat within Topock Marsh (Guay, 2012).

To address the needs of the FWS described above, the project was divided into four tiers. We address the need of the FWS to understand effects of operational changes by using Tier 1 assessments (aquatic biota and water quality), which incorporate the same methods used previously to examine water quality and aquatic biota (J.S. Daniels and J.C. Haegele, USGS, unpub. data, 2016). Tier 2 assessments (emergent vegetation) used remote sensing data from satellite and small unmanned aircraft systems (sUAS) to collect digitized high-resolution aerial imagery to quantify emergent vegetation coverage for Topock Marsh. To address the need for a DSS tool, in Tier 3 (hydrologic model development) we led a topographic survey of the marsh, assembled historical marsh inflow and elevation data, and generated three historical hydrologic scenarios to be analyzed. Using the information from Tiers 1 through 3 , we then implemented Tier 4 (development of a DSS) to develop a GIS-aided package of historical marsh data, habitat indices, and analytical tools to synthesize outputs for the three historical hydrologic scenarios as well as three examples of hypothetical hydrologic scenarios associated with maximum available habitat for species of concern. With the completion of the Havasu NWR DSS version 1.0.1, we have coordinated with the FWS to train Havasu NWR staff on how to use this tool to assist them in analyzing current and future management of Refuge resources and preparation of the CCP. 


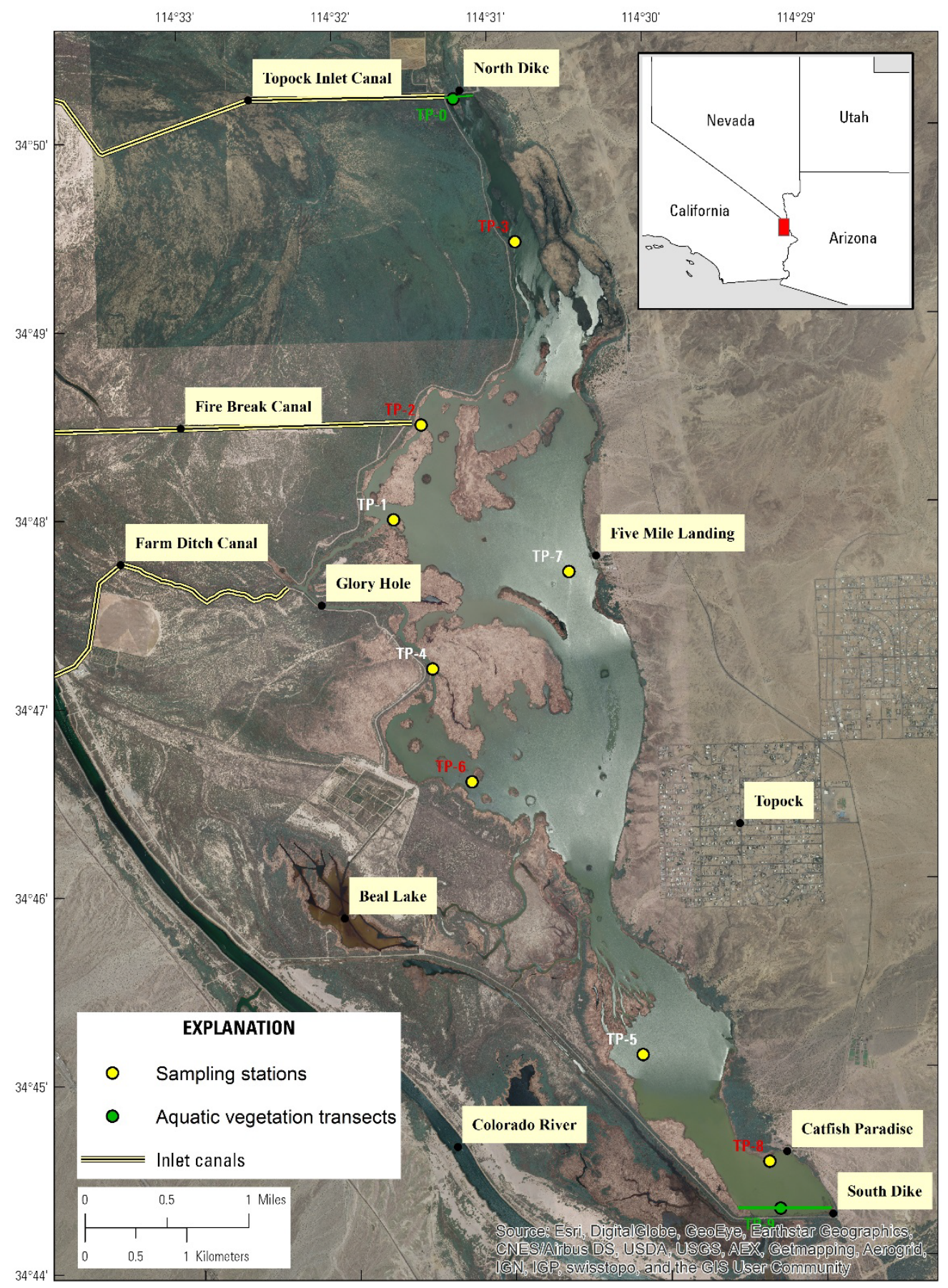

Figure 1. Location of 3 water irrigation canals (Inlet, Fire Break, and Farm Ditch) and 10 biotic and abiotic sampling stations (TP-0 through TP-9) within Topock Marsh, Arizona. Four sampling stations (names in red; TP-3, TP-2, TP-6, and TP-8) are 2011-14 U.S. Geological Survey sample collection locations. Two transects, TP-0 and TP-9 (shown as green lines), were used to collect aquatic vegetation data. 


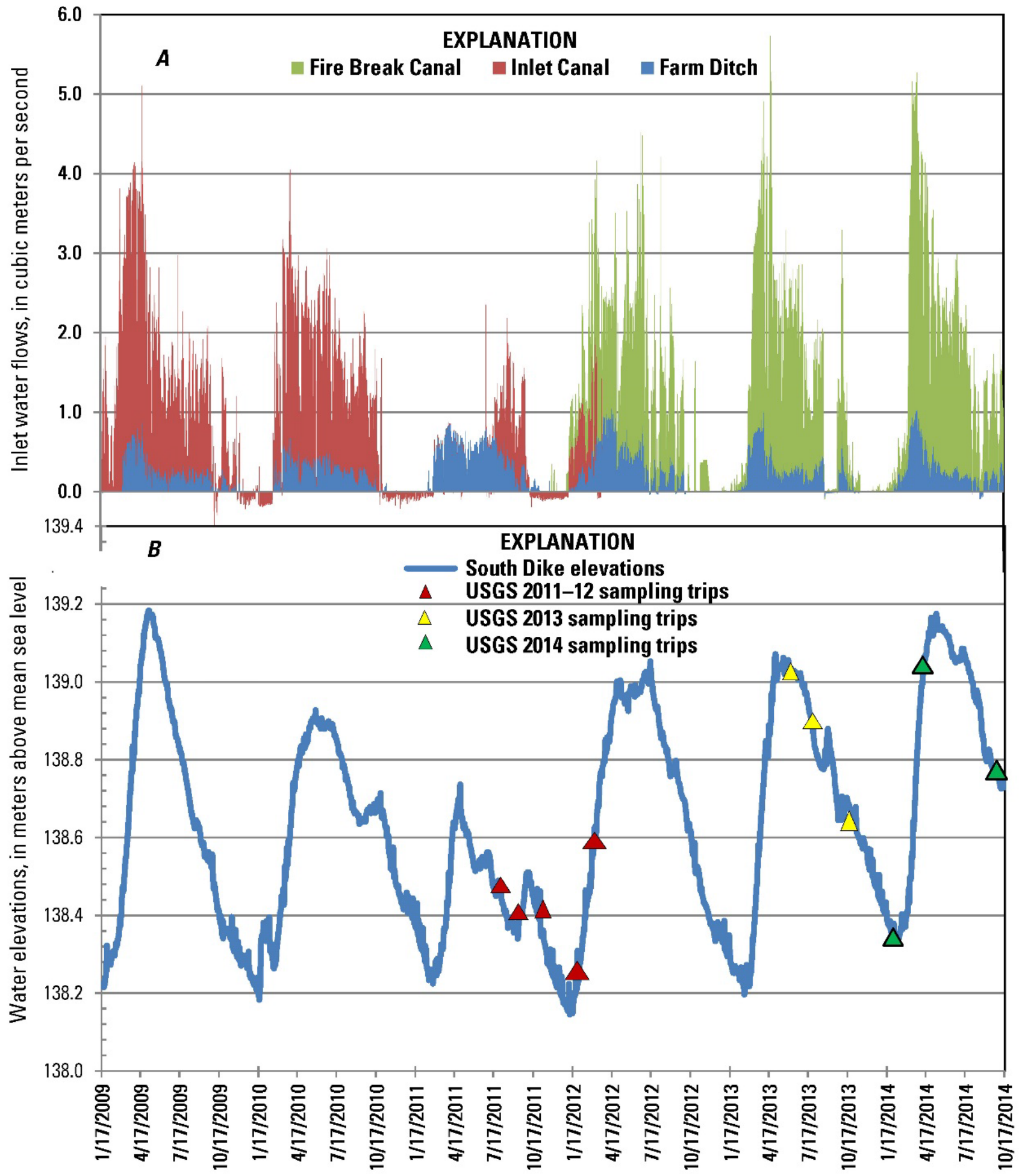

Figure 2. Topock Marsh, Arizona, inlet flows and water elevations at the South Dike from January 2009 through October 2014. A, Inlet flows. $B$, Water elevations. 


\section{Tier 1-Water Quality and Aquatic Biota Assessment}

At the request of the FWS Region 2 office, biologists from the USGS FORT conducted water quality and aquatic biota sampling from July 2011 through March 2012 to evaluate conditions at Topock Marsh during the unusually low water elevations. Subsequently, sampling resumed beginning in June 2013 through October 2014 to assess the same parameters under more typical water elevations. In total, the marsh was sampled 11 times (fig. 2) at 4 sampling stations labeled from north to south: TP-3, TP-2 (located at the mouth of Fire Break Canal), TP-6, and TP-8. Sampling stations were chosen to represent water quality and aquatic biota throughout the length of the marsh (fig. 1). The full description of water quality and aquatic biota sampling methods and the results and discussion associated with Tier 1 are presented in a separate standalone report by J.S. Daniels and J.C. Haegele, USGS (unpub. data, 2016). The most noteworthy findings are summarized here.

\section{Water Quality}

Water temperatures within Topock Marsh followed the local seasonal and diurnal air temperatures and exhibited little variation through the mostly shallow water column (J.S. Daniels and J.C. Haegele, USGS, unpub. data, 2016). The exception occurred where Colorado River water entered the marsh from the Fire Break Canal (fig. 1). Multiparameter instruments deployed at this location (TP2) captured temperatures that varied with depth depending on whether the river water was cooler (which sank) or warmer (staying on the surface) than the marsh water during the various times of year.

Specific conductance (SC) within the marsh showed distinct spatial patterns relative to sampling station locations and inflows from the Colorado River (fig. 1), in a pattern similar to water temperature. There was no inflow from the Inlet Canal for a 260-day period in 2011, and during these low water conditions, SC concentrations were higher at the northern (upstream) sampling stations than at the southern or downstream stations; inflow was still entering the marsh from the Farm Ditch. Once the Fire Break Canal was put into operation (sporadically in late 2011 for testing and operationally thereafter beginning January 2012) bringing river water into the northwestern section of the marsh, depth profiles taken during that time tracked the higher SC concentrations moving downstream as water at the northern sampling stations became fresher (with lower conductivities). The average SC throughout the marsh during this initial 2011-12 sampling period was 1,718 microsiemens per centimeter $(\mu \mathrm{S} / \mathrm{cm})$ at 25 degrees Celsius (table 1).

Once regular inflows resumed into the marsh from the Fire Break Canal, SC fell to an average 1,458 $\mu \mathrm{S} / \mathrm{cm}$ for the 2013-14 sampling period, and the highest concentrations were consistently measured at the southernmost sampling stations. Conductivity decreased at TP-2, the station closest to the Fire Break Canal inflow, as well as at TP-3, the most northern sampling station, where SC remained only slightly ( 89 to $205 \mu \mathrm{S} / \mathrm{cm}$ ) higher than TP-2 values (table 1 ).

Average $\mathrm{pH}$ measured at the four sampling stations was 8.3 (range of 7.9 to 9.0) in 2011-12 and 8.5 (range of 7.9 to 9.3) in 2013-14 (J.S. Daniels and J.C. Haegele, USGS, unpub. data, 2016). Seasonal increases driven by diurnal dynamics in photosynthesis and respiration created higher daily averages during the fall with even larger diurnal fluctuations because of the maximum coverage of the dense submerged aquatic vegetation (SAV) and phytoplankton during that time.

Similar to the $\mathrm{pH}$ response, large diurnal dissolved oxygen (DO) fluctuations (J.S. Daniels and J.C. Haegele, USGS, unpub. data, 2016) were most likely caused by photosynthesis from dense SAV communities at TP-6 and TP-3, particularly in October 2013 and 2014, and from the dense phytoplankton in September-October 2014 at TP-8 (fig. 3). All locations had DO concentrations well 
above the minimum threshold of 3.0 milligrams per liter $(\mathrm{mg} / \mathrm{L})$, established as the one-day criteria required for other lifestages of warm-water fish by U.S. Environmental Protection Agency (1986).

Table 1. Topock Marsh, Arizona, water chemistry July, September, and October 2011; February and March 2012; June, July, and October 2013; and February, April, and September/October 2014.

$[\mu \mathrm{S} / \mathrm{cm}$, microSiemens per centimeter at 25 degrees Celsius; $\mathrm{mg} / \mathrm{L}$, milligrams per liter; NTU, nephelometric turbidity units; TSS, total suspended solids; $\mathrm{CaCO}_{3}$, calcium carbonate; $\mathrm{P}$, phosphorus; Org-N, organic nitrogen; TN, total nitrogen; ND, no data]

\begin{tabular}{|c|c|c|c|c|c|c|c|c|}
\hline & \multicolumn{2}{|c|}{ Surface values from Quanta } & \multicolumn{5}{|c|}{ Laboratory analyses from surface samples } \\
\hline $\begin{array}{l}\text { Sample } \\
\text { station }^{2}\end{array}$ & $\begin{array}{c}\text { Sample } \\
\text { date }\end{array}$ & $\begin{array}{c}\text { Specific } \\
\text { conductance } \\
\mu \mathrm{S} / \mathrm{cm}\end{array}$ & $\begin{array}{c}\text { Turbidity } \\
\text { NTUs }\end{array}$ & $\begin{array}{c}\text { Alkalinity as } \\
\mathrm{CaCO}_{3} \\
\mathrm{mg} / \mathrm{L}\end{array}$ & $\begin{array}{l}\text { Total P } \\
\mathrm{mg} / \mathrm{L}\end{array}$ & $\begin{array}{l}\text { Org-N33 } \\
\mathrm{mg} / \mathrm{L}\end{array}$ & $\begin{array}{l}\text { Total N } \\
\mathrm{mg} / \mathrm{L}\end{array}$ & $\begin{array}{c}\text { Org-N/TN } \\
\%\end{array}$ \\
\hline TP-3 & $7 / 26 / 11$ & 2,470 & 66.6 & 156.0 & 0.029 & 0.916 & 0.923 & 99.2 \\
\hline TP-2 & $7 / 26 / 11$ & 2,600 & 68.9 & 161.6 & 0.036 & 0.973 & 0.995 & 97.7 \\
\hline TP-6 & $7 / 27 / 11$ & 1,970 & 39.3 & 147.2 & 0.026 & 0.626 & 0.649 & 96.4 \\
\hline TP-8 & $7 / 28 / 11$ & 1,158 & 53.0 & 144.8 & 0.038 & 0.651 & 0.664 & 98.0 \\
\hline TP-3 & $9 / 21 / 11$ & 995 & 58.4 & 99.2 & 0.053 & 0.321 & 0.338 & 95.0 \\
\hline TP-2 & $9 / 21 / 11$ & 1,412 & 51.4 & 114.4 & 0.053 & 0.538 & 0.543 & 99.0 \\
\hline TP-6 & $9 / 21 / 11$ & 1,780 & 19.9 & 54.4 & 0.049 & 0.609 & 0.614 & 99.1 \\
\hline TP-8 & $9 / 20 / 11$ & 1,550 & 30.5 & 93.6 & 0.055 & 0.933 & 0.938 & 99.4 \\
\hline TP-3 & $10 / 25 / 11$ & 1,165 & 60.3 & 112.8 & 0.026 & ND & 0.388 & ND \\
\hline TP-2 & $10 / 25 / 11$ & 1,183 & 45.0 & 86.4 & 0.025 & ND & 0.483 & ND \\
\hline TP-6 & $10 / 25 / 11$ & 2,300 & 37.4 & 48.8 & 0.025 & ND & 0.719 & ND \\
\hline TP-8 & $10 / 23 / 11$ & 1,940 & 35.8 & 72.0 & 0.075 & ND & 1.050 & ND \\
\hline \multicolumn{2}{|c|}{2011 Average } & 1,710 & 47.2 & 107.6 & 0.041 & 0.696 & 0.692 & 98.0 \\
\hline TP-3 & $2 / 1 / 12$ & 1,478 & 72.6 & 148.0 & 0.040 & 0.392 & 0.614 & 63.8 \\
\hline ТP-2 & $2 / 1 / 12$ & 1,253 & 13.2 & 144.0 & 0.014 & 0.263 & 0.613 & 42.9 \\
\hline TP-6 & $2 / 1 / 12$ & 2,110 & 49.8 & 163.0 & 0.043 & 0.676 & 0.770 & 87.8 \\
\hline TP-8 & $2 / 1 / 12$ & 2,330 & 81.1 & 158.0 & 0.087 & 1.296 & 1.330 & 97.4 \\
\hline TP-3 & $3 / 8 / 12$ & 1,209 & 87.4 & 140.0 & 0.039 & 0.326 & 0.616 & 53.0 \\
\hline ТP-2 & $3 / 8 / 12$ & 1,210 & 51.8 & 142.0 & 0.037 & 0.346 & 0.655 & 52.9 \\
\hline ТP-6 & $3 / 8 / 12$ & 1,850 & 63.1 & 150.0 & 0.051 & 0.611 & 0.769 & 79.5 \\
\hline TP-8 & $3 / 9 / 12$ & 2,390 & 70.3 & 164.0 & 0.081 & 1.070 & 1.190 & 89.9 \\
\hline \multicolumn{2}{|c|}{2012 Average } & 1,729 & 61.2 & 151.1 & 0.049 & 0.622 & 0.820 & 70.9 \\
\hline \multicolumn{2}{|c|}{$\begin{array}{r}\text { Initial 2011-2012 } \\
\text { Study Average } \\
\end{array}$} & 1,718 & 52.8 & 125.0 & 0.044 & 0.659 & 0.743 & 84.4 \\
\hline ТP-3 & $6 / 13 / 13$ & 1,311 & 58.8 & 179 & 0.034 & 0.47 & 0.464 & 96.8 \\
\hline TP-2 & $6 / 13 / 13$ & 1,140 & 66.8 & 164 & 0.023 & 0.40 & 0.408 & 98.0 \\
\hline ТР-6 & $6 / 13 / 13$ & 1,291 & 19.5 & 173 & 0.026 & 0.52 & 0.483 & 99.0 \\
\hline TP-8 & $6 / 13 / 13$ & 2,030 & 88.2 & 181 & 0.085 & 1.16 & 1.170 & 99.4 \\
\hline
\end{tabular}


Table 1. Topock Marsh, Arizona, water chemistry July, September, and October 2011; February and March 2012; June, July, and October 2013; and February, April, and September/October 2014.-Continued

$[\mu \mathrm{S} / \mathrm{cm}$, microSiemens per centimeter at 25 degrees Celsius; $\mathrm{mg} / \mathrm{L}$, milligrams per liter; NTU, nephelometric turbidity units; TSS, total suspended solids; $\mathrm{CaCO}_{3}$, calcium carbonate; P, phosphorus; Org-N, organic nitrogen; TN, total nitrogen; ND, no data]

\begin{tabular}{|c|c|c|c|c|c|c|c|c|}
\hline & \multicolumn{2}{|c|}{ Surface values from Quanta } & \multicolumn{5}{|c|}{ Laboratory analyses from surface samples } \\
\hline $\begin{array}{l}\text { Sample } \\
\text { station }^{2}\end{array}$ & $\begin{array}{c}\text { Sample } \\
\text { date }\end{array}$ & $\begin{array}{c}\text { Specific } \\
\text { conductance } \\
\mu \mathrm{S} / \mathrm{cm}\end{array}$ & $\begin{array}{c}\text { Turbidity } \\
\text { NTUs }\end{array}$ & $\begin{array}{c}\text { Alkalinity as } \\
\mathrm{CaCO}_{3} \\
\mathrm{mg} / \mathrm{L}\end{array}$ & $\begin{array}{c}\text { Total P } \\
\mathrm{mg} / \mathrm{L}\end{array}$ & $\begin{array}{c}\text { Org-N33 } \\
\mathrm{mg} / \mathrm{L}\end{array}$ & $\begin{array}{c}\text { Total N } \\
\mathrm{mg} / \mathrm{L}\end{array}$ & $\begin{array}{c}\text { Org-N/TN } \\
\%\end{array}$ \\
\hline TP-3 & $7 / 24 / 13$ & 1,389 & 18.0 & ND & 0.027 & 0.49 & 0.495 & 99.8 \\
\hline TP-2 & $7 / 24 / 13$ & 1,244 & 11.8 & ND & 0.031 & 0.48 & 0.500 & 96.5 \\
\hline TP-6 & $7 / 24 / 13$ & 1,259 & 17.7 & ND & 0.027 & 0.59 & 0.562 & 99.1 \\
\hline TP-8 & $7 / 23 / 13$ & 2,000 & 26.5 & ND & 0.066 & 1.31 & 1.407 & 92.8 \\
\hline TP-3 & $10 / 31 / 13$ & 1,000 & 11.3 & 86.6 & 0.015 & 0.26 & 0.275 & 92.7 \\
\hline TP-2 & $10 / 31 / 13$ & 911 & 7.8 & 130.0 & 0.008 & 0.20 & 0.427 & 46.8 \\
\hline ТР-6a & $10 / 31 / 13$ & 1,440 & 11.2 & 110.0 & 0.017 & 0.49 & 0.508 & 97.2 \\
\hline TP-6b & $10 / 31 / 13$ & ND & ND & 110.0 & 0.018 & 0.51 & 0.480 & 99.0 \\
\hline ТР-8 & $10 / 31 / 13$ & 1,880 & 134.0 & 163.0 & 0.188 & 1.21 & 1.410 & 85.5 \\
\hline \multicolumn{2}{|c|}{2013 Average } & 1,408 & 39.3 & 144.1 & 0.043 & 0.62 & 0.661 & 92.5 \\
\hline TP-3 & $2 / 12 / 14$ & 1,675 & 50.3 & 178.0 & 0.053 & 0.635 & 0.726 & 87.5 \\
\hline TP-2 & $2 / 11 / 14$ & 1,540 & 56.8 & 146.0 & 0.063 & 0.762 & 0.854 & 89.2 \\
\hline TP-6 & $2 / 12 / 14$ & 1,880 & 38.7 & 191.0 & 0.047 & 0.819 & 0.863 & 94.9 \\
\hline TP-8 & $2 / 11 / 14$ & 2,030 & 112.0 & 193.0 & 0.154 & 1.554 & 1.860 & 83.5 \\
\hline TP-3 & $4 / 19 / 14$ & 1,092 & 72.6 & 156.0 & 0.056 & 0.461 & 0.477 & 96.7 \\
\hline TP-2 & $4 / 19 / 14$ & 993 & 34.6 & 148.0 & 0.026 & 0.348 & 0.521 & 66.8 \\
\hline TP-6 & $4 / 19 / 14$ & 1,379 & 33.6 & 169.0 & 0.033 & 0.582 & 0.598 & 97.3 \\
\hline TP-8 & $4 / 19 / 14$ & 2,020 & 140.0 & 192.0 & 0.171 & 1.444 & 1.470 & 98.2 \\
\hline TP-3 & $10 / 1 / 14$ & 1,353 & 73.7 & 150.0 & 0.057 & 0.592 & 0.624 & 94.9 \\
\hline TP-2 & $9 / 30 / 14$ & 1,149 & 41.5 & 145.0 & 0.031 & 0.364 & 0.460 & 79.1 \\
\hline ТР-6а & $9 / 30 / 14$ & 1,174 & 11.4 & 72.6 & 0.018 & 0.423 & 0.445 & 95.1 \\
\hline TP-6b & $9 / 30 / 14$ & ND & ND & 78.2 & 0.023 & 0.438 & 0.458 & 95.7 \\
\hline TP-8 & $10 / 1 / 14$ & 1,810 & 83.7 & 118.0 & 0.133 & 1.378 & 1.410 & 97.8 \\
\hline \multicolumn{2}{|c|}{2014 Average } & 1,508 & 62.4 & 149.0 & 0.066 & 0.754 & 0.828 & 90.5 \\
\hline \multicolumn{2}{|c|}{$\begin{array}{l}\text { 2013-2014 Study } \\
\text { Average } \\
\end{array}$} & 1,458 & 50.9 & 147.0 & 0.055 & 0.688 & 0.744 & 91.5 \\
\hline
\end{tabular}

${ }^{1}$ All laboratory analyses were done by the U.S. Geological Survey National Water Quality Laboratory, and all samples, including the Quanta values, were taken at the sampling stations from just below the water's surface.

${ }^{2}$ Sampling stations are displayed in upstream-to-downstream order.

${ }^{3}$ Values for Org-N were calculated using half of "less than" detection limits for analyzed parameters. Formulas to calculate nitrogen forms follow those by Bales and others, 2001.

${ }^{4}$ The standards recommended by the Arizona Department of Environmental Quality (ADEQ) are specific to warm-water lakes and reservoirs designated for aquatic and wildlife use. Ranges apply to peak season (April to October for warm-water lakes). All criteria were obtained from ADEQ (2009). 
The low water and windy conditions of 2011-12 contributed to generally higher turbidity values from suspended sediments than turbidity measurements taken between 1996 and 1998 by Alanen (1998) and Guay (2001). During the deeper water conditions in 2013-14, turbidity values generally improved (table 1) but varied widely spatially as well as seasonally. Higher turbidity values at the terminal end of the marsh (TP-8) were largely due to higher concentrations of phytoplankton and zooplankton (figs. 3 and 4). Meanwhile, dense SAV coverage at TP-6 and TP-3 tended to trap suspended sediments and hold the soft loamy sand, clay loam, and silty clay loam substrate in place (J.S. Daniels and J.C. Haegele, USGS, unpub. data, 2016), particularly in the fall. Turbidities were low at TP-2, most likely due to the deep channel and the Colorado River water entering through the concrete lined Fire Break Canal at that location.

We compared total nitrogen (TN), organic nitrogen (org-N), and total phosphorus (TP) values as measured from the surface water at each sampling station. Sampling station TP-8 consistently contained one-third to more than one-half more TN, org-N, and TP concentrations as the other sampling stations from October 2011 through October 2014 (table 1). The high average ratio (as a percentage) of org-N to $\mathrm{TN}$ throughout the study period provides evidence that most of the TN was likely due to the phytoplankton in the water column (fig. 3). Lower ratios of org-N to TN obtained regularly at TP-2 and TP-3 likely was due to relatively less phytoplankton in the fresh water flowing in from the Colorado River, which contained higher mean concentrations of inorganic nitrogen ( 0.35 milligrams per liter $[\mathrm{mg} / \mathrm{L}]$, data from S. O'Meara, unpub. data, 2014). Concentrations of elements of concern in water samples (arsenic [As], mercury [Hg], selenium [Se], and chromium [Cr]) were below State and Federal toxicity standards (Arizona Department of Environmental Quality, 2009; Eisler, 1988; U.S. Environmental Protection Agency, 2015) for aquatic wildlife. 

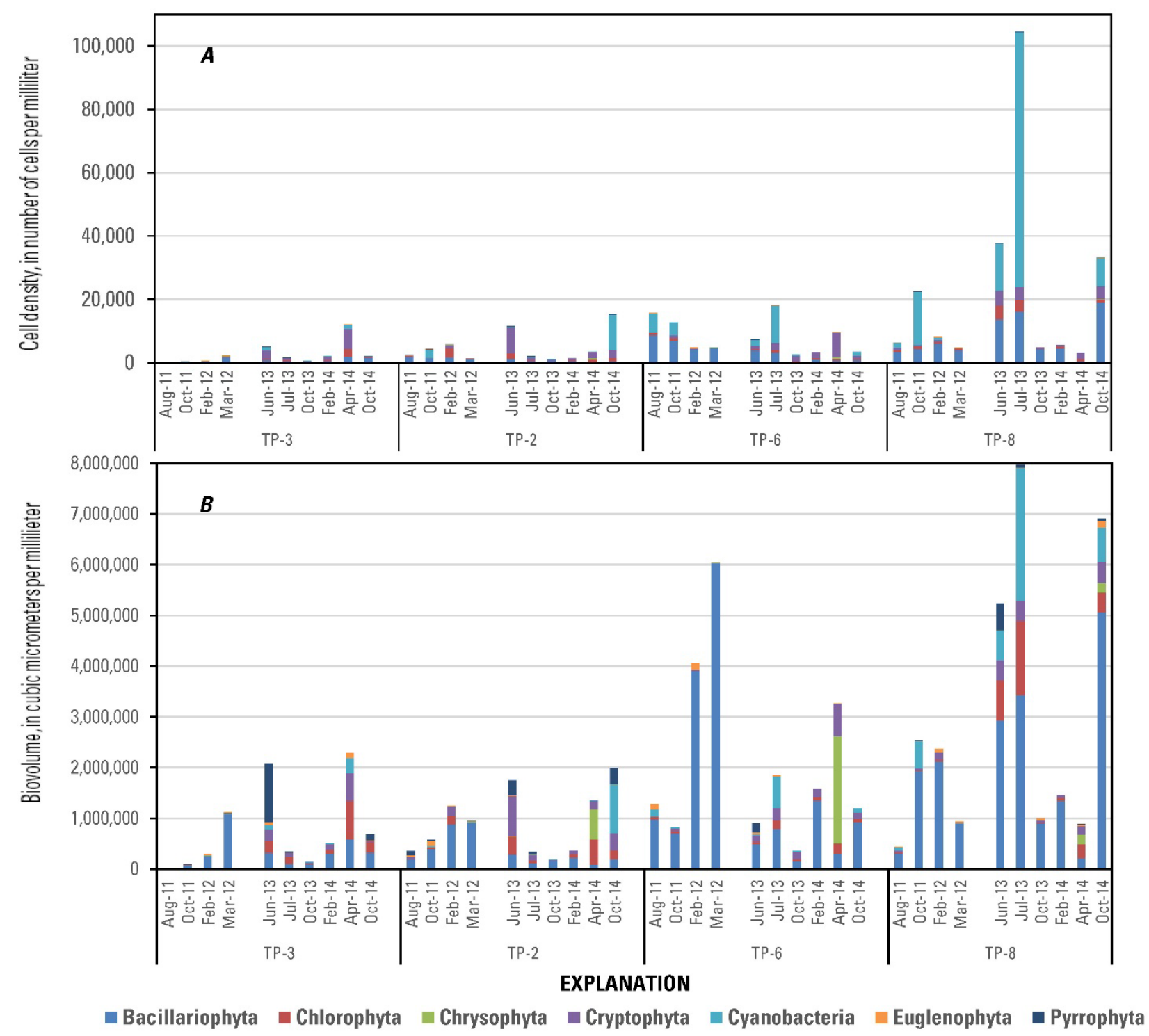

Figure 3. Density and biovolume phytoplankton data from sampling stations in Topock Marsh, Arizona, during August and October 2011; February and March 2012; June, July, and October 2013; and February, April, and October 2014. A, Total density of phytoplankton. B, Biovolume of phytoplankton. Note stations are shown in upstream-to-downstream order. 


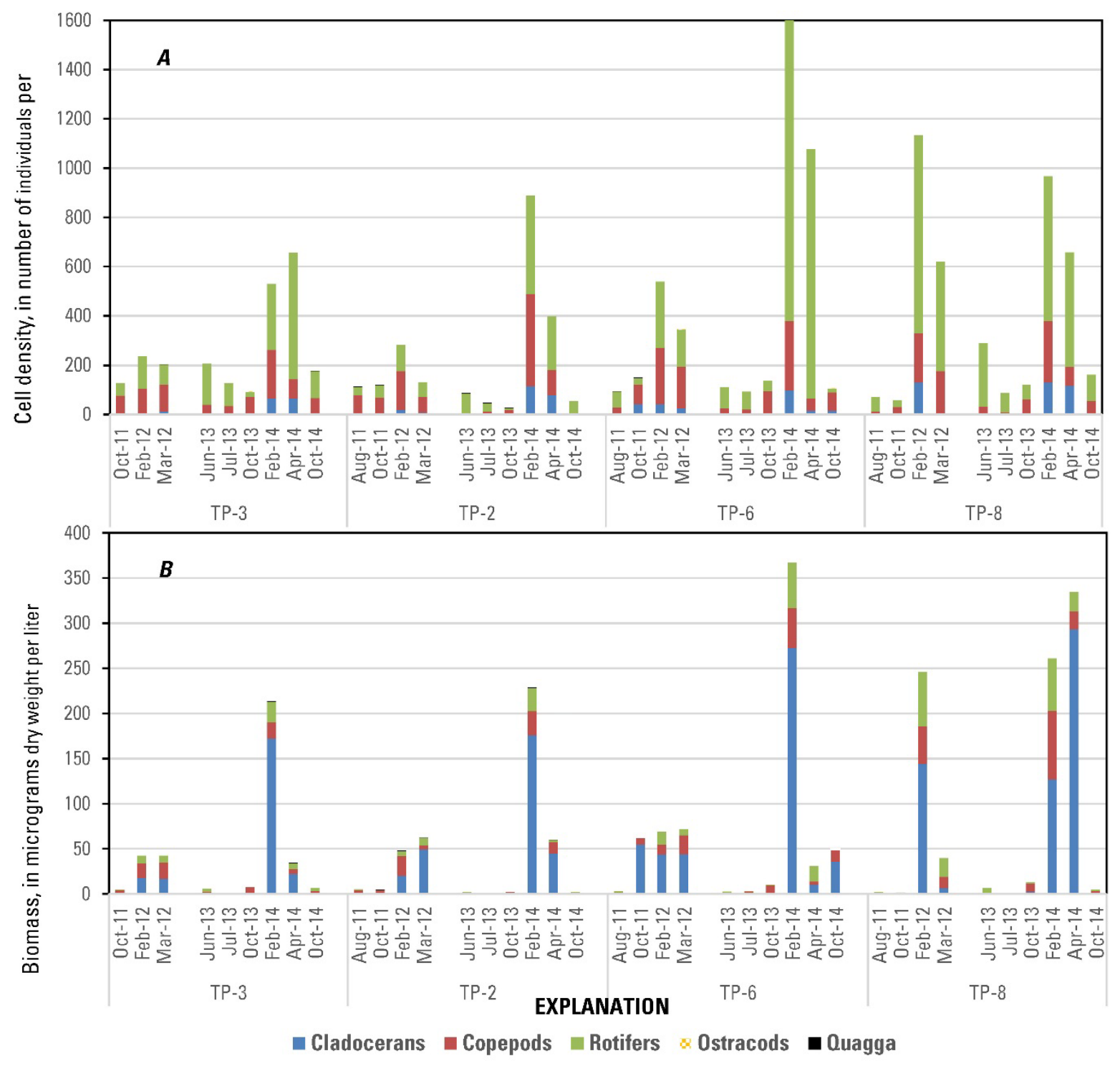

Figure 4. Density and biomass zooplankton data from sampling stations in Topock Marsh, Arizona, during August and October 2011; February and March 2012; June, July, and October 2013; and February, April, and October 2014. A, Total density of zooplankton. B, Biomass of zooplankton. Note stations are shown in upstream-todownstream order.

Chlorophyll $a$ concentrations were consistently highest at TP-8. This fact along with the higher org-N and phytoplankton density and biovolumes values (fig. 3) authenticate the cause of the higher turbidity at TP-8. Meanwhile, chlorophyll $a$ concentrations were consistently lowest at TP-2, following the completion of the Fire Break Canal and subsequent inflow from the Colorado River beginning in January 2012. The exception being that the lowest chlorophyll $a$ concentration occurred at TP-6 during the September-October 2014 sampling period, when the submerged aquatic vegetation was very dense and water clarity $(85.7$ centimeters $[\mathrm{cm}]$ Secchi depth with a turbidity of 11.4 nephelometric turbidity units [NTU]) was the highest. 
Comparing the ionic composition of water (displayed on Stiff diagrams, J.S. Daniels and J.C. Haegele, USGS, unpub. data, 2016) of the four sampling locations to the Colorado River water illustrates that where the Colorado River enters the marsh (at TP-2), the marsh water was most similar to river water (compared in October 2011, July 2013, and October 2014). Whereas at TP-8, the sampling station furthest downstream of the Fire Break Canal and the Farm Ditch, the marsh water differed the most from river water. The ionic compositions of TP-3 and TP-6 differ less than TP-8, so there appeared to be a gradual change in ionic composition as the water moved farther away from the inflow.

\section{Sediment and Aquatic Plant Chemistry}

Sediment was sampled and analyzed in 2011,2013, and 2014 and aquatic vegetation was sampled and analyzed in 2013 and 2014. Most noteworthy is that although the analytical results represent a wide variation in chemistry within the sediments and plants throughout the marsh (J.S. Daniels and J.C. Haegele, USGS, unpub. data, 2016), no potential problems or toxicity issues were noted - with the exception of one slightly elevated arsenic concentration in sediment near the Fire Break inlet in October 2014. Besides the possible threat of bioaccumulation through time (none found to date at the site), the remaining sediment samples contained concentrations of $\mathrm{As}, \mathrm{Cr}, \mathrm{Hg}$, and Se below the established threshold effects on wildlife (MacDonald and others, 2000; Lemly, 2002). Likewise, concentration results of $\mathrm{As}, \mathrm{Cr}, \mathrm{Hg}$, and Se were all below established threshold effects in plant material (MacDonald and others, 2000; Lemly, 1993, 2002).

\section{Aquatic Biota}

The predominant SAV in Topock Marsh during the 2011-14 study period was spiny naiad (Najas marina) with smaller quantities and occurrences of sago pondweed (Stuckenia pectinata). Turbidity and water depth were important in explaining their coverage success (fig. 5), and both species achieved their maximum coverage during October each year (J.S. Daniels and J.C. Haegele, USGS, unpub. data, 2016). Spiny naiad was particularly abundant in shallow water $0.60-0.76$ meter $(\mathrm{m})$ in depth (2-2.5 feet [ft]), in somewhat protected areas where water clarity was relatively high (such as, turbidity $\leq 39$ NTUs). Sago pondweed occurred in low to moderate amounts in clear, typically shallower areas of $0.30-0.46 \mathrm{~m}$ in depth (1-1.5 ft). The microalgae, chara (Chara sp.), was found infrequently during this time and only in small clusters throughout the marsh.

Eurasian watermilfoil (Myriophyllum spicatum), an invasive SAV, was first noted in early 2012 near TP-2 at the mouth of the Fire Break Canal. By October 2014, Eurasian watermilfoil was well established and thriving around that same location as well as where Colorado River water enters the marsh through the Farm Ditch (fig. 1).

The two predominant emergent vegetation species in Topock Marsh were cattail (Typha sp.) and California bulrush (Schoenoplectus californicus). The emergent vegetation assessment is reported in the Tier 2 section of this document, along with the associated land cover report by Young and others (2015) in appendix 2. In addition to quantifying the emergent vegetation coverage, we also noted during the low water conditions of 2011 that in many areas cattail plants were brown as their roots and rhizomes were $30 \mathrm{~cm}$ (12 inches [in]) or more above the waterline. Meanwhile, California bulrush grew farther out in deeper water. As water levels resumed more normal conditions, cattails recovered and thrivedperhaps healthier than before - and the already established California bulrush continued to thrive in deeper water. 


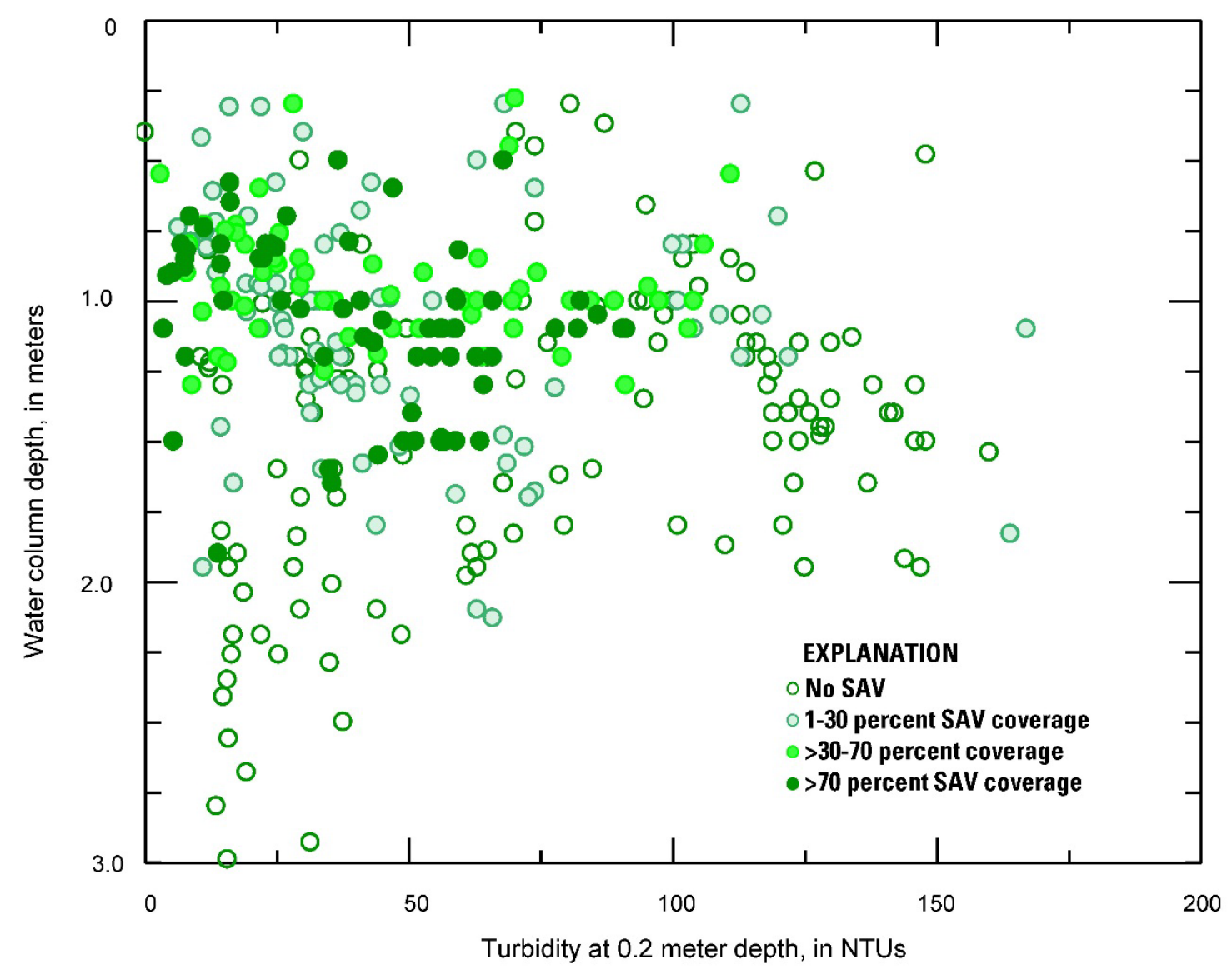

Figure 5. Scatterplot of coverage values for the submerged aquatic vegetation (SAV) in Topock Marsh, Arizona, during October 2011, 2013, and 2014 in relation to water depth and turbidity measurements for each observation point. (NTUs, nephelometric turbidity units).

Fish gill net surveys in the marsh have been conducted by the Arizona Game and Fish Department (AGFD) each February from 2010 through 2015 and their data, divided into five general regions (provided by Gregg Cummins [AGFD, Region III Office, Kingman, Ariz.]), are shown in table 2. Locations where the 10 gill nets were set each year are illustrated in figures 6 and 7. 
Table 2. Summary of fish captured per net by Arizona Game and Fish Department (AGFD) using experimental gill nets each February from 2010 through 2015. Locations where gill nets were set are divided into five regions ${ }^{1}$ within Topock Marsh and illustrated in figures 6 and 7.

[NE, North End; FB, Fire Break Canal; BO, Beal Lake Outlet; CF, Catfish Paradise; SD, South Dike]

\begin{tabular}{|c|c|c|c|c|c|c|c|c|c|c|c|c|c|c|}
\hline \multirow[b]{2}{*}{ Year } & \multirow[b]{2}{*}{ Region $^{1}$} & \multirow[b]{2}{*}{$\begin{array}{c}\text { Number } \\
\text { of gill } \\
\text { nets set }\end{array}$} & \multicolumn{12}{|c|}{ Number of fish captured per net in each region ${ }^{1}$} \\
\hline & & & $\begin{array}{c}\text { Razorback } \\
\text { sucker }\end{array}$ & $\begin{array}{l}\text { Gizzard } \\
\text { shad }\end{array}$ & $\begin{array}{c}\text { Threadfin } \\
\text { shad }\end{array}$ & $\begin{array}{c}\text { Channel } \\
\text { catfish }\end{array}$ & $\begin{array}{l}\text { Yellow } \\
\text { bullhead }\end{array}$ & $\begin{array}{c}\text { Largem } \\
\text { outh } \\
\text { bass }\end{array}$ & $\begin{array}{c}\text { Striped } \\
\text { bass }\end{array}$ & $\begin{array}{l}\text { Sunfish } \\
\text { species }^{2}\end{array}$ & $\begin{array}{c}\text { Black } \\
\text { crappie }\end{array}$ & $\begin{array}{c}\text { Carp } \\
\text { and } \\
\text { goldfish }\end{array}$ & $\begin{array}{l}\text { Total } \\
\text { no. of } \\
\text { fish in } \\
\text { region }\end{array}$ & $\begin{array}{l}\text { Total } \\
\text { fish } \\
\text { minus } \\
\text { gizzard } \\
\text { shad }\end{array}$ \\
\hline 2010 & $\mathrm{NE}$ & 3 & 0.0 & 0.0 & 0.0 & 4.0 & 1.3 & 15.3 & 2.0 & 1.0 & 0.0 & 5.3 & 29.0 & 29.0 \\
\hline 2011 & $\mathrm{NE}$ & 3 & 1.7 & 0.0 & 0.3 & 4.3 & 1.0 & 10.3 & 0.0 & 0.7 & 3.0 & 2.7 & 24.0 & 24.0 \\
\hline 2012 & $\mathrm{NE}$ & 1 & 1.0 & 1.0 & 0.0 & 6.0 & 1.0 & 5.0 & 6.0 & 0.0 & 3.0 & 2.0 & 25.0 & 24.0 \\
\hline 2013 & $\mathrm{NE}$ & 1 & 0.0 & 1.0 & 0.0 & 15.0 & 4.0 & 4.0 & 0.0 & 0.0 & 2.0 & 3.0 & 29.0 & 28.0 \\
\hline 2014 & $\mathrm{NE}$ & 2 & 1.5 & 10.0 & 0.0 & 19.5 & 1.0 & 3.0 & 7.5 & 0.0 & 1.0 & 1.0 & 44.5 & 34.5 \\
\hline 2015 & $\mathrm{NE}$ & 2 & 0.0 & 36.0 & 0.5 & 4.5 & 0.0 & 0.5 & 8.5 & 0.0 & 2.0 & 1.0 & 53.0 & 17.0 \\
\hline 2010 & FB & 2 & 0.5 & 0.0 & 2.0 & 3.0 & 1.0 & 2.5 & 0.5 & 0.0 & 0.0 & 5.0 & 14.5 & 14.5 \\
\hline 2011 & FB & 2 & 0.0 & 0.0 & 0.0 & 2.5 & 2.0 & 2.0 & 0.0 & 0.5 & 3.0 & 2.5 & 12.5 & 12.5 \\
\hline 2012 & FB & 4 & 2.3 & 1.3 & 0.5 & 4.0 & 0.8 & 2.0 & 6.3 & 0.0 & 1.0 & 1.5 & 19.5 & 18.3 \\
\hline 2013 & FB & 4 & 2.5 & 1.3 & 0.0 & 12.3 & 3.0 & 3.5 & 1.3 & 0.5 & 0.8 & 4.8 & 29.8 & 28.5 \\
\hline 2014 & FB & 3 & 1.3 & 19.7 & 0.0 & 6.7 & 2.0 & 1.7 & 14.7 & 0.3 & 1.3 & 1.0 & 48.7 & 29.0 \\
\hline 2015 & FB & 2 & 0.0 & 39.5 & 0.5 & 12.0 & 3.0 & 0.0 & 17.5 & 0.0 & 0.5 & 1.0 & 74.0 & 34.5 \\
\hline 2010 & $\mathrm{BO}$ & 1 & 0.0 & 0.0 & 0.0 & 0.0 & 0.0 & 1.0 & 0.0 & 1.0 & 0.0 & 6.0 & 8.0 & 8.0 \\
\hline 2011 & $\mathrm{BO}$ & 0 & \multicolumn{12}{|c|}{ No nets set in this region } \\
\hline 2012 & $\mathrm{BO}$ & 2 & 0.0 & 0.0 & 0.0 & 0.5 & 0.0 & 1.0 & 0.0 & 1.0 & 0.5 & 3.5 & 6.5 & 6.5 \\
\hline 2013 & $\mathrm{BO}$ & 3 & 0.7 & 3.3 & 0.0 & 1.0 & 0.0 & 1.0 & 0.3 & 0.3 & 0.0 & 1.7 & 8.3 & 5.0 \\
\hline 2014 & $\mathrm{BO}$ & 2 & 0.0 & 2.5 & 0.0 & 2.0 & 1.0 & 2.5 & 0.0 & 0.5 & 0.5 & 5.0 & 14.0 & 11.5 \\
\hline 2015 & $\mathrm{BO}$ & 2 & 0.0 & 20.0 & 0.0 & 4.0 & 0.5 & 0.5 & 0.5 & 0.0 & 0.5 & 0.0 & 26.0 & 6.0 \\
\hline
\end{tabular}


Table 2. Summary of fish captured per net by Arizona Game and Fish Department (AGFD) using experimental gill nets each February from 2010 through 2015. Locations where gill nets were set are divided into five regions ${ }^{1}$ within Topock Marsh and illustrated in figures 6 and 7 . - Continued [NE, North End; FB, Fire Break Canal; BO, Beal Lake Outlet; CF, Catfish Paradise; SD, South Dike]

\begin{tabular}{|c|c|c|c|c|c|c|c|c|c|c|c|c|c|c|}
\hline \multirow[b]{2}{*}{ Year } & \multirow[b]{2}{*}{ Region ${ }^{1}$} & \multirow[b]{2}{*}{$\begin{array}{c}\text { Number } \\
\text { of gill } \\
\text { nets set }\end{array}$} & \multicolumn{12}{|c|}{ Number of fish captured per net in each region ${ }^{1}$} \\
\hline & & & $\begin{array}{c}\text { Razorback } \\
\text { sucker }\end{array}$ & $\begin{array}{c}\text { Gizzard } \\
\text { shad }\end{array}$ & $\begin{array}{c}\text { Threadfin } \\
\text { shad }\end{array}$ & $\begin{array}{l}\text { Channel } \\
\text { catfish }\end{array}$ & $\begin{array}{c}\text { Yellow } \\
\text { bullhead }\end{array}$ & $\begin{array}{c}\text { Largem } \\
\text { outh } \\
\text { bass }\end{array}$ & $\begin{array}{c}\text { Striped } \\
\text { bass }\end{array}$ & $\begin{array}{l}\text { Sunfish } \\
\text { species }^{2}\end{array}$ & $\begin{array}{c}\text { Black } \\
\text { crappie }\end{array}$ & $\begin{array}{c}\text { Carp } \\
\text { and } \\
\text { goldfish }\end{array}$ & $\begin{array}{l}\text { Total } \\
\text { no. of } \\
\text { fish in } \\
\text { region }\end{array}$ & $\begin{array}{c}\text { Total } \\
\text { fish } \\
\text { minus } \\
\text { gizzard } \\
\text { shad }\end{array}$ \\
\hline 2010 & $\mathrm{CF}$ & 3 & 1.3 & 0.0 & 1.7 & 2.7 & 1.0 & 5.3 & 0.0 & 2.0 & 2.7 & 11.0 & 27.7 & 27.7 \\
\hline 2011 & $\mathrm{CF}$ & 4 & 1.0 & 0.0 & 0.0 & 1.5 & 0.0 & 2.3 & 0.0 & 0.3 & 2.5 & 3.0 & 10.5 & 10.5 \\
\hline 2012 & $\mathrm{CF}$ & 2 & 1.0 & 2.0 & 0.0 & 1.0 & 0.0 & 3.5 & 1.0 & 0.0 & 3.5 & 2.0 & 14.0 & 12.0 \\
\hline 2013 & $\mathrm{CF}$ & 1 & 1.0 & 7.0 & 0.0 & 3.0 & 3.0 & 1.0 & 0.0 & 0.0 & 1.0 & 1.0 & 17.0 & 10.0 \\
\hline 2014 & $\mathrm{CF}$ & 2 & 1.5 & 21.5 & 0.0 & 6.5 & 0.0 & 1.5 & 0.0 & 0.0 & 1.0 & 2.0 & 34.0 & 12.5 \\
\hline 2015 & $\mathrm{CF}$ & 2 & 0.0 & 9.5 & 0.0 & 11.0 & 1.0 & 2.0 & 0.0 & 1.5 & 1.0 & 1.0 & 27.0 & 17.5 \\
\hline 2010 & SD & 1 & 8.0 & 0.0 & 0.0 & 3.0 & 0.0 & 1.0 & 0.0 & 2.0 & 5.0 & 21.0 & 40.0 & 40.0 \\
\hline 2011 & SD & 1 & 8.0 & 0.0 & 1.0 & 1.0 & 0.0 & 2.0 & 1.0 & 0.0 & 0.0 & 5.0 & 18.0 & 18.0 \\
\hline 2012 & SD & 1 & 10.0 & 6.0 & 0.0 & 1.0 & 0.0 & 1.0 & 11.0 & 0.0 & 3.0 & 3.0 & 35.0 & 29.0 \\
\hline 2013 & SD & 1 & 2.0 & 1.0 & 0.0 & 2.0 & 0.0 & 0.0 & 0.0 & 0.0 & 2.0 & 0.0 & 7.0 & 6.0 \\
\hline 2014 & SD & 1 & 4.0 & 38.0 & 0.0 & 5.0 & 1.0 & 4.0 & 0.0 & 0.0 & 0.0 & 2.0 & 54.0 & 16.0 \\
\hline 2015 & SD & 1 & 0.0 & 36.0 & 11.0 & 7.0 & 0.0 & 3.0 & 2.0 & 0.0 & 2.0 & 0.0 & 61.0 & 25.0 \\
\hline
\end{tabular}

${ }^{1}$ Regions where AGFD set gill nets in Topock Marsh.

${ }^{2}$ Sunfish species included bluegill, green sunfish, and redear. 


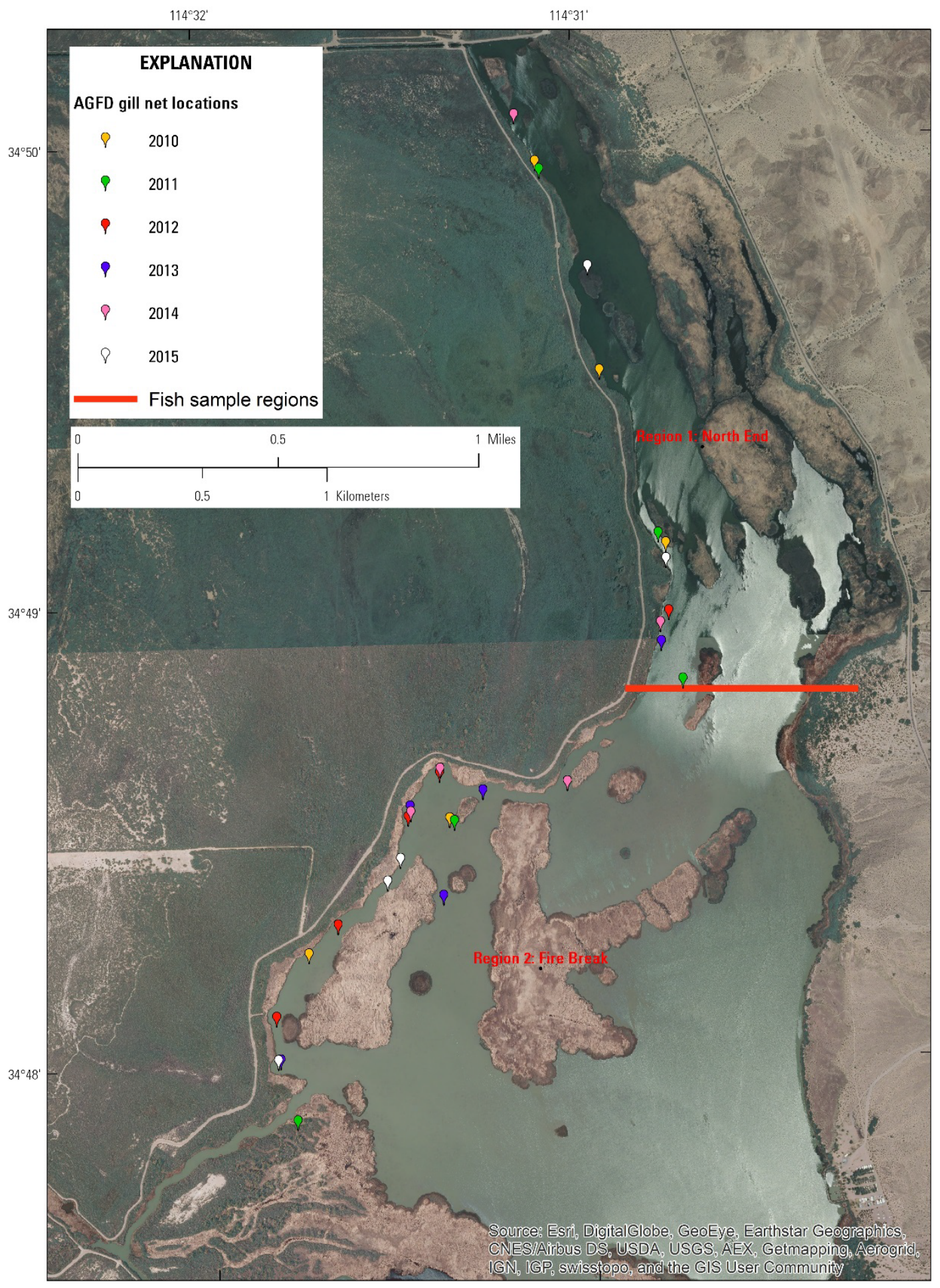

Figure 6. Northern part of Topock Marsh, Arizona, showing gill net locations for the Arizona Game and Fish Department (AGFD), 2010-15. See table 2 for fish numbers captured per net in each region by year. 


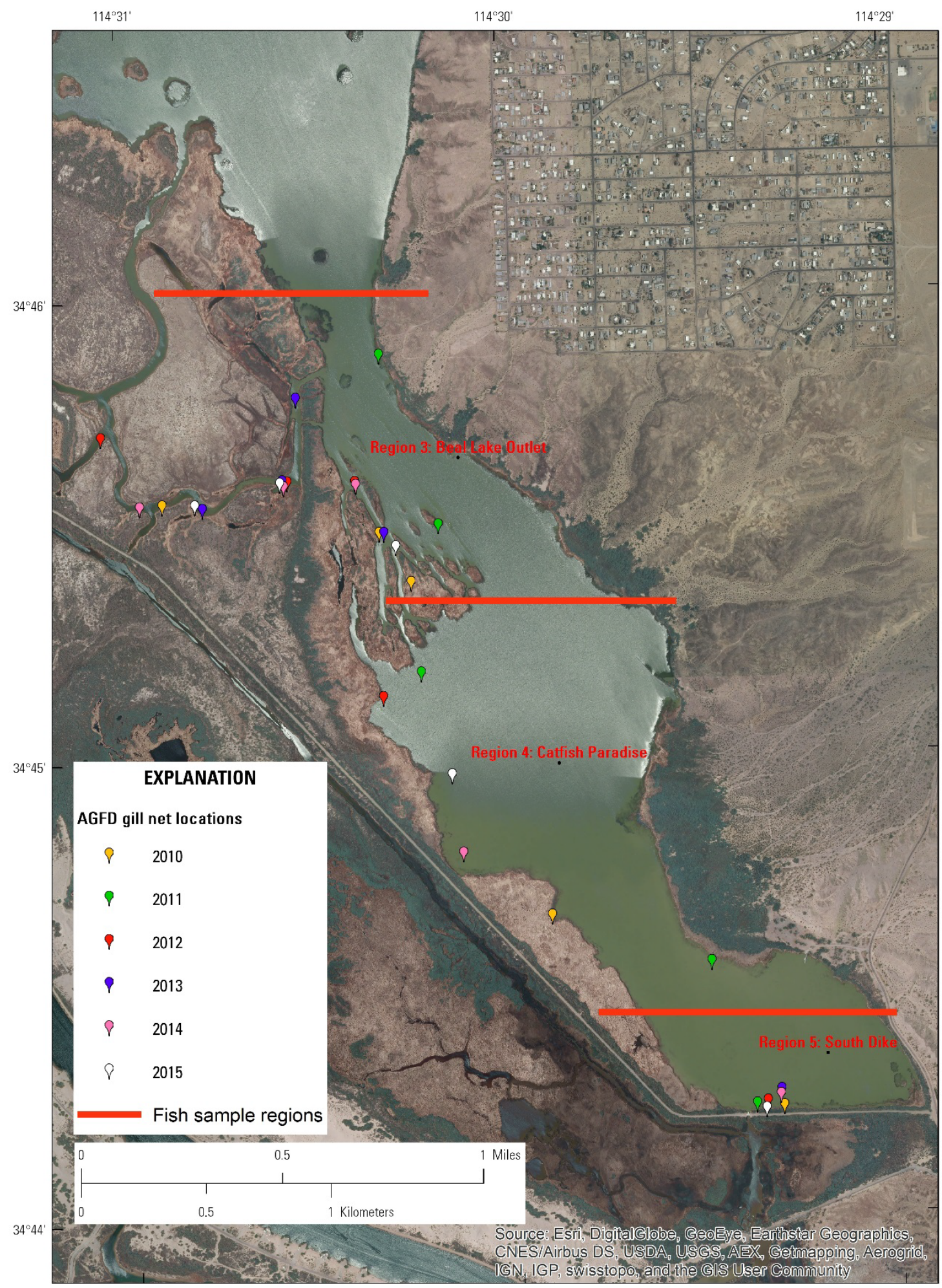

Figure 7. Southern part of Topock Marsh, Arizona showing gill net locations for the Arizona Game and Fish Department (AGFD), 2011-15. See table 2 for fish numbers captured per net in each region by year. 
The total number of fish caught in gill nets increased over time at all locations except Catfish Paradise, where numbers remained relatively the same. However, gizzard shad (Dorosoma cepedianum) first appeared in Topock Marsh in August 2011 (Mitch Thorson, Arizona Fish and Wildlife Conservation Office, written commun., 2011), and they quickly proliferated in subsequent years. If we remove gizzard shad numbers from the totals, the trend changes (table 2). Excluding gizzard shad shows that in the northern end of the marsh, most species decreased from 2010 through 2015. Only striped bass (Morone saxatilis) and channel catfish (Ictalurus punctatus) increased in the northern end of the marsh (although channel catfish declined in 2015 after steadily increasing from 2010 through 2014). Similarly, only channel catfish and striped bass numbers increased in gill nets set near the Fire Break inlet between 2010 and 2015, whereas other species slightly declined or were captured sporadically. In the Catfish Paradise and South Dike regions, common carp (Cyprinus carpio), goldfish (Carassius auratus), and black crappie (Pomoxis nigromaculatus) declined from 2010 to 2015, whereas channel catfish increased, and largemouth bass (Micropterus salmoides) numbers were sporadic. In general, numbers of channel catfish and striped bass increased over time throughout the marsh, whereas carp, goldfish, and largemouth bass numbers decreased (table 2). Razorback sucker (Xyrauchen texanus), the only native fish (and a federally endangered species) in Topock Marsh, was reintroduced in 2010; its numbers increased until 2013; unfortunately, no razorback suckers were observed in 2015 (table 2). These data, along with the water quality data discussed above, suggest that Topock Marsh was suitable habitat for fish after switching inflow from the Inlet Canal to the Fire Break Canal (fig. 1). Perhaps a more relevant fact is that with the rapid increase in gizzard shad, most other fish declined. It is suggested this is a common phenomenon in the area (see http://www.azbassfederation.com/2013/04/17/conservation-alertgizzard-shad-on-roosevelt/) as gizzard shad are considered a potential threat to native and recreational fisheries through competition and predation (Mueller and Brooks, 2004).

Total density and biovolume of phytoplankton at TP-8 were consistently higher than the upstream sampling stations throughout the sampling periods (fig. 3). More specifically, during the period with little to no flow, Bacillariophyta (diatoms) dominated the total phytoplankton biovolume and most of the density in Topock Marsh, with the exception of a large number of cyanobacteria (bluegreen algae) cells that appeared in October 2011. Arizona Department of Environmental Quality (2009) suggests a maximum threshold criterion of 50 percent for cyanobacteria (as percent of total cell count) in warm-water lakes designated for aquatic and wildlife use. This percent threshold was exceeded in October 2011 (fig. 3A), however, according to Dr. John Beaver (BSA Environmental Services, Inc., written commun., 2012) and the World Health Organization (2003), their absolute biovolume and density values were low compared to problem areas elsewhere. During the period of higher flows (2013-14) diatoms remained dominant, with cyanobacteria exceeding the maximum percent threshold during July 2013 (fig. 3A). Still, their biovolume and density values were relatively low.

Rotifers (Rotifera) and copepods (Copepoda) outnumbered all other zooplankton within Topock Marsh throughout 2011-14, but the cladoceran (Cladocera), especially the water flea (Daphnia spp.), biomass far exceeded the rest of the zooplankton (fig. 4). Maximum zooplankton density and biomass were recorded in February 2012, February 2014, and April 2014 at all sampling stations displaying definite seasonal cycles.

Macroinvertebrate taxa collected in Topock Marsh during 2013-14 increased appreciably from the 2011-12 sampling period; however, in 2013-2014 we had more sampling trips where we would expect to collect higher numbers and diversity of macroinvertebrates (spring through fall). During the entire four-year study period, gastropods (specifically Physa sp.) and chironomids (several in the

Chironomidea family) were abundant in all seasons. However, other taxa were also numerous at various times and places. For example, there were relatively high numbers of mayflies (Caenis sp.) in March 
2012 (TP-2) and June 2013 (TP-2 and TP-3); glass/grass shrimp (Palaemonetes sp.) in October 2013 (TP-8); water boatmen (Corixidae) larvae in February and March 2012 (TP-8 and TP-2, respectively) and April 2014 (TP-8); and aquatic oligochaete worms (Oligochaeta) in June 2013 (TP-2), February 2014 (TP-8), April 2014 (TP-2), and October 2014 (TP-2 and TP-8) (J.S. Daniels and J.C. Haegele, USGS, unpub. data, 2016). October tended to have the most individual organisms (in 2011, 2013, and 2014), but the highest number of taxa were collected in June 2013 and April 2014. Large variations occurred between the sampling stations but the total number of individual organisms collected at TP-8 were 4.7 times, 1.8 times, and 2.9 times more than TP-3, TP-2, or TP-6, respectively.

The most notable macroinvertebrate taxa identified was quagga mussels (Dreissena bugensis) and was first discovered at TP-2, near the Fire Break Canal outflow in 2012, soon after river water began flowing into the marsh from this new canal. We expected an increase in numbers of both veligers (larval stage - collected in phytoplankton nets) and adults (with shells - collected from substrate samplers or in macroinvertebrate nets) over time; however; we collected only 12 individual adults (1 each from TP-3, TP-6, and TP-9 and 9 from TP-2) and 20 veligers (from TP-2) during 2013. Nine more adults were counted in February 2014 (three from TP-3 and six from TP-2) and only one veliger (TP-3) individual was collected in 2014. We suspect that quagga mussel have not proliferated in the marsh because of high summer temperatures and turbidity levels (Mackie and Claudi, 2010; Dzialowski and others, 2011), but subsequent monitoring is essential to verify this hypothesis.

\section{Management Relevancy}

Based on the water quality and aquatic biota data we collected and summarized here, we can expect certain water management scenarios to potentially affect various parameters within Topock Marsh. The ideas expressed here can be used as information for the FWS, specifically the Havasu NWR, to better prepare for their future water management needs.

If low inflows and no outflow occur for any length of time in Topock Marsh, specific conductivity will increase throughout Topock Marsh because of evaporation and concentration of solutes, particularly at the southern end of the marsh. Lower water elevations will eventually occur under this scenario, which will encourage more emergent plant growth into currently open water areas, and possibly less submerged vegetation because of potentially more turbid conditions. Although we found no evidence of less fish production because of shallower, more turbid and warmer conditions, those conditions possibly could restrict quagga mussel, Eurasian watermilfoil, and toxic cyanobacteria proliferation.

When the planned infrastructure upgrades are completed, however, the low-flow conditions of 2010-11 are less likely to reoccur. Adequate inflow from the Colorado River and outflow through the South Dike will reduce the potential for evaporation-induced specific conductivity increases and other stagnant water issues not addressed here (that is, avian botulism, avian cholera, and so on; U.S. Geological Survey, 1999), as well as a reduction in the buildup of nutrients, phytoplankton, chlorophyll $a$, and turbidity. Greater water depths maintained at least through the end of June will provide proper soil moisture for southwestern willow flycatcher (Empidonax traillii extimus) habitat (McLeod and Pellegrini, 2012), will control emergent vegetation proliferation but encourage SAV, and possibly reduce water temperatures during the summer, which would benefit fish (Beitinger and others, 2000), not excluding the gizzard shad.

The current Havasu NWR practice of maintaining shallower water depths from late October through mid-December to provide better access to SAV for migrating and overwintering waterfowl is still a viable management practice. Additional adaptive management scenarios incorporating the many conflicting habitat needs can best be determined using the new Havasu NWR DSS which is described in 
the Tier 4 section of this report. By using an adaptive management approach with the Havasu NWR DSS to help analyze various hydrologic scenarios, FWS will be able to evaluate the most effective water management strategies to be incorporated into the Havasu NWR CCP.

Lastly, we suggest continued monitoring and statistical analysis to evaluate long-term impacts of quagga mussels, gizzard shad, cyanobacteria, and Eurasian watermilfoil on the native aquatic flora, fauna, and water quality of Topock Marsh.

\section{Tier 2-Emergent Vegetation Mapping and Assessment using Unmanned Aircraft and Remote Sensing Data}

\section{Introduction}

The primary objective of Tier 2 of the funded project through the 2013 FWS managed monies of the Desert LCC includes using small unmanned aircraft systems (sUAS) to obtain high-resolution, classified aerial imagery to quantify and assess emergent vegetation within the 4,000-acre Topock Marsh in Havasu NWR. This imagery provides a new source of information and data to managers as there are no current or planned aerial surveys for Topock Marsh. The imagery and remote sensing data used to conduct the vegetation assessment that is included in the decision support system (DSS) were developed to help refuge managers understand current marsh resources and suitable wildlife habitats.

\section{Background}

The proposal included flying the RQ-11A Raven sUAS (fig. 8) during the fall, when aquatic vegetation is at its maximum growth stage and high winds are less frequent. The Raven sUAS is a handlaunched reconnaissance and data-gathering tool developed for the U.S. Department of Defense by AeroVironment, Inc., originally designed to provide aerial observation, day or night, at ranges up to 6.2 miles. The Raven sUAS has a wingspan of $4.5 \mathrm{ft}$ and weighs 4.2 pounds. A 60 -minute lithium-ion rechargeable battery powers the system, which also transmits live video (color or infrared imagery), compass headings, and location information to a ground control station. The Raven sUAS has two flight-control methods to navigate the plane, either manually or autonomously, and five modes of flight (manual, altitude, home, loiter, and navigating waypoints). In the manual flight-control method, the pilot controls the plane's flight path and altitude, whereas in the autonomous flight-control method, the plane is flown using pre-established mapped coordinates. The Raven sUAS video cameras are located in the nosecone and have fixed focal length, aperture, and depth of field settings. During flight, the aircraft altitude is used to change the camera's field of view and obtain sufficient pixel resolution to identify the item of interest. As designed, the Raven sUAS has the option of using two types of onboard cameras (a visible wavelength electro-optical [EO] or a thermal infrared [IR] video camera) and two camera positions (either at a 45-degree forward-looking or 45-degree side-looking position). U.S. Geological Survey staff modified the nosecone to allow for the addition of an off-the-shelf point-and-shoot style camera oriented in a straight-down (nadir) view. The Raven sUAS typically is operated by a threeperson flight crew consisting of a pilot, a mission operator, and a trained observer. 


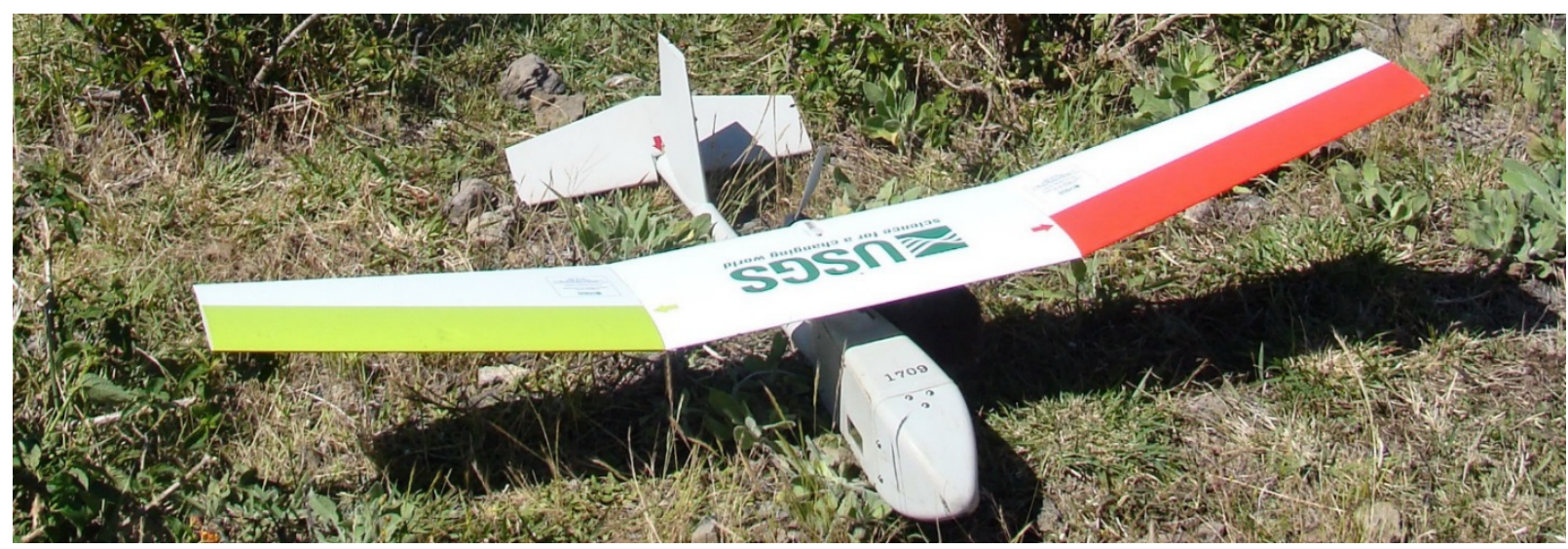

Figure 8. Raven RQ-11A small Unmanned Aircraft System (USGS image).

Approval to fly sUAS in the national airspace requires a Certificate of Authorization (COA) from the Federal Aviation Administration (FAA). Before submitting the COA proposal to the FAA, written approvals from the landowner/land manager and permission for radio frequency use must be secured. Because the Raven sUAS is a decommissioned military vehicle, radio frequency approval is granted from the U.S. Army and the National Telecommunications and Information Administration (NTIA). Additionally, the FAA COA proposal package must contain information about the project, proposed flight operations area (fig. 9), class of airspace, specific airframe description and capabilities, aircraft airworthiness certification, emergency procedures, flight crew qualifications, and any specialuse permits relating to the project. Within the USGS, the COA package is reviewed by the USGS National UAS Project Office, the Bureau Aviation Manager, and the DOI Office of Aviation Services before the package is submitted to the FAA. The FAA-approved COA contains operating provisions specific to the flights (operational altitude, flight area restrictions, and so on), flight crew, safety, local and regional air traffic control centers notifications, and flight reporting requirements. The FAA required having a sUAS pilot who also is a current FAA-certified private pilot at the sUAS control center during flights over the southwestern part of Topock Marsh, as that part of the marsh is within 5 nautical miles of the Needles, California, airport.

To analyze the imagery and discern vegetation types, we used an altered Canon Powershot S100, which was modified to allow infrared wavelengths of light to pass through the camera and be recorded in the image digital file. The use of color infrared photography to study vegetation began in the mid1970s with early research classifying wetland vegetation (Cowardin and Myers, 1974; Williamson, 1975) and has expanded to be a routine tool used in vegetation analysis (Lillesand and others, 2004). Color infrared (CIR) imagery has three wavelength bands: near-infrared (0.7 to 1.5 micrometer $[\mu \mathrm{m}])$, red $(0.6$ to $0.7 \mu \mathrm{m})$, and green $(0.5$ to $0.6 \mu \mathrm{m})$. Color infrared imagery captures information from the vegetation leaf structure; through the analysis of these data, differentiating between species of vegetation is possible (Avery and Berlin, 1992). The near-infrared (NIR) band is useful for examining the spectral signatures of vegetation and by differencing NIR and red digital data using the equation NIR-red/NIR+red to obtain a Normalized Difference Vegetation Index (NDVI). This band ratio equation compensates for surface slope, viewing aspect, and sun-illumination changes (Avery and Berlin, 1992), making it a robust analysis technique. Results of this equation have been used extensively, and since 1984, NDVI-derived maps have been a primary source of growing season data used by the National Weather Service field stations to estimate local crop harvests (Avery and Berlin, 1992). 


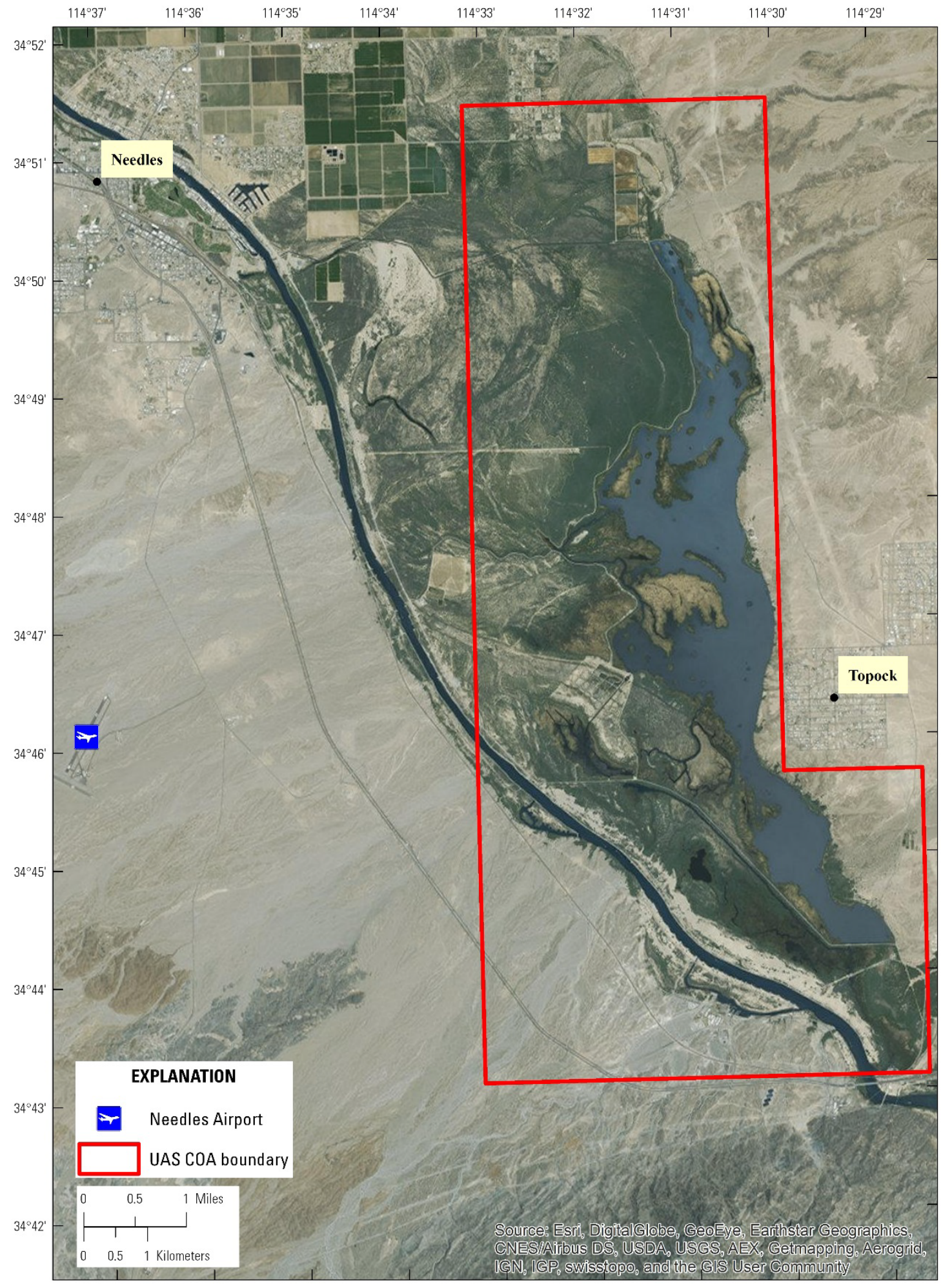

Figure 9. Project area map showing unmanned aircraft system flight operation boundary, Needles airport, Needles, California, and Topock, Arizona. 
Combining aerial imagery with ground collected vegetation data increases the accuracy of maps and vegetation classification products. The land cover map is used as the vegetation layer in the Havasu NWR DSS and underlying habitat data for the three focal species identified by project stakeholders: Yuma Ridgway's rail (Rallus obsoletus yumanensis), southwestern willow flycatcher, and black rail (Laterallus jamaicensis). Project personnel collected 3,842 real-time kinematic Global Positioning System (RTK-GPS) point locations of vegetation, of which 2,836 points were used to ground truth imagery and ensure accurate species classifications. In addition, 12,182 water surface RTK-GPS points were collected by boat and used to classify open water. Our classification includes nine land cover types (table 3): arrowweed (Pluchea sericea), bulrush (Schoenoplectus californicus), cattail (Typha spp.), mesquite (Prosopis glandulosa), no vegetation (bare ground), open water, common reed (Phragmites australis), SAV, and tamarisk (Tamarix spp.).

Table 3. Nine cover types identified in vegetation classification of Topock Marsh, Havasu National Wildlife Refuge, Arizona.

[GPS, Global Positioning System]

\begin{tabular}{|l|c|}
\hline \multicolumn{1}{|c|}{ Land cover type } & $\begin{array}{c}\text { Number of GPS } \\
\text { points collected }\end{array}$ \\
\hline Arrowweed (Pluchea sericea) & 206 \\
\hline Bulrush (Schoenoplectus californicus) & 1,015 \\
\hline Cattail (Typha spp.) & 1,528 \\
\hline Mesquite (Prosopis glandulosa) & 58 \\
\hline No vegetation (bare ground) & 212 \\
\hline Open water & 12,182 \\
\hline Phragmites (Phragmites australis) & 30 \\
\hline Submerged aquatic vegetation (SAV) & 92 \\
\hline Tamarisk (Tamarix spp.) & 238 \\
\hline
\end{tabular}

Aerial image data collection was scheduled to begin fall 2013 but was delayed by the U.S. Federal Government shutdown. Because data collection timing was critical to being able to determine differences between vegetation species, imagery collection was postponed to the fall of 2014 . Twentyfive flights totaling 14.8 hours were conducted between September 29 and October 6, 2014. Transects were made traveling in the north-south direction and were generally collected from west to the east over Topock Marsh. Some adjustments were made with flight timing and the east-west flight order to collect imagery at the beginning and end of each day's flights with approximately the same solar angle to make stitching the imagery together easier. During sUAS data collection flights, we were made aware of the availability of WorldView-2 imagery through the NextView agreement between USGS and DigitalGlobe, Inc.

The WorldView-2 satellite was launched in October 2009, is equipped to collect high-resolution imagery around the globe, is sun-synchronous, and has a re-visit time of 1.1 days. Onboard sensors collect data in the panchromatic $(0.45-0.80 \mu \mathrm{m})$ and eight multispectral (MSS) bands including coastal $(0.400-0.450 \mu \mathrm{m})$, blue $(0.450-0.510 \mu \mathrm{m})$, green $(0.510-0.580 \mu \mathrm{m})$, yellow $(0.585-0.625 \mu \mathrm{m})$, red $(0.630-0.690 \mu \mathrm{m})$, red edge $(0.705-0.745 \mu \mathrm{m})$, near-IR $1(0.770-0.895 \mu \mathrm{m})$, and near-IR $2(0.860$ $1.040 \mu \mathrm{m})$. Ground resolution of the MSS bands range from $1.85 \mathrm{~m}$ at nadir and $2.07 \mathrm{~m}$ at 20 degrees off-nadir look (DigitalGlobe, 2015). Arrangements were made to request a WorldView-2 data collection over Havasu NWR while we were at the refuge and collecting CIR imagery using the sUAS. To obtain a WorldView-2 data collection from DigitalGlobe, a request is submitted to the USGS NextView agreement coordinator, who reviews the request and forwards it to DigitalGlobe for consideration. Our request was submitted and forwarded to DigitalGlobe, and the cloudless data acquisition was made on 
October 11, 2014, five days after we completed CIR data collection with the sUAS. Additionally, cloudless WorldView-2 imagery of Havasu NWR also was available for July 22, 2014. Because of the delay in data collection, and necessity to complete the project under a compressed timeframe, the decision was made to use WorldView-2 imagery instead of processing the 1TB of sUAS-collected CIR imagery. Project personnel used an agreement between USGS FORT and Colorado State University (CSU) Natural Resource Ecology Lab (NREL)/NASA DEVELOP Program and were able to coordinate the processing of the WorldView-2 imagery and obtain a final land cover map. NREL-DEVELOP students used the October 2014 WorldView-2 scene to create a 2-m resolution land cover map of Topock Marsh within Havasu NWR.

\section{Methodology}

Image processing and land cover map development is included in the June 2015 NREL USGS report "Mapping Land Cover and Invasive Tamarisk in Havasu National Wildlife Refuge, AZ" (Young and others, 2015) and provided in appendix 2 of this report.

\section{Results}

Land cover results within the marsh extent as reported in Young and others (2015) includes 10.3 square kilometer $\left(\mathrm{km}^{2}\right)$ open water, $1.31 \mathrm{~km}^{2} \mathrm{SAV}, 7.14 \mathrm{~km}^{2}$ cattail, $1.89 \mathrm{~km}^{2}$ bulrush, $31.1 \mathrm{~km}^{2}$ bare ground, $14.11 \mathrm{~km}^{2}$ tamarisk, $8.09 \mathrm{~km}^{2}$ arrowweed, $0.04 \mathrm{~km}^{2}$ phragmites, and $0 \mathrm{~km}^{2}$ mesquite. Emergent Vegetation coverage was calculated using the CSU land cover model and the GPS ground-truthing we conducted along with the bathymetry data collection. The total coverage by all the emergent species was $10.34 \mathrm{~km}^{2}$. While we pinpointed the specific plant species at a number of locations, the modeling didn't always accurately identify the correct species. Even so, the model fairly accurately predicted the areas covered by either California bulrush (Schoenoplectus californicus) or cattail (Typha spp.), so the area covered by the combination of the two is fairly accurate (fig. 10). 


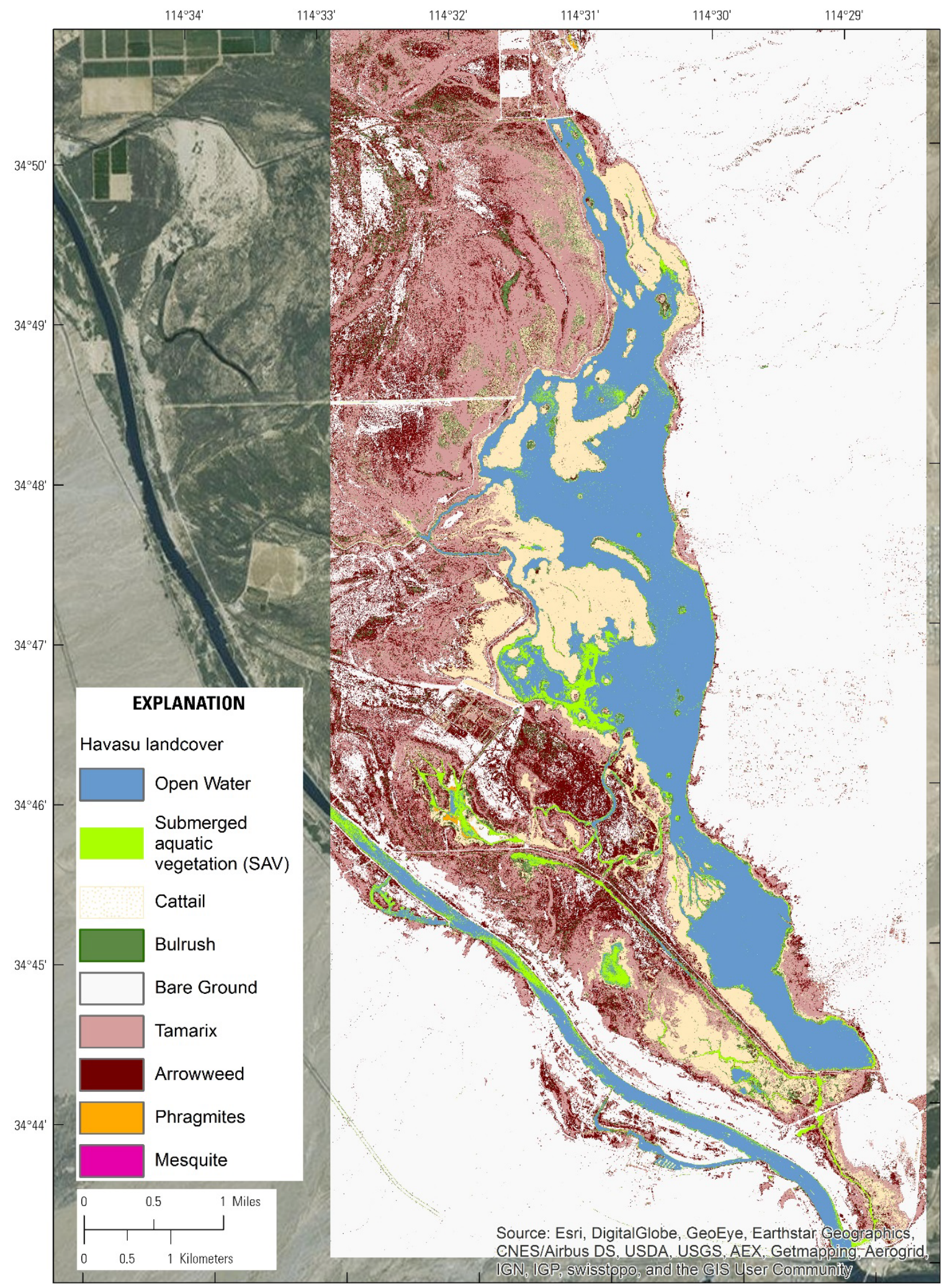

Figure 10. Topock Marsh, Arizona, land cover map displayed in the decision support system (DSS) (from Young and others, 2015). 


\section{Tier 3-Hydrologic Model Development and Marsh Topography}

\section{Topock Marsh Hydrology and Management Requirements}

Topock Marsh is located in the Mojave Desert adjacent to and on the east side of the Colorado River between Needles, California, and Lake Havasu City, Arizona (fig. 1). The marsh is approximately $10 \mathrm{mi}$ long and $2 \mathrm{mi}$ wide at its widest point, and the surface area of the wetland is approximately 4,000 acres (Guay, 2012). The legal history that led to the establishment of Havasu NWR and its water right is reviewed by Shoreline Engineering and Restoration (Shoreline Engineering and Restoration, 2006). The Arizona versus California U.S. Supreme Court Decree of March 9, 1964 (376 U.S. 340 (84 S.Ct. 755, 11 L.Ed.2d 757)), allocated certain water rights to the Havasu NWR to fulfill the purposes of the refuge not to exceed 41,839 acre-feet (acre-ft) of water diverted from the mainstream or 37,339 acre-ft of consumptive use of mainstream water (diversions minus return flows), whichever is less. Given the complexity of the water resources and management needs at Havasu NWR, the FWS collaborated with the U.S. Army Research Office to put together a Water Resource Guide (Guay, 2012) as a primer for decision makers and operation mangers at Havasu NWR. The purpose of the report was to concisely describe and quantify the entitlement, recent diversions, consumptive use, and water availability of the refuge, all in the context of recent and significant infrastructure changes in 2011. Havasu NWR and the other refuges on the Lower Colorado River must plan their management goals and objectives as part of a CCP that identifies issues and opportunities to improve habitat for flora and fauna. The establishment of a CCP for Havasu NWR was a driving factor in the current study and development of the Havasu DSS. Using the background information pertaining to the legal framework, historical marsh operations and management requirements at Havasu NWR documented by Guay (2012), in conjunction with the development of the Havasu DSS and refuge staff expertise, will be instrumental in making sciencebased decisions on operating the current infrastructure system at the Marsh and preparation of a CCP.

\section{Historical Inflows and Water Surface Elevations}

The water that feeds the marsh comes from the Colorado River through the Inlet Canal (built in 1965) at the northern end of the marsh, the Farm Ditch (built in 1968) on the west side of the marsh, and from the Fire Break Canal (completed in September 2011), which is roughly halfway between the Inlet Canal and Farm Ditch (fig. 1). To date, all water has flowed into the marsh by gravity feed. The marsh drains through outlet works in the South Dike (built in 1965) only sporadically when adequate water is available. Each of the diversion canals have bi-directional flow meters and are maintained by Reclamation and USGS, and near real-time data are available from both Reclamation and USGS Web sites (http://www.usbr.gov/lc/riverops.html and http://waterdata.usgs.gov/az/nwis/current/?type=flow). The historical inflows to the marsh from July 2005 to December 2014 are presented in figure 11 and show how the total inflow to the marsh was provided by each gravity-fed diversion canal. 


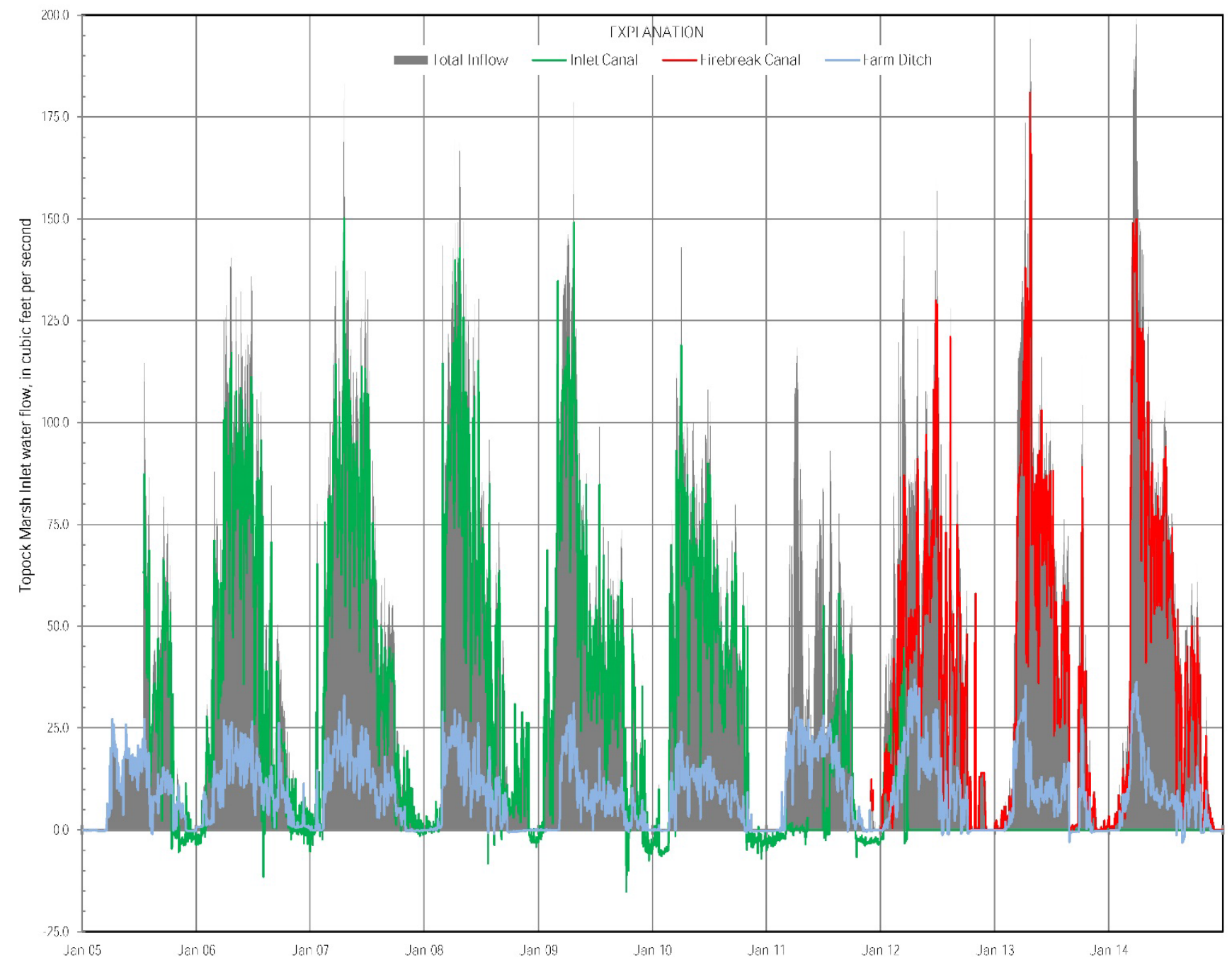

Figure 11. Topock Marsh, Arizona, inlet flows from January 2005 through December 2014.

The historical water surface elevation (WSE) at the South Dike is plotted for July 2005 through December 2014 (fig. 12). The marsh WSE was low in 2010 (maximum elevation $455.8 \mathrm{ft}$ on May 29, 2010) and even lower in 2011 because of the drawdown of the marsh for construction of the Fire Break Canal (maximum elevation $455.17 \mathrm{ft}$ on April 30, 2011), compared to the previous norm during 2006 through 2009 (maximum elevation $456.4 \mathrm{ft}$ ) and a representative high marsh level in 2014 (maximum elevation $456.62 \mathrm{ft}$ on May 11, 2014). The extreme low WSE in the marsh during the sampling period was $453.25 \mathrm{ft}$ on January 15-16, 2012. 


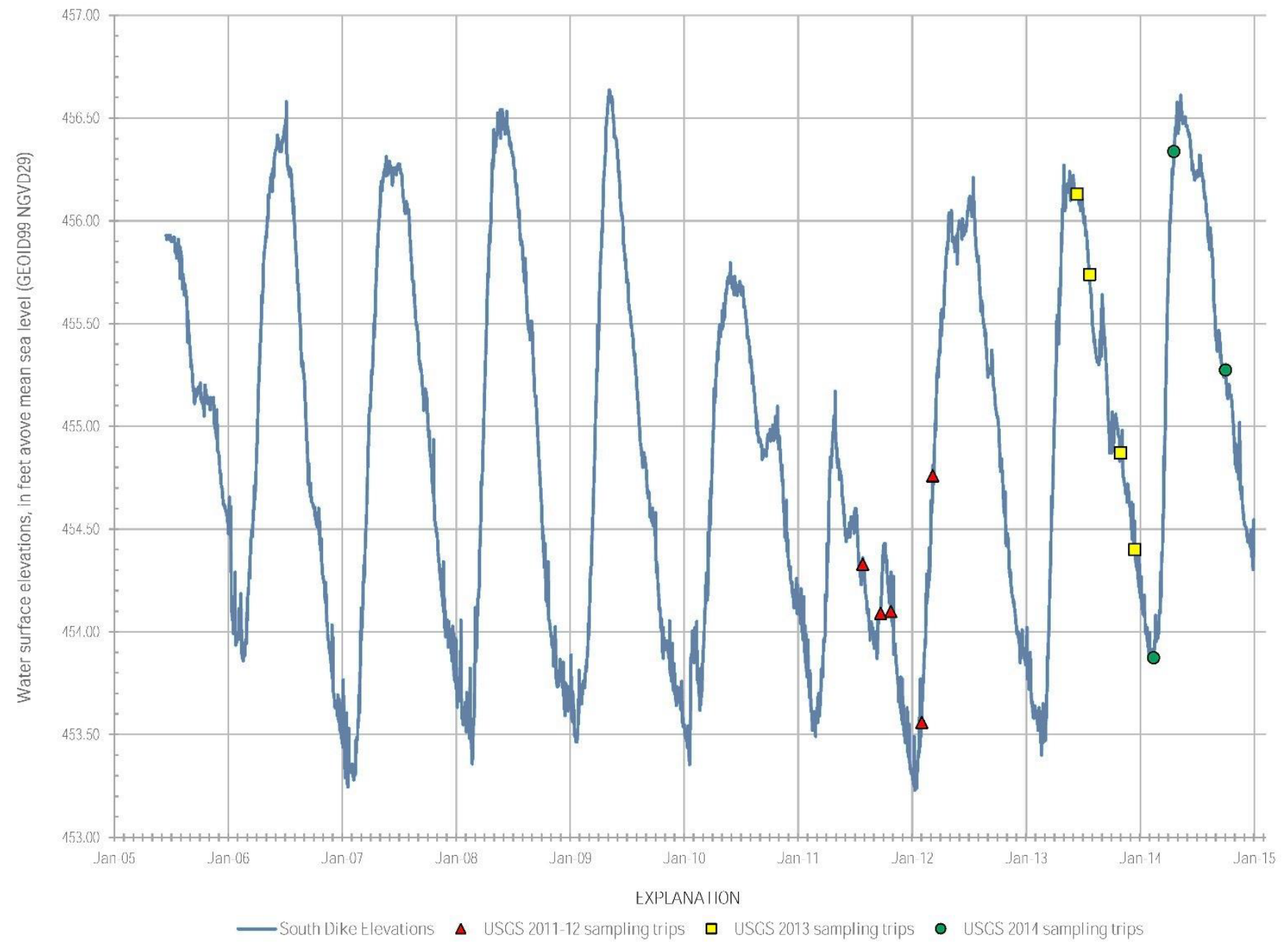

Figure 12. Topock Marsh, Arizona, water surface elevations (WSE) at the South Dike from January 2005 through December 2014. Marsh WSE is based on National Geodetic Vertical Datum 1929 (NGVD29).

Based on feedback from Refuge staff, it was determined that WSEs associated with three historical marsh hydrologic scenarios (high WSE in 2014, historical average WSE, and low WSE in 2011) would be used to provide the initial inputs to the Havasu DSS. Figure 13 shows the three selected hydrologic scenarios plotted by month for comparison. Using these three scenarios provides a comparison of how the differing management scenarios that resulted in the three varying marsh WSE affect available habitat at the marsh for various species. 


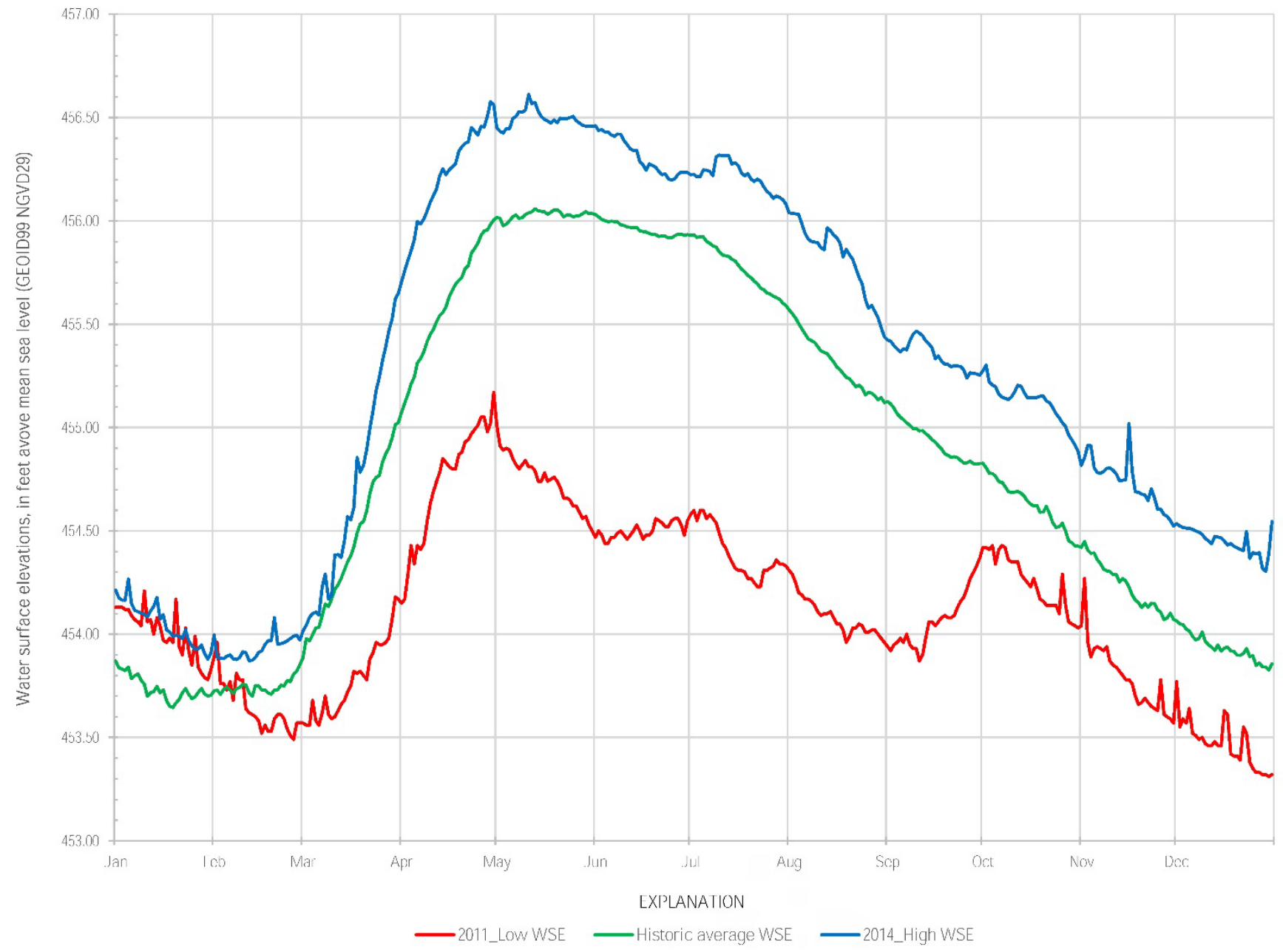

Figure 13. Topock Marsh, Arizona, water surface elevations (WSE) for three historical hydrologic scenarios (wet, average, and dry). Marsh WSE is based on National Geodetic Vertical Datum 1929 (NGVD29).

\section{Topographic Data Collection}

At the study site, a semi-permanent benchmark was established using the Wide Area Augmentation System (WAAS) differentially corrected Global Positioning System. Secondary benchmarks were installed at additional locations within the marsh by real-time kinematic Global Positioning System (RTK-GPS) in the event that the primary benchmark was disturbed and to ensure continuity in radio transmissions from the base station (fig. 14). Precision estimates for survey data relative to the primary benchmarks were approximately $2 \mathrm{~cm}(0.8$ in) horizontally and vertically. All data were projected to the Universal Transverse Mercator (UTM) coordinate system, zone $11 \mathrm{~N}$, using the National Geodetic Vertical Datum (NGVD 29) and the Continental United States (CONUS) 1999 geoid model. 


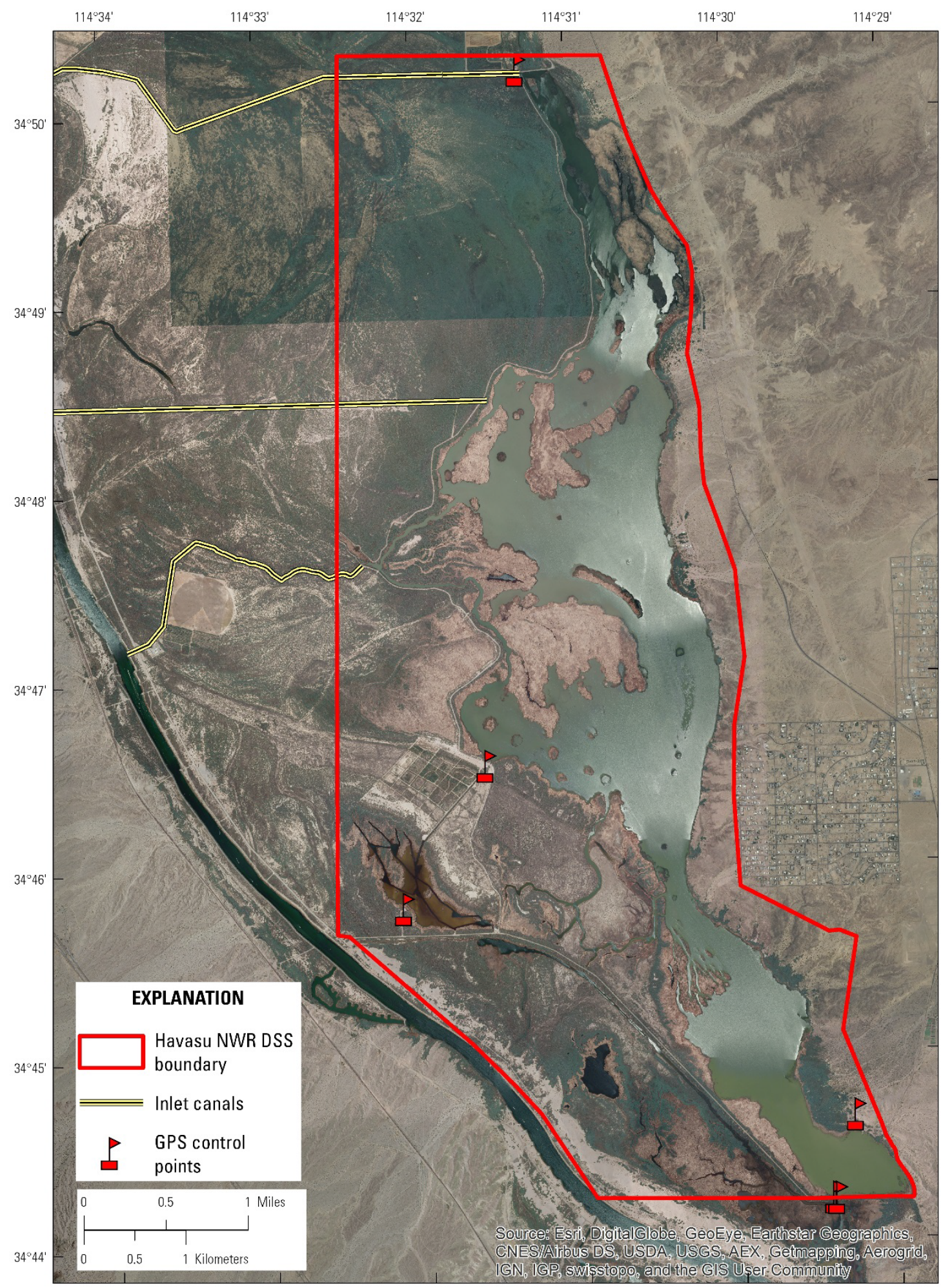

Figure 14. Global Positioning System (GPS) survey control points established at Topock Marsh, Arizona, for the Havasu National Wildlife Refuge (NWR) decision support system (DSS). 
Topographic data were collected remotely using a boat-mounted Acoustic Doppler Current Profiler (ADCP) for deep-water areas and directly using ground surveys of shallow water less than 0.3 meters (1 ft) and exposed areas. Bathymetric data were collected with an RDI Rio Grande Workhorse ADCP equipped with a four-beam (20 degree head angle) transducer mounted in an inboard acoustic well in conjunction with a RTK-GPS receiver. The GPS equipment provided a three-dimensional position of the ADCP transducer. Thus, the horizontal and vertical position of the transducer and water surface elevation is known for each sonar ping. Subtracting the measured depth from the ADCP from the corresponding water surface elevation for each ping gives an elevation of the marsh bottom. Using this equipment, features such as margins, islands, and secondary channels were traced with the ADCP. Three or more bed profiles were measured in the main open-water portion of the marsh and all side channels, with two profiles tracing each bank, one profile down the centerline of the channel, and additional profiles added between the centerline and the bank as needed (fig. 15). The ADCP was calibrated by comparing depths recorded directly by the ADCP with depths measured with a RTK-GPS survey rod at stationary locations within the marsh. In this setting, the accuracy of depth measurements was approximately $10 \mathrm{~cm}(4 \mathrm{in})$.

Where the water was too shallow for the ADCP $(<0.3 \mathrm{~m}$ deep $)$ and in areas that were inaccessible by boat, we collected ground survey data using the RTK-GPS (Trimble R8-3 rover and base station with a Trimble TLD450 radio). Direct survey measurements were taken along breaklines defining the top and bottom of banks, perimeter of vegetated islands, cross-sections of floodplain areas and islands where accessible, and in areas that were too shallow to measure with the ADCP (fig. 16). Water surface elevations and positions were measured using the boat mounted GPS at 10-m (32.8-ft) intervals throughout the marsh to generate a longitudinal profile of the water surface throughout the study site. Marsh elevations were also obtained from the Reclamation stage recorder located at the South Dike outlet structure (http://www.usbr.gov/lc/region/g4000/riverdata/gage-ytd-dailytable.cfm?GAGE=500). 


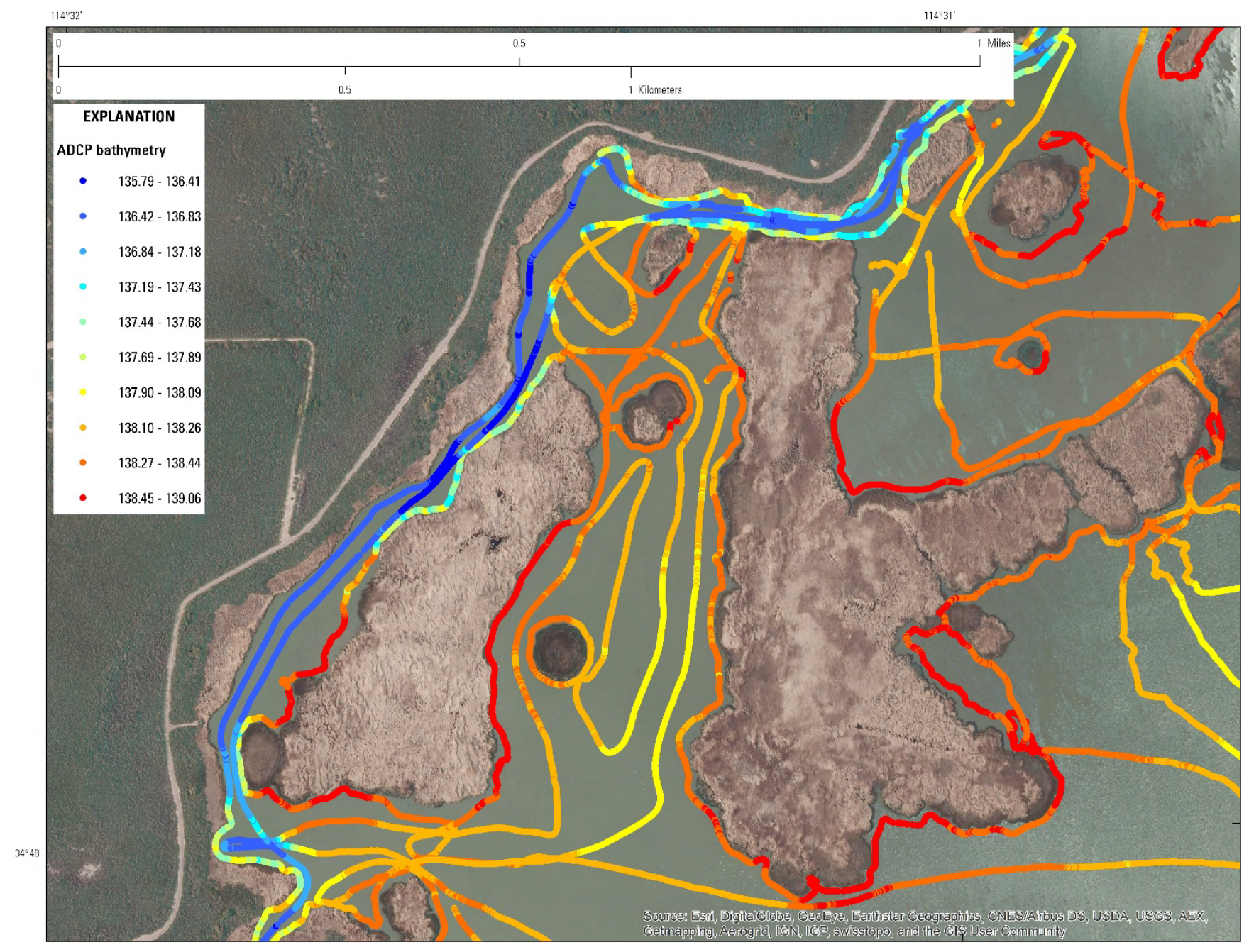

Figure 15. Sample bathymetric data collected at Topock Marsh along various boat traces using Acoustic Doppler Current Profiler (ADCP) and boat-mounted real-time kinematic Global Positioning System (RTK-GPS). 

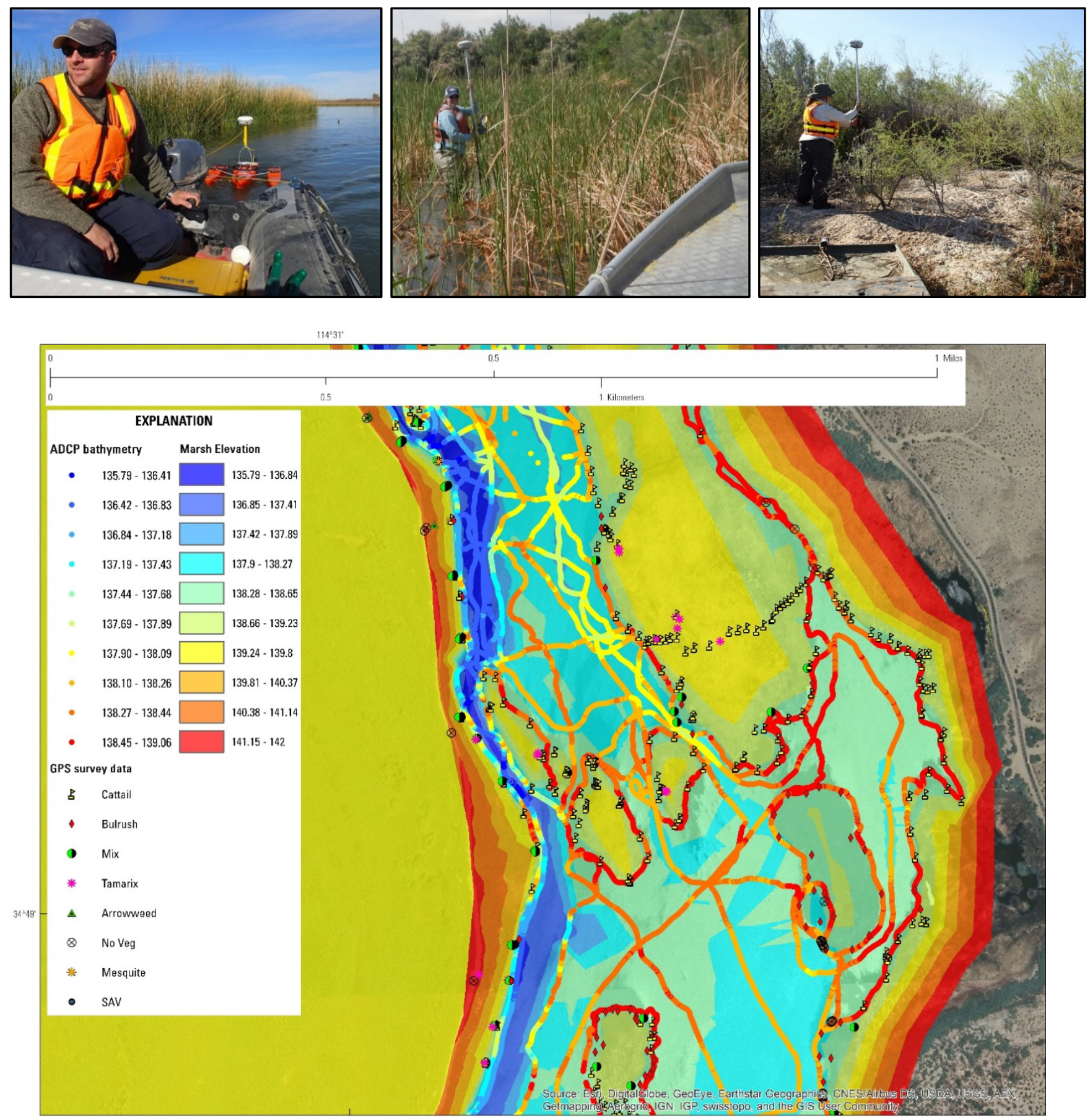

Figure 16. Data sources for input to the digital elevation model describing the marsh topography at Topock Marsh. Contours were derived from digital elevation model (10-meter National Elevation Data for upland areas), marsh bathymetry collected using an Acoustic Doppler Current Profiler (ADCP) (top left panel), and data fill points surveyed directly using a Global Positioning System (GPS) receiver (top center and right panels). Marsh elevation is based on National Geodetic Vertical Datum 1929 (NGVD29) (U.S. Geological Survey images). 


\section{Digital Elevation Model of Topock Marsh}

Raw bathymetry data are rarely, if ever, suitable for immediate use in creating a digital elevation model. Depths measured with the ADCP must be converted into elevations and these elevations merged with direct survey data. The resulting three-dimensional topography file (known as a digital elevation model) must be edited to connect features such as bank edges, islands, or thalweg points and to smooth jagged contour lines that result from spurious triangulations among measured points.

\section{Conversion of ADCP Depths to Elevations}

The elevation of the marsh bed at any point can be calculated as the water surface elevation minus the measured depth at a given location. ADCP data were recorded every second as depths and geographic locations in latitude and longitude. These data were converted to ASCII format using WinRiver II software and projected from latitude-longitude geographic reference into the UTM coordinate system used with the direct survey data. The data were screened for duplicate points and obvious outliers and converted to a $1.0-\mathrm{m}$ by $1.0-\mathrm{m}$ grid in ArcGIS. ADCP data consisted of depth and $\mathrm{x}, \mathrm{y}$ coordinates measured using a RTK-GPS recorded at one-second intervals along the boat traces. Corresponding ADCP water surface elevations (WSE) were measured using the RTK-GPS mounted on the boat at 10-m intervals along the boat traces. Using ArcGIS, a surface of ADCP depths was constructed from the processed WindRiver II output using the TIN (Triangulated Irregular Network) function in ArcGIS and converted to a $1.0-\mathrm{m}$ by $1.0-\mathrm{m}$ grid. Similarly, a water surface elevation layer was constructed from the RTK-GPS data and converted to a $1.0-\mathrm{m}$ by $1.0-\mathrm{m}$ grid, from which the ADCP depth grid was subtracted. The resulting grid of bed elevations was then converted back to point data that could be used compatibly with the direct ground survey data.

Data from digitized aerial photogrammetry, ADCP, and ground surveys were processed and combined to provide topographic input for generating the digital elevation model of the marsh. ADCP data were processed to obtain bed elevations based on ADCP data and concurrently collected GPS positions and elevations. Through this process, a filtering algorithm based on a $0.33-\mathrm{m}$ ( 1 - $\mathrm{ft}$ ) minimum distance between points was used to eliminate duplicate points and flag questionable GPS values (for example, bad GPS reception, loss of base radio link, loss of ADCP/GPS connection). Additionally, a 10-m (30-ft) point spacing along an ADCP trace was selected to represent the marsh topography. A total of 246,217 points were collected using the ADCP, of which 22,129 were selected and used to represent the marsh bathymetry based on the filtering algorithm and flagged GPS points. Based on previous experience, as well as equipment specifications for the ADCP and GPS equipment, we approximate the precision of ADCP-based elevations at plus or minus $10 \mathrm{~cm}$ (4 in). Ground survey GPS data were collected using an RTK survey style that typically provides plus or minus $2 \mathrm{~cm}(0.8 \mathrm{in})$ accuracy in three dimensions. A total of 6,248 points were collected directly using the ground survey GPS. In addition to surveying features and filling in gaps in topographic coverage, ground GPS was used to validate data from the ADCP. Data from all sources were combined to construct a digital elevation model of the marsh. Combining the data from all sources resulted in a total of 28,722 points that were used in creating the digital elevation model.

\section{Quality Control for Echosounder Data}

Before constructing the digital elevation models, we conducted an error analysis by comparing the bed elevations derived from ADCP data with those obtained by direct survey. We located a total of 334 comparable points that were within $2 \mathrm{~m}$ (6.6 ft) of each other and computed the difference in surveyed elevations from those measured by the ADCP. The error distribution chart (fig. 17) indicated 
that 85 percent of the elevations derived from the ADCP were within plus or minus $10 \mathrm{~cm}(4 \mathrm{in})$ of the surveyed elevation, 82 percent were within plus or minus $5 \mathrm{~cm}(2 \mathrm{in})$ and that the errors were nearly normally distributed. Differences in elevations were related to the type of bed material found within most of the marsh as well as the specific point locations that were surveyed with the GPS survey rod (that is, top of cattail rhizome clump versus bottom of rhizome clump) compared with the ADCP measurements which were typically 0.5 to $2.5 \mathrm{~m}(1.6$ to $8.2 \mathrm{ft})$ away from the actual vegetation. The typical bed materials in the marsh consist of silt and clay (J.S. Daniels and J.C. Haegele, USGS, unpub. data, 2016) with local areas of gravel deposits where a small number of arroyos drain into the marsh along the eastern marsh edge. Bed material dominated by silt and clay can be problematic when using acoustic devices as the return signal or backscatter is not as strong or definitive because of the "soft" nature of the material. According to the manufacture specifications (Teledyne RDI Instruments, 2007), the measurement precision of the Rio Grande Workhorse ADCP for bathymetric data collection is two times the bin size which was set to the minimum value of $0.05 \mathrm{~m}$ ( 2 in) during data collection (plus or minus $10 \mathrm{~cm}$ ), so these differences were considered reasonable and acceptable. Because direct survey measurements are inherently more precise than ADCP data, precedence was given to surveyed data points when disparities in contoured elevations were apparent in the bathymetry file. 


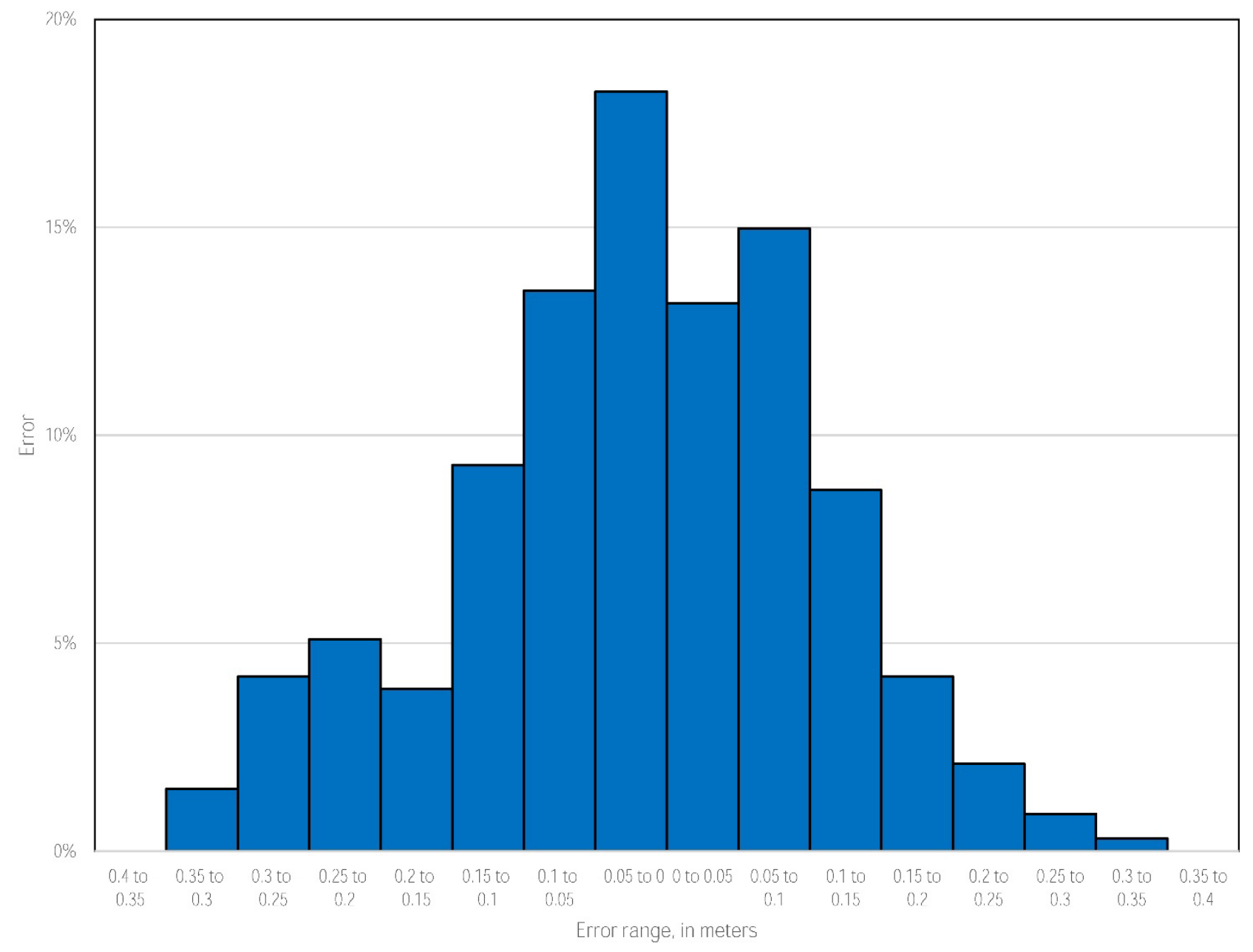

Figure 17. Error distribution of Topock Marsh bed elevations derived from Acoustic Doppler Current Profiler (ADCP) data compared with those obtained by direct survey methods.

\section{Marsh Topography}

In addition to accurate and extensive field data, judgment and experience are necessary to connect the scattered mass data points into a digital surface representation of the marsh and create a digital elevation model. One of the components of the ArcGIS suite of programs is a TIN editor, capable of rapid triangulation and contouring of point data. Generally, elevation transitions in rivers and marshes are relatively smooth (except for the toe-of-bank contour) and highly anisotropic (continuous features are aligned longitudinally in correspondence to the banks and thalweg, Turner and others, 2001). Triangulation of the raw elevation data, however, invariably results in localized areas of sharp transitions, discontinuities of contours in continuous features, and other unrealistic geometry. By addition or deletion of points and by connecting common points with breaklines, a contour is forced to override the ArcGIS default computation. The locations and orientations of the "correct" contours were usually fairly obvious, based on aerial imagery we used as background, and from descriptive coding (for example, for edge-of-bank and island measurements) in the direct survey data. Where definitive information was unavailable, we relied on our collective experience and knowledge of the sites to modify contours. An example of using breaklines to correct for unrealistic geometry that was created by 
the automatic TIN generation within ArcGIS is provided in figure 18. In this example, breaklines were used to properly connect the top of the bank along the edge of a vegetated island and not allow the surveyed bed point connection to a top bank measurement on the opposite side of the island.
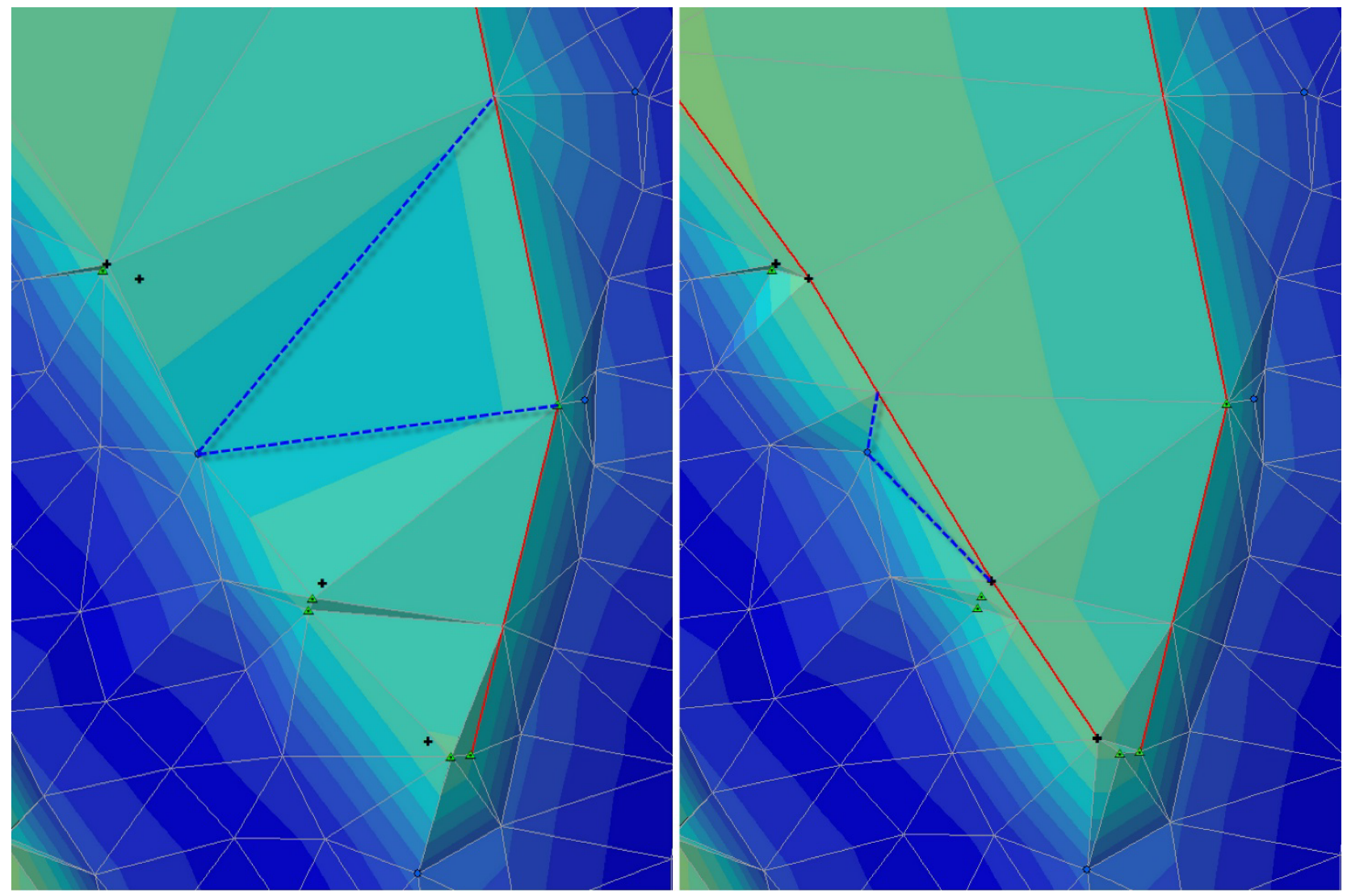

Figure 18. Example of using breaklines to assist in proper triangulated irregular network (TIN) generation from mass point data. Breaklines (shown in red) were used to properly connect the top of the bank along the edge of a vegetated island (shown as blue dashed line on right panel) and not allow the surveyed bed point connection to a top bank measurement on the opposite side of the island (shown as blue dashed line on left panel).

The final digital elevation model representing the topography of Topock Marsh is presented in figure 19. This topography is used by the DSS to calculate water depths throughout the marsh for varying hydrologic scenarios and assess how they affect habitat conditions for various focal species at the refuge. The "Tier 4-Development of Decision Support System for Water and Resource Management" section describes the development of the Havasu NWR DSS for Topock Marsh and how it can be used to better understand the health and function of Topock Marsh under various hydrologic conditions. 


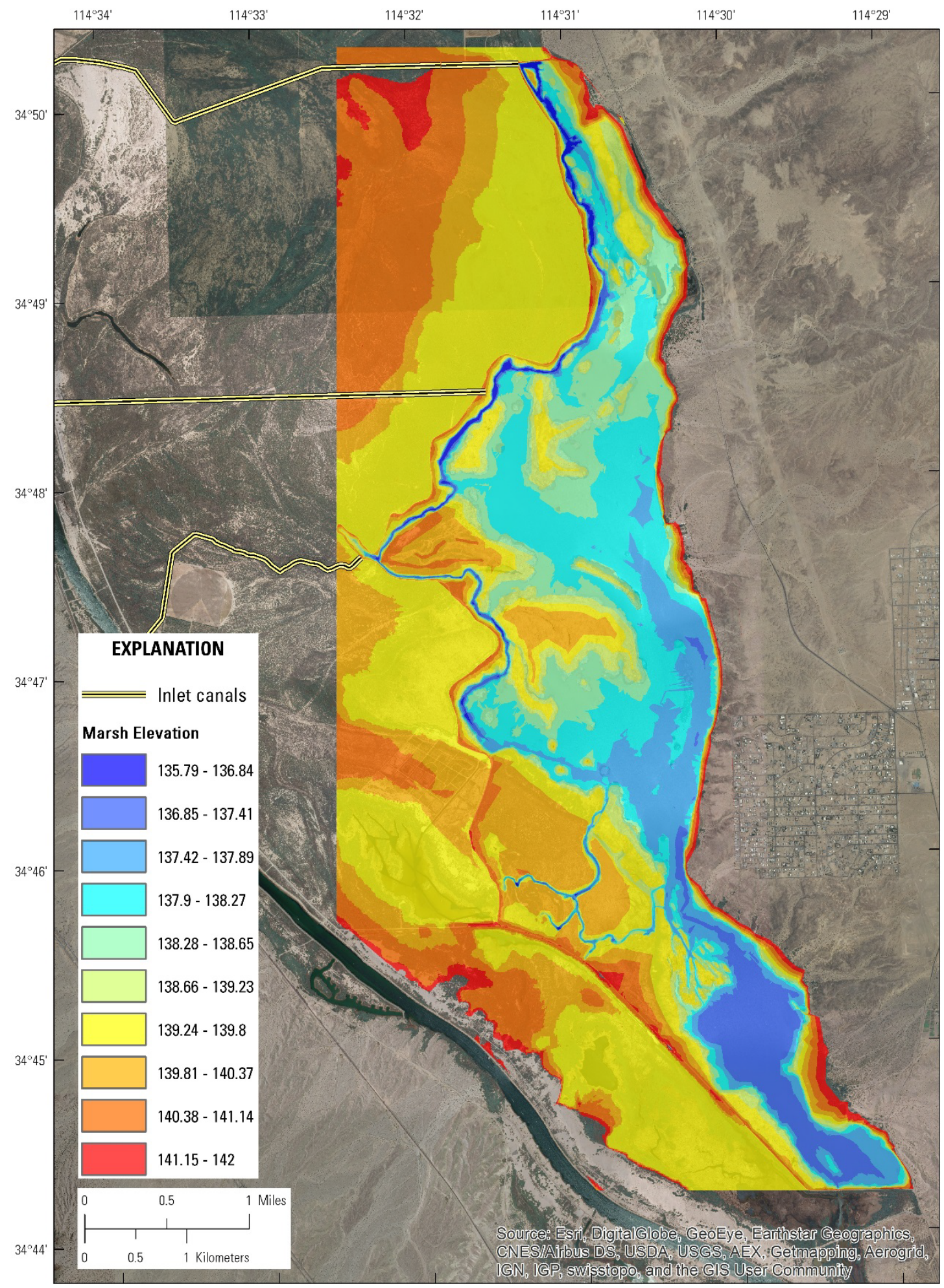

Figure 19. Digital elevation model (DEM) for Topock Marsh, Arizona, using 2014 survey data based on National Geodetic Vertical Datum 1929 (NGVD29). 


\section{Tier 4-Development of Decision Support System for Water and Resource Management}

In developing the Havasu NWR DSS for Topock Marsh, we used the marsh topography and other data obtained in Tiers 1-3 to develop a hindcasting model to create a DSS tool (fig. 20). The Havasu NWR DSS provides spatial habitat analysis at different water elevations within Topock Marsh so that Havasu NWR managers can evaluate various hydrologic scenarios and examine the likely relative changes for a given habitat of concern. The Havasu NWR DSS does not produce any specific biological output (that is, clutch size, plant growth, or juvenile survival) but rather a relative habitat rating. This approach helps the FWS use the best available science to determine more effective water management strategies and assist with developing their CCP. The following sections describe the types of data input, outputs, and relative management scenario comparisons that can be conducted and are available in the current version (1.0.1) of the Havasu NWR DSS.

\section{Decision Support System (DSS) Framework}

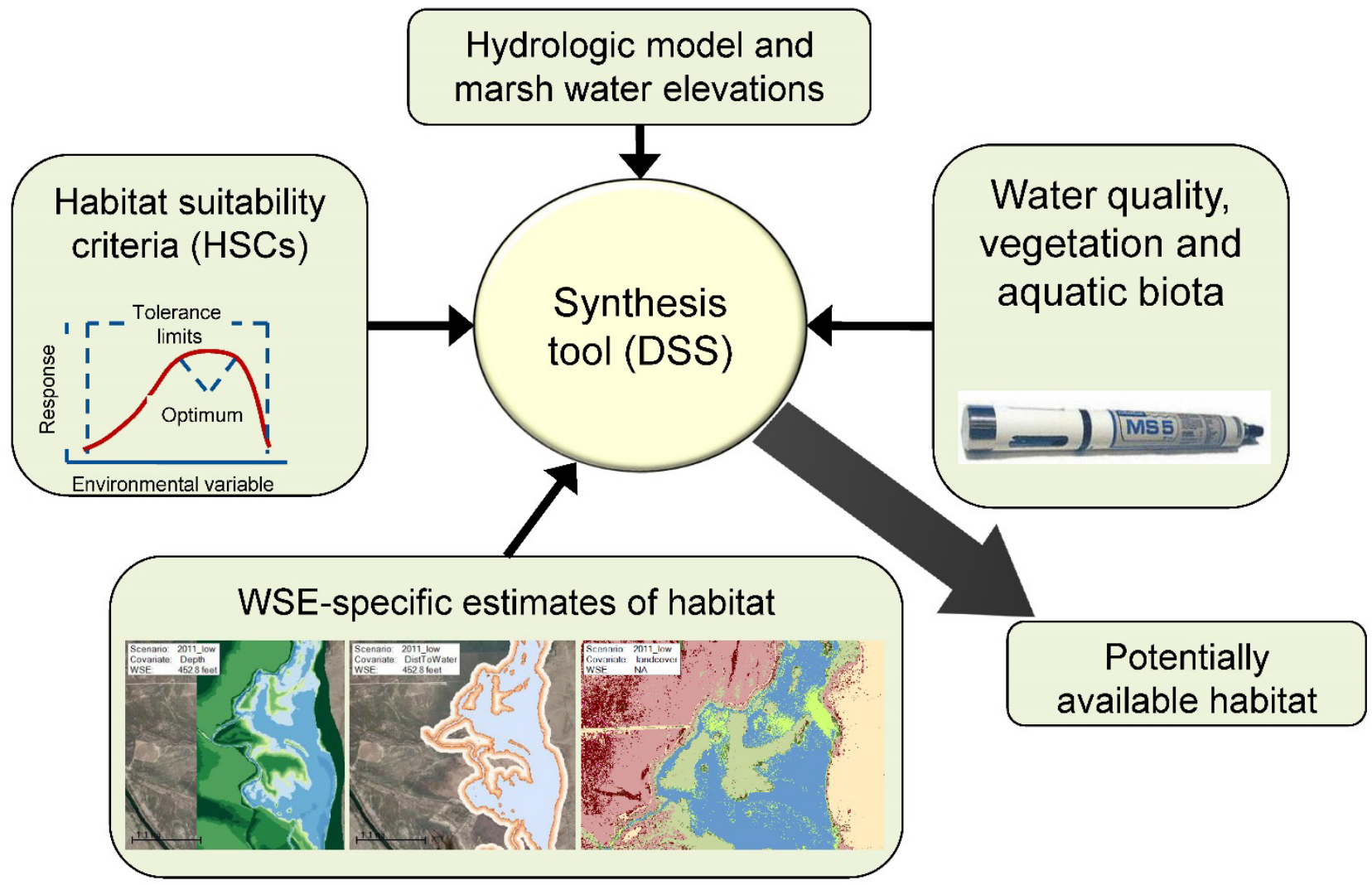

Figure 20. Havasu National Wildlife Refuge (NWR) decision support system framework. 


\section{DSS Inputs}

The following sections describe the types of data input used in the current version (1.0.1) of the Havasu NWR DSS. Inputs to the DSS include information pertaining to water quality and aquatic biota assessments, marsh hydrology and associated water surface elevations, marsh topography, vegetation and land cover, habitat suitability criteria for species of concern, and historic marsh bird survey information.

\section{Tier 1 Water Quality and Aquatic Biota Assessment}

USGS biologists conducted water quality and aquatic biota sampling in 2011 and 2012 to evaluate conditions at Topock Marsh during the unusually low water elevations. This sampling continued throughout 2013-14 to record conditions during more typical water elevations. In total, the marsh was sampled 11 times (indicated on fig. 2) at 4 sampling stations, TP-3, TP-2, TP-6, and TP-8 located north to south, from upstream to downstream and parallel to the Colorado River (fig. 1).

The Tier 1 data portion of the DSS (fig. 21) includes 12 data tables and 26 figures (J.S. Daniels and J.C. Haegele, USGS, unpub. data, 2016). These data are made available through the DSS to illustrate and explain the water quality, sediment and plant chemistry, phytoplankton, zooplankton, macroinvertebrates, fish, and submerged aquatic vegetation measured during the sampling periods. Raw Excel data sheets also are available for a more thorough view of the abiotic and biotic parameters during that time, including the raw submerged aquatic vegetation coverage data. For each abiotic and biotic parameter sampled, the data for the low water period (July 2011 through March 2012) are displayed separately from the more typical hydrological period (June 2013 through October 2014) in each of the figures and tables for comparison. The data are presented as such to enable a quick view of the differences or similarities between the two hydrologic conditions. 


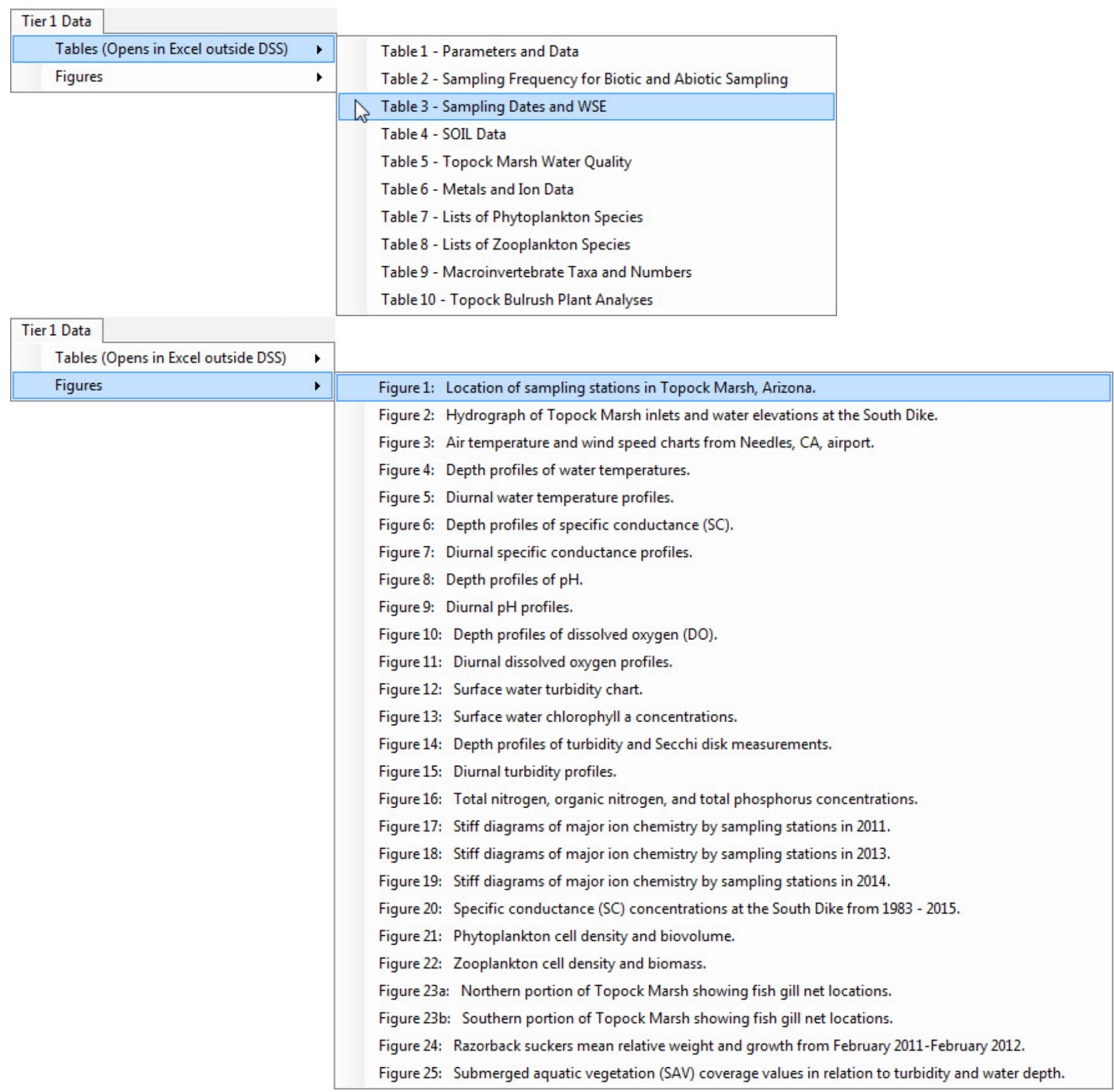

Figure 21. Screenshot example of decision support system Tier 1 data tables and figures menu. 


\section{Marsh Hydrology and Associated Water Surface Elevation}

Water surface elevations (WSEs) associated with three historical marsh hydrologic scenarios (high WSE in 2014, historical average WSE, and low WSE in 2011) are provided as initial inputs to the DSS (fig. 22).

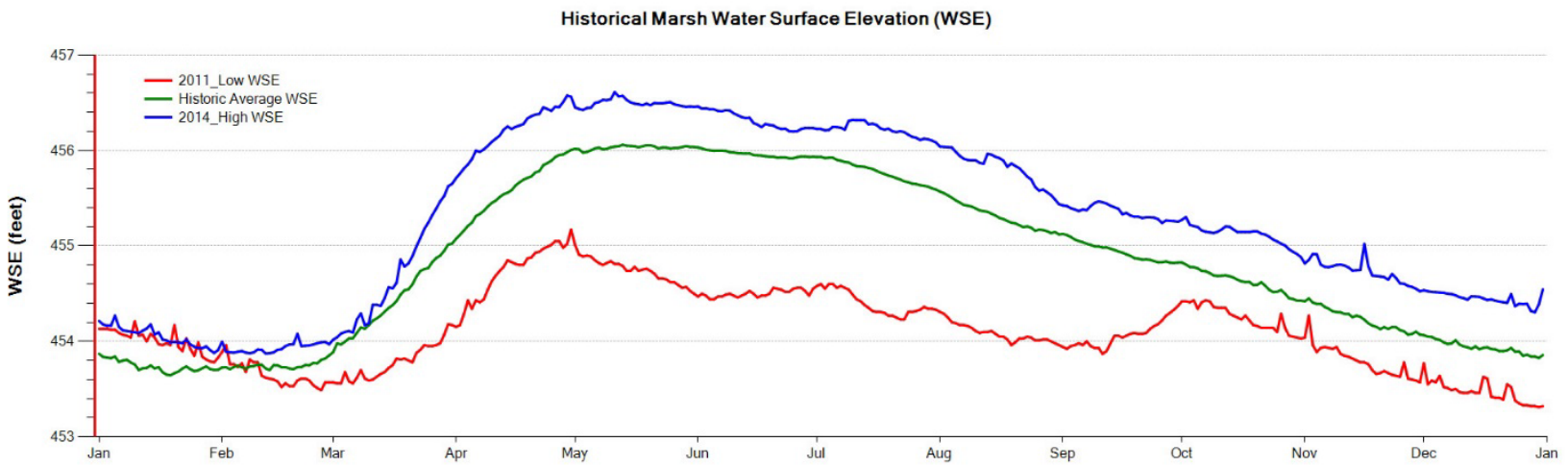

Figure 22. Screenshot example of historical marsh water surface elevations (WSE) for three hydrologic scenarios (wet, average, and dry).

Additionally, the DSS provides the option to add additional water surface elevation (hydrologic) scenarios as needed (see appendix 1 for details). The current version of the DSS (Havasu NWR DSS v1.0.1) contains additional hydrologic marsh elevations associated with three hypothetical hydrologic conditions that provide the maximum amount of available habitat for the three focal species (Yuma Ridgway's rail, southwestern willow flycatcher, and black rail) identified by stakeholders (fig. 23). Although these scenarios may not be viable options for managing the marsh in terms of flow, it provides an example of how marsh elevations affect the available habitat for various species at different spatial and temporal scales.

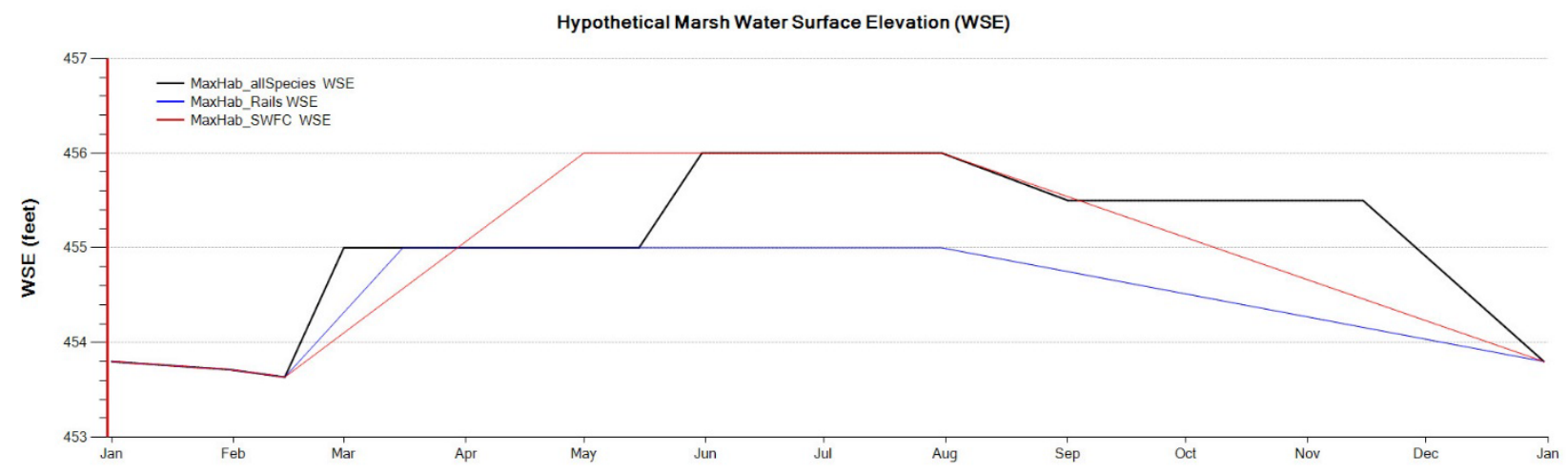

Figure 23. Screenshot example of hypothetical marsh water surface elevation (WSE) scenarios associated with maximum available habitat for three focal species. 


\section{Topography}

The input data for the marsh topography are based on aerial imagery, ground survey points, and ADCP bathymetry collected in 2014. The digital elevation model (fig. 19) derived from the 2014 survey of the marsh provides a "snapshot in time" of the marsh topography (see appendix 1 for DEM input requirements). Although the current topography provided in the DSS is based on 2014 data, future water management scenarios can be analyzed using these data to assess the relative effects future marsh elevations might have on available habitat within the marsh. An example of this type of analysis is provided at the end of this report.

\section{Vegetation/Land Cover}

The vegetation land cover map of Havasu NWR is used as one of the background visual layers within the DSS (fig. 10), and each cell, with its vegetation classification, is used in calculating habitat suitability for the species and lifestages included in the DSS (table 4). As described in Young and others (2015), the vegetation land cover map was developed through computer-processed statistical analysis (radomForest in Program R) of RTK-GPS vegetation points, field data plots collected by CSU staff, and WorldView-2 imagery. Using randomForest as a data analysis tool requires smoothing using a three by three moving window filter to increase classification accuracy. To obtain the best classification possible considering most of the vegetation training data were collected within Topock Marsh (compared to Refuge uplands), Young and others (2015) subdivided their imagery into wetland compared to upland areas. Further misclassifications and noise were filtered out by checking for multicolinearity among the vegetation data. Young and others (2015) presented their interim land cover map to field botanists and refuge managers to obtain feedback on model classification performance. The final land cover model performed well in classifying open water and bare ground but did poorly in classifying phragmites and mesquite. Misclassification also occurred in locations where SAV and dead, standing trees were found within the marsh. The most accurate vegetation classifications occurred with species having the largest training data sample sizes - cattail, bulrush and tamarisk (table 3). This project focused on collecting vegetation data within the wetland area (Topock Marsh) of Havasu NWR; future land cover maps that represent the entire refuge will have better classification accuracy if vegetation training data are collected in both wetland and upland Refuge areas. Multi-temporal vegetation and habitat analysis within the existing DSS framework would be possible with the addition of land cover change maps and incorporating vegetation growth criteria based on modeled hydrologic conditions within Topock Marsh.

\section{Habitat Suitability Data for Species of Concern}

The Habitat Suitability Criteria (HSC) data included in the DSS were developed through combing information from a literature review, summarization of known species-specific and lifestagedependent criteria by Brenda Zaun (FWS Inventory and Monitoring Program Zone Biologist) and input from the staff of Havasu NWR and the U.S. Bureau of Reclamation Lower Colorado River MultiSpecies Conservation Program. These data include HSC information for the 11 species and 3 species groups identified by stakeholders (table 4). Project stakeholders further identified three primary focal species of concern (Yuma Ridgway's rail, southwestern willow flycatcher, and black rail) for inclusion in the initial Havasu NWR DSS development. Included HSC are based on lifestage timeframe, vegetation cover, distance to water, marsh depth, and distance to open water (table 5). As additional sites, species, and lifestage-specific habitat data are collected, better defined, and become available, HSC values should be modified in the DSS to better represent specific habitat conditions used at Topock Marsh by various species. 
Table 4. Eleven species and three species groups included in the Havasu National Wildlife Refuge (NWR) decision support system (DSS) for Topock Marsh, Havasu National Wildlife Refuge, Arizona.

\begin{tabular}{|l|}
\hline \multicolumn{1}{|c|}{ Species } \\
\hline Yuma Ridgway's rail (Rallus obsoletus yumanensis) \\
\hline Southwestern willow flycatcher (Empidonax traillii extimus) \\
\hline Yellow-billed cuckoo (Coccyzus americanus) \\
\hline Black rail (Laterallus jamaicensis) \\
\hline Sora (Porzana carolina) \\
\hline Least bittern (Ixobrychus exilis) \\
\hline Virginia rail (Rallus limicola) \\
\hline Western grebe (Aechmophorus occidentalis) \\
\hline Pied-billed grebe (Podilymbus podiceps) \\
\hline Black-necked stilt (Himantopus mexicanus) \\
\hline American avocet (Recurvirostra americana) \\
\hline \multicolumn{1}{c|}{ Species groups } \\
\hline Geese \\
\hline Dabbling Ducks \\
\hline $\begin{array}{l}\text { Colonial Nesting Bird Guild: Great blue heron (Ardea herodias), Great egret (Ardea alba) } \\
\text { Double-crested cormorant (Phalacrocorax auritus) }\end{array}$ \\
\hline
\end{tabular}

The HSC data included in the Havasu NWR DSS for the three focal species are shown in table 5 and include three lifestages (breeding, breeding combined with foraging, and breeding combined with nesting), the timeframe (identified in months) these species lifestages occur at Havasu NWR, the type of vegetation cover needed by these species during each lifestage, and any identified distance to water, distance to open water, and depth of water criteria required for the species during the identified lifestage. This HSC information is compared cell by cell using the land cover map and appropriate vegetation cover and modeled hydrologic conditions present (water surface elevation, depth, distance to water, and distance to open water) in the marsh during the timeframe for each species and lifestage. Cells meeting all of the HSC for each species and species lifestage are color-coded to display on the various map overlays available to the DSS user. By comparing these maps to the low, average, and high water years included in the DSS, the user "sees" a relative representation of where suitable habitat exists for each species and lifestage for the three hydrologic conditions included in the DSS. These HSC criteria can be adjusted/modified as needed within the DSS to see how it affects the resulting habitat availability (see appendix 1 for detailed description of how to adjust habitat curves).

Table 5. Three focal species, lifestages, and habitat suitability criteria identified by project stakeholders for inclusion in the Havasu National Wildlife Refuge (NWR) decision support system (DSS) for Topock Marsh, Havasu National Wildlife Refuge, Arizona.

[SAV, submerged aquatic vegetation; $\mathrm{ft}$, feet]

\begin{tabular}{|l|l|l|l|l|l|l|}
\hline \multicolumn{1}{|c|}{ Species } & \multicolumn{1}{|c|}{ Lifestage } & Timeframe & Vegetation cover & $\begin{array}{c}\text { Distance to } \\
\text { water }\end{array}$ & $\begin{array}{l}\text { Distance to } \\
\text { open water }\end{array}$ & \multicolumn{1}{|c|}{ Water depth } \\
\hline Yuma Ridgway's rail & Breeding/foraging & $\begin{array}{c}\text { Mid-March } \\
\text { thru July }\end{array}$ & Open water, SAV & $\begin{array}{c}\text { None } \\
\text { specified }\end{array}$ & $\begin{array}{l}\text { None } \\
\text { specified }\end{array}$ & Less than 12 inches \\
\hline Yuma Ridgway's rail & Breeding/nesting & $\begin{array}{c}\text { Mid-March } \\
\text { thru July }\end{array}$ & $\begin{array}{c}\text { Bulrush, cattail, } \\
\text { tamarisk }\end{array}$ & $\begin{array}{c}\text { None } \\
\text { specified }\end{array}$ & $\begin{array}{c}\text { None } \\
\text { specified }\end{array}$ & $0-40$ inches above water \\
\hline Black rail & Breeding/foraging & $\begin{array}{c}\text { March thru } \\
\text { July }\end{array}$ & Bulrush & $\begin{array}{c}\text { None } \\
\text { specified }\end{array}$ & $\begin{array}{c}\text { None } \\
\text { specified }\end{array}$ & $\begin{array}{c}\text { Wet soil to } 2 \text { inches (highest } \\
\text { preference) or } 4 \text { inches } \\
\text { (moderate preference) }\end{array}$ \\
\hline $\begin{array}{c}\text { Southwestern willow } \\
\text { flycatcher }\end{array}$ & Breeding & $\begin{array}{c}\text { May thru } \\
\text { August }\end{array}$ & $\begin{array}{c}\text { Cottonwood, willow, } \\
\text { tamarisk }\end{array}$ & $\begin{array}{c}\text { None } \\
\text { specified }\end{array}$ & $\begin{array}{c}\text { Maximum } \\
1,755 \mathrm{ft}\end{array}$ & None specified \\
\hline
\end{tabular}




\section{Marsh Birds Surveys}

Another information layer included in the DSS is marsh bird survey data. The FWS conducts annual marsh bird surveys within Topock Marsh within Havasu NWR to assess changes in species detected over time at 64 long-standing survey points along 9 survey routes. At each survey point, biologists use a standardized survey protocol, using broadcast bird calls, to both visually and audibly survey for nearby marsh birds. This methodology is thoroughly described in Wildlife Research Report \#2008-01, "Standardized North American Marsh Bird Monitoring Protocols," by Courtney J. Conway (Conway, 2008; Conway, 2011). Briefly stated, the survey methodology prescribes that, at each location, the surveyor will start with a 5-minute passive (silent) period, followed by 30 seconds of black rail, least bittern, Virginia rail, and Ridgway's rail calls, with 30 seconds of silence after each series of calls. This protocol results in a 9-minute site occupation period during which the surveyor will record all marsh birds seen and heard along with an estimated distance to each observation. The FWS provided access to the marsh bird survey data from 2009 to 2015 for the 64 point locations within Topock Marsh. These survey data are accessible through the DSS as a spatial layer, having a blue cross symbol on the map. The DSS user can display, using a dropdown menu, the survey data for a single marsh bird for a single year or all years. Once the user selects the species of interest to display, a compiled layer for each selected year and each selected species will display indicating locations where that species was detected with a circle overlay on the blue cross symbol (fig. 24). The diameter of the circle represents the distance recoded by the marsh bird surveyor on their data sheet. Displaying these data within the DSS allows the user to "see" the data and better understand spatially where the selected species were detected. For the DSS developers, this dataset is extremely helpful in better understanding if the modeled species-specific habitat correlates to real-life species occupancy of these areas-basically providing a qualitative model validation method. As additional marsh bird surveys are conducted, these datasets can be added to the DSS framework by working with the USGS FORT DSS development team if a properly formatted .csv file is available for upload. 


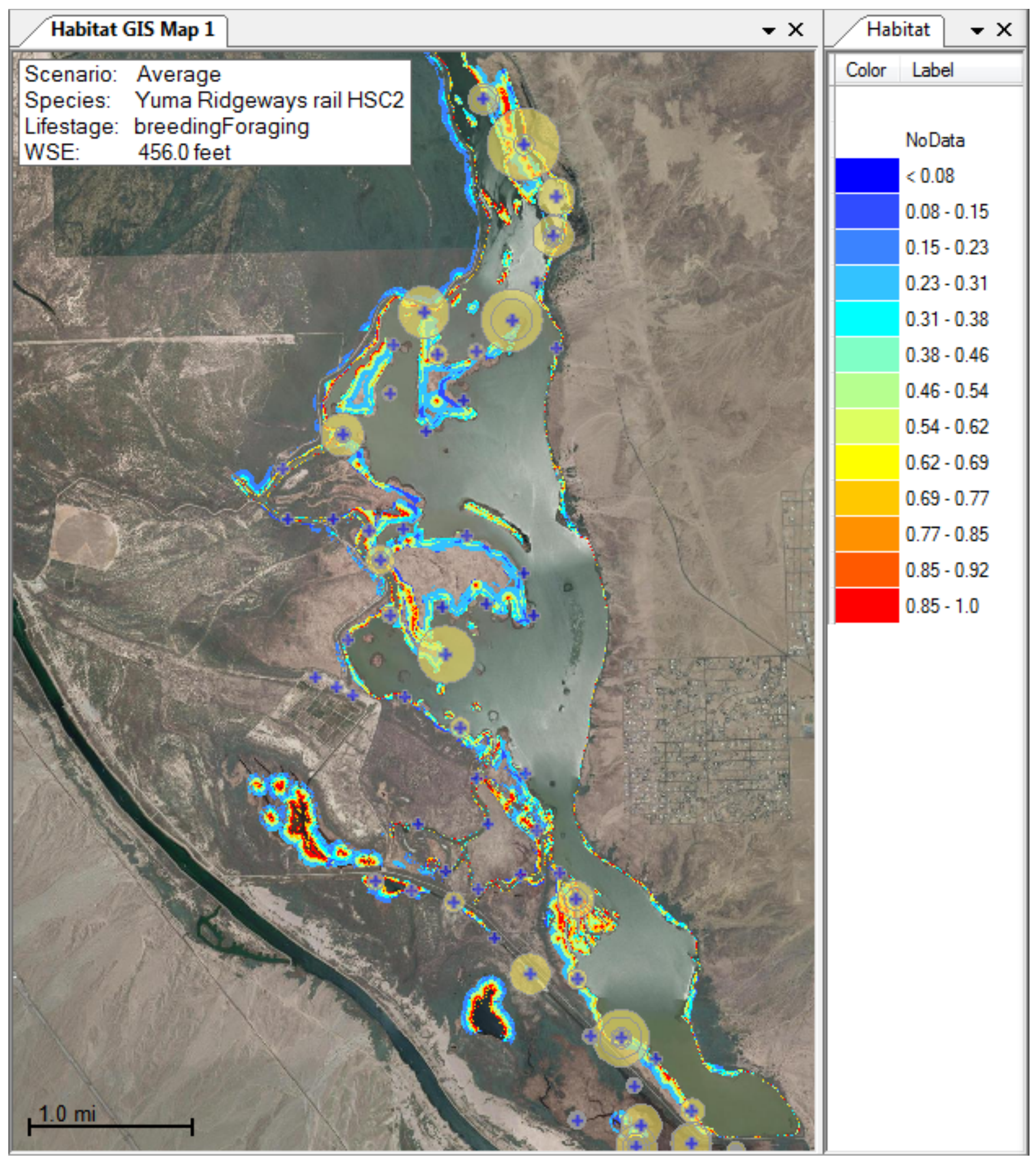

Figure 24. Screenshot example of bird survey data from 2009 to 2014 for Yuma Ridgway's rail at Topock Marsh. 


\section{DSS Output and Predefined Views}

The following sections describe the predefined views that are provided in the DSS to view the input covariates along with various outputs generated by the DSS. These predefined views provide a starting point for users in analyzing the effects of marsh elevations on available habitat and water storage and inflow requirements at Topock Marsh. Although the DSS does not produce any specific biological output (that is, clutch size, plant growth, or juvenile survival), it does provide a tool to identify relative effects of water operations on ecological processes and species-specific habitats that can be used by refuge staff and managers.

\section{Examine Covariates View}

The first predefined view provided within the DSS is the "examine covariates" view (fig. 25). This provides a series of spatial overview maps of Topock Marsh displaying three different covariates (depth, distance to water, and land cover) for the 2011_low water and 2014_high water scenarios. The segment maps provide basic GIS map controls allowing the user to move, zoom in/out, and identify information as needed using the mapping toolbar. The lower part of the screen shows the marsh water surface elevations throughout the year for each hydrologic scenario (2011_low water, historical average, and 2014_high water). Using this view, the user can compare how the depth within the marsh, as well as the distance to water, varies based on a given marsh water surface elevation. Figure 25 shows that for the same time of year (April 1) under differing hydrologic scenarios, in 2011 the marsh water surface elevation was $0.46 \mathrm{~m}(1.5 \mathrm{ft})$, lower than in 2014. The lower water surface elevation in 2011 resulted in more exposure and less inundation of the cattail and bulrush islands. 


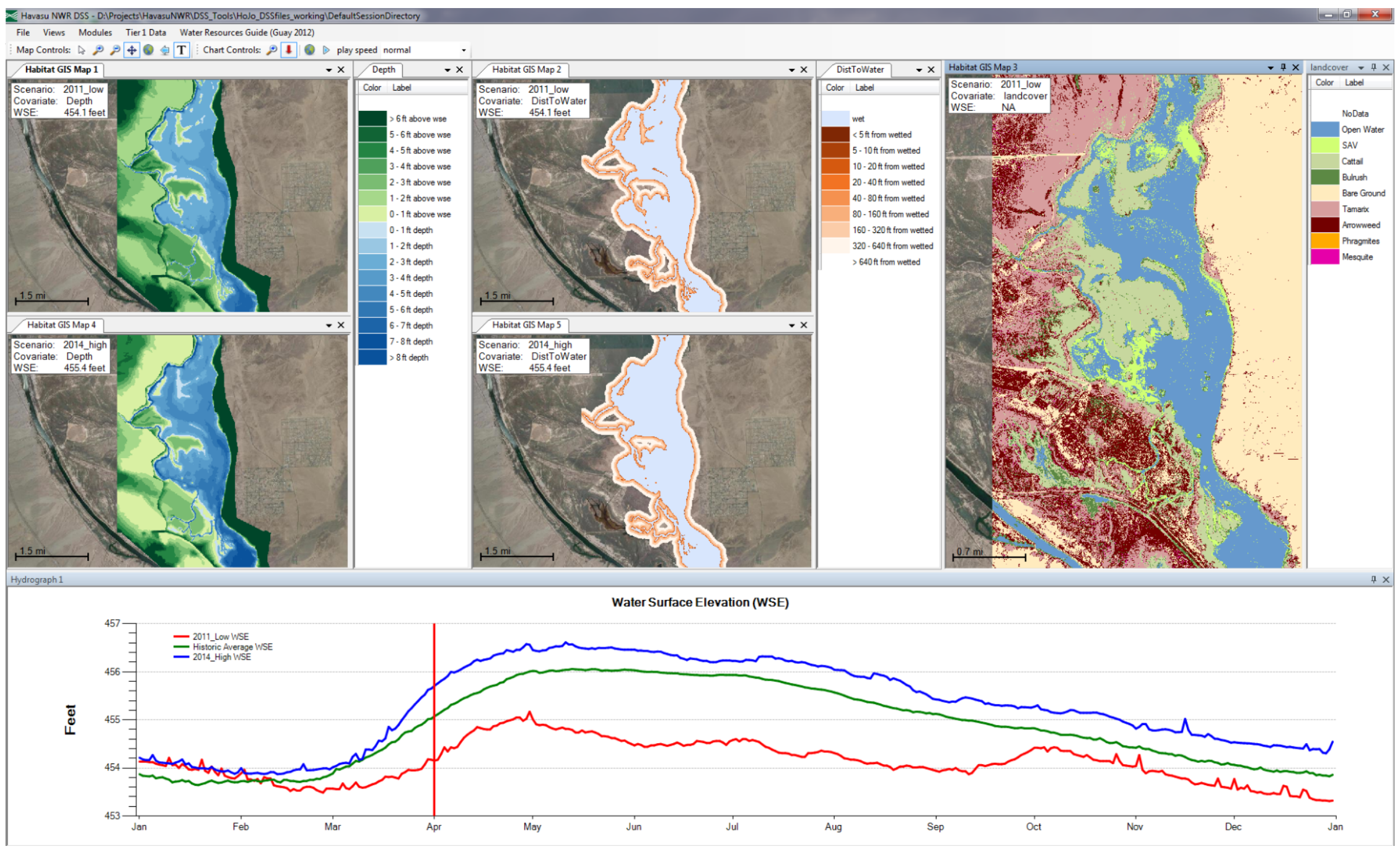

Figure 25. Screenshot example of covariates view within the decision support system (DSS) showing historical comparison of marsh depth and distance to water on April 1 for the 2011_low and 2014_high marsh hydrologic scenarios. 


\section{Habitat versus Water Surface Elevation (WSE) Curves}

The habitat versus WSE curves view provides a summary plot of suitable habitat using the HSC criteria for a given species and lifestage as a function of marsh elevation (fig. 26). This is calculated for the entire range of marsh elevations ranging from $452.8 \mathrm{ft}$ to $456.7 \mathrm{ft}$ at prescribed 4-inch increments. Based on the marsh topography and each water surface elevation, the HSC data are applied to the associated water depth, distance to water, distance to open water, and land cover type to calculate the amount of available habitat for the entire range of marsh elevations. This process provides a way to identify the range of marsh elevations that provide the maximum amount of suitable habitat for each species and lifestage. The lower graph in figure 26 shows the daily marsh WSE for a given scenario along with the amount of available habitat that was calculated based on the HSC data for the selected species and lifestage. The yellow box represents the timeframe for the breeding/foraging lifestage for Yuma Ridgway's rail. This shows how available habitat for a given species and lifestage changes through time based on a given hydrologic scenario.

The default HSC values (for example, HSC1) that are delivered with the DSS are very broad in nature and based on general habitat preferences for each species and lifestage found in the literature. We are currently (2016) working with refuge staff to identify possible site-specific habitat criteria for Topock Marsh. As additional sites, species, and lifestage-specific habitat data are collected, better defined, and become available, the HSC values should be modified in the DSS to better represent specific habitat conditions used at Topock Marsh by the various species. To illustrate the importance of having more refined site-specific HSC criteria and how they might affect the amount of suitable habitat that is estimated using the DSS, we have provided the option to enter a second set of HSC values (HSC2) for sensitivity testing purposes for the three identified focal species (fig. 27). 


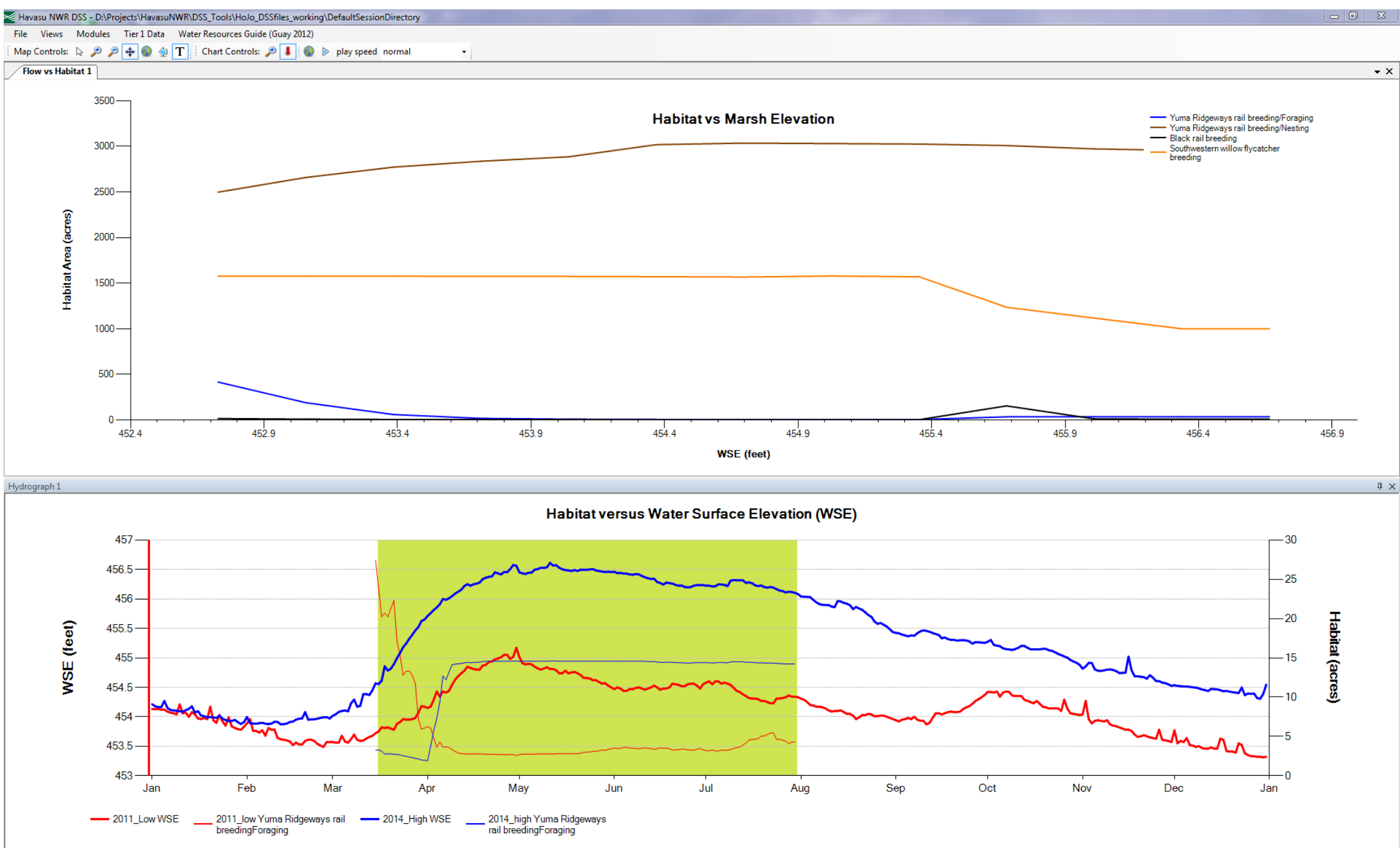

Figure 26. Screenshots of habitat versus marsh elevation for three focal species (Yuma Ridgway's rail, black rail, southwestern willow flycatcher) using the default HSC1 data and associated habitat calculated for each hydrologic scenario for Yuma Ridgway's rail HSC1 breeding/foraging. 


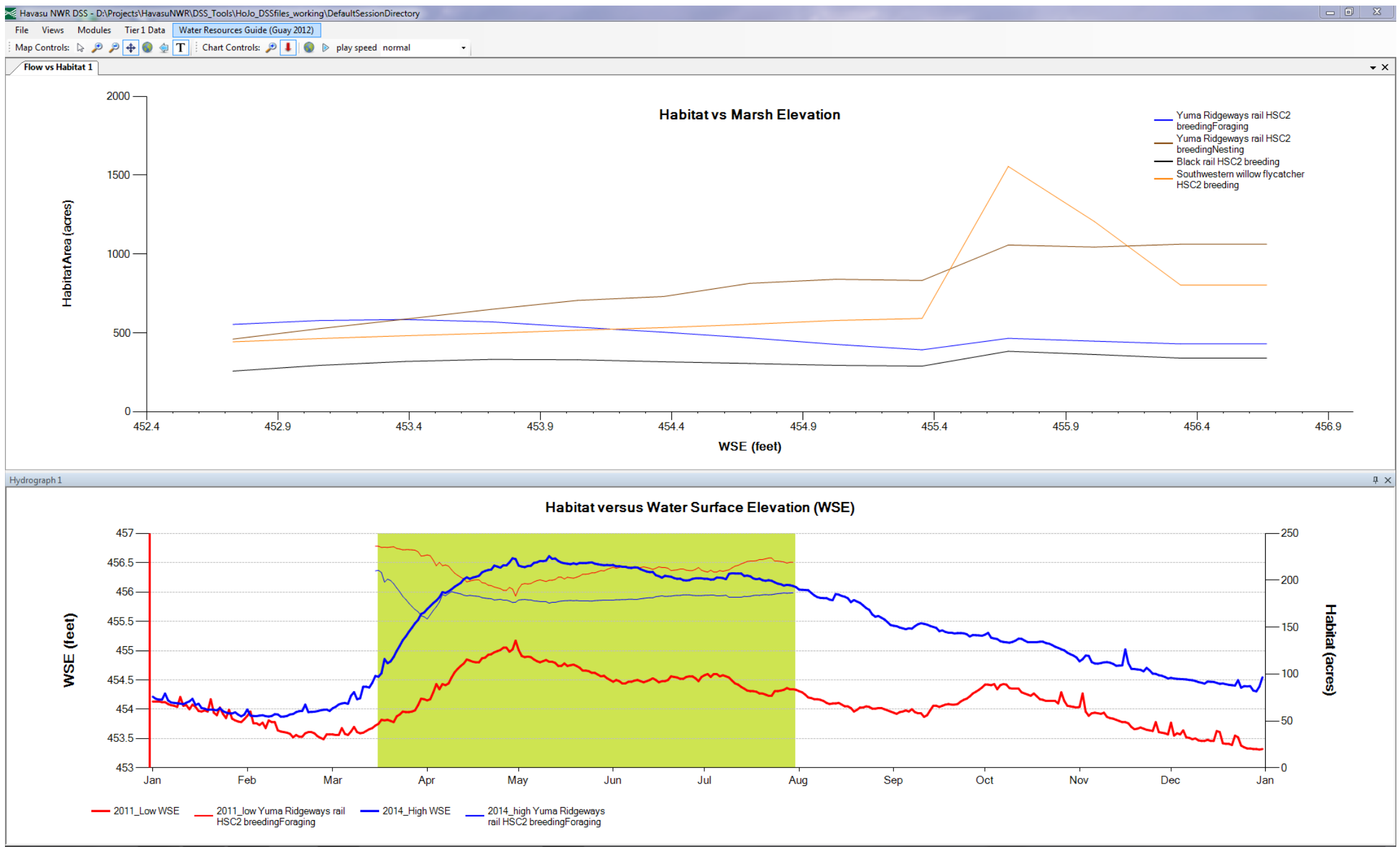

Figure 27. Screenshots of habitat versus marsh elevation for three focal species (Yuma Ridgway's rail, black rail, southwestern willow flycatcher) using hypothetical HSC2 data and associated habitat calculated for each hydrologic scenario for Yuma Ridgway's rail HSC2 breeding/foraging. 


\section{Edit Habitat Suitability}

The edit habitat suitability view (fig. 28) provides a series of Topock Marsh spatial overview maps displaying four different covariates (depth, distance to water, distance to open water, and land cover) for a specified water management scenario as well as the resulting available habitat based on the HSC for a given species and lifestage. The segment maps provide basic GIS map controls allowing the user to pan, zoom in/out, and identify information as needed using the mapping toolbar. The lower left part of the screen shows the marsh water surface elevations throughout the year for each hydrologic scenario (2011_low water, historical average, and 2014_high water). Using this view, the user can compare how the HSC covariates change based on a given marsh water surface elevation. The user can change the existing HSC values by either adjusting the line within the chart or by entering numeric values directly into the table. Appendix 1 provides a detailed description of how to adjust the HSC curves. This view is used to enter the HSC data as well as determine how variations in HSC affect the available habitat based on a given water management scenario.

We have provided the option in the DSS to enter a second set of HSC values (HSC2) for sensitivity testing purposes for the three identified focal species. Providing the second set of hypothetical HSC data values provides a method for researchers and refuge staff to conduct a sensitivity type analysis to compare how variations in HSC data affect what is considered suitable habitat for a given species and lifestage at Topock Marsh. Using refuge staff expertise and their local knowledge of the types of habitat conditions that are used by the focal species can greatly assist in developing siteand species-specific HSC data for Topock Marsh. 


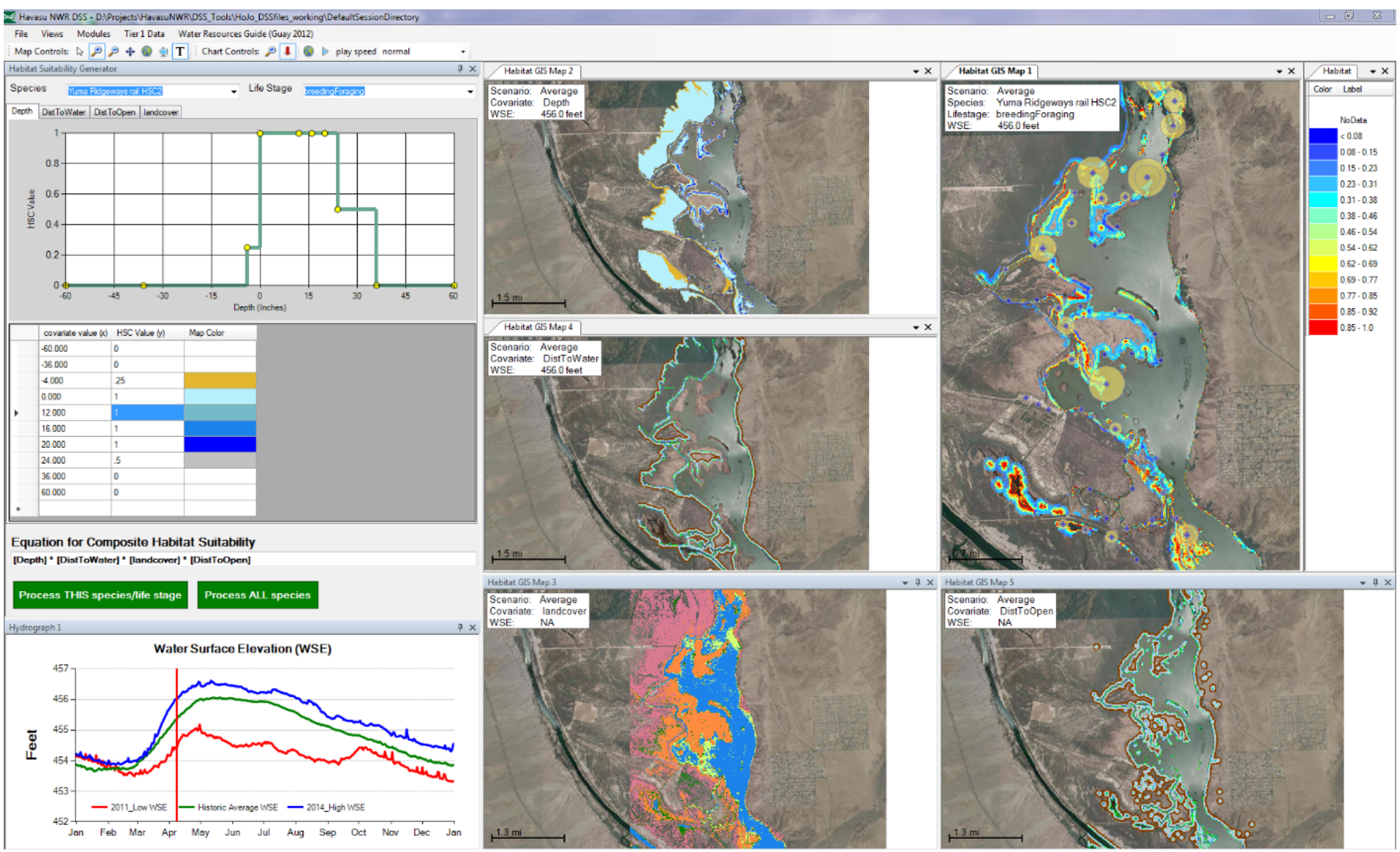

Figure 28. Screenshot example of edit habitat suitability view with segment maps displaying available habitat for Yuma Ridgway's rail HSC2 breeding/foraging at water surface elevation equal to 455 feet. 


\section{Suitable Habitat Comparison-HSC1 versus HSC2}

The suitable habitat comparison-HSC1 versus HSC2 view (fig. 29) provides a series of spatial overview maps of Topock Marsh displaying the resulting suitable habitat conditions based on the default HSC1 and hypothetical HSC2 criteria for a given species and lifestage and two water management scenarios. The segment maps provide basic GIS map controls allowing the user to pan, zoom in/out, and identify information as needed using the mapping toolbar. The far right part of the screen shows the marsh water surface elevations throughout the year for each hydrologic scenario (2011_low water, historical average, and 2014_high water). Using this view, the user can compare side by side how the amount of suitable habitat changes between the two differing HSC criteria (HSC1 versus HSC2) based on a given point in time for two differing hydrologic scenarios. The user can change which species and lifestage as well as which hydrologic scenarios are compared and displayed by right clicking on the chart and overview maps and selecting the variables of interest from the context menu. In addition to displaying the suitable habitat, this view also displays the marsh bird survey data for Topock Marsh. Displaying both of these sets of data at the same time is extremely helpful in better understanding if the modeled species-specific habitat associated with differing HSC criteria correlates to real-life species occupancy of these areas. During initial DSS development, this process of comparing the modeled suitable habitat with real-life species occupancy is what led to the inclusion of the hypothetical HSC 2 criteria for sensitivity testing purposes and provides a method for refuge staff to investigate the possibility of more site-specific habitat criteria for the species and habitat conditions used within Topock Marsh. 


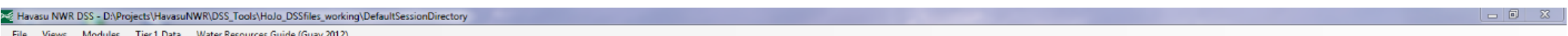

File -

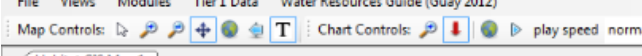

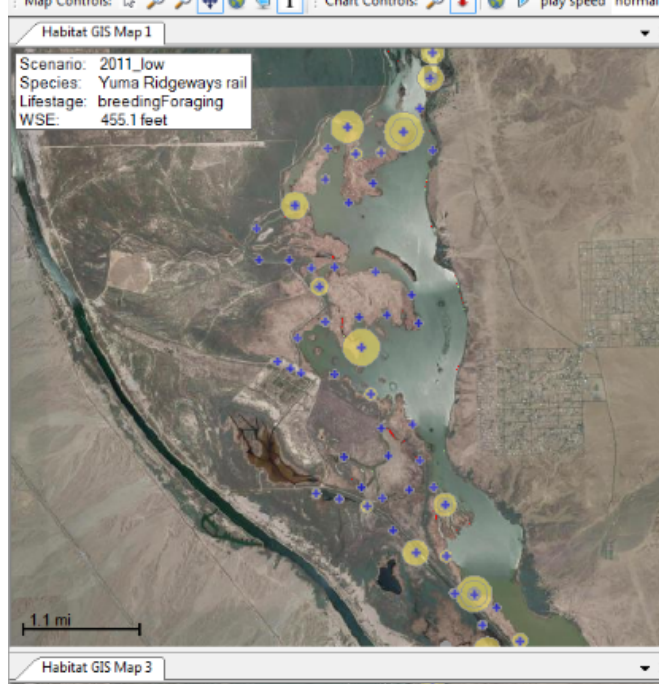

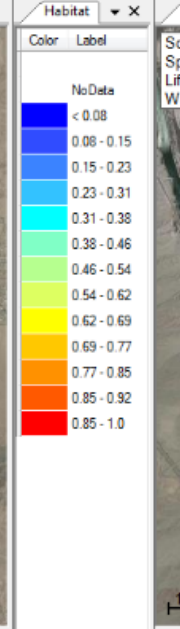
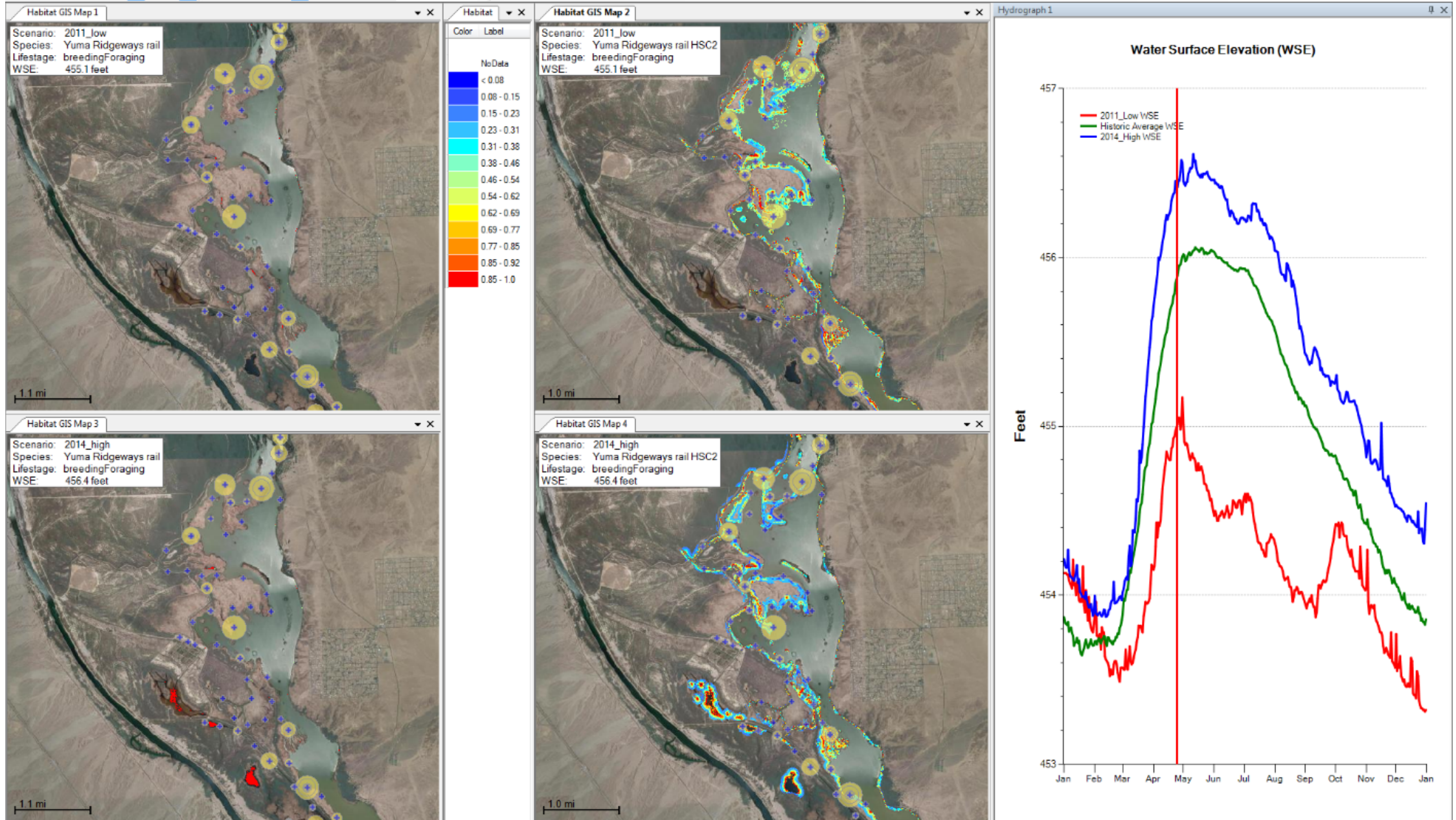

Figure 29. Screenshot example of suitable habitat comparison HSC1 vs HSC2 for Yuma Ridgway's rail breeding/foraging for two hydrologic scenarios. 


\section{Summary Habitat Results-All Scenarios}

The summary habitat results - all scenarios view (fig. 30) provides a bar chart showing the mean annual available habitat for six species within each management scenario compared to the historical average baseline. The "Summary Habitat Results" chart allows a user to select a baseline scenario to compare the other scenarios against as well as select which species and lifestages to display by right clicking on the chart and using the Select Data option from the context menu. The percent change between this baseline and each chart is displayed above each bar on the chart. If one scenario performs 10 percent or more above the baseline, its bar is highlighted in green; a decrease of 10 percent or more from baseline will be highlighted in red. Using this view, the user can identify which scenarios might provide an increase in available habitat for a given species and lifestage compared to the baseline condition. The summary chart also allows the user to identify which species and lifestage habitat conditions are most affected by changes in marsh WSE based on a given hydrologic scenario. Refuge staff and managers can then use this information to assist them in analyzing future water operation scenarios based on their current management needs for a particular species. 


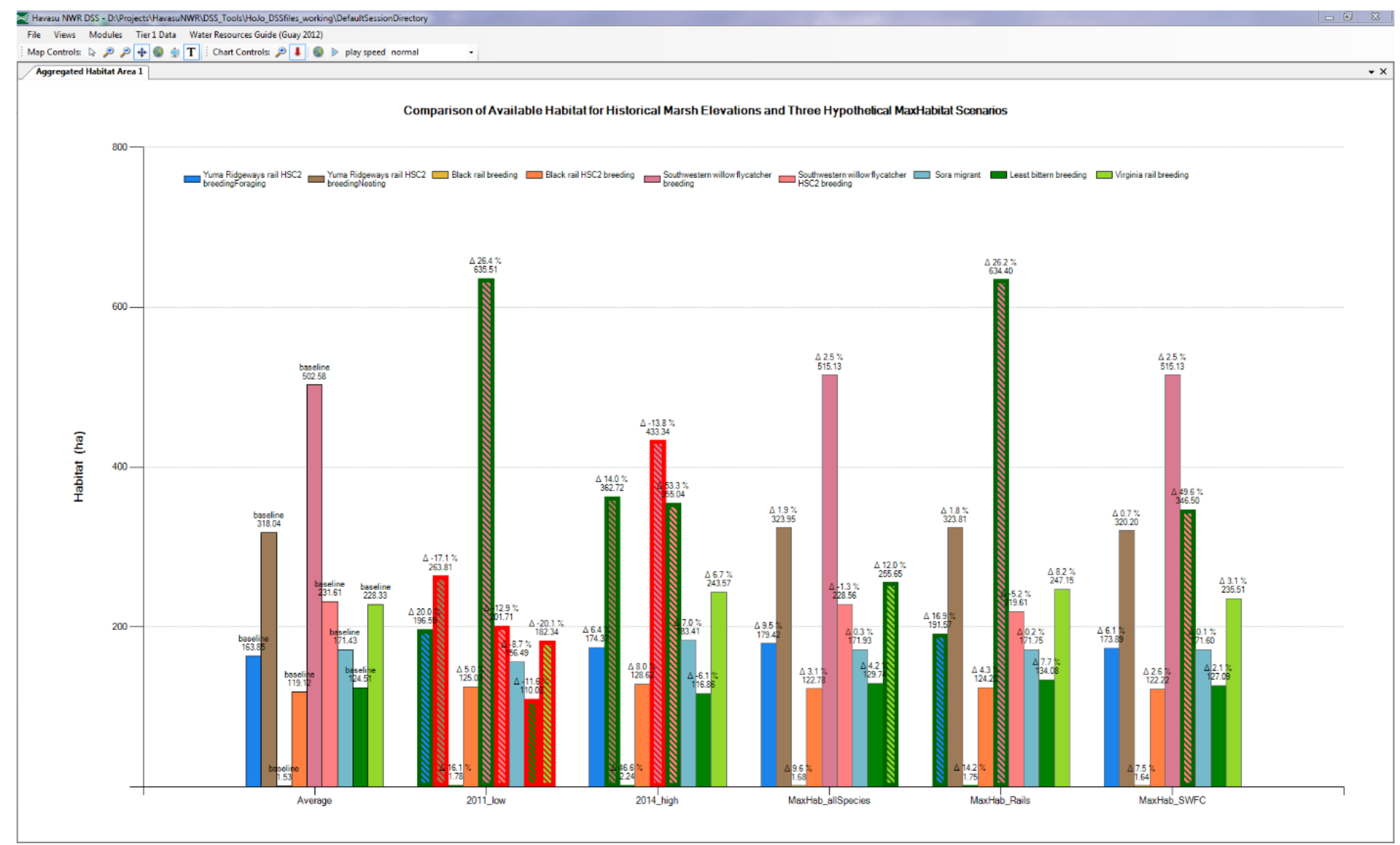

Figure 30. Screenshot example of summary habitat results for six species/lifestages for three historical and three hypothetical maximum habitat scenarios. 


\section{Water Storage and Inflow Requirements Comparison}

The water storage and inflow requirements comparison view (fig. 31) provides a series of hydrographs displaying the marsh water surface elevations throughout the year for each hydrologic scenario (2011_low water, historical average, and 2014_high water). The bar chart shown on the secondary axis displays the amount of inflow required in acre-feet to meet a given water surface elevation, the volume of water in the marsh at a given point in time, the change in marsh storage, and amount of evapotranspiration (ET) loss on a monthly basis. The ET loss is only used/displayed for new scenarios that are added in the DSS that include an estimate of ET loss as part of the input (see appendix 1 for details regarding adding additional scenarios). The estimated ET loss for the marsh that is provided within the DSS inputs were based on results from Guay (2012), which estimated that during the summer months (June 1 through September 1) the average ET loss was 120 acre-ft per day and that on average annual ET loss was approximately 28,720 acre-ft (105 acre-ft/day during the 9 months of water diversion) for the 4,000 acre marsh. These values can be adjusted or modified by the user through adding additional scenarios with the updated information.

The hypothetical water storage and inflow requirements comparison view (fig. 32) provides a series of hydrographs displaying the hypothetical marsh water surface elevations throughout the year for three hypothetical maximum habitat scenarios (MaxHabitat_AllSpecies, MaxHabitat_Rails, and MaxHabitat_SWFC). Refuge staff can use this information in conjunction with the report by Guay (2012) to determine if required inflow for future hypothetical scenarios can be met under current diversion capabilities and water right allocations. If not they can estimate what the shortage in inflows might be and how they might be able to meet those requirements in the future. In the case where there is excess water available it could be used for flow through to refresh the marsh and improve water quality (J.S. Daniels and J.C. Haegele, USGS, unpub. data, 2016). 


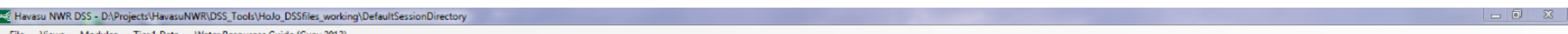
File Viens Modules Tier1 Data Water Resources Guide (Guay 2012)

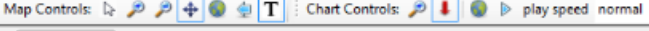

Hydrograph 1

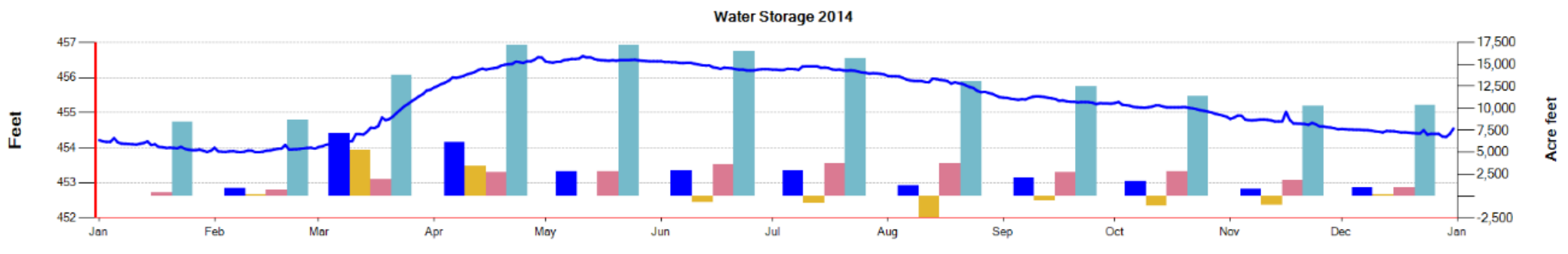

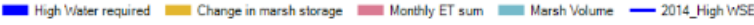
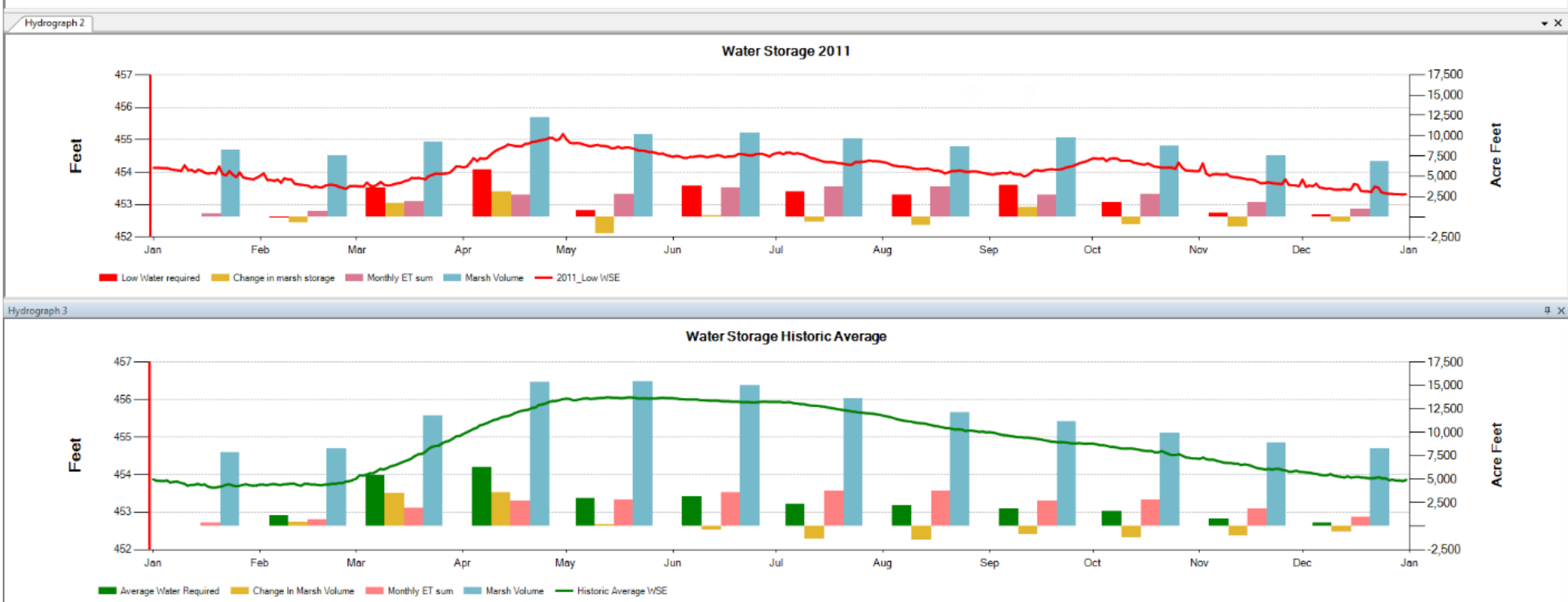

Figure 31. Screenshot of historical water storage and inflow requirements for historical scenarios. 


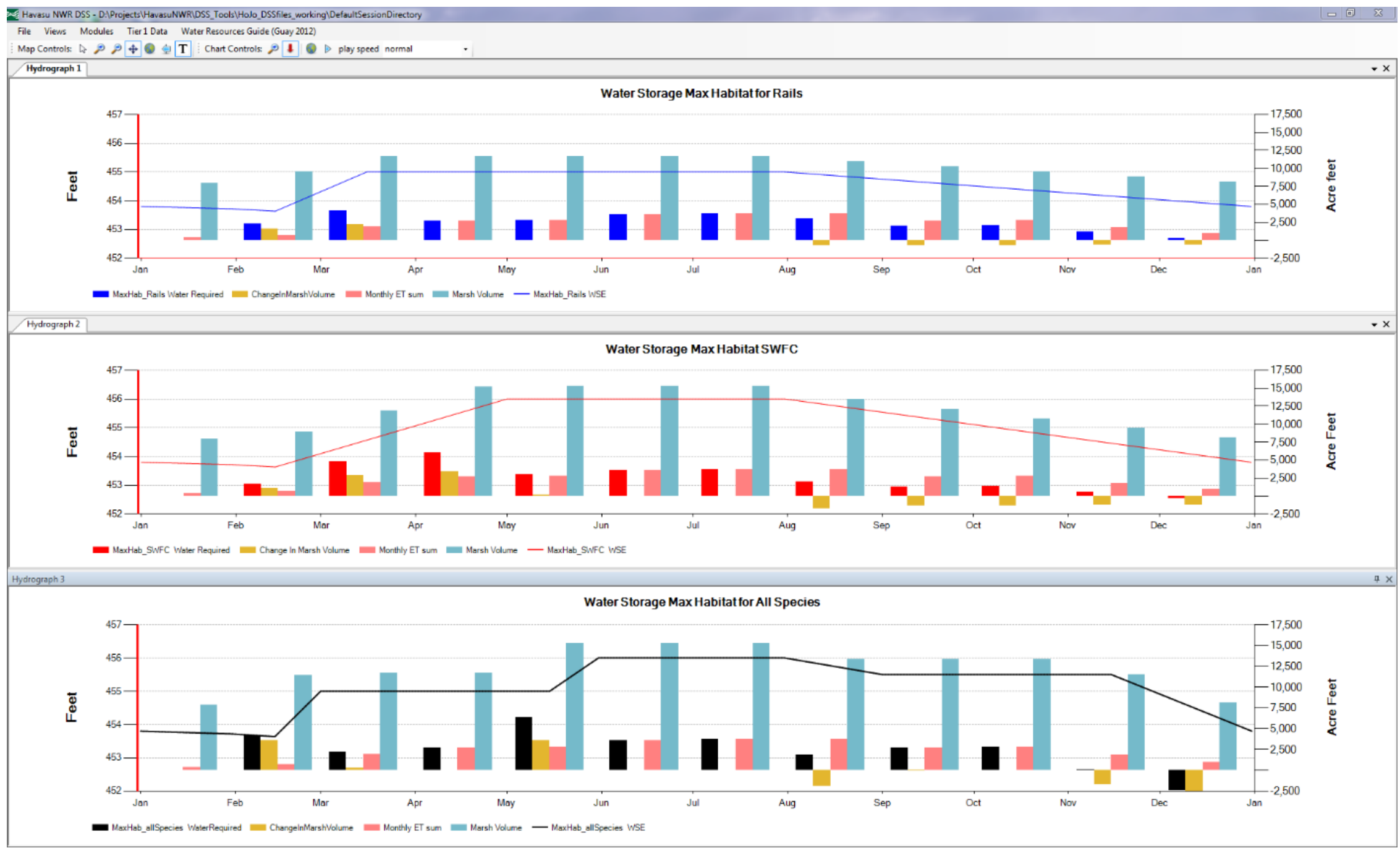

Figure 32. Screen shot of hypothetical maximum habitat scenario water storage and inflow requirements comparison. 


\section{Example Application of DSS to Assess Habitat Effects Associated with Historical Water Management Operations at Havasu NWR}

It is suggested that the user reads the Havasu NWR DSS user manual provided in appendix 1 before continuing with the example application described below as several of the sections/steps are better understood with a working knowledge of the Havasu NWR DSS.

The following provides an example of how the Havasu NWR DSS can be used to assess the relative effects of three historical hydrologic scenarios and three maximum habitat hydrologic scenarios on available habitat for three focal species identified by stakeholders. Given the broad nature of the default HSC data provided for these species at Topock Marsh, an example case of how to modify the HSC data using the HSC2 option for each species is also presented. It should be noted that the HSC2 data used in this example are purely for demonstration purposes of how differences in HSC data (that is, site-specific HSCs) alter the amount of available habitat associated with a given scenario and should be interpreted as such. As additional sites, species, and lifestage-specific habitat data are collected, better defined, and become available, the HSC2 values should be modified in the DSS to better represent specific habitat conditions used at Topock Marsh by the various species.

After downloading and installing the Havasu NWR DSS program and acquiring the input data as described in appendix 1, the user can then begin exploring the DSS to assess how various hydrologic scenarios affect available habitat conditions within Topock Marsh. The predefined views that have been included in the current version (1.0.1) of the DSS are organized in chronological order that might be useful for an end user to navigate through the DSS and conduct an analysis. Utilizing the first predefined view, "Examine Covariates," the user can compare how the depth within the marsh as well as the distance to water varies based on a given marsh water surface elevation. Figure 33 shows that for the same time of year (June 1) for differing hydrologic scenarios, the marsh water surface elevation in 2011 was $0.58 \mathrm{~m}(1.9 \mathrm{ft})$ lower than in 2014, resulting in more exposure and less inundation of the cattail and bulrush islands. The next step in the analysis is to determine how these variations in marsh elevations affect the available habitat for a given species and lifestage throughout the year. 


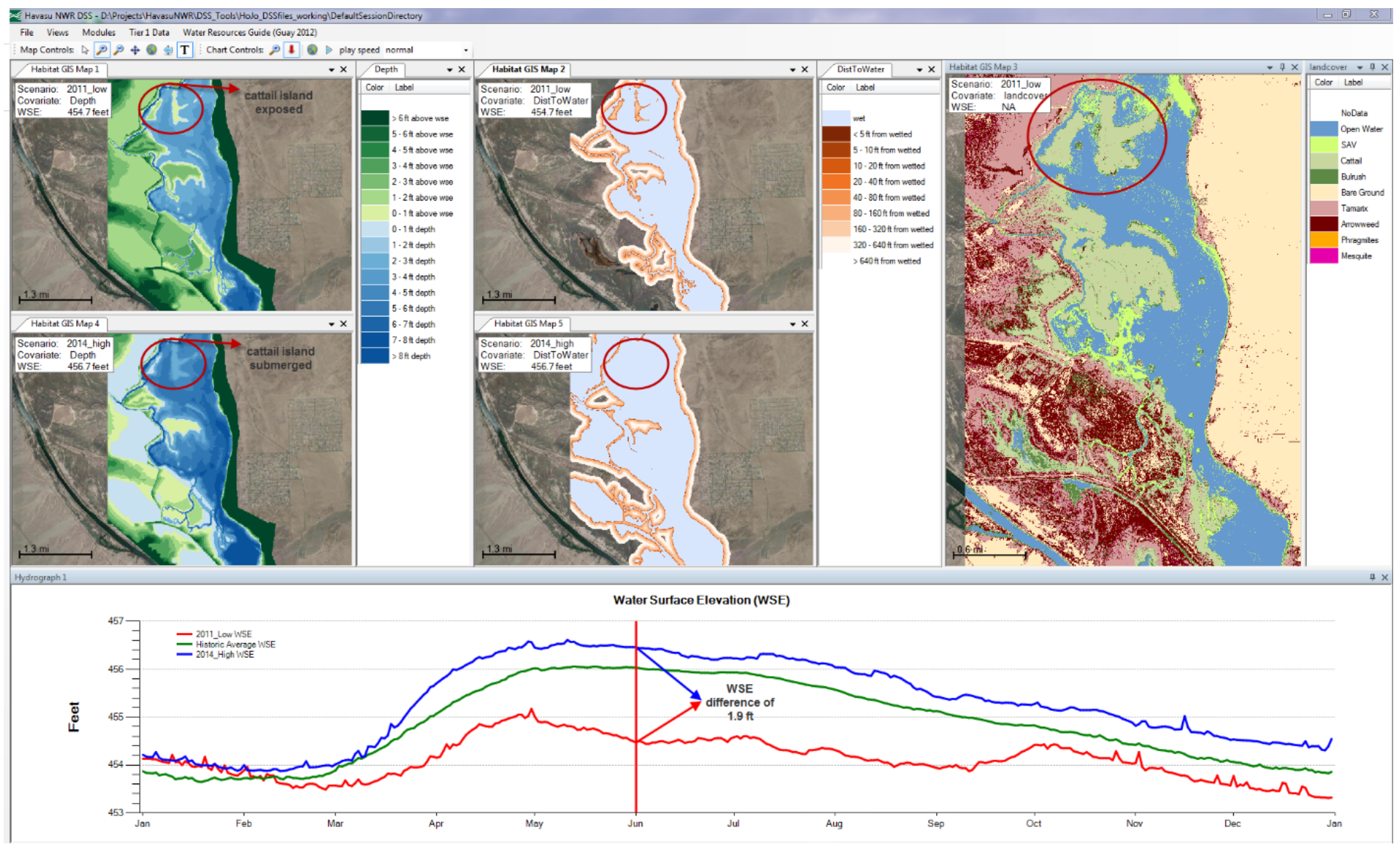

Figure 33. Screenshot of covariates view within the decision support system (DSS) showing historical comparison of marsh depth and distance to water on June 1 for the 2011_low and 2014_high marsh hydrologic scenarios. 
The next predefined view, "Habitat vs WSE - HSC1," provides two summary plots (fig. 34); the upper plot provides a summary of suitable habitat using the default HSC1 criteria for a given species and lifestage as a function of marsh elevation, whereas the lower plot shows the daily marsh WSE for a given scenario (2011_low WSE and 2014_high WSE in this example) along with the amount of available habitat that was calculated based on the HSC1 data for the selected species and lifestage. The upper plot shows that, based on the broad HSC1 data provided for the three focal species, variations in marsh elevation do not drastically change the amount of available habitat. Discussions with refuge staff related to these results have given rise to further investigation into the applicability of the default HSC1 data provided and whether the species present at Topock Marsh are using different habitat conditions than found in the general literature.

The lower graph in figure 34 illustrates that while the higher marsh elevations that occurred in 2014 appear to provide approximately three times the amount of suitable habitat compared to the lower marsh elevations in 2011 for the hydroperiod from mid-March to August, the overall difference (15 acres versus 5 acres) is relatively small compared to the overall size of the marsh (4,000 acres). Since the amount of suitable habitat in the DSS is derived from the HSC data, it is important to be able to identify how applicable these criteria are to the conditions found at Topock Marsh. As mentioned previously, we have provided the option in the DSS to enter a second set of HSC values (HSC2). Providing the second set of hypothetical HSC data provides a tool for refuge staff to conduct a sensitivity type analysis to compare how variations in HSC data affect what is considered suitable habitat within Topock Marsh. Utilizing refuge staff expertise and their local knowledge of the types of habitat conditions that are used by the focal species can greatly assist in developing site- and speciesspecific HSC data for Topock Marsh. A description of what modifications were made to the default $\mathrm{HSC} 1$ curves to establish the hypothetical HSC2 data is described in the "Edit Habitat Suitability" view. 


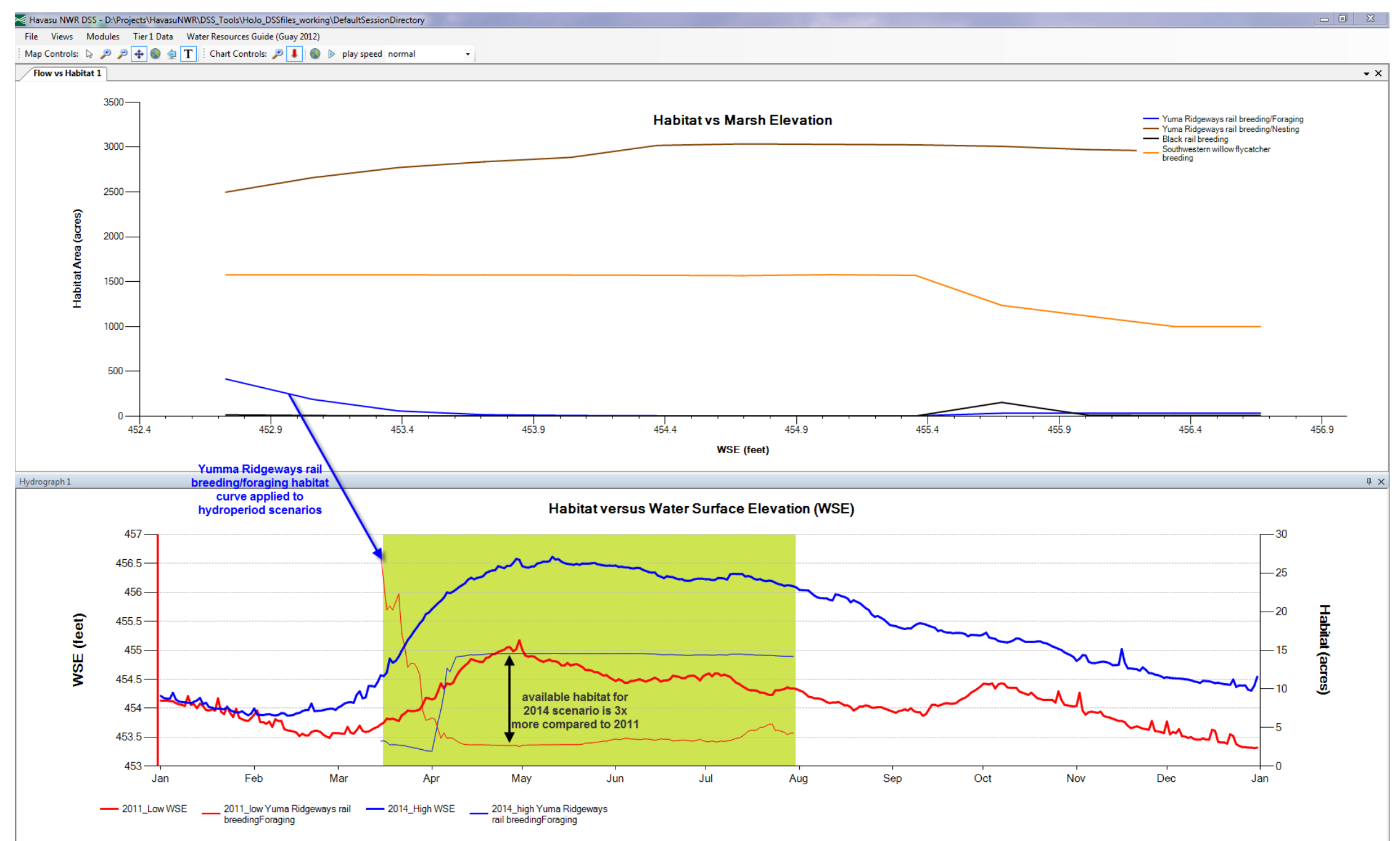

Figure 34. Screenshot of habitat versus water surface elevation (WSE) using the default HSC1 data and associated habitat calculated for 2011 and 2014 hydrologic scenario for Yuma Ridgway's rail HSC1 breeding/foraging. 
To illustrate the importance of having more refined site-specific HSC criteria and how they might affect the amount of suitable habitat that is estimated using the DSS, we have provided an additional "Habitat versus WSE-HSC2" view (fig. 35). This additional predefined view provides a summary of suitable habitat using the hypothetical $\mathrm{HSC} 2$ criteria for a given species and lifestage as a function of marsh elevation. Utilizing the second set of HSC values (HSC2) provides a method of sensitivity testing of the HSCs for the three identified focal species. The lower graph in figure 35 illustrates that utilizing the $\mathrm{HSC} 2$ criteria shows an order of magnitude increase in the amount of calculated suitable habitat compared to the HSC1 criteria (fig. 34). Although the percent difference between the two scenarios (14 percent) is not a lot (203 acres versus 174 acres), using the hypothetical HSC 2 criteria shows how establishing site-specific HSC data for Topock Marsh may drastically improve the applicability of the DSS for resource managers and refuge staff.

An additional example of how these two differing HSCs produce almost inverse relationships is by comparing the upper graph for southwestern willow flycatcher. The plot in figure 34 shows that suitable habitat remains constant for all marsh elevations below $455.7 \mathrm{ft}$ and then decreases once the marsh reaches a high level where the marsh seeps/overflows into the western floodplain, which contains low lying areas outside the main confinements of the marsh. Discussions with refuge staff regarding the habitat conditions used by the southwestern willow flycatcher were contrary to what the HSC data were showing. Further discussions resulted in the generation of the HSC2 data, and the results can be seen in the upper plot of figure 35 that shows that as marsh elevation increases the amount of suitable habitat also increases. Especially once the elevation of the marsh reaches a level where the low lying areas outside the marsh contacted by shallow water (less than 2-4 inches), which refuge staff consider provides suitable breeding/foraging habitat for the southwestern willow flycatcher at Topock Marsh. These modified criteria will be described in more detail in the following section. 


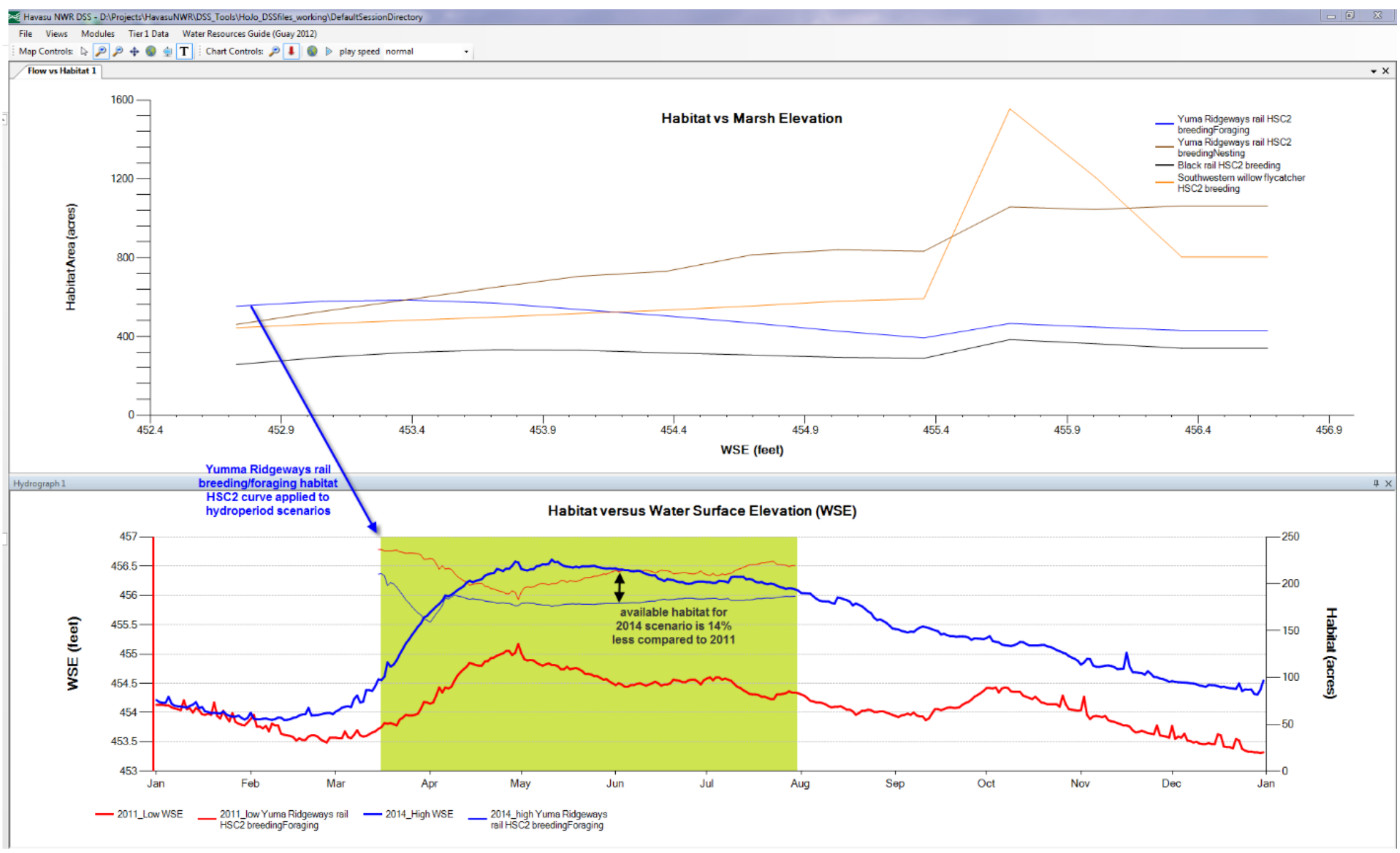

Figure 35. Screenshot of habitat versus water surface elevation (WSE) using the hypothetical HSC2 data and associated habitat calculated for 2011 and 2014 hydrologic scenario for Yuma Ridgway's rail HSC2 breeding/foraging. 
The next predefined view, "Edit Habitat Suitability," provides a series of spatial overview maps displaying four different covariates (depth, distance to water, distance to open water, and land cover) for a specified water management scenario as well as the resulting available habitat based on the HSC for a given species and lifestage (fig. 36). By examining this view, the user can compare how the HSC covariates change based on a given marsh water surface elevation scenario. This view is used to enter the HSC data as well as determine how variations in HSC affect the available habitat based on a given water management scenario. Figure 36 shows that for the original HSC1 criteria for Yuma Ridgway's rail breeding/foraging (table 4), under the 2011_low water scenario there is very little suitable habitat available during the hydroperiod of interest (mid-March through August). When comparing the habitat suitability map (Habitat GIS Map 1) for the marsh elevation in June, it is evident that the available habitat does not correspond spatially where the selected species were detected in the historical marsh bird surveys displayed in the DSS. For the DSS developers as well as refuge staff, this dataset is extremely helpful in better understanding if the modeled species-specific habitat correlates to real-life species occupancy of these areas. Again, discussions with refuge staff regarding the habitat conditions used by the Yuma Ridgway's rail at Topock Marsh were contrary to what the HSC1 data were showing. For example, the HSC1 criteria for Yuma Ridgway's rail breeding/foraging include the following two covariates: land cover (open water and SAV) and depth (less than 12 inches). Criteria for distance to water and distance to open water were not specified and therefore were not included in the habitat suitability equation. Further discussions with refuge staff determined that open-water parts of marsh are typically greater than 12 inches deep even at low marsh elevations and therefore resulted in the generation of the $\mathrm{HSC} 2$ data (table 6) which included greater water depths and added cattail and bulrush to the land cover criteria (fig. 37). The effects of the HSC2 criteria can be seen in each of the spatial overview covariate maps as well as the suitable habitat results (Habitat GIS Map 1) shown in figure 37. 


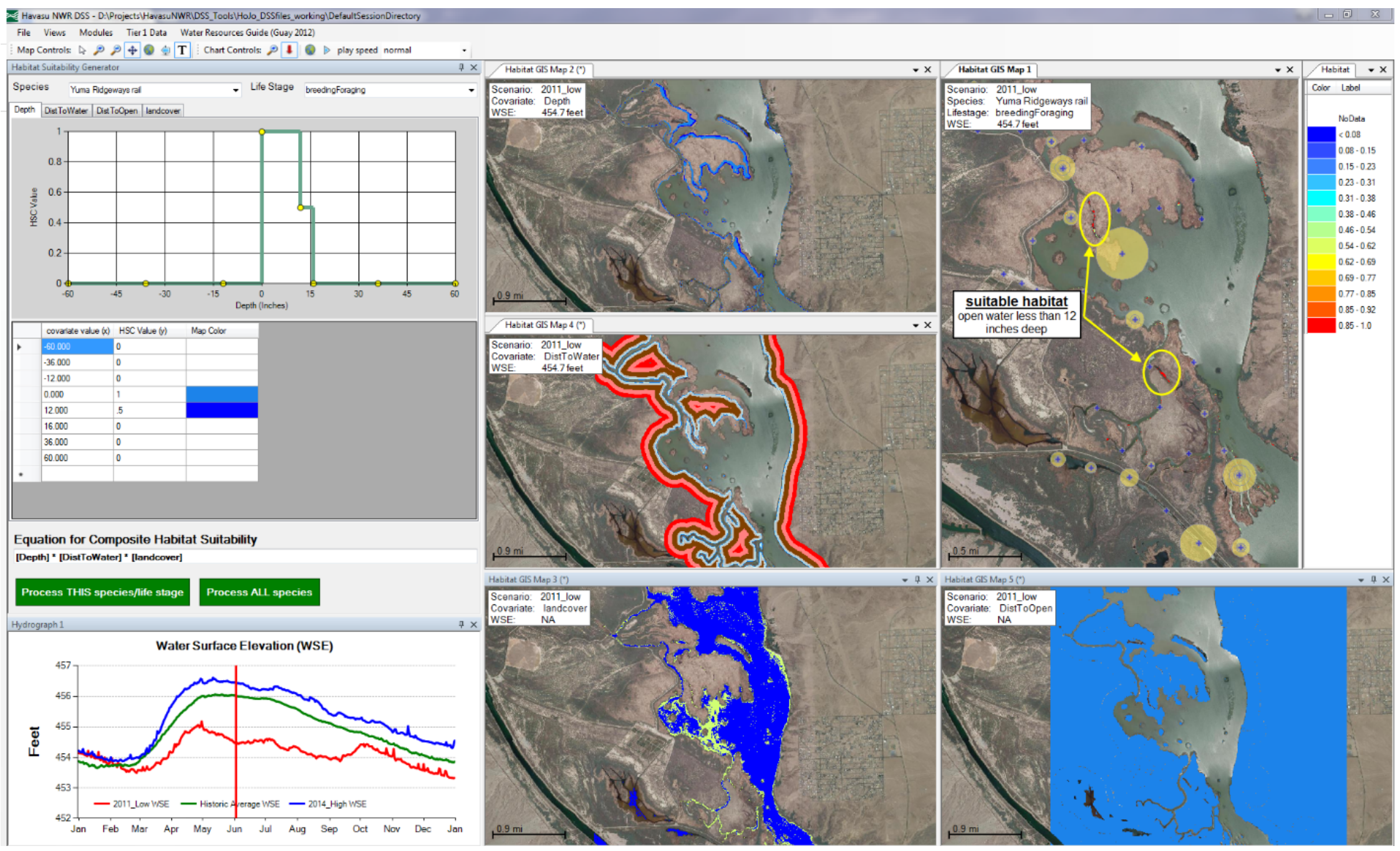

Figure 36. Screenshot of example of Edit Habitat Suitability view and segment map displaying available habitat for Yuma Ridgway's rail HSC1 breeding/foraging at water surface elevation (WSE) equals 454.7 feet. 


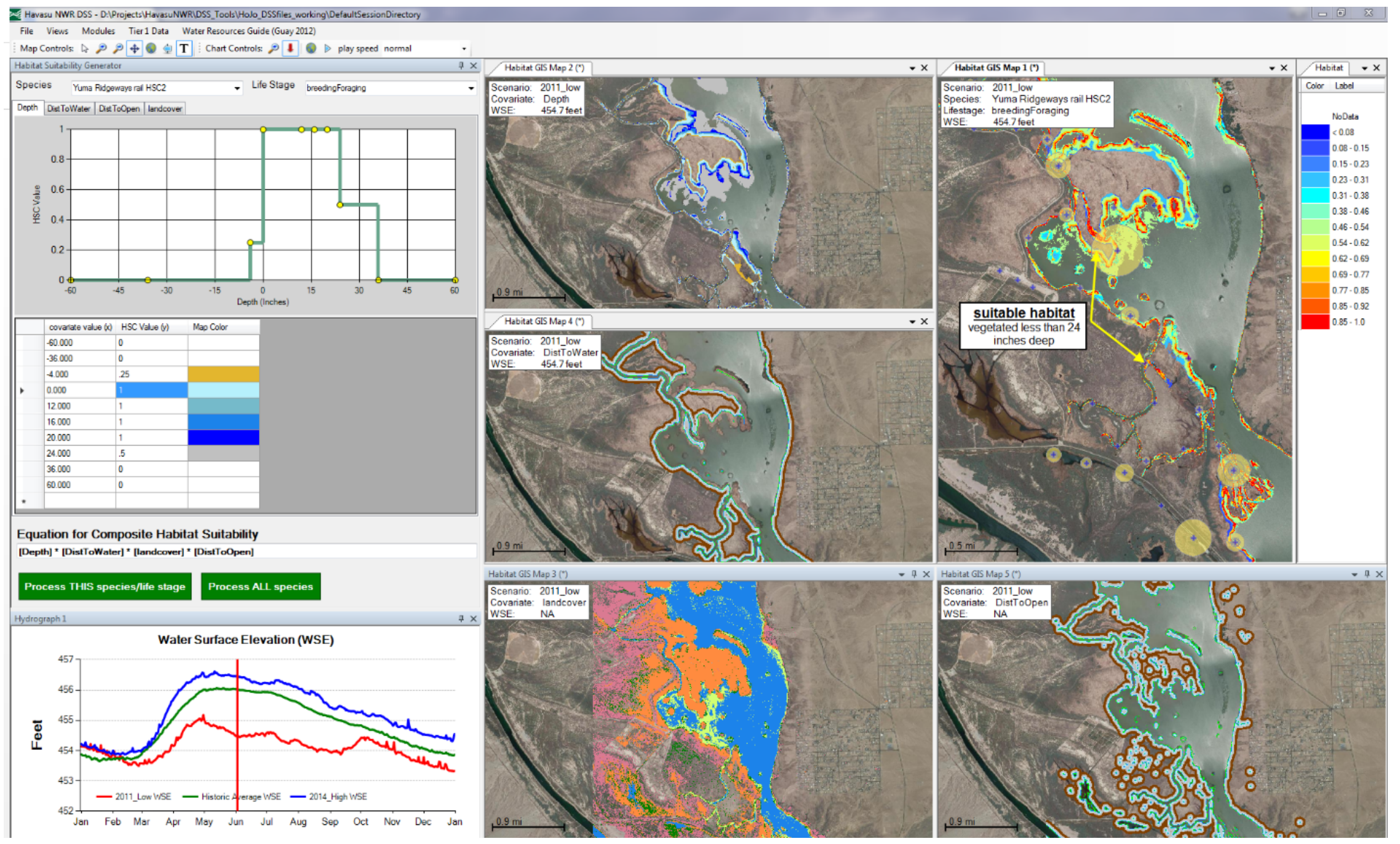

Figure 37. Screenshot of example of Edit Habitat Suitability view and segment map displaying available habitat for Yuma Ridgway's rail HSC2 breeding/foraging at water surface elevation (WSE) equals 454.7 feet. 
Table 6. Three focal species, lifestages, and hypothetical habitat suitability criteria (HSC2) identified by U.S. Geological Survey (USGS) Fort Collins Science Center (FORT) and Refuge staff for inclusion in the Havasu National Wildlife Refuge (NWR) decision support system (DSS) for Topock Marsh, Havasu National Wildlife Refuge, Arizona.

[SAV, submerged aquatic vegetation; $\mathrm{ft}$, feet]

\begin{tabular}{|c|c|c|c|c|c|c|}
\hline Species & Lifestage & Timeframe & $\begin{array}{c}\text { Vegetation } \\
\text { cover }\end{array}$ & $\begin{array}{c}\text { Distance to } \\
\text { water }\end{array}$ & $\begin{array}{l}\text { Distance to } \\
\text { open water }\end{array}$ & Water depth \\
\hline $\begin{array}{l}\text { Yuma } \\
\text { Ridgway’s } \\
\text { rail }\end{array}$ & Breeding/foraging & $\begin{array}{c}\text { Mid-March } \\
\text { thru July }\end{array}$ & $\begin{array}{c}\text { SAV, cattail, } \\
\text { bulrush, } \\
\text { tamarisk }\end{array}$ & $\begin{array}{c}0-50 \mathrm{ft} \\
50-100 \mathrm{ft} \\
100-350 \mathrm{ft}\end{array}$ & $\begin{array}{c}0-50 \mathrm{ft} \\
50-100 \mathrm{ft} \\
100-200 \mathrm{ft} \\
200-350 \mathrm{ft}\end{array}$ & $\begin{array}{c}\text { Less than } 24 \\
\text { inches, } \\
\text { 24-36 inches } \\
\text { marginal }\end{array}$ \\
\hline $\begin{array}{l}\text { Yuma } \\
\text { Ridgway’s } \\
\text { rail }\end{array}$ & Breeding/nesting & $\begin{array}{c}\text { Mid-March } \\
\text { thru July }\end{array}$ & $\begin{array}{l}\text { Bulrush, } \\
\text { cattail, } \\
\text { tamarisk }\end{array}$ & $\begin{array}{c}0-50 \mathrm{ft} \\
50-100 \mathrm{ft} \\
100-200 \mathrm{ft} \\
200-500 \mathrm{ft} \\
500-750 \mathrm{ft}\end{array}$ & $\begin{array}{c}0-200 \mathrm{ft} \\
200-350 \mathrm{ft} \\
350-500 \mathrm{ft}\end{array}$ & $\begin{array}{c}\text { Less than } 16 \\
\text { inches and } \\
0-12 \text { inches above }\end{array}$ \\
\hline Black rail & Breeding/foraging & $\begin{array}{c}\text { March thru } \\
\text { July }\end{array}$ & $\begin{array}{r}\text { Bulrush, } \\
\text { cattail }\end{array}$ & $\begin{array}{c}0-50 \mathrm{ft} \\
50-100 \mathrm{ft} \\
100-350 \mathrm{ft}\end{array}$ & $\begin{array}{c}0-100 \mathrm{ft} \\
100-200 \mathrm{ft} \\
200-350 \mathrm{ft} \\
350-500 \mathrm{ft}\end{array}$ & $\begin{array}{c}\text { Less than } 16 \\
\text { inches and } \\
0-4 \text { inches above }\end{array}$ \\
\hline $\begin{array}{l}\text { Southwestern } \\
\text { willow } \\
\text { flycatcher }\end{array}$ & Breeding & $\begin{array}{l}\text { May thru } \\
\text { August }\end{array}$ & $\begin{array}{c}\text { Cottonwood, } \\
\text { willow, } \\
\text { tamarisk }\end{array}$ & $\begin{array}{c}0-100 \mathrm{ft} \\
100-250 \mathrm{ft} \\
250-500 \mathrm{ft}\end{array}$ & $\begin{array}{c}0-1,000 \mathrm{ft} \\
1,000-1,755 \mathrm{ft}\end{array}$ & $\begin{array}{c}\text { Less than } 8 \text { inches } \\
\text { and } 0-36 \text { inches } \\
\text { above }\end{array}$ \\
\hline
\end{tabular}

As mentioned previously, we have provided the option in the DSS to enter a second set of HSC values (HSC2) for sensitivity testing purposes for the three identified focal species. Using the next predefined view, "Suitable Habitat Comparison-HSC1 versus HSC2" (fig. 38), provides a method of comparing the results of the two HSCs by displaying them side by side. As illustrated below, providing the second set of hypothetical HSC data values provides a method for researchers and refuge staff to conduct a sensitivity type analysis to compare how variations in HSC data affect what is considered suitable habitat for a given species and lifestage at Topock Marsh. Using refuge staff expertise and their local knowledge of the types of habitat conditions that are used by the focal species can greatly assist in developing site- and species-specific HSC data for Topock Marsh. 


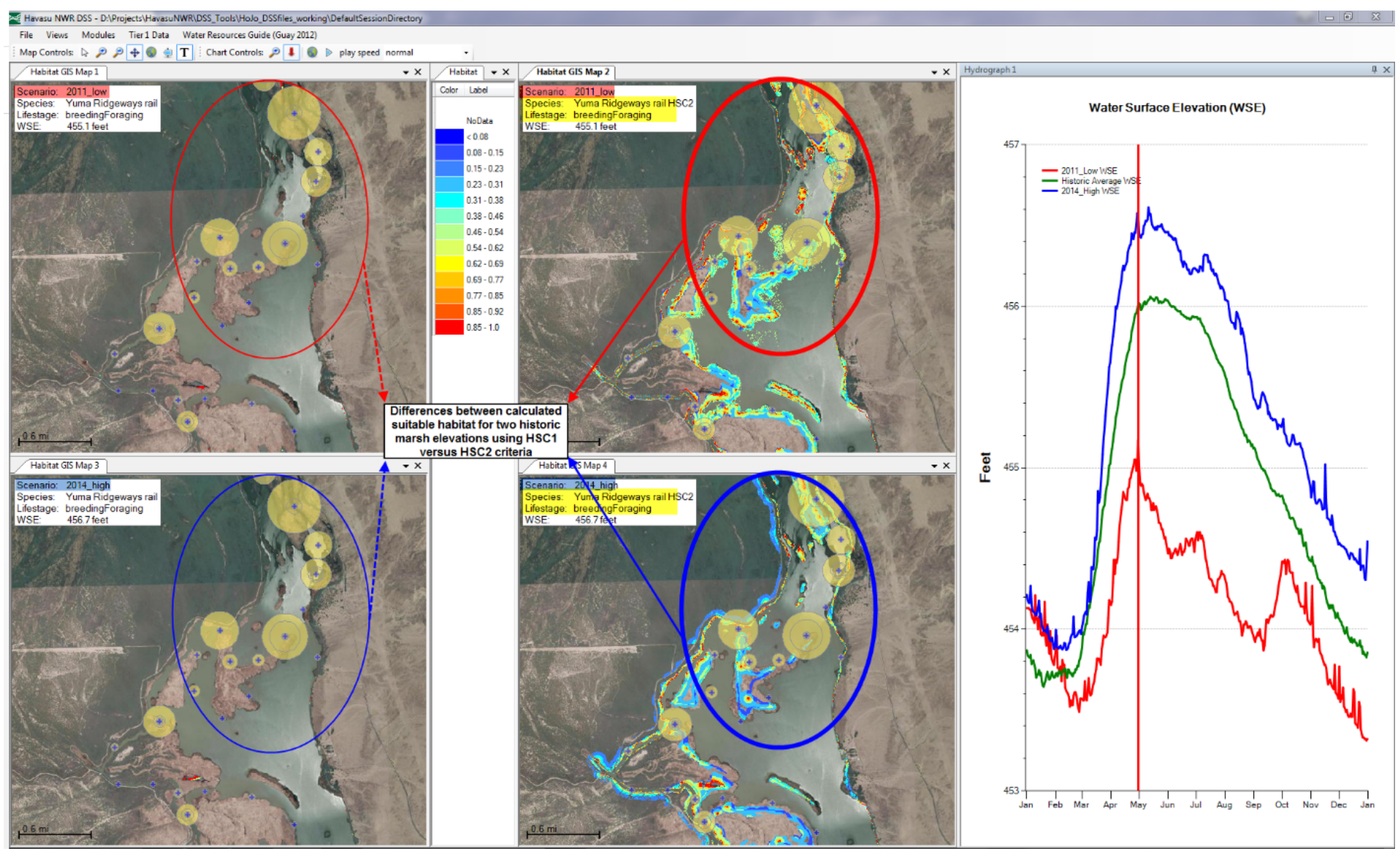

Figure 38. Screenshot example of suitable habitat comparison HSC1 vs HSC2 for Yuma Ridgway's rail breeding/foraging for two hydrologic scenarios. 
The next predefined view, "Summary Habitat Results—All Scenarios," provides a bar chart showing the mean annual available habitat for each species and lifestage for each management scenario compared to the historical average baseline (fig. 39). The summary chart also allows the user to identify which species and lifestage habitat conditions are most affected by changes in marsh WSE based on a given hydrologic scenario. In this example, we also include the habitat results from the HSC1 and HSC2 criteria to illustrate how modifications to the HSC criteria can affect the total suitable habitat that might be available for a given hydrologic scenario. Figure 39 below provides a simplified application of this view by only selecting the three focal species $\mathrm{HSC} 1$ and $\mathrm{HSC} 2$ results for the three historical hydrologic scenarios. The results for the 2011_low hydrologic scenario show that based on the HSC1 criteria there was more than a 10-percent increase in the amount of available habitat for all three of the focal species (23 percent, 16 percent, and 26.4 percent). The 2014 high hydrologic scenario shows an increase in habitat for the Yuma Ridgway's rail (214 percent) and black rail (46.6 percent) but a decrease for the southwestern willow flycatcher (-13.8 percent). A reduction in available habitat for the southwestern willow flycatcher at higher marsh elevations does not correspond with what refuge staff have observed at Topock Marsh.

Using the HSC2 criteria show that for the 2011_low hydrologic scenario there is an increase in the amount of available habitat for the Yuma Ridgway's rail breeding/foraging (20 percent) but a decrease for Yuma Ridgway's rail breeding/nesting (-17.1 percent) and southwestern willow flycatcher (-12.9 percent), whereas the 2014_high hydrologic scenario shows less than a 10-percent increase in habitat for the Yuma Ridgway's rail breeding/foraging ( 6.4 percent) and black rail ( 8 percent) and more than a 10 percent increase in Yuma Ridgway's rail breeding/nesting (14 percent) and southwestern willow flycatcher (53.3 percent). These results illustrate how alterations to the HSC criteria greatly affect the amount of available habitat calculated, especially for southwestern willow flycatcher under both hydrologic scenarios. 


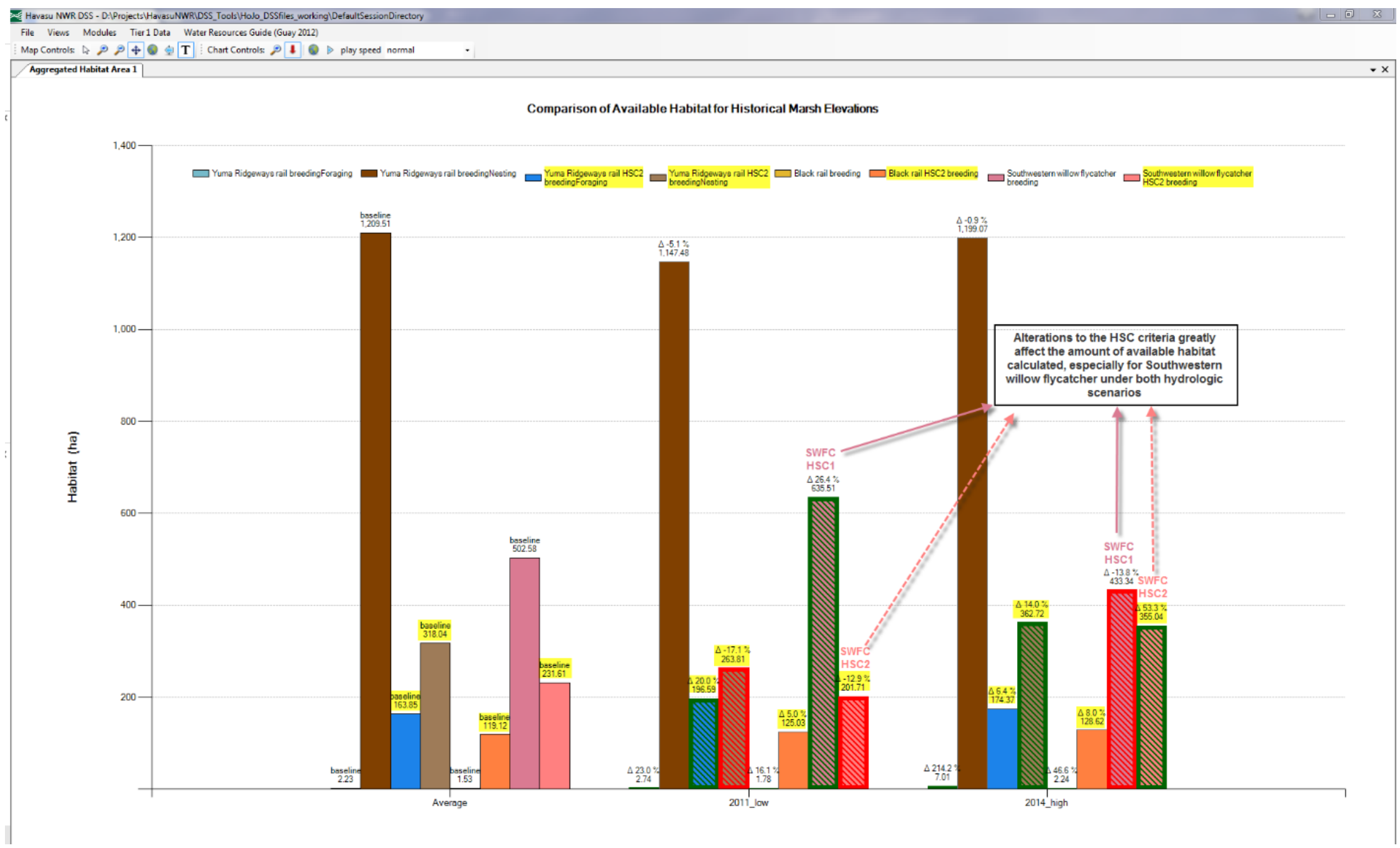

Figure 39. Screenshot example of summary habitat results for three focal species for three historical hydrologic scenarios. Available habitats for each species of concern associated with HSC2 are highlighted in yellow. 


\section{Limitations}

The data and methodology used in the DSS have significant uncertainty and should be used as a starting point for assessing management options. Further investigation could be used to improve the accuracy of the current inputs such as the vegetation classification layer. Model accuracy potentially also could be improved by adding new input layers that map additional, biologically relevant drivers such as prey density or vegetation structure. The HSCs used in the DSS are derived from current literature but could be improved for the specific ecology of Topock Marsh within the Havasu NWR system by including more local expert knowledge and new studies of the local ecological or physiological limiting factors for the species of interest. Field validation of model outputs should be conducted to verify accuracy and applicability to specific management questions. Therefore, continued data collection of the various parameters (that is, habitat requirements, critical water quality needs, and vegetation coverage, as well as others) is suggested to further evaluate and develop future versions of the DSS. Although the DSS does not produce any specific biological output (that is, clutch size, plant growth, or juvenile survival), it does provide a tool to identify relative effects of water operations on ecological processes and species-specific habitats that can be used by refuge staff and managers. The adaptability of the DSS tool as time goes on is one of the DSS's most valuable capabilities.

\section{Summary}

The Havasu National Wildlife Refuge (Havasu NWR or Refuge) decision support system (DSS) is an adaptive management tool designed for local and regional resource managers to better understand how various ecological conditions at Havasu NWR are affected by management actions made at the Refuge. By exploring the DSS capabilities to compare and visualize multiple datasets simultaneously, managers will better understand the ecological results of their management actions. The DSS will be improved by continually updating the water quality, fish, abiotic, biotic, and marsh bird sampling data and improving the Habitat Suitability Criteria (HSC), land cover, and hydrologic data layers.

To continue to improve on the work that has been conducted at Topock Marsh, U.S. Geological Survey Fort Collins Science Center, U.S. Fish and Wildlife Service (FWS), Bureau of Reclamation, and other science partners could continue to collaborate and work towards developing a Phase 2 (forecasting model) of the Havasu NWR DSS. This Phase 2 DSS would build on the current Desert Landscape Conservation Cooperative funded Phase 1 hindcasting model DSS and would incorporate output from water management operations and hydrodynamic (water quantity and quality) modeling based on marsh bathymetry, Colorado River hydrology, and future water delivery methods used by the Refuge. Synthesis of these additional model outputs would allow FWS to compare different hydrologic scenarios, water management operations, and delivery methods and their influences on species-specific habitat. Once these tools are developed, they could be valuable for, and directly applicable to, future analysis needs such as in-depth evaluation of climate change impacts. The Phase 2 DSS would be a powerful illustration of management of water for optimized biological outcomes that could be applied to other locations beyond the Havasu NWR, thus providing resource managers the best available science to determine the most effective water management strategies. 


\section{References Cited}

Alanen, M.I., 1998, Factors affecting the distribution and abundance of submersed aquatic vegetation in Topock Marsh, an impounded desert wetland: Tucson, Ariz., University of Arizona, M.S. thesis, 64 p. Arizona Department of Environmental Quality, 2009, Water quality standards for surface waters: Unofficial Copy of Final Rules, 18 A.A.C. 11, art.1, accessed March 18, 2016, at http://www.azdeq.gov/environ/water/standards/download/SWQ_Standards-1-09-unofficial.pdf.

Avery, T.E., and Berfin, G.L., 1992, Fundamentals of remote sensing and airphoto interpretation: Upper Saddle River, N.J., Prentice-Hall, Inc, 472 p.

Beitinger, T.L., Bennett, W.A., and McCauley, R.W., 2000, Temperature tolerances of North American freshwater fishes exposed to dynamic changes in temperature: Environmental Biology of Fishes, v. 58, p. 237-275.

Conway, C.J., 2008, Standardized North American marsh bird monitoring protocols, version 2008-3: Tucson, Ariz., U.S. Geological Survey, Arizona Cooperative Fish and Wildlife Research Unit Wildlife Research Report \#2008-01.

Conway, C.J., 2011, Standardized North American marsh bird monitoring protocols: Waterbirds, v. 34, no. 3, p. 319-346.

Cowardin, L.M., and Myers, V.I., 1974, Remote sensing for identification and classification of wetland vegetation: Wildlife Management, v. 38, no. 2, p. 308-314.

DigitalGlobe, 2015, WorldView-2 datasheet: DigitalGlobe, accessed October 6, 2015, at https://www.digitalglobe.com/pages/our-constellation.

Dzialowski, A.R., Smith, V.H., Wang, S.H., Martin, M.C., and deNoyelles, F., Jr., 2011, Effects of nonalgal turbidity on cyanobacterial biomass in seven turbid Kansas reservoirs: Lake and Reservoir Management, v. 27, p. 6-14.

Eisler, R., 1988, Arsenic hazards to fish, wildlife, and invertebrates-A synoptic review: U.S. Fish and Wildlife Service, Biological Report 85(1.12), 92 p.

Guay, B.E., 2001, Preliminary hydrologic investigation of Topock Marsh, Arizona 1995-98: Tucson, Ariz., University of Arizona, Ph.D. dissertation, 335 p.

Guay, B.E., 2012, Water resource guide, Topock Marsh Unit, Havasu National Wildlife Refuge: U.S. Fish and Wildlife Service, Region 2, 41 p.

Lemly, A.D., 2002, Selenium assessment in aquatic ecosystems-A guide for hazard evaluation and water-quality criteria: New York, Springer-Verlag, $161 \mathrm{p}$.

Lillesand, T.M., Kiefer, R.W., and Chipman, J.W., 2004, Remote sensing and image interpretation: New York, John Wiley and Sons, Inc., 763 p.

MacDonald, D.D., Ingersoll, C.G., and Berger, T., 2000, Development and evaluation of consensusbased sediment quality guidelines for freshwater ecosystems: Archives of Environmental Contamination and Toxicology, v. 39, p. 20-31.

Mackie, G.L., and Claudi, R., 2010, Monitoring and control of macrofouling mollusks in fresh water systems (2d ed.): Boca Raton, Fla., CRC Press, Taylor and Francis Group, 508 p.

McLeod, M.A., and Pellegrini, A.R., 2012, Southwestern willow flycatcher surveys, demography, and ecology along the lower Colorado River and tributaries, 2008-2012: Draft summary report submitted to U.S. Bureau of Reclamation, Boulder City, Nev., by SWCA Environmental Consults, Flagstaff, Ariz., 289 p.

Mueller, G.A., and Brooks, J.E., 2004, Collection of an adult gizzard shad (Dorosoma cepedianum) from the San Juan River, Utah: Western North American Naturalist, v. 64, p. 135-136. 
Shoreline Engineering and Restoration, 2006, Havasu National Wildlife Refuge water management plan-Final: U.S. Fish and Wildlife Service, prepared by Shoreline Engineering and Restoration, available at http://www.fws.gov/filedownloads/ftp_lcr_hmps/Supporting_Materials/Plans/Water_Mgt_Plans/Hava su\%20WMP\%20Final\%209-14-06.pdf.

Teledyne RD Instruments, 2007, WorkHorse Rio Grande acoustic Doppler current profiler technical manual, P/N 957-6241-00 (November 2007): Teledyne RD Instruments, 264 p.

Turner, M.G., Gardner, R.H., and O'Neill, R.V., 2001, Landscape ecology in theory and practicePattern and process: New York, Springer, p. 73-90.

U.S. Environmental Protection Agency, 1986, Ambient water quality criteria for dissolved oxygen: U.S. Environmental Protection Agency, EPA 440/5-86-003, National Technical Information Service, 46 p.

U.S. Environmental Protection Agency, 2015, National recommended water quality criteria-Aquatic life criteria table: U.S. Environmental Protection Agency Web site, accessed August 6, 2015, at http://water.epa.gov/scitech/swguidance/standards/criteria/current/index.cfm.

U.S. Geological Survey, 1999, Field manual of wildlife diseases - General field procedures and diseases of birds: Biological Resources Division, Information and Technology Report 1999-001, 426 p.

U.S. Supreme Court, State of Arizona, Plaintiff, v. State of California et al., Defendants. 376 U.S. 340 (84 S.Ct. 755, 11 L.Ed.2d 757): accessed June 8, 2014 at https://www.law.cornell.edu/supremecourt/text/376/340.

Williamson, F.S.L., 1975, Classification of wetlands vegetation using small scale color infrared imagery-Annual report, 9 October 1973-20 December 1974: National Aeronautics and Space Administration, prepared by Smithsonian Institution, NASA CR-62091, 27 p.

World Health Organization, 2003, Algae and cyanobacteria in fresh water, chap. 8 of Coastal and fresh waters. Guidelines for safe recreational water environments, v. 1: World Health Organization, p. $136-158$. 


\section{Appendix 1. User's Manual for the Havasu NWR Decision Support System (DSS)}




\section{Contents}

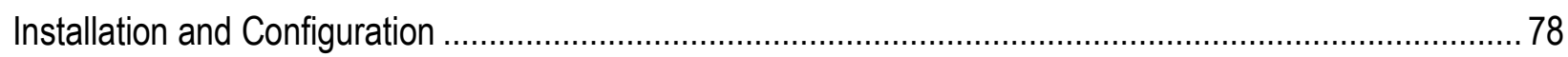

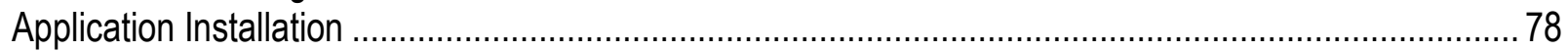

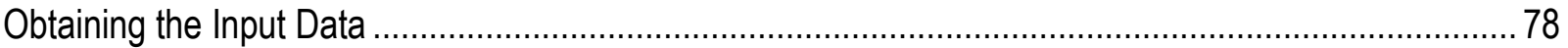

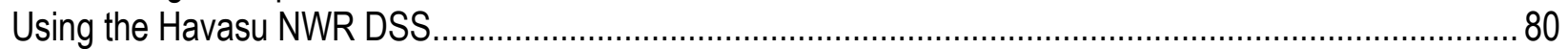

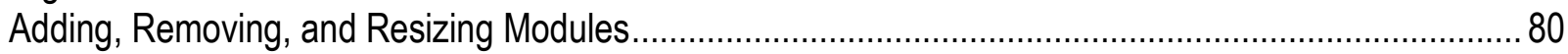

Using Views to Facilitate Organizing Multiple Modules ................................................................... 82

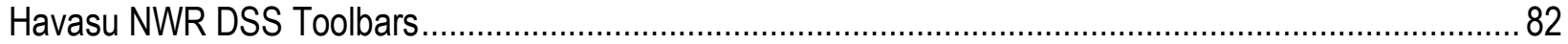

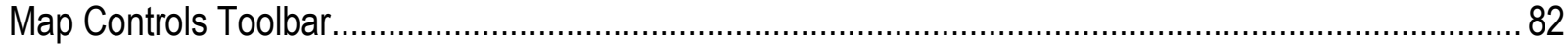

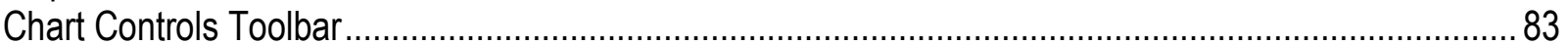

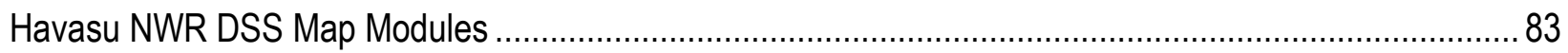

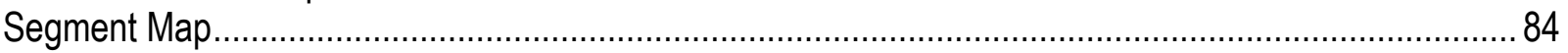

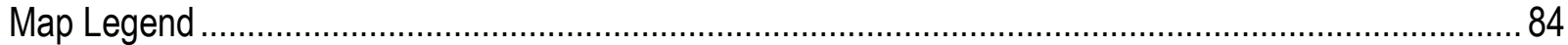

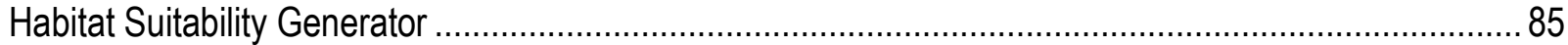

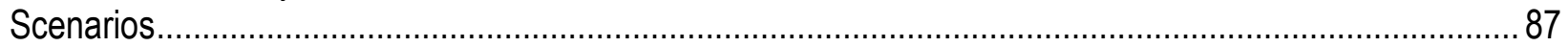

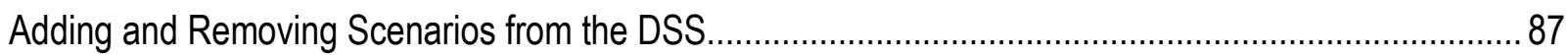

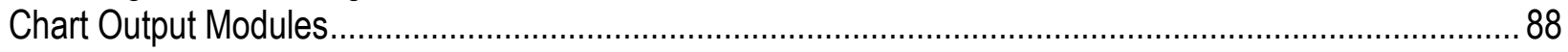

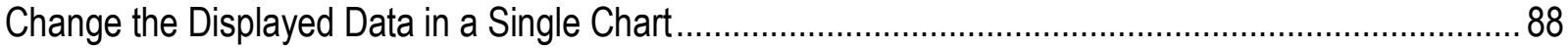

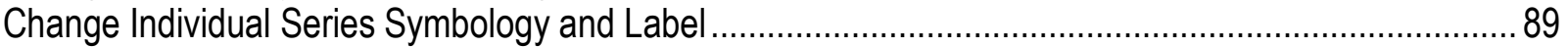

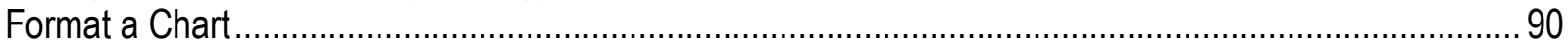

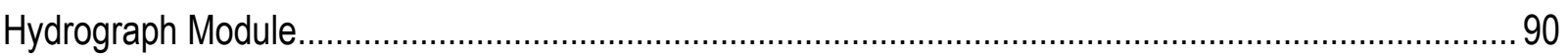

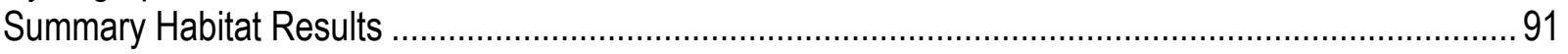

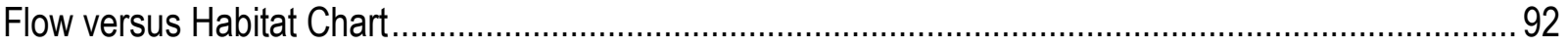

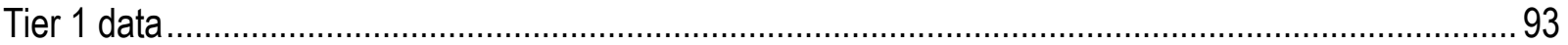

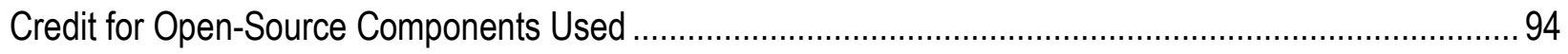

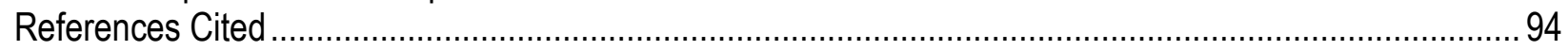

\section{Figures}

1-1. Screenshot example of download data option screen …………………................................... 79

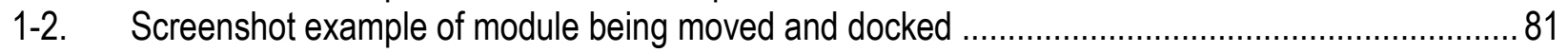

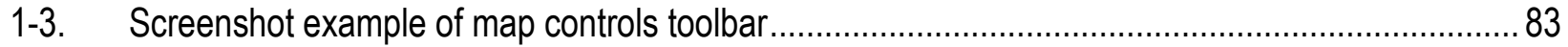

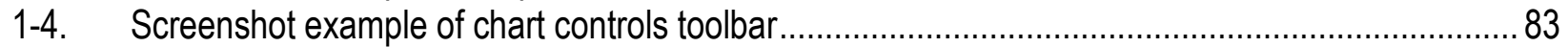

1-5. Screenshot example of segment map module displaying the land cover covariate ........................84 84

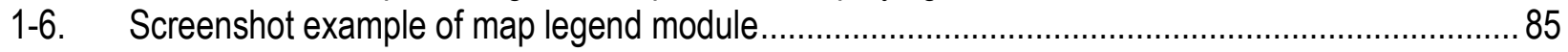

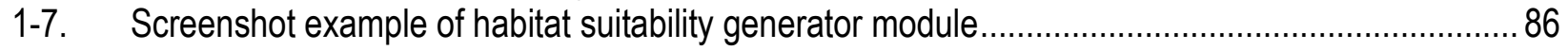

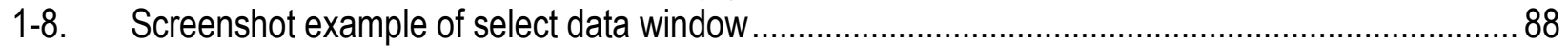

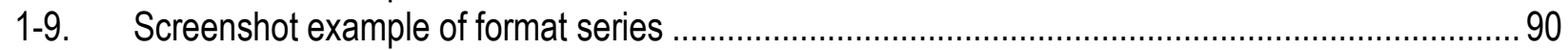

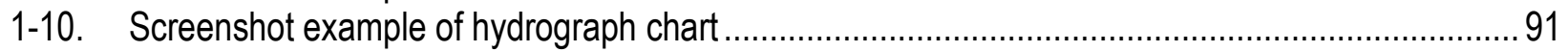

1-11. Screenshot example of summary habitat chart................................................................... 92

1-12. Screenshot example of flow habitat chart ........................................................................... 93

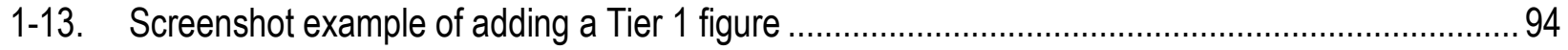

\section{Tables}

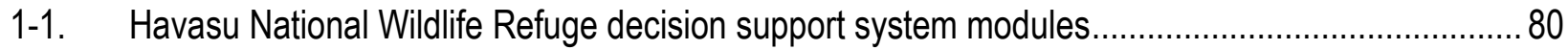

1-2. Havasu National Wildlife Refuge decision support system built-in module views ........................... 82 


\title{
User's Manual for the Havasu NWR Decision Support System (DSS)
}

\author{
By Colin Talbert
}

\section{Installation and Configuration}

\section{Application Installation}

Installation of the Havasu National Wildlife Refuge (NWR) decision support system (DSS) requires a two-step process. The components required for both steps are available from the U.S. Geological Survey (USGS) ScienceBase Catalog at https:/www.sciencebase.gov/catalog/folder/55ad8535e4b066a2492421ab. The first step is to install the open source mapping library called MapWinGIS, which is used by the application. This requires administrative privileges for your computer and is accomplished by downloading and running the "MapWinGIS 4.8 installer" component available from the ScienceBase folder link above. The next step is to download and install the "Havasu NWR DSS installer" from the same folder. This second step does not require administrative privileges. For both steps, all default installation options should be fine.

Because of the heavy computational demands inherent in the methodology, a 64-bit computer is required. Most new computers are 64-bit, but there are still 32-bit systems in use. You will need to have at least 25 gigabytes (GB) of hard drive storage space available on the computer to store the inputs and derived data required by the application. This data storage space can be located on an external or network drive as well.

\section{Obtaining the Input Data}

Installation of the application as described in the previous section "Application Installation" does not provide the input data required by the DSS. The first time you open the Havasu NWR DSS application, a form will pop up alerting you that the input data were not found and providing options for obtaining them (fig. 1-1). The Auto download option is suggested for most first-time users. This is accomplished by clicking the "Download Initial Data" button and selecting a folder to save the data in. A progress bar will appear as the data is downloaded from ScienceBase and extracted. Once the download finishes, the application will open automatically.

The second, optional, method of obtaining this core data is to manually download the required data directly from ScienceBase at https://www.sciencebase.gov/catalog/item/56b501a7e4b0cc799980a85d, which also can be navigated to by clicking on the ScienceBase link on the form below (fig. 1-1). All of the data needed by the application are in a zipped bundle called Full.zip, which can be found by clicking the SourceData folder from the site below and then clicking on the InitialWorkspace.zip item.

The third method is to obtain the data directly from another user or the developers of the application. This might be the best or only option for users that do not have a reliable or high-speed internet connection. 
With either of these last two options, click "OK" on this form to dismiss it and open the actual application. Then in the top menu click "File" and select "Open Session Directory" and navigate to the "DefaultSessionDirectory" subfolder in the unzipped data obtained in the previous two steps.

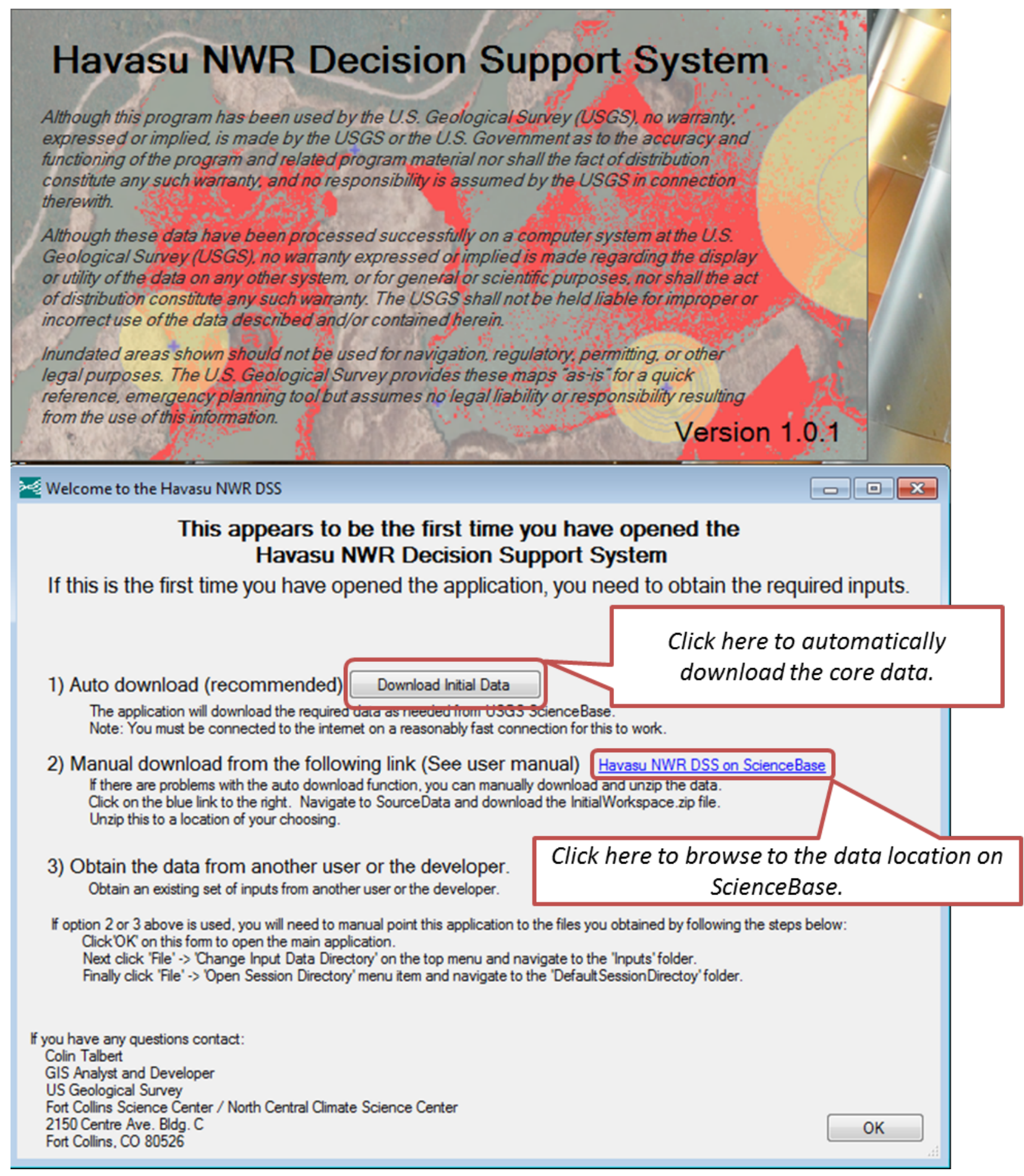

Figure 1-1. Screenshot example of download data option screen. 


\section{Using the Havasu NWR DSS}

The Havasu NWR DSS application is set up in a modular manner to allow flexibility in the content displayed at any time. In the current version (1.0.1), there are seven different modules in the application (table 1-1). Each module consists of an independent window configured for viewing a specific type of data or summary. When using the application, any number of modules can be used at any time. Each module is independently configurable, resizable, and moveable. Although each open module is independent, they do interact to facilitate data exploration. For example, moving the cursor on a hydrograph and clicking once will update the maps to display the selected water surface elevation (WSE). If the user does not want an individual module updated relative to other modules, the user can lock individual modules by right clicking anywhere on the module and selecting "Lock." Locked modules are denoted with an asterisk $\left(^{*}\right)$ after their name. Each module will be described in detail in subsequent sections.

Table 1-1. Havasu National Wildlife Refuge (NWR) decision support system (DSS) modules.

\begin{tabular}{|c|c|}
\hline Module & Description \\
\hline Segment Map & Map display of spatial data. \\
\hline Map Legend & Display color legend for an individual map. \\
\hline $\begin{array}{l}\text { Habitat Suitability } \\
\text { Generator }\end{array}$ & $\begin{array}{l}\text { Used to view and modify the habitat suitability criteria used in the Havasu NWR DSS. Also used to } \\
\text { regenerate the spatial habitat map output. }\end{array}$ \\
\hline Hydrograph & Chart of the daily water surface elevation (WSE), habitat, or other metrics. \\
\hline $\begin{array}{l}\text { Summary Habitat } \\
\text { Results }\end{array}$ & $\begin{array}{l}\text { Chart of available habit across the period of record. Also used to identify scenarios that deviate } \\
\text { more than } 10 \text { percent from the baseline scenario. }\end{array}$ \\
\hline $\begin{array}{l}\text { Flow Versus } \\
\text { Habitat Chart }\end{array}$ & Chart of the normalized habitat versus water surface elevation functions. \\
\hline Tabular Data & Spreadsheet of the data used to create any of the charts or non-spatial inputs. \\
\hline
\end{tabular}

\section{Adding, Removing, and Resizing Modules}

New modules can be added to the application through use of the "Modules" menu. The selected module will appear with the default size and docking (right, left, top, or bottom). A module can be resized by hovering the cursor over one of the edges; when the resize icon appears, the user can click and drag the module to the desired size. A module can be moved by clicking and dragging the title bar of that module to a new position. While the module is being dragged, a set of docking icons will be visible as well as a ghost-blue image of the module's new location (fig. 1-2). Modules can be removed by clicking on the $\mathrm{X}$ in the upper right corner. In addition to the basic docking locations within the application, users also can dock modules within other modules, drag modules outside the main application window, stack multiple modules onto one another, and pin modules so they auto hide when not in use. 


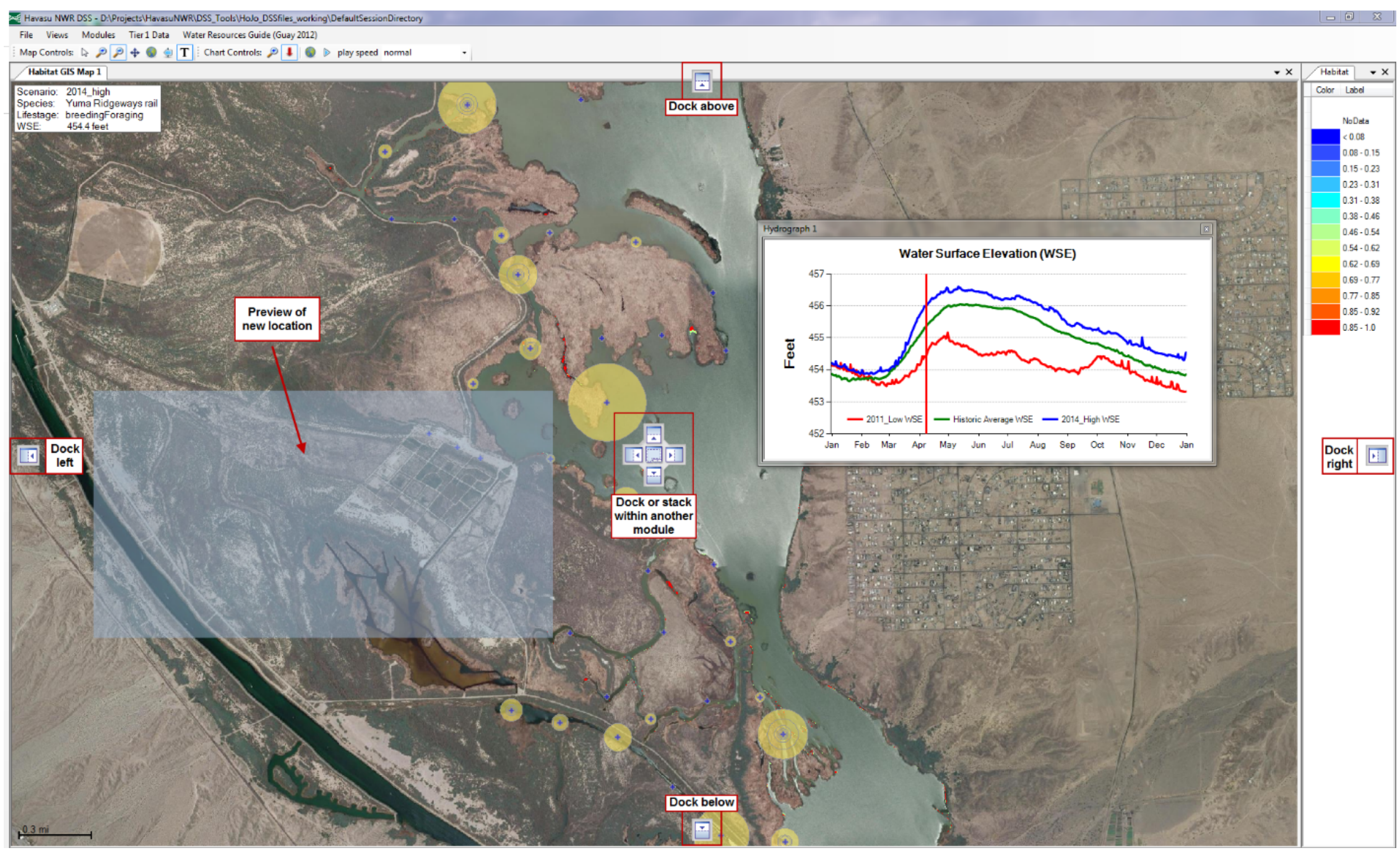

Figure 1-2. Screenshot example of module being moved and docked. 


\section{Using Views to Facilitate Organizing Multiple Modules}

The user will most often interact with multiple modules at once in the DSS. Although it is possible to bring in and set up multiple modules individually, the DSS provides the ability to easily open, switch between, and save views. The Havasu NWR DSS comes with several built-in views that users can select to open a specific module configuration. Built-in views (table 1-2) can be selected using the "Views" menu. User-defined custom views can be saved by clicking the "Views" menu and selecting "Save current view." The user will then be prompted to name the new view. "Remove view" is used for deleting a no longer needed view. Be careful when removing views as the view, even the built-in view, is permanently deleted.

Table 1-2. Havasu National Wildlife Refuge (NWR) decision support system (DSS) built-in module views.

\begin{tabular}{|c|c|}
\hline View & Description \\
\hline Examine Covariates & $\begin{array}{l}\text { Comparison of covariates (depth, distance to water, and land cover) for differing WSE } \\
\text { scenarios. }\end{array}$ \\
\hline $\begin{array}{l}\text { Habitat versus WSE } \\
\text { Curves-HSC1 }\end{array}$ & $\begin{array}{l}\text { Display of how the area of suitable habitat for the three focal species changes across a } \\
\text { range of marsh elevations utilizing the default HSC data provided. }\end{array}$ \\
\hline $\begin{array}{l}\text { Habitat versus WSE } \\
\text { Curves-HSC } 2\end{array}$ & $\begin{array}{l}\text { Display of how the area of suitable habitat for the three focal species changes across a } \\
\text { range of marsh elevations utilizing modified HSC data (used to test alternative HSCs). }\end{array}$ \\
\hline Edit Habitat Suitability & View or edit the habitat suitability curves (HSC) and run habitat recalculation. \\
\hline $\begin{array}{l}\text { Suitable Habitat } \\
\text { Comparison-HSC1 versus } \\
\text { HSC2 }\end{array}$ & $\begin{array}{l}\text { Comparison of suitable habitat calculated using differing HSCs (default vs modified) for } \\
\text { the same species and lifestage and two different WSE scenarios. }\end{array}$ \\
\hline $\begin{array}{l}\text { Summary Habitat Results- } \\
\text { All Scenarios }\end{array}$ & Summary of habitat and water requirements for all scenarios. \\
\hline $\begin{array}{l}\text { Water Storage Historical } \\
\text { Comparison }\end{array}$ & Comparison of water storage and requirement for historic scenarios. \\
\hline $\begin{array}{l}\text { Water Storage Hypothetical } \\
\text { Comparison }\end{array}$ & Comparison of water storage and requirements for hypothetical habitat driven scenarios. \\
\hline
\end{tabular}

\section{Havasu NWR DSS Toolbars}

Two toolbars are docked at the top of the Havasu NWR DSS application that can be used for interacting with various modules. The "Map Controls" toolbar is used to manipulate the map modules; the "Chart Controls" toolbar is used to manipulate the various output charts.

\section{Map Controls Toolbar}

The Map Controls toolbar contains various items useful for interacting with the map modules (fig. 1-3). The first four icons change the type of interaction and cursor that the mouse has with the map. Users of online mapping or GIS will be familiar with these icons. The next two icons are used to either zoom to the full extent or the previous extent. The last icon will turn on or off the maps title box. 


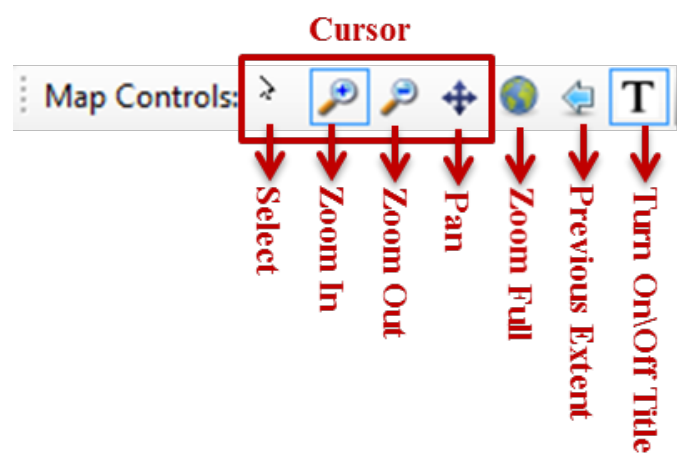

Figure 1-3. Screenshot example of map controls toolbar.

\section{Chart Controls Toolbar}

This toolbar contains items specific to the various chart modules (fig. 1-4). The first two items change the type of interaction/cursor that the mouse has with charts. The "Zoom In" cursor is used to display a section of the chart in greater detail. This can be done by selecting the "Zoom In" button and then clicking and dragging over a section of a chart to make that subset of the data fill the chart area. The "Select" cursor is specialized to only work on the hydrograph chart modules. Clicking on a point in the hydrograph with the "Select" cursor will update a corresponding segment map based on the nearest representative flow/Water Surface Elevation (WSE) used in the DSS. This can be used to determine how input covariates and output habitat change across a range of flows/WSEs. The final two items on the Chart Controls toolbar allow the user to play a time-lapse animation of the map display showing the changes in response metrics to the hydrograph values. The view named "Edit habitat suitability" is set up to provide a demonstration of this selection and animation. If the user opens this view and clicks on the hydrograph, the maps update to display layers corresponding to the selected flow. Clicking the "Play" button allows the user to view the animation; clicking "Play" again stops the animation.

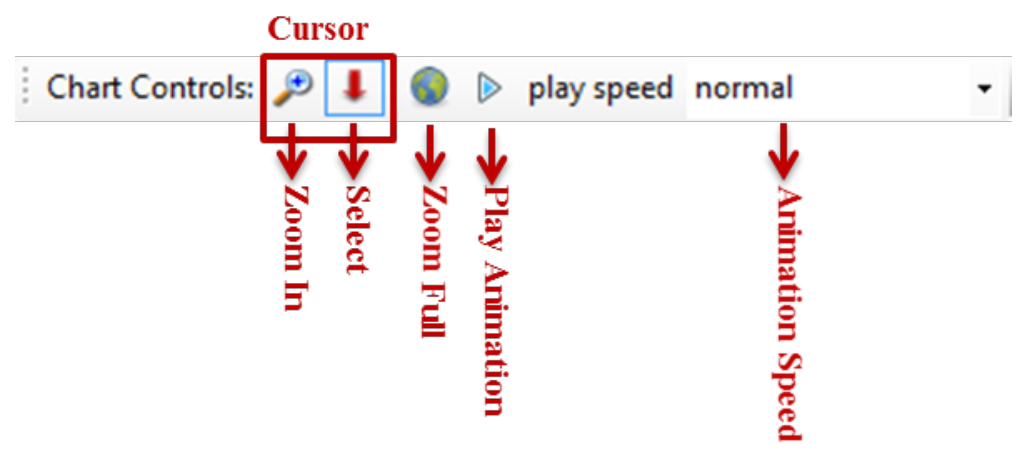

Figure 1-4. Screenshot example of chart controls toolbar.

\section{Havasu NWR DSS Map Modules}

The following sections describe the various map modules that are available in the current version of the DSS (1.0.1). Each of the various map modules can be used to create specific customized layouts 
that contain multiple modules within a single view and can be saved for future analysis and repeated access to a particular map module layout.

\section{Segment Map}

The Segment Map module provides a means of viewing a detailed map for an individual study segment. On top of an aerial image of the segment, the user can display one of the covariates or outputs. To change either the study segment or the overlaid map layer, right click on the map or its title bar and a context menu will appear. Hover your mouse over the scenario, segment, time period, species, lifestage, covariate, or flow/WSE that you are interested in viewing. The list of available items under that category will appear (fig. 1-5). To display or remove the title box, click the " $T$ " icon on the map toolbar.

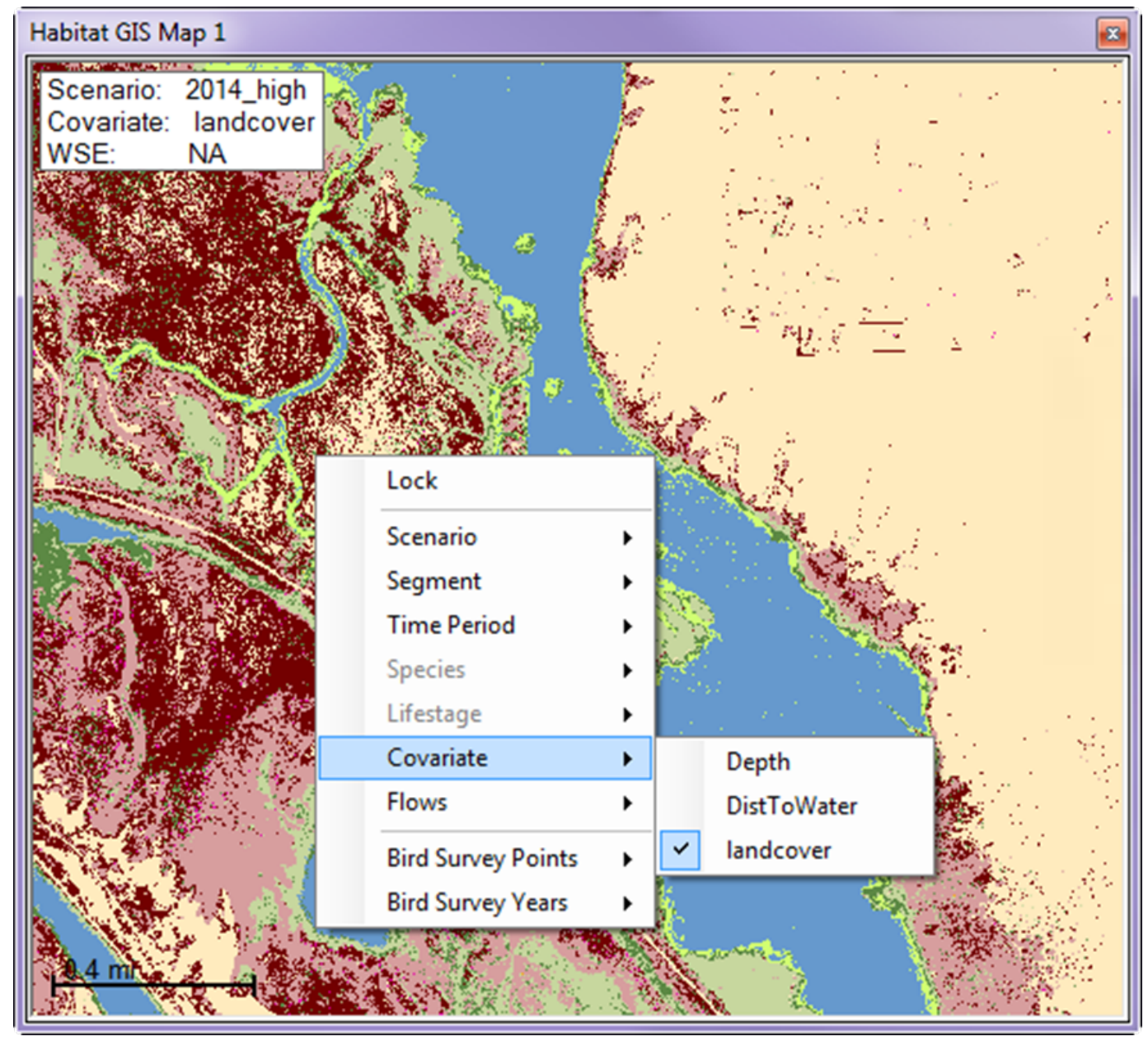

Figure 1-5. Screenshot example of segment map module displaying the land cover covariate.

\section{Map Legend}

The Map Legend module (fig. 1-6) is used to show what the colors on a segment map signify. After adding a map legend module you will need to change the display to match the variable of interest by right clicking in the module and selecting from the list that pops up. For clarity you will probably 
want to dock the module next to its corresponding segment map and resize it to be fairly narrow. Note that the color ramp being displayed only corresponds to the default ramp for each variable, if you are modifying the HSC values the colors displayed on the segment map will correspond to the values and colors shown in the Habitat Suitability Generator module (described below).

\begin{tabular}{|c|c|c|c|}
\hline habitat & & & $x$ \\
\hline \multirow[t]{14}{*}{ Color } & Label & & \\
\hline & NoData & & \\
\hline & $<0.08$ & & \\
\hline & $0.08-0.15$ & & \\
\hline & $0.15-0.23$ & & \\
\hline & $0.23-\sqrt{\square}$ & Habitat & \\
\hline & $0.31-?$ & Depth & \\
\hline & $0.38-6$ & DistToWater & \\
\hline & $0.54-d$ & landcover & \\
\hline & $0.62-0.69$ & & \\
\hline & $0.69-0.77$ & & \\
\hline & $0.77-0.85$ & & \\
\hline & $0.85-0.92$ & & \\
\hline & $0.85-1.0$ & & \\
\hline
\end{tabular}

Figure 1-6. Screenshot example of map legend module.

\section{Habitat Suitability Generator}

The Habitat Suitability Generator module provides functionality to view and change the HSC used to generate habitat maps for the Havasu NWR DSS. Additionally, it allows the user to view and edit the equation used to generate the habitat maps. It also contains functions to regenerate the map outputs when changes to the HSCs or equations have been made (fig. 1-7). Any changes to the HSC are automatically saved, replacing the original values. To undo these changes and revert to the original HSC values, click "File" and select the "Reset Habitat Suitability Curves (HSCs)" option. The default HSC values that are delivered with the DSS are very broad in nature and based on general habitat preferences. The default HSC values in the current version (1.0.1) are undergoing literature verification and we are working with refuge staff to identify possible site-specific habitat criteria and may be modified in the future as more data become available. 


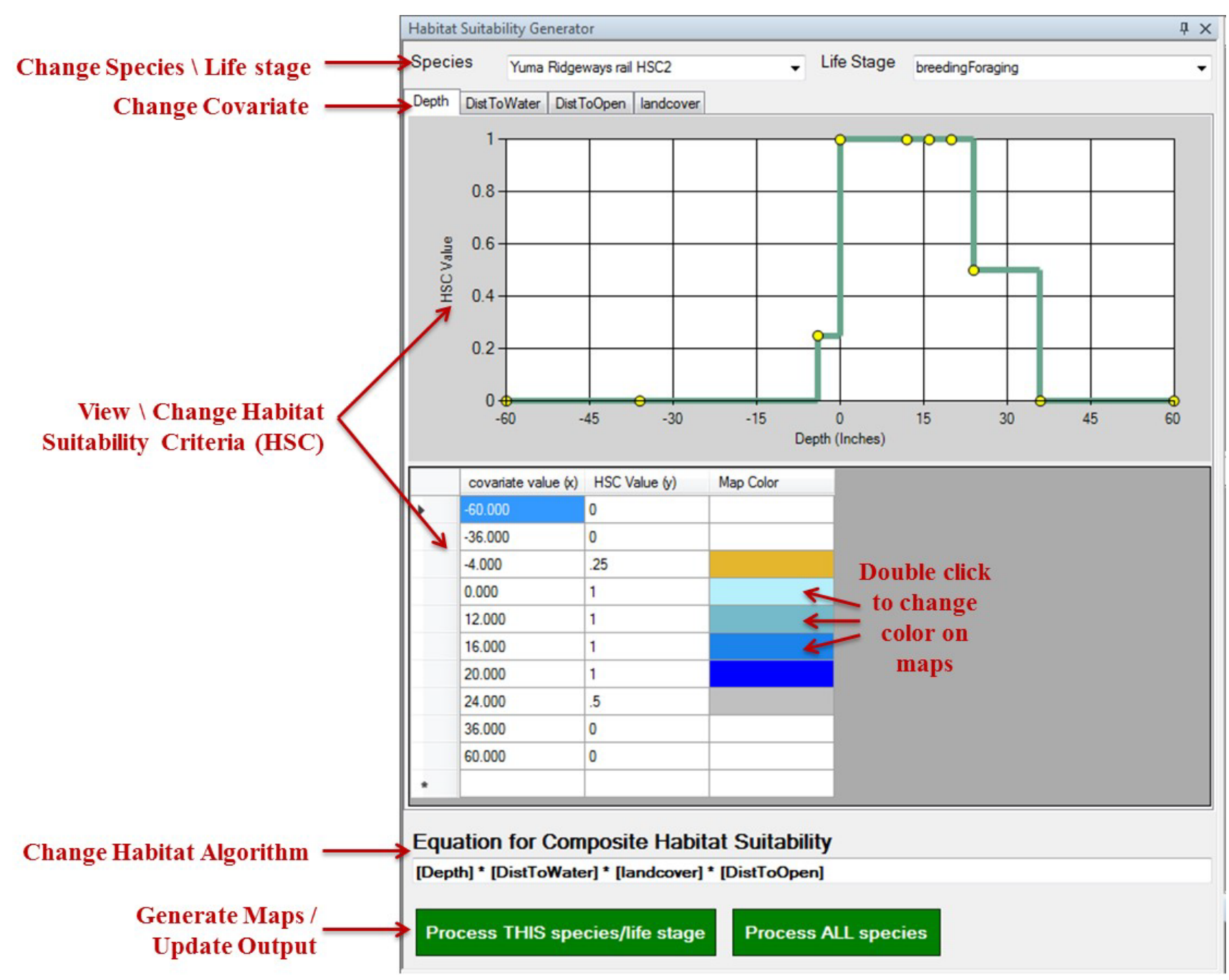

Figure 1-7. Screenshot example of habitat suitability generator module.

In the center of this module, there is a chart that displays an HSC curve for a single species, lifestage, and covariate. Beneath that curve is a list of its $x$ and $y$ values. Edits to the curve can be made by either changing the values in the table or clicking and dragging on one of the yellow dots on the curve chart. The drop-down boxes at the top of the module can be used to change the species or lifestage HSC displayed. To switch between different input covariates (for example, Depth and DistToWater), select the tabs immediately above the chart.

If a segment map module is visible, any changes to the HSC will be reflected in the spatial habitat inputs. To try this, open the "Edit habitat suitability" view. Change one of the HSC values in either the chart or table to get the segment map modules to update their display. The four segment map modules are displaying depth, distance to water, distance to open water, and land cover using the default symbology for those layers. The third column in the table below the HSC chart shows the color that will appear on the map for that portion of the HSC. Double click on the colored box to change this color. White indicates areas that will be displayed as transparent on the map.

Once all changes to the HSC have been made, the user can update the equation used in the text box entitled "Equation for Composite Habitat Suitability." Standard mathematical symbols can be used 
with the covariates contained in square brackets. For example, in the riverine environment the default algorithm for brown trout spawning (after Bovee and others, 2007) is "[Depth] * [Velocity]." This means that the depth grid (or map) will be reclassified according to the depth HSC and then multiplied by the velocity grid and reclassified according to the velocity HSC. If the user wanted to change this algorithm to be the square root of (depth squared * velocity squared), for example, the equation would be entered as “([Depth $\left.\left.]^{\wedge} 2 *[\text { Velocity }]^{\wedge} 2\right)^{\wedge} 0.5\right) "$.

Once the equations have been set, the outputs can be regenerated. To process the outputs for a single species/lifestage, click the "Process THIS species/life stage" button. The processing time for a single species depends on the speed and memory of the computer but should be around 30 minutes. To reprocess all of the species and lifestages, click the "Process ALL species" button. The processing time for all species takes considerably longer, somewhere around 8 hours, as of the time of the writing of this publication.

\section{Scenarios}

Within the DSS, scenarios represent management or environmental conditions that result in a different time series of daily water surface elevations (WSEs) and (or) evapotranspiration (ET). For the Havasu NWR implementation of the DSS framework these are limited to a single calendar year. The application starts with three historical scenarios representing an extreme low water year (2011), a high water year (2014) and a scenario representing the daily average values for 2005-14. In addition, there are three scenarios representing hypothetical management options in which the marsh surface is regulated in a manner to maximize habitat for two of the species of interest, Southwestern willow fly catcher and rails (combined Yuma Ridgway's rail and black rail HSC). The last hypothetical scenario is a compromise that attempts to simultaneously maximize the habitat for all species. For each of these hypothetical scenarios no attempt was made to account for additional requirements (water quality, recreational use) or feasibility (diversion capacity) within Havasu NWR. As such, these hypothetical scenarios do not represent suggestions, only examples of how one might use the DSS to compare scenarios.

\section{Adding and Removing Scenarios from the DSS}

Users potentially will want to compare new scenarios that are not included in the DSS. This can be done by creating a new scenario file and adding it to the application. To do this, navigate to the Inputs subfolder at the location you specified in the "Obtaining the Input Data" section. If you do not recall where these inputs were saved, click on File $>$ Change Input Data Directory from the main menu to find the path to this folder. Make a copy of one of the existing scenarios files such as wse_2011.xlsx and open this copy in Excel. Change the daily WSE values in column two and the ET values in column three. The WSE values are in meters in the NGVD29 datum. The evapotranspiration (ET) values are in acre feet. Once the edits are complete save and close the file in Excel. Now back in the DSS click File $>$ Add Scenario and navigate to the file just created. A text box will pop up prompting you to enter a name for this scenario. Choose a new short name with no spaces and click "ok." The data from the Excel worksheet will be imported into the current database. This process can take a few minutes. If you make a mistake, or want to remove some of the current scenarios click File $>$ Remove Scenario and select the scenario to remove from the list to the right. Be careful as there is no way to undo this removal, other than reimporting the scenario. 


\section{Chart Output Modules}

These modules, which include Hydrograph, Summary Habitat Results, and Flow Versus Habitat Chart, are used to display various outputs in a graphical or chart-based form. Each module has a context menu that can be opened by right clicking in the module or its title bar. The context menu lists several useful options including printing the chart, saving a .jpeg image of the chart, or copying it to the clipboard (for use in another application, for example).

\section{Change the Displayed Data in a Single Chart}

The context menu (obtained by right clicking on a chart) contains an option titled "Select Data" which allows the user to change the data that the chart is displaying. Selecting this opens an interface that allows the user to select multiple items for display. This interface will be slightly different for each of the output chart modules (fig. 1-8). For example, the scenario and baseline selection box will not be visible in a "Flow Versus Habitat Chart" because they are the same for all scenarios. When multiple items are selected in each of the categories, the total number of items displayed in the resulting chart can quickly lead to indecipherable charts. It is best to limit the number of elements in any given chart and instead have multiple charts, each with a specific item of interest.

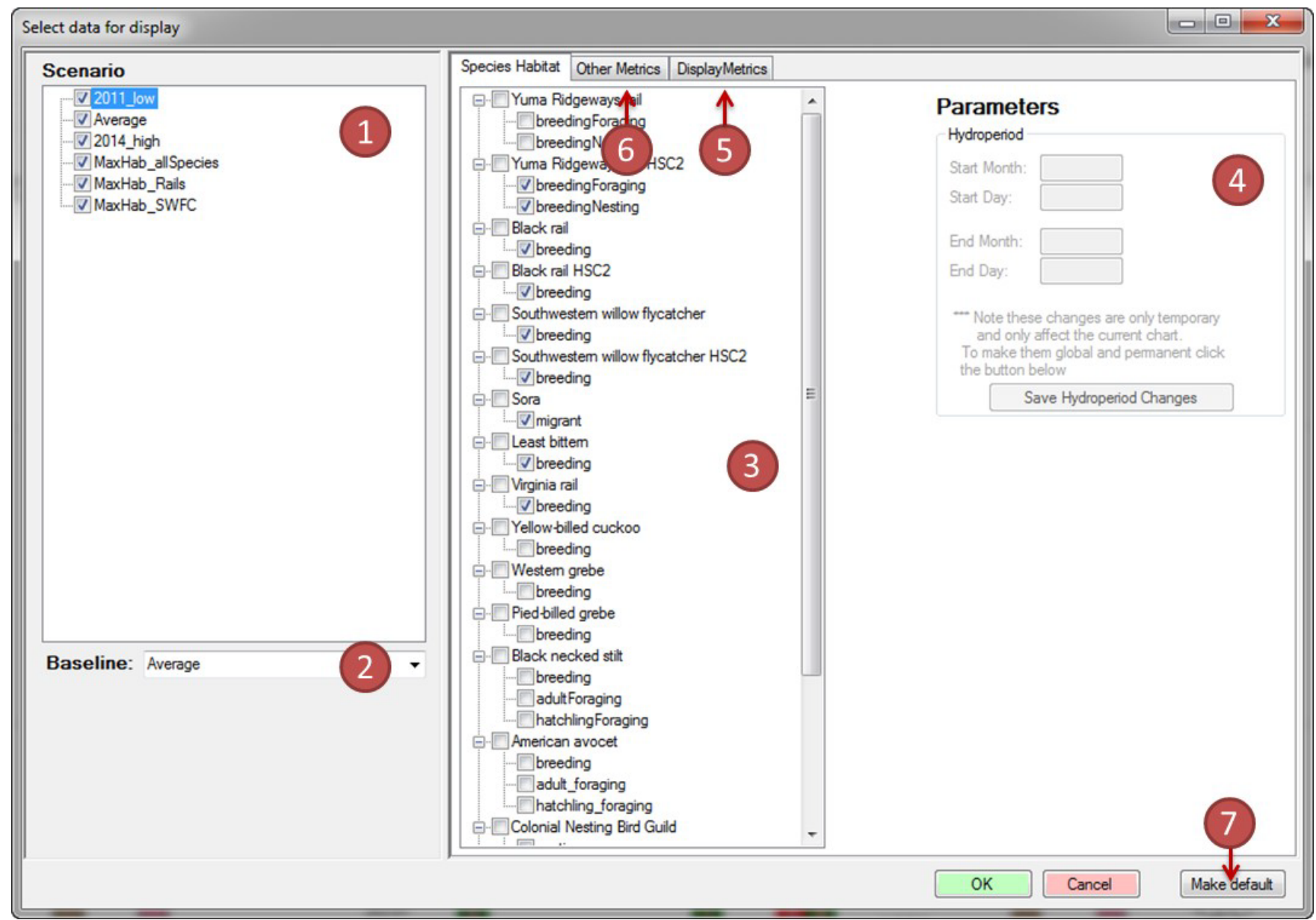

Figure 1-8. Screenshot example of select data window. 
Although there are numerous elements on the "Select Data window," their use is relatively straightforward. Note that not all options will be available for selecting data for all charts. The options are as follows:

1. Scenario-Select which of the available scenarios to compare.

2. Baseline-Select one of the flow scenarios to be used as a baseline to compare against the remaining flow scenarios. This is used in the "Summary Habitat Chart" and the "Tabular Data" modules to measure percent change. Changes greater or less than 10 percent are flagged in green and red, respectively.

3. Species Habitat - Specify which species/lifestages will be displayed. The top level check boxes next to each species do not have an effect; there is not a way of summarizing across all lifestages for a given species in the current version (1.0.1).

4. Parameters (for species habitat) — With a lifestage selected, the hydroperiod parameters are enabled and display the values used for that lifestage. The values in the hydroperiod boxes can be changed, but changes are temporary and only apply to the single module linked to this "Select Data" window. To make changes permanent and global, click the "Save Hydroperiod Changes" button.

5. Display Metrics - Change the aggregation algorithm used to calculate the yearly and entire hydroperiod summaries. The default value "Average of bottom 25 percent of habitat" is equivalent to what was used in the original DSS. In addition, "Minimum single habitat" in which the available habitat from the time step with the least area is reported and "Average all Habitat" in which the available habitat is averaged across all time steps in the hydroperiod are available.

6. Other Metrics - Display water storage and inflow requirements on chart.

7. Make Default — Save the current selections to be the default for all new modules of this type.

\section{Change Individual Series Symbology and Label}

Adjustments can be made to the color, line width, line type, and displayed title for improved chart readability. To do this, click on the series symbol in the chart legend to bring up a simple interface for changing these attributes (fig. 1-9). These changes are saved globally so the next time users bring this series into a new chart it will have this label and symbology. 


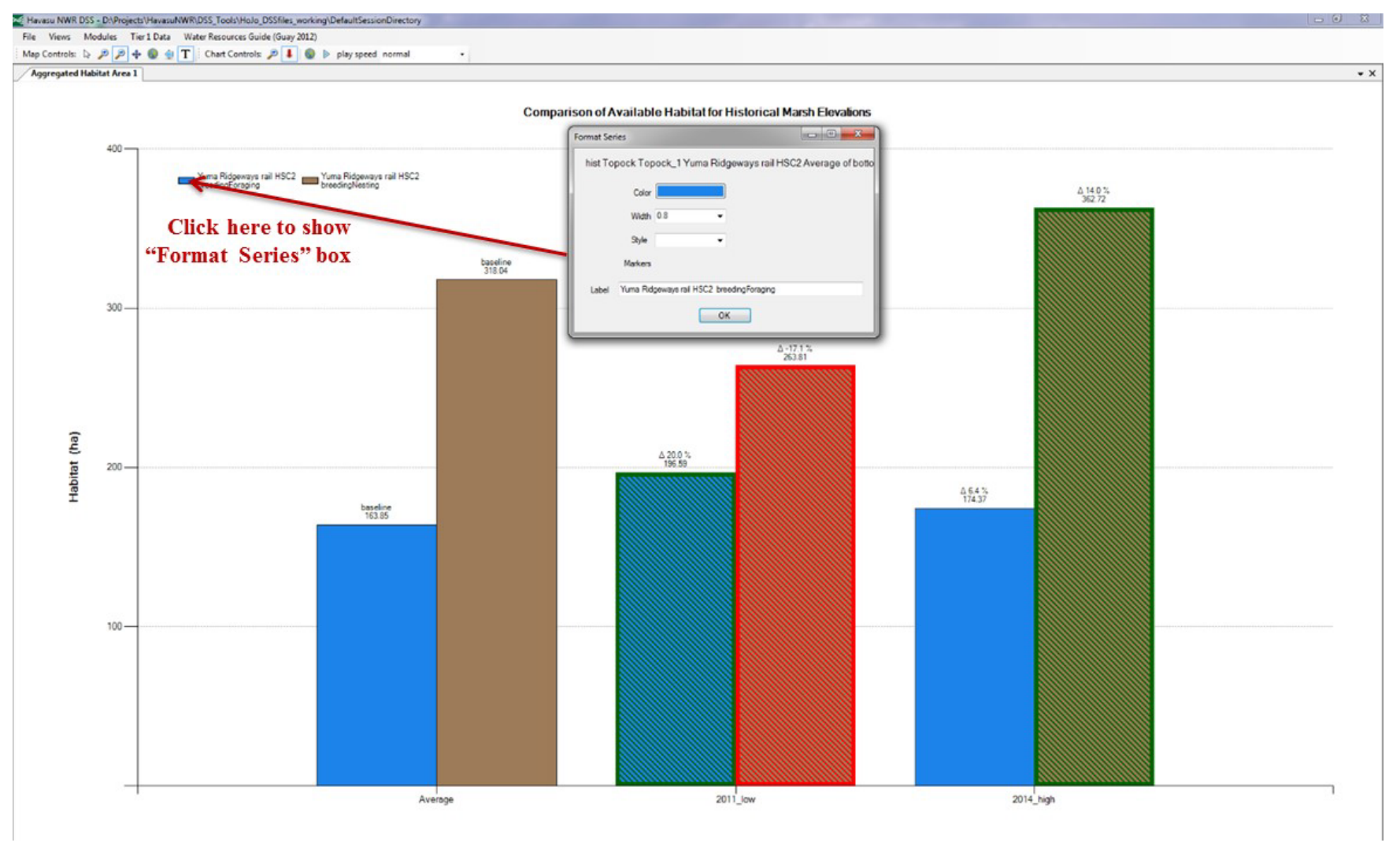

Figure 1-9. Screenshot example of format series.

\section{Format a Chart}

To change the default chart display settings, right click on a chart and select "Format Chart." A window will appear that allows users to change the following elements: title text, title font, title location, axis labels, axis font, axis scale, tick marks, and grid lines. Much like the Select Data window, changes can be saved as the default for this chart type using the "Make default" option.

\section{Hydrograph Module}

The "Hydrograph" module can be used to display a line graph of daily water surface elevation (WSE), habitat, or any of the other metrics (fig. 1-10). Water surface elevation (WSE) series are depicted on the left or primary y-axis while other daily series are represented on the right or secondary $\mathrm{y}$-axis. Note that when displaying multiple disparate metrics, they might not be readable on a single scale.

To zoom in on a section of the chart, click the zoom icon on the Chart Controls toolbar and click and drag a box around a section of interest. When zoomed in, users can scroll using the scroll bar at the bottom or left of the chart. To zoom back out, either double click the global extent icon on the Chart Toolbar, one of the small circles at the left end of the $\mathrm{x}$-axis scroll bar or the top of the y-axis scroll bar.

When displaying habitat areas on the hydrograph chart, only data for the time periods corresponding to the hydroperiod will be shown. These temporal extents will be highlighted with colored boxes on the chart. If a segment map is displayed and set to the same flow scenario depicted on the hydrograph, the map will sync with the selected flow/WSE. To try this, open the "Edit Habitat 
Suitability" view. Click Select cursor on the Chart Controls toolbar and click on the hydrograph. All three maps will update to display the habitat or covariate data for the flow/WSE that most closely matches that selected on the hydrograph. An animation of these flows through time can be viewed by clicking the "play" button on the Chart Controls toolbar.

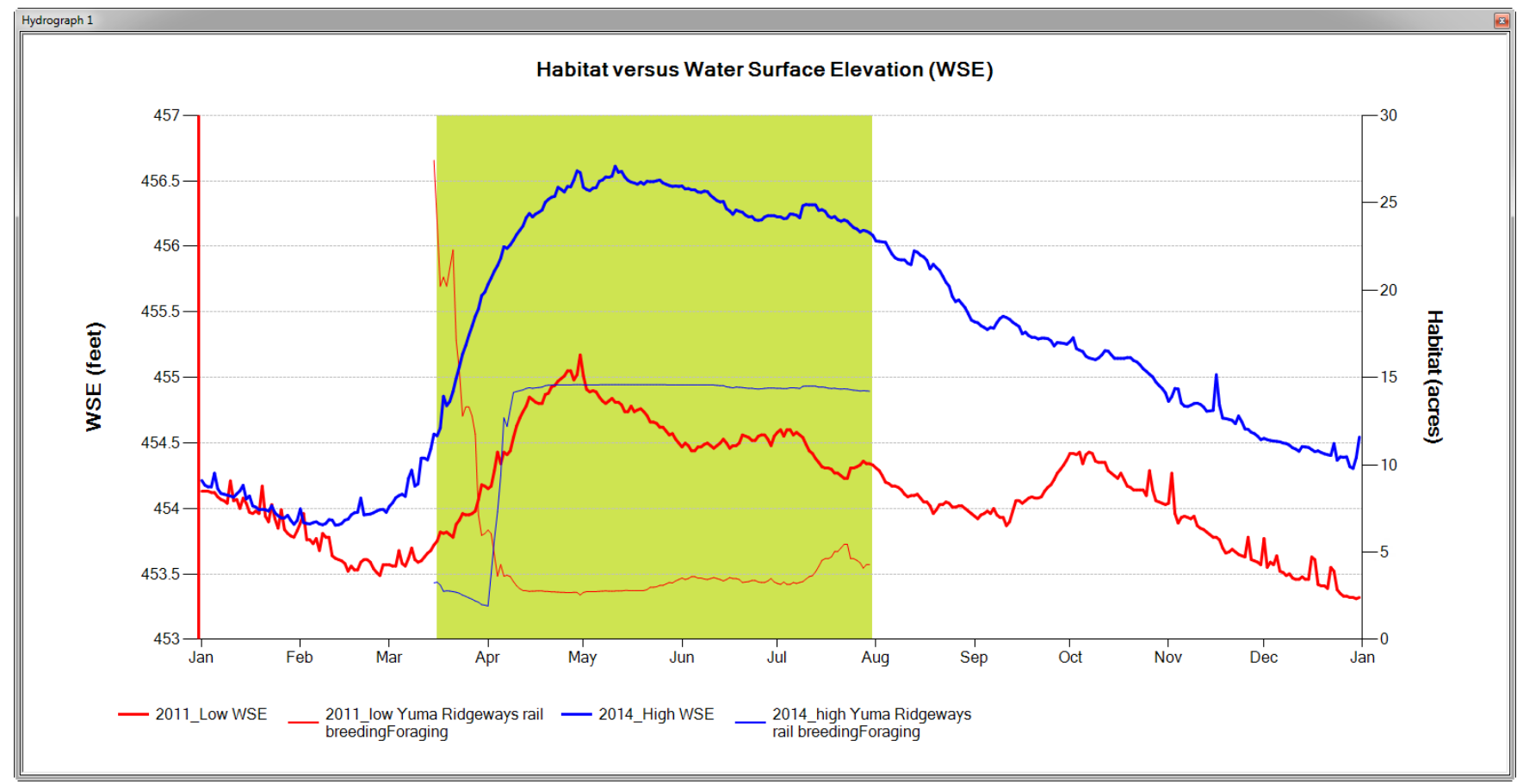

Figure 1-10. Screenshot example of hydrograph chart.

\section{Summary Habitat Results}

The "Summary Habitat Results" module presents a bar chart of habitat area for a given species/lifestage (fig. 1-11). The Summary Habitat Results chart allows a user to select a baseline scenario to compare the other scenarios against (using the Select Data option from the context menu). The percent change between this baseline and each chart is displayed above each bar on the chart. If one scenario performs 10 percent or more above the baseline, its bar is highlighted in green (fig. 1-11); a decrease of 10 percent or more from baseline will be highlighted in red. 


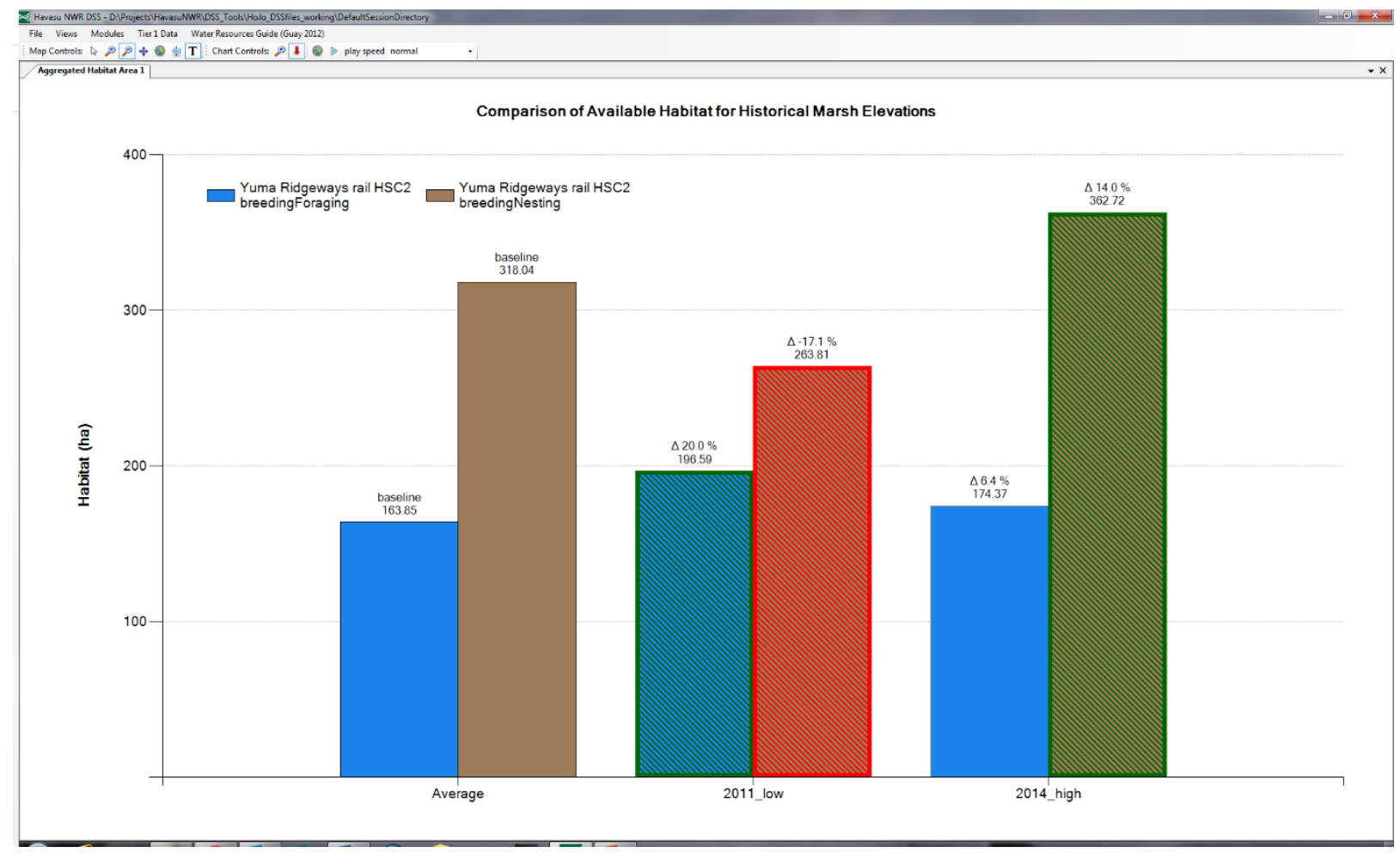

Figure 1-11. Screenshot example of summary habitat chart.

\section{Flow versus Habitat Chart}

The "Flow Versus Habitat Chart" module presents a means of visualizing the habitat area as a function of water surface elevation (fig. 1-12). This information can be used to determine which range of marsh elevations provide the maximum amount of suitable habitat for a given species and lifestage. Identifying the range of marsh elevations that provide the most suitable habitat can assist refuge staff in determining the best management scenarios and identify effects of water operations on species-specific habitat and ecological processes. 


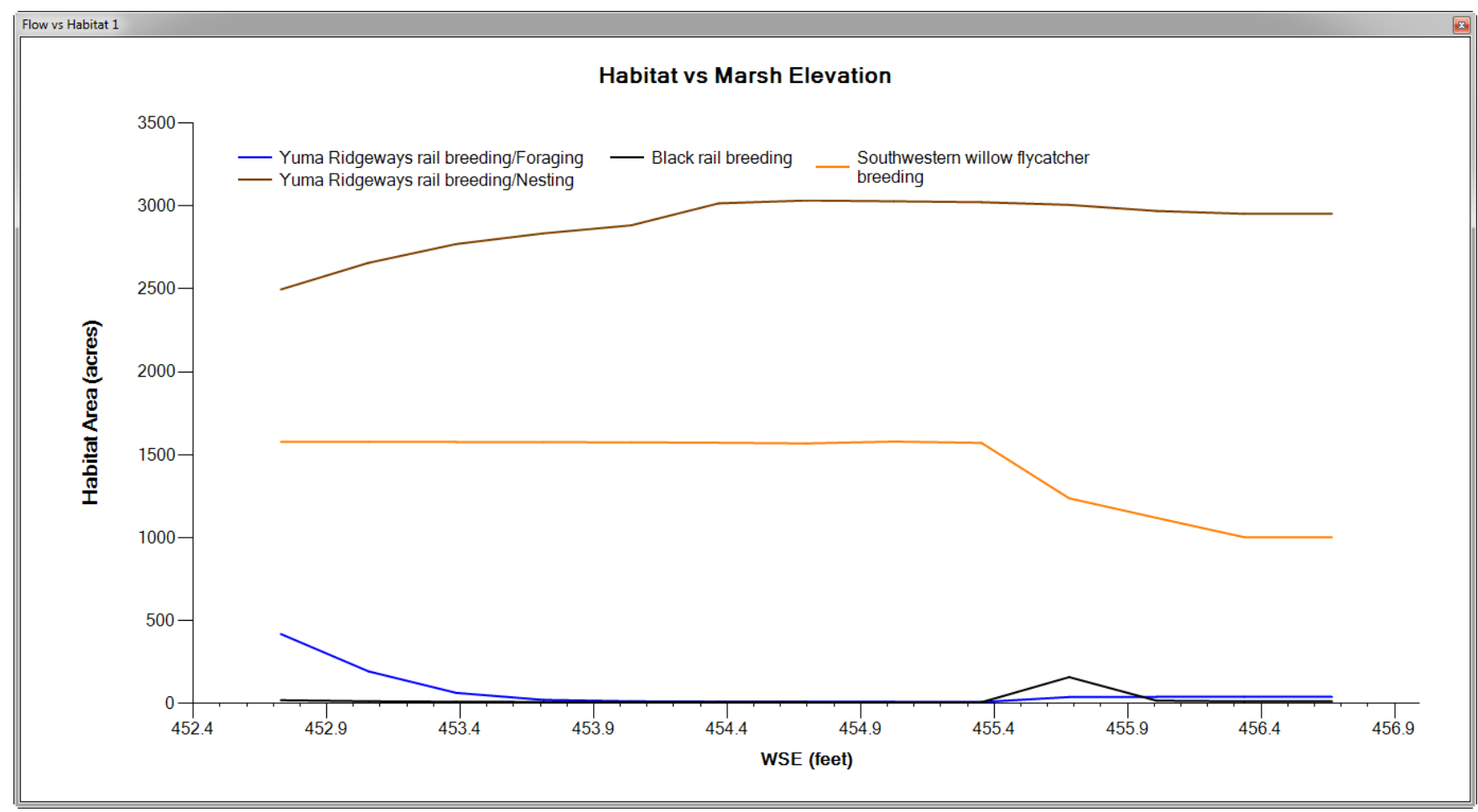

Figure 1-12. Screenshot example of flow habitat chart.

\section{Tier 1 Data}

Tier 1 (water quality, aquatic species, and other) data are accessible from within the DSS using a separate dropdown menu found on the main menu bar (fig. 1-13). The tabular data, which are available in an Excel workbook file format, opens directly in Excel. Chart and image versions of these data are viewable in the DSS application in popup windows. These Tier 1 figure modules can be resized and docked in the application in same manner as other DSS modules. To change the zoom display extent, use the mouse wheel to zoom in and out and click and drag on the chart image to re-center the image in the window. The save button in the upper left of the module can be used to save a copy of the image to the file system. Note that unlike other chart and map outputs in the DSS the contents of the Tier 1 figure modules are static, so the user will not be able to change the data displayed or format options such as line colors or font sizes. 


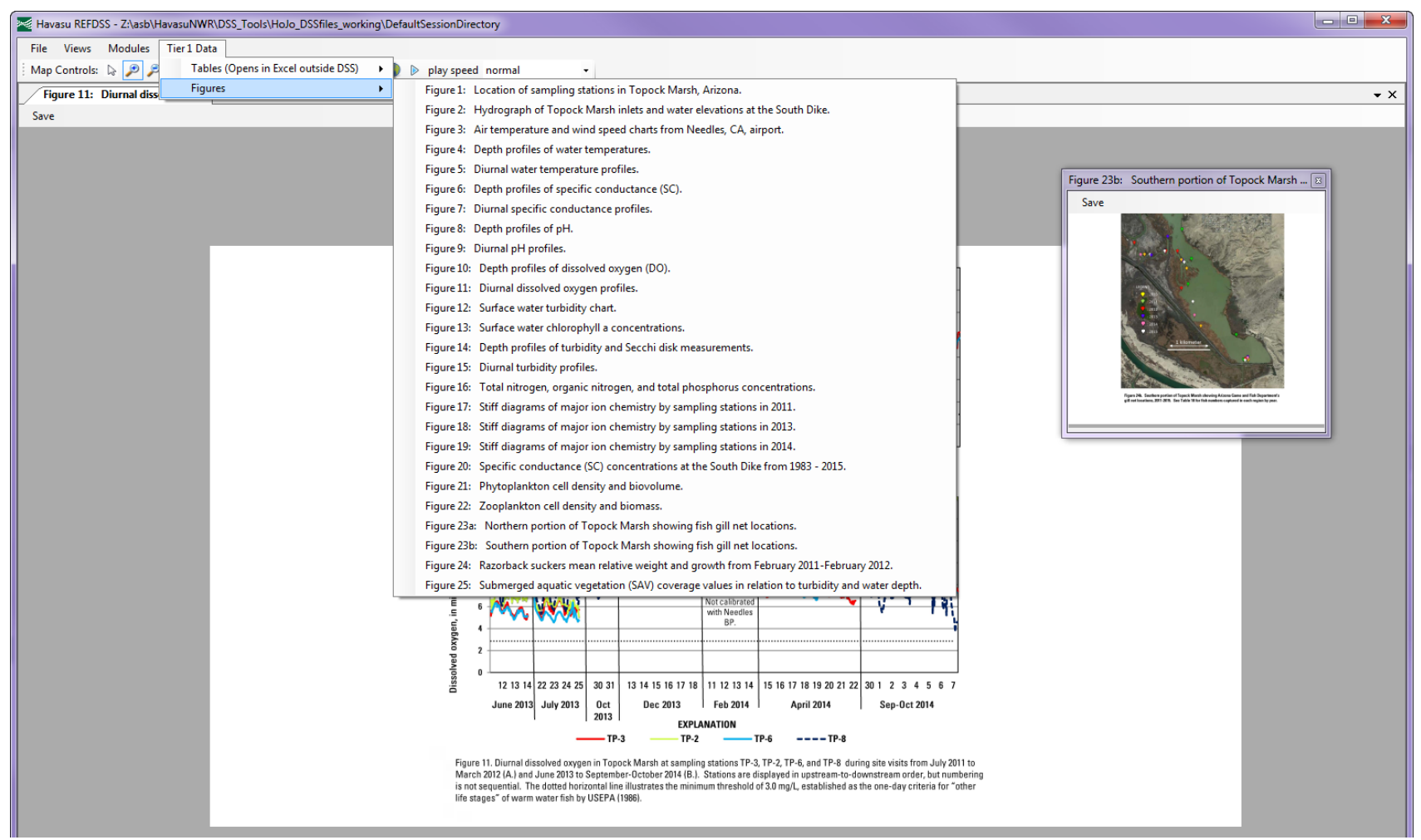

Figure 1-13. Screenshot example of adding a Tier 1 figure.

\section{Credit for Open-Source Components Used}

The development of the Havasu NWR DSS would not have been possible without the use of several open-source and free projects.

- GIS map display is provided by the MapWinGIS ActiveX Control Project which is part of the MapWindow GIS Open Source Project (http://www.mapwindow.org/).

- The user configurable docking windows are from the DockPanel suite available at http://dockpanelsuite.sourceforge.net/.

- The database back end uses SQLite with the dot.net bindings (http://www.sqlite.org/about.html).

- Unzipping functionality uses the DotNetZip Library (http://dotnetzip.codeplex.com/).

- Charting functionality was through the built-in Microsoft Charting Library.

\section{References Cited}

Bovee, K.D., Waddle, T.J., Bartholow, J., and Burris, L., 2007, A decision support framework for water management in the upper Delaware River: U.S. Geological Survey Open-File Report 2007-1172, 122 p. [Available at http://www.fort.usgs.gov/ASTA/Products.asp.] 


\section{Appendix 2. Report by Colorado State University: Mapping Land Cover and Invasive Tamarisk in Havasu National Wildlife Refuge, AZ}

Note: Appendix 2 is a report published by Colorado State University, the results of which are utilized in Tier 2 and Tier 4 of this open-file report. It is being provided for reference purposes only, as it is not available online. Because it is not a U.S. Geological Survey (USGS) product, it has not gone through the USGS publication review process and is not formatted to USGS specifications. Page numbers have been updated for inclusion in this report, but figure and table numbers appear as originally published. 


\title{
Mapping Land Cover and Invasive Tamarisk in Havasu National Wildlife Refuge, Arizona
}

\author{
Nicholas E. Young ${ }^{1}$, Amanda West ${ }^{12}$, Ryan S. Anderson ${ }^{1}$, Stephen Chignel1 ${ }^{12}$, Paul H. Evangelista ${ }^{12}$, \\ Catherine S. Jarnevich ${ }^{3}$
}

\footnotetext{
${ }^{1}$ Natural Resource Ecology Laboratory, Colorado State University Fort Collins, CO 80523-1499

${ }^{2}$ NASA DEVELOP Fort Collins Node, Colorado State University Fort Collins, CO 80523-1499
}

${ }^{3}$ U.S. Geological Survey, Fort Collins Science Center 2150 Centre Ave. Building C. Fort Collins, CO 80526-8118

June 5, 2015

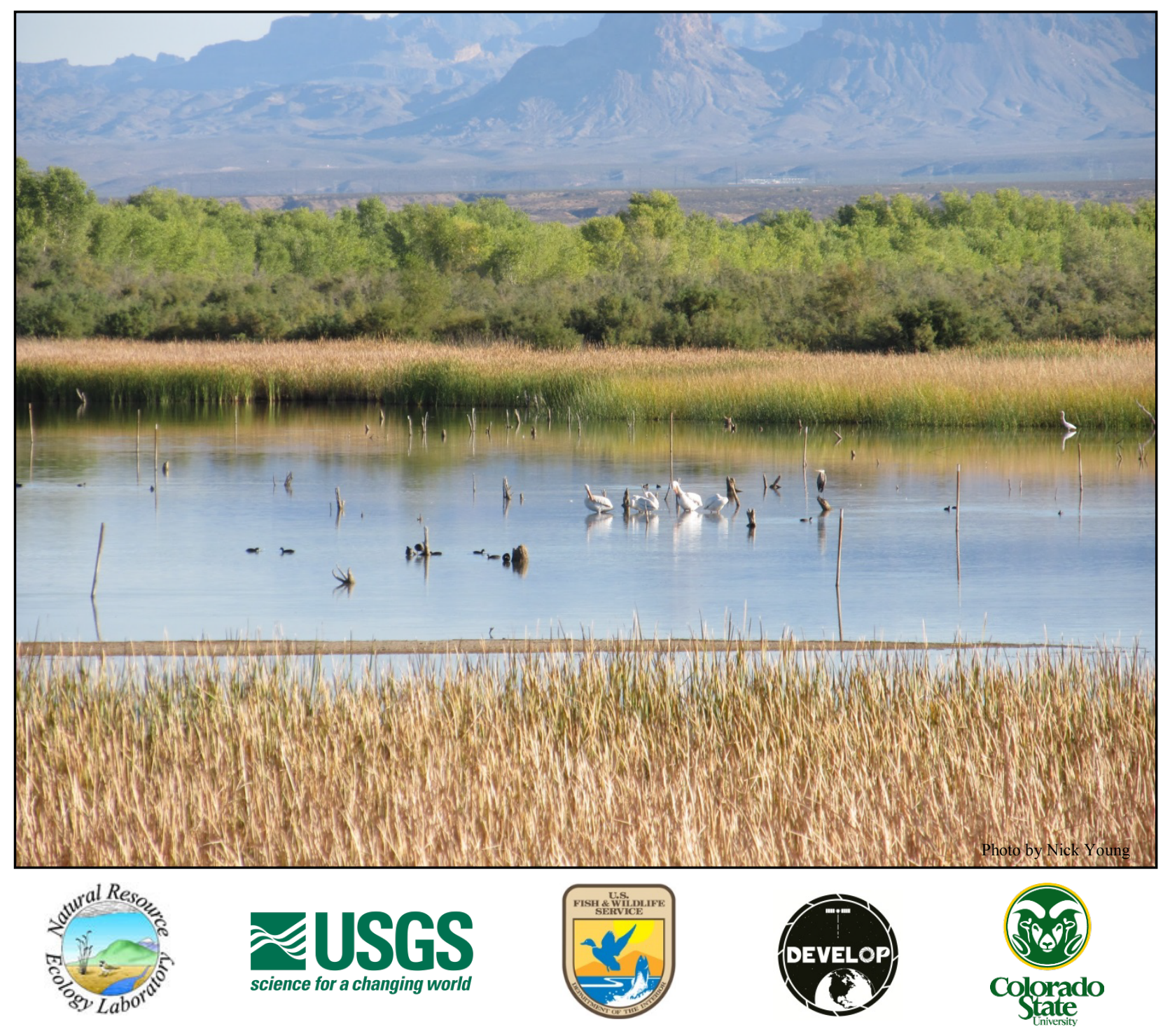


TABLE OF CONTENTS

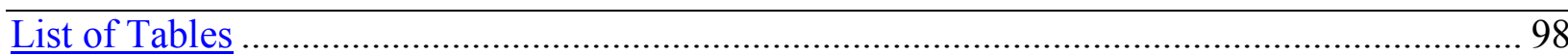

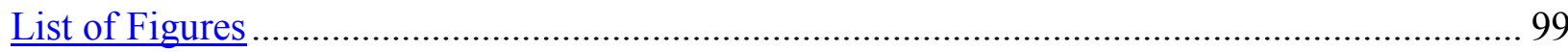

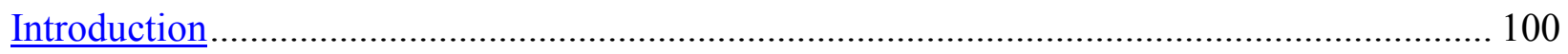

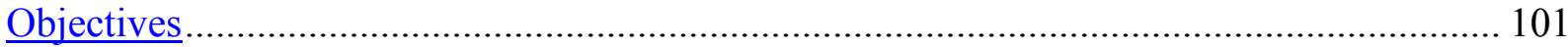

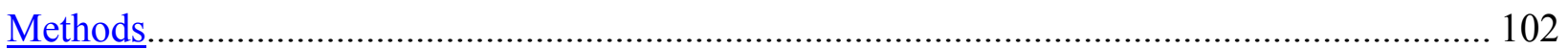

Study Area

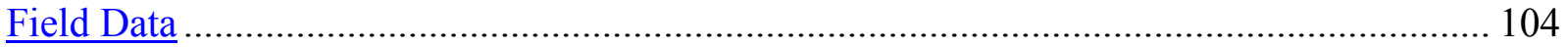

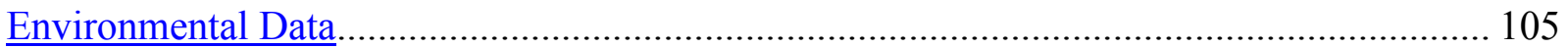

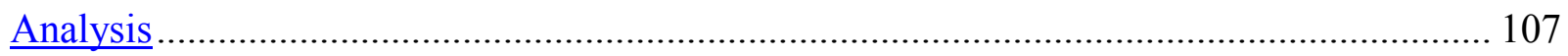

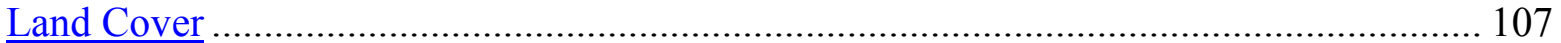

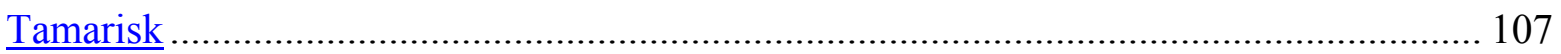

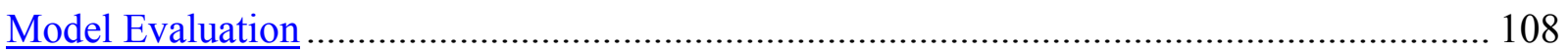

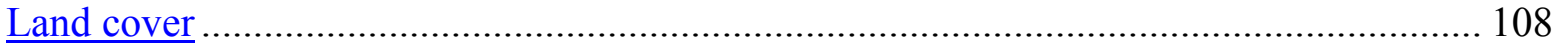

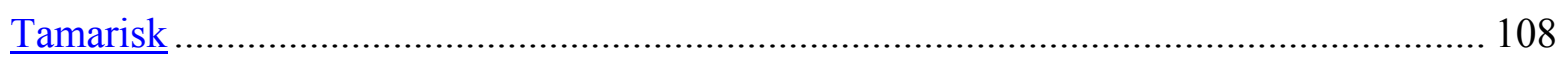

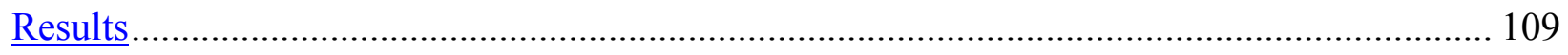

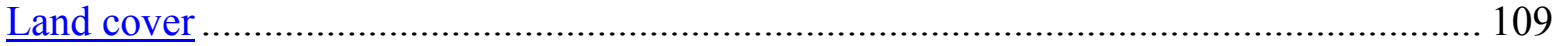

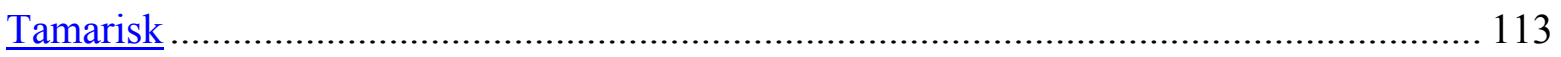

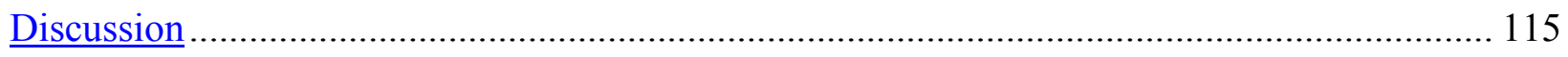

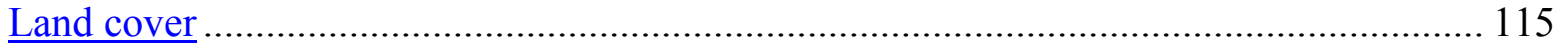

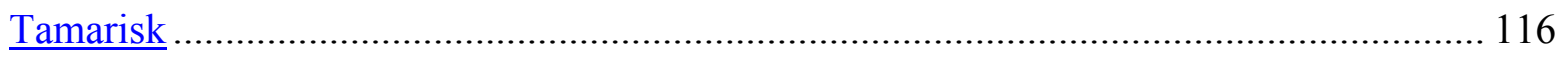

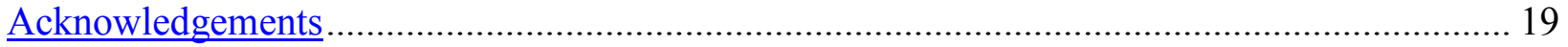

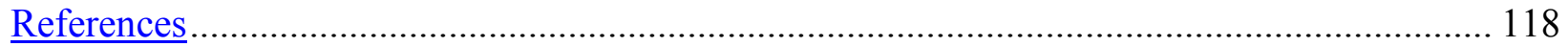

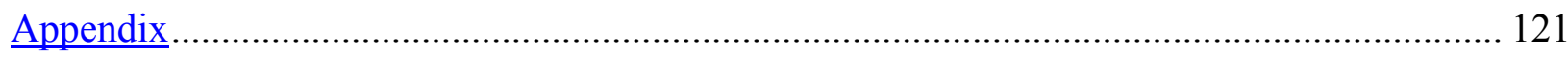




\section{LIST OF TABLES}

Table 1. Training data used for the land cover classification model. The far right column represents the number of additional points added via visual interpretation of the satellite imagery and in situ knowledge. 105

Table 2. Environmental variables considered for the land cover model. Variables shown in red were assessed but not included in the final model due to high correlation with other variables. 106

Table 3. Environmental variables considered for the tamarisk model. Variables that were specific to Worldview-2 imagery or Landsat 8 imagery are denoted with WV-2 and LS8, respectively while WV-2/LS8 indicates that the variable generated from both sensors. Variables shown in red were assessed but not included in the final model due to high correlation with other variables. 106

Table 4. Area $\left(\mathrm{km}^{2}\right)$ from the land cover model of each land cover type for two extents with original and smoothed data. SAV refers to submerged aquatic vegetation.

Table 5. Statistical evaluation metrics for both random forests models, including percent correctly classified, sensitivity, specificity, area under the receiver-operating characteristic curve (AUC), and true skill statistic (TSS)............................................................................. 113

Table 6. Decision matrix for comparing the utility of Landsat 8 and WorldView-2 2................ 117 


\section{LIST OF FIGURES}

Figure 1. A dense monoculture of invasive tamarisk in Havasu National Wildlife Refuge. Photo

by Amanda West. 101

Figure 2. Study area map showing the extent considered in the tamarisk modeling process (red)

and the region that encompasses the Topock Marsh extent (green). 103

Figure 3 Independent field data collection using survey-grade Trimble GPS for tamarisk distribution modeling. Photo by Nick Young.

Figure 4. Diagram depicting the general workflow methodology for both the land cover map and the tamarisk distribution map projects. 108

Figure 5. Model environmental variable importance used in the land cover classification. Variables with a higher mean decrease in accuracy had more influence in classifying land cover types in the random forests model. 110

Figure 6. Land cover model results for nine classes across the Topock marsh study are in Havasu National Wildlife Refuge. SAV refers to submerged aquatic vegetation. 111

Figure 7. Example of smoothed model results (left) compared with original results (right) for the land cover classification model. SAV refers to submerged aquatic vegetation.

Figure 8. Relative Performance of predictors used in the A) WV-2 RF model and the B) LS8 RF model. 114

Figure 9. Random forests model results within Topock Marsh for Landsat 8 (left) and WorldView-2 (right). The continuous raster map shows the probability of $>50 \%$ tamarisk canopy cover in each cell. 


\section{Introduction}

Land managers rely on accurate and current information to guide planning decisions and meet organizational objectives. However, limited financial resources, competing land uses, and ecological complexity can present significant and compounding challenges for successful data collection and interpretation. Maps provide an intuitive and powerful medium with which to display and compare multiple types of information, and thus spatially explicit inventories of land and vegetation serve as key tools for targeting management and monitoring efforts. Historically, color infrared aerial photography has served as the primary data source for mapping in the U.S. since the middle of the 20th century. However, satellite remote sensing has seen significant growth in recent years due to improvements in spatial resolution, computing power, temporal coverage, and data availability.

These advancements have been paralleled by the development of increasingly powerful algorithms for image classification. These algorithms identify the relationships between spectral reflectance values on the earth's surface, and subsequently organize them into similar and informative landscape classes. Such techniques have the advantages of being able to incorporate a range of variables from multiple dates in order to capture seasonal and phenological characteristics on the landscape, as well as the flexibility to be adapted for many broad ecological applications. For example, when paired with georeferenced field plots, spatial modeling can be used to create both regional land cover maps with broad categories, as well as more detailed maps that capture nuances in the distribution of a single species of interest.

Using spectral indices derived from Landsat sensors with species distribution models (SDM) such as the Random Forests algorithm (Breiman 2001) has proved to be a robust approach to classifying land cover ( $\mathrm{Pal}$ 2005; Rodriguez-Galiano et al. 2012) and detecting invasive species such tamarisk (Tamarix spp; Evangelista et al. 2009; York et al. 2011). Furthermore, the launch of the WorldView-2 satellite in 2009 with its unique combination of high spatial and spectral resolution (eight multispectral bands with 2 meter resolution) may provide enhanced capabilities for classifying land cover and detecting tamarisk, as well as offer useful validation and comparison to moderate resolution remote sensing platforms such as Landsat. Recent studies have explored the benefits of using high-resolution WorldView-2 imagery for mapping invasive grasses (Marshall et al. 2012), incorporating WorldView-2 data and SDMs for distinguishing tree vegetation classes (Immitzer et al. 2012), and distinguishing green, desiccated, and dead tamarisk canopies (Dennison and Meng 2015). However, limited work has been done to compare its efficacy to that of moderate resolution imagery like Landsat. Sankey and colleagues (2014) found WorldView-2 to be 30 percent more accurate than Landsat 7 at mapping Sahara mustard. Yet, more research is suggested to evaluate the efficacy of using these different sensors for land management applications.

Land cover mapping serves as a way to catalogue the extent and abundance of the physical material on the earth's surface within an area. Most often these are grouped into meaningful categories such as vegetation types or human land uses. The resultant digital inventory, and the ability to readily visualize its spatial distribution across the landscape, can considerably inform the design and implementation of regional-scale management plans. This increases the efficiency of field assessments and promotes targeted monitoring of ecosystem health. Moreover, the availability of repeat satellite 
imagery in the same location enables detection of change and the ability to assess and mitigate its impacts (Hansen and Loveland 2012).

One of the most consuming and critical tasks for land managers is invasive species management. Impacts and management of non-native invasive species are estimated to cost nearly five percent of the world's economy (Pimentel et al. 2002), or approximately \$3.9 trillion USD for the year 2014. Of growing concern is the threat posed by woody invasive plants, such as tamarisk, which is ranked among the world's 100 worst invasive alien species (Figure 1; Lowe et al. 2000).

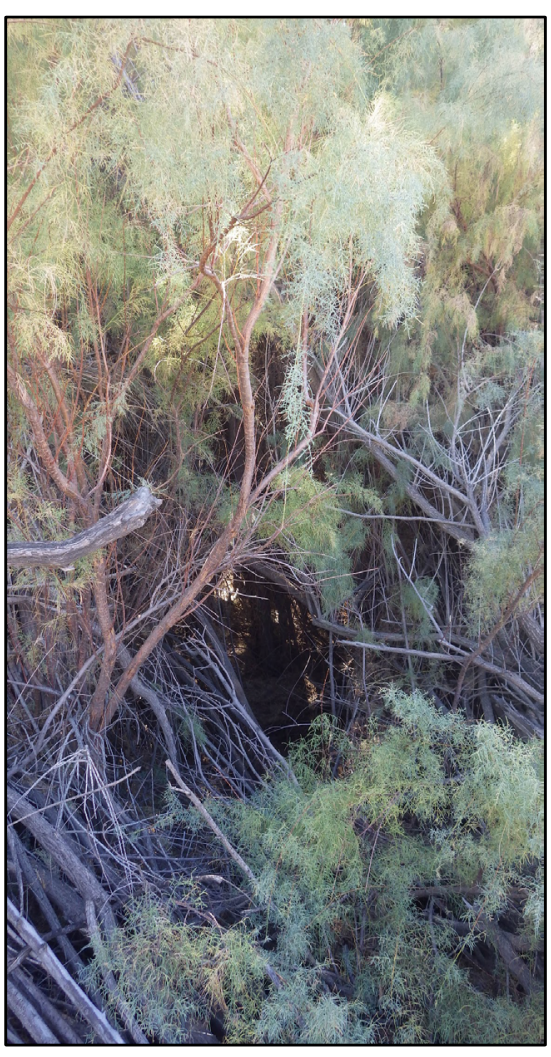

Figure 1. A dense monoculture of invasive tamarisk in Havasu National Wildlife Refuge. Photo by Amanda West.

Tamarisk is an aggressive shrub that was introduced into the United States in the late 1800s from Eurasia (DiTomaso 1998). This deep-rooted phreatophyte (groundwater-dependent plant) often has significant effects on the water table in arid environments, particularly in thick-canopied stands with high evapotranspiration (Shafroth et al. 2005). Dense tamarisk monocultures on stream banks accumulate sediment in their extensive root systems, which may benefit erosion control in some habitats, while in others may narrow stream channels and increase flooding potential (Sher and Quigley 2013). Similarly, these monocultures may provide nesting habitat for birds, shade for other wildlife and livestock, and $\mathrm{CO}_{2}$ fixation at the local level. However, tamarisk has been found to negatively alter soil nutrient cycling, fire behavior, and rapidly change the structure of wetland and riparian habitat that wildlife are well adapted to at the ecosystem level (Sher and Quigley 2013). Efficient methods for mapping tamarisk are therefore needed to accurately target mitigation of this species and its varied impacts on ecosystem function.

Using field plot data, advanced statistical algorithms, and multi-date imagery from WorldView-2 and Landsat 8, we addressed multiple challenges in Topock Marsh at the USFWS Havasu

National Wildlife Refuge, Arizona. Our objectives were to develop a land cover classification map using high resolution satellite imagery, map invasive tamarisk distribution, and offer a comparison of the benefits and challenges of using different types of remotely sensed data.

\section{Objectives}

The specific objectives of this project were as follows:

1. Create a high-resolution land cover map of Topock Marsh and its surrounding upland area comprised of nine broad land cover classes.

2. Create detailed maps of tamarisk cover distribution across Topock Marsh using both high- and moderate-spatial resolution imagery.

3. Provide an assessment and suggestions regarding the benefits and limitations of using Landsat 8 and WorldView-2 for mapping invasive vegetation to assist land managers in their decision-making process 


\section{Methods}

Study Area

Located in southern Arizona, the 4,000-acre Topock Marsh (Figure 2) is considered the crown jewel of the Lower Colorado River. The marsh is a part of the Havasu National Wildlife Refuge, which was established to protect wildlife species at risk of extinction after the creation of the Hoover Dam in 1936. The marsh is dominated by five main land cover classes including open water, bare ground, cattail, bulrush, and tamarisk. In addition, the marsh has a large area of submerged aquatic vegetation that is important to many of the resident and migrant wildlife species found on the refuge. Tamarisk is a relatively recent establishment in Topock Marsh among a few other invasive plant species, such as arrowweed (Plucha sericea) and Phragmites spp. This woody shrub has been observed growing in monoculture from the banks of the marsh to the upland arid desert of Havasu National Wildlife Refuge. Water and nutrient depletion, coupled with habitat degradation, make tamarisk a primary threat to the federally endangered razorback sucker fish (Xyrauchen texanus) that have been reintroduced in the backwaters of Beal Lake in the Refuge, and other native fish species such as the humpback chub (Gila cypha). Additionally, 318 bird species have been recorded in this area (HNWR 2015), including the federally endangered southwestern willow flycatcher (Empidonax traillii extimus) and Yuma clapper rail (Rallus longirostris yumanensis). Tamarisk displaces native cottonwood (Populus spp.) and willow (Salix spp.) in Topock Marsh and the surrounding upland area-habitats to which birds are well adapted. Tamarisk may also increase fire frequency and intensity around the marsh, as it accumulates significant leaf litter - particularly when growing in monoculture stands. These concerns make detection and mitigation of tamarisk in Havasu National Wildlife Refuge high priority in addition to understanding the distribution of the main land cover classes. 


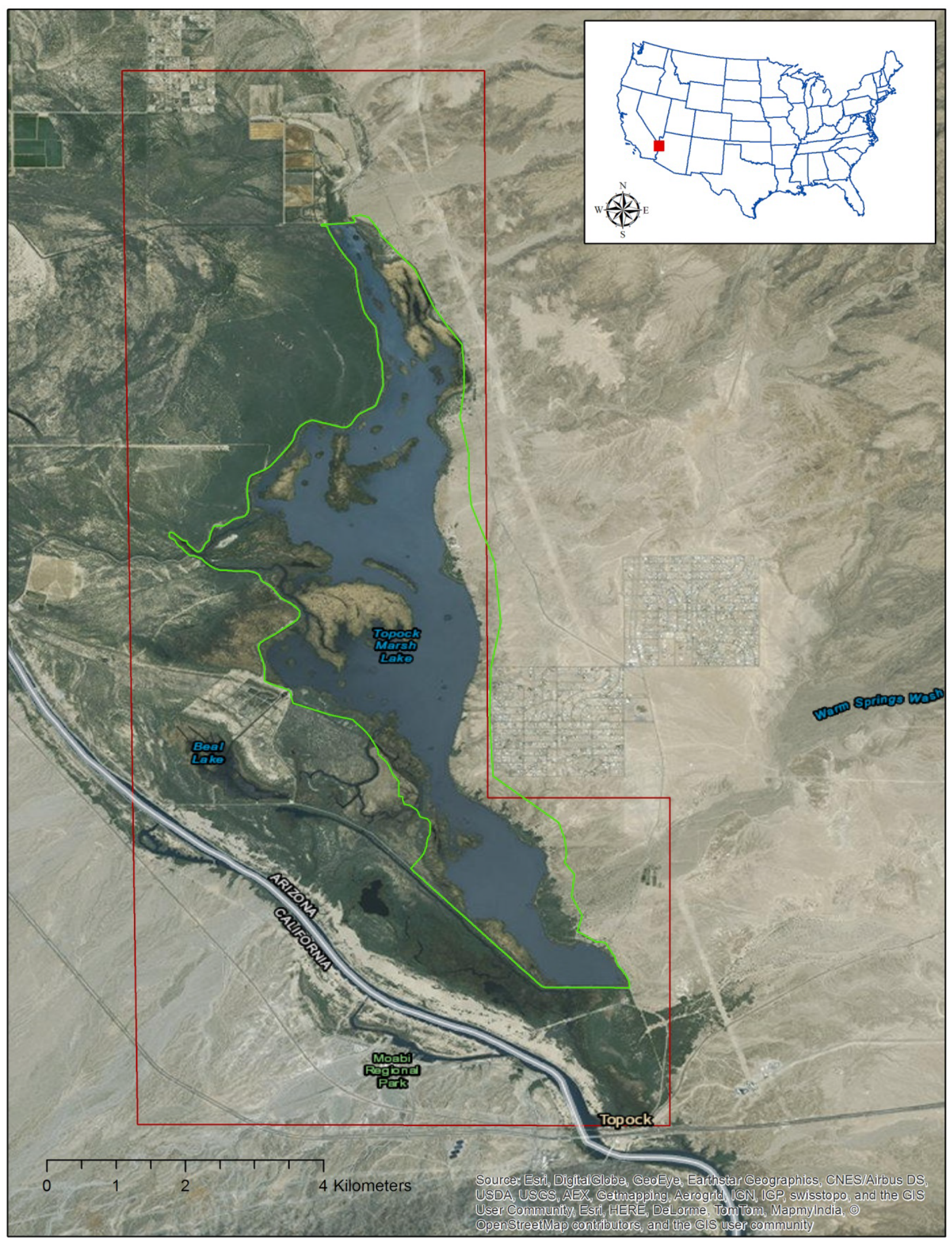

Figure 2. Study area map showing the extent considered in the tamarisk modeling process (red) and the region that encompasses the Topock Marsh extent (green). 


\section{Field Data}

We acquired field survey vegetation data from the U.S. Geological Survey that were collected as a part of a Desert Landscape Conservation Cooperative project. These data consisted of 6,482 GPS points capturing a variety of land cover classes and mixed classes, as well as an additional 201 transect points for open water and submerged aquatic vegetation. These were located primarily along the marsh edge with very few occurrences in the upland areas. All point locations were recorded using surveygrade Trimble GPS units, species composition and their respective canopy cover were estimated for the immediate area surrounding each point (approximately a 2-meter radius circle around the center).

We collected additional independent field survey data in October, 2014. We generated field survey points using stratified random sampling in the upland areas of the study site; with a 30 meter (one Landsat pixel) minimum distance from each other to ensure only one sample location within a Landsat pixel prevent bias from spatial autocorrelation. This resulted in 80 points that were collected in the field that were georeferenced using survey-grade Trimble GPS units (Figure 3) to estimate species

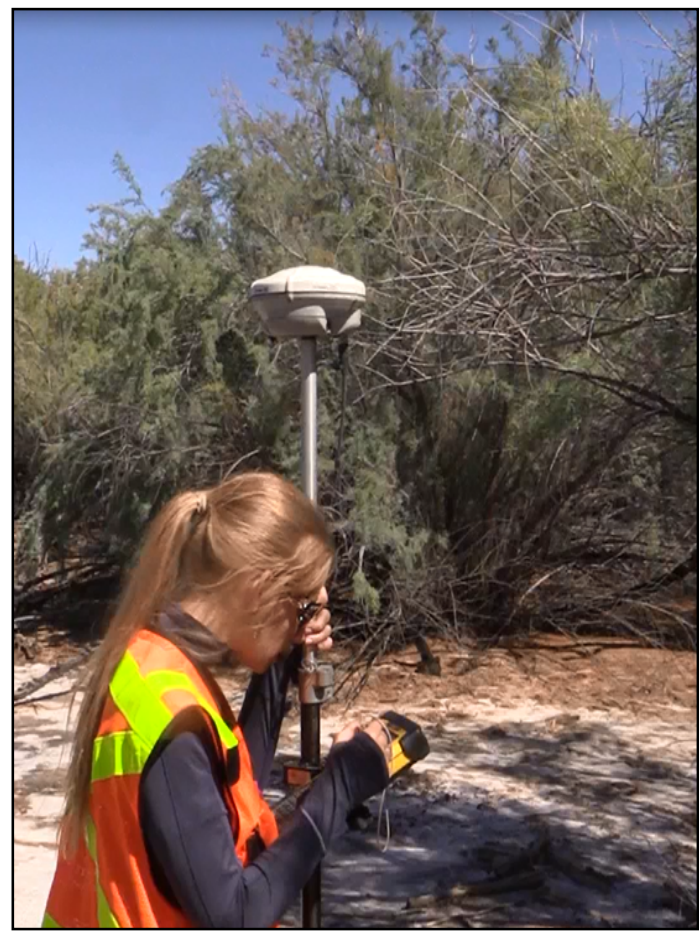

Figure 2. Independent field data collection using survey-grade Trimble GPS for tamarisk distribution modeling. Photo by Nick Young. composition and respective canopy cover for the immediate area surrounding each plot. Additionally, 7.32 meter radius circular plots were established at each of these locations; this plot size calibrates well with Landsat imagery (Stohlgren et al. 2005). Within each 7.32 meter radius plot, all vegetation was identified and the percent cover of each species was cataloged. These data were used to test a tamarisk distribution model that was trained with 176 tamarisk occurrences from the data provided by U.S. Geological Survey.

For the land cover classification model, we also used the presence data from the U.S. Geological Survey. Only occurrences which represented a discrete, homogenous sample of the species of interest were used, rather than a mix of species or margin between species. For some classes that had a small number of records or were spatially clustered, additional points were added based on expert visual interpretation of georectified imagery. Table 1 shows the number of presence points recorded for each species class. 
Table 1. Training data used for the land cover classification model. The far right column represents the number of additional points added via visual interpretation of the satellite imagery and in situ knowledge.

\begin{tabular}{lcc}
\hline \multicolumn{1}{c}{ Land cover type } & $\begin{array}{c}\text { Presence count (including } \\
\text { points visually added) }\end{array}$ & Points visually added \\
\hline \hline Open water & 371 & 257 \\
Submerged aquatic vegetation & 129 & 17 \\
Cattail & 423 & 0 \\
Bulrush & 196 & 8 \\
Bare Ground & 1658 & 0 \\
Tamarisk & 176 & 0 \\
Arrowweed & 143 & 0 \\
Phragmites spp. & 19 & 11 \\
Mesquite & 14 & 0 \\
Total & $\mathbf{3 1 2 9}$ & $\mathbf{2 9 3}$ \\
\hline
\end{tabular}

\section{Environmental Data}

We acquired three Landsat 8 scenes (L1T-level; $<10 \%$ cloud cover) of the study site from the U.S. Geological Survey Earth Explorer website (earthexplorer.usgs.gov). Scene dates were February 04 2014 (Path 38, Row 36), June 032014 (Path 39, Row 36), and October 02, 2014 (Path 38, Row 36). We used ENVI 5.1 to process the multispectral bands collected by the satellite's Operational Land Imager (OLI) sensor and to radiometrically calibrate the Landsat 8 OLI data to top of atmosphere reflectance. Then, the multispectral bands were used to generate a number of spectral indices (Appendix 1). Additionally, we calibrated band 10 from the Landsat 8 Thermal Infrared Sensor (TIRS) to brightness temperature values.

In addition to the Landsat imagery, we were provided two pre-processed, 8-band multispectral WorldView-2 scenes from the U.S. Geological Survey. These high-resolution (2.4 meter) images were captured on July 22, 2014 and October 11, 2014, and were cloudless within the study site. For the land cover model, the WorldView-2 images were calibrated to top of atmosphere reflectance using ENVI 5.2 software. The images were georeferenced using the ESRI basemap where control points were placed to transform the image until adequate alignment with the basemap was achieved. Model variables were created by calculating fifteen spectral indices and exporting each of the eight individual spectral bands using the Remote Sensing Indices Derivation Tool (https://github.com/rander38/Remote-SensingIndices-Derivation-Tool). The July imagery did not show strong presence of submerged aquatic vegetation, which was a priority land cover class for the refuge, and thus only the October imagery was used for land cover classification. The variables considered in the final land cover model are shown in Table 2. For the tamarisk model, we used the multispectral WorldView-2 bands to generate three spectral indices; NDVI, NDWI, and WorldView-2 Soil Index (WVSI) using formulas derived for the WorldView-2 sensor (Wolf 2010). These variables are listed in Table 3. 
Table 2. Environmental variables considered for the land cover model. Variables shown in red were assessed but not included in the final model due to high correlation with other variables.

\begin{tabular}{ll}
\hline \multicolumn{1}{c}{ Model Variables } & \multicolumn{1}{c}{ Description } \\
\hline \hline Spectral Bands & Individual Spectral Bands \\
NDVI & Normalized Difference Vegetation Index \\
EVI & Enhanced Vegetation Index \\
EVI2 & Enhanced Vegetation Index 2 \\
SAVI & Soil Adjusted Vegetation Index \\
MSAVI2 & Modified Soil Adjusted Vegetation Index 2 \\
NDWI & Normalized Difference Water Index \\
Iron Oxide & Iron Oxide Ratio \\
WVII & WorldView New Iron Index \\
WVSI & WorldView Soil Index \\
BAI & Burn Area Index \\
NDSI & Normalized Difference Snow Index \\
NHFD & Non-Homogenous Feature Difference \\
Brightness & Tasseled Cap Transformation \\
Greenness & Tasseled Cap Transformation \\
Wetness & Tasseled Cap Transformation \\
\hline
\end{tabular}

Table 3. Environmental variables considered for the tamarisk model. Variables that were specific to Worldview-2 imagery or Landsat 8 imagery are denoted with WV-2 and LS8, respectively while WV-2/LS8 indicates that the variable generated from both sensors. Variables shown in red were assessed but not included in the final model due to high correlation with other variables.

\begin{tabular}{llcc}
\hline \multirow{2}{*}{ Model Variables } & \multicolumn{1}{c}{ Description } & \multicolumn{2}{c}{ Source and image dates } \\
\cline { 2 - 4 } & & WV-2 & LS8 \\
\hline \hline Spectral Bands & Individual Spectral Bands & July, Oct & Feb, June, Oct \\
Spectral Band & Red Edge & -- & -- \\
Thermal Band 1 & Brightness Temperature & July, Oct & Feb, June, Oct \\
NDVI & Normalized Difference Vegetation Index & July, Oct & Feb, June, Oct \\
NDWI & Normalized Difference Water Index & -- & Feb, June, Oct \\
MNDWI & Modified Normalized Diff. Water Index & July, Oct & -- \\
WVSI & WorldView Soil Index & -- & Feb, June, Oct \\
NDMI & Normalized Difference Moisture Index & -- & Feb, June, Oct \\
NMDI & Normalized Multi-band Drought Index & -- & Feb, June, Oct \\
Brightness & Tasseled Cap Transformation & -- & Feb, June, Oct \\
Greenness & Tasseled Cap Transformation & -- & Feb, June, Oct \\
Wetness & Tasseled Cap Transformation & & \\
\hline
\end{tabular}


Analysis

Land Cover

The land cover classification model was developed using the randomForest Package (http://cran.r-project.org/web/packages/randomForest/index.html) in Program R using the GPS training data and the environmental variables from the WorldView-2 imagery (Figure 4). Random Forest is an ensemble decision tree statistical method that utilizes a bagging approach, combining a multitude of trees and averaging to produce more accurate classifications (Breiman 2001). Random Forest has high classification accuracy and the ability to model complex interactions among predictors. We generated an alternative result by smoothing the model output using a three by three moving window filtering process, where the class majority within the moving window was assigned as the new cell value. Filtered results were produced to help eliminate noise in the data and remove some erroneous classifications (e.g., dead mesquite in the marsh). Further, a second extent was used for more specific area calculation in the marsh area (versus the upland area) since the majority of the training data fell within this region and there were limited training data outside of this area. Each of the environmental variables were assessed for multi-colinearity and only one of each pair of correlated variables were kept in the final model, resulting in the removal of ten variables.

\section{Tamarisk}

To model the tamarisk distribution across the refuge, we combined the indices, raw spectral bands, and field survey data using the U.S. Geological Survey Software for Assisted Habitat Modeling (SAHM; Morisette et al. 2013) to develop the tamarisk distribution models (Figure 4). The SAHM program is an open source modeling platform that expedites pre-processing and execution of species distribution models and habitat suitability models. First, we used the Project, Aggregate, Resample, and Clip (PARC) module within SAHM to ensure consistency between all remotely sensed indices. The CovariateCorrelation and ModelSelection module was then applied to evaluate cross-correlation among all variables and address the issue of multi-colinearity (Dormann et al., 2013). When two variables had a Pearson, Spearman, or Kendall correlation coefficient, $|\mathrm{r}| \geq 0.70$, only one of each pair was selected for model development based on the variables' percent deviance explained in a generalized additive model (GAM) and ecological importance for tamarisk distribution.

We then developed models of tamarisk distribution using four species distributions models in SAHM: generalized linear model (GLM), boosted regression trees (BRT), random forests (RF), and multivariate adaptive regression splines (MARS). Only plots with greater than 50 percent tamarisk canopy cover were used to develop the models, based on preliminary sensitivity analyses. 


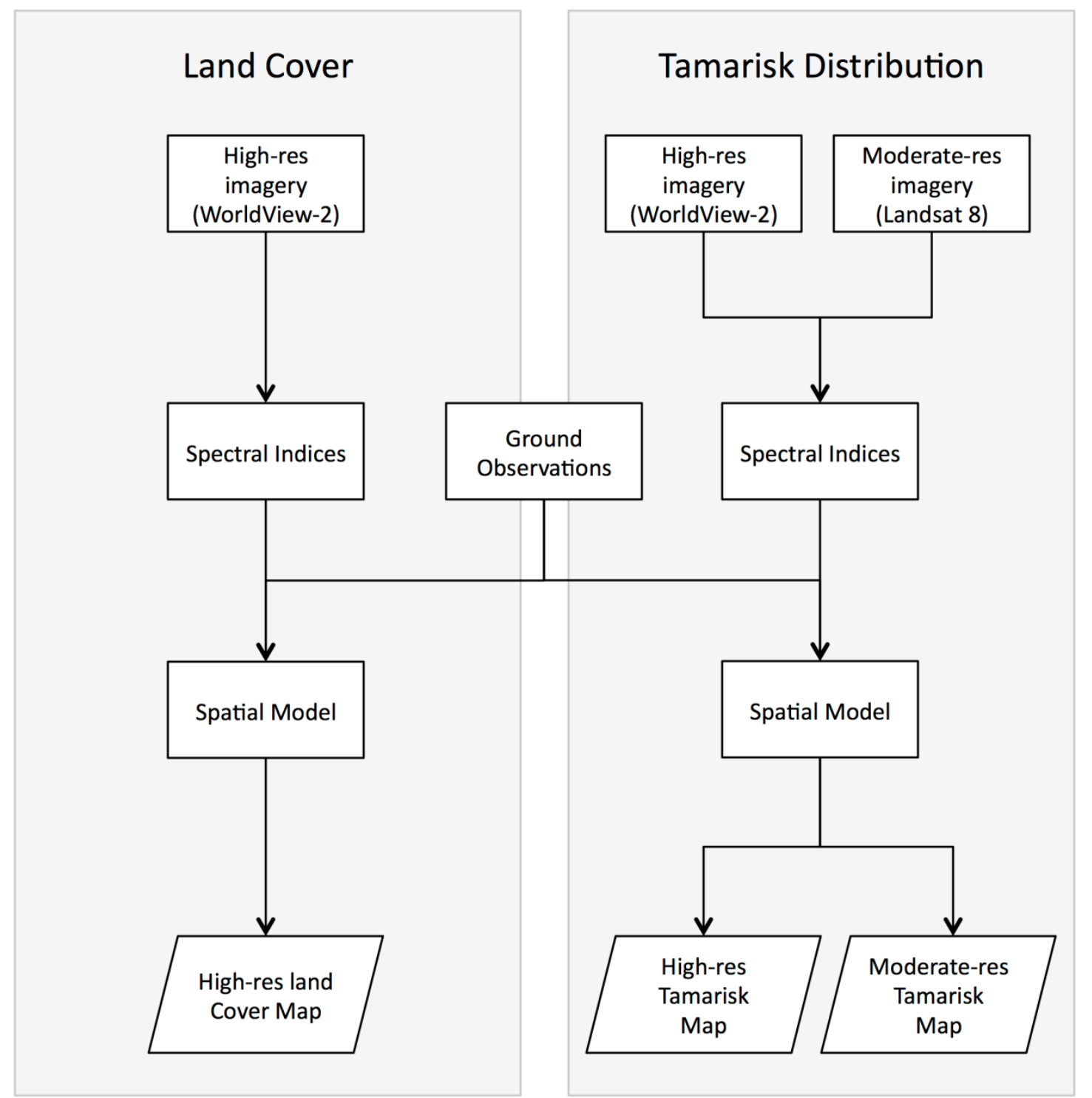

Figure 3. Diagram depicting the general workflow methodology for both the land cover map and the tamarisk distribution map projects.

\section{Model Evaluation}

\section{Land cover}

The random forest model provides no internal validation method (e.g., cross-validation) to assess model performance when using the model to predict categorical responses. Furthermore, there were no independent datasets available to provide a statistical evaluation of the land cover model results. However, we were able to collect qualitative feedback from expert field biologists and refuge managers on the model performance.

\section{Tamarisk}

For our tamarisk models, each model run provides a raster output of a continuous raster map, with the predicted probability of tamarisk $>50$ percent canopy cover for each cell. In order to quantitatively test model accuracy, each continuous model output was converted into a binary (tamarisk 
presence/absence) map using an objective, statistically determined probability threshold that maximizes the sum of sensitivity and specificity ((sensitivity + specificity)/2). Each binary map was then validated using the 80 independent points taken during the field survey. This enabled the creation of a number of statistical evaluation metrics, including area under the receiver-operating characteristic curve (AUC), percent correctly classified, true skill statistic and sensitivity and specificity metrics.

The AUC is a threshold-independent metric that measures a model's ability to discriminate a true occurrence point from an absence or background point. The AUC values range from 0 to 1 , with a value of less than 0.5 indicating that model predictions are worse than random, a value of 0.5 no better than random, and a value of 1.0 indicating perfect discrimination (Peterson et al. 2011). Percent correctly classified reveals the percentage of test data correctly classified by the model (Talbert \& Talbert 2012). True Skill Statistic (TSS) is similar to Kappa but not dependent on prevalence, and is especially useful for determining if forecasts lead to a noticeable increase in false positives. The TSS score has values of -1 to 1 , with negative values representing perverse forecasts, 0 representing no skill and positive values representing more skilled forecasting (Allouche et al. 2006). Sensitivity and specificity metrics provide an estimate of the proportion of actual presence and background points from

the test data being accurately predicted by the model, thus expressing the uncertainty associated with the final map predictions (Alatorre et al. 2011).

\section{Results}

\section{Land cover}

Overall, the model performed well at capturing general land cover patterns. The model was the most accurate for the open water and bare ground land cover classes but performed the poorest when predicting Phragmites spp. and mesquite. Submerged aquatic vegetation was generally over-predicted. The top three important model variables were NDSI, NDVI, and spectral band 1 (coastal), shown in Figure 5. 


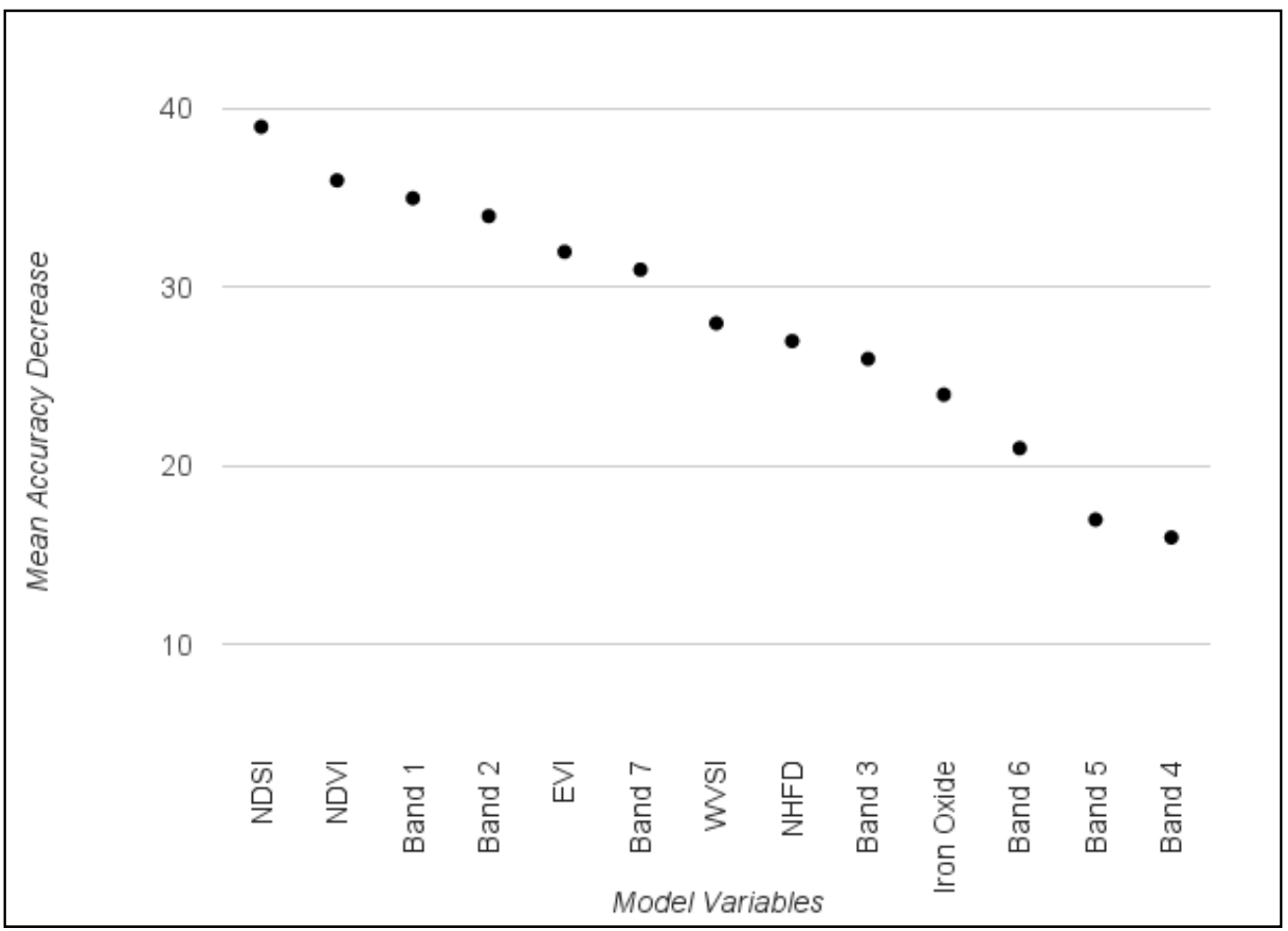

Figure 4. Model environmental variable importance used in the land cover classification. Variables with a higher mean decrease in accuracy had more influence in classifying land cover types in the random forests model.

In general, the land cover model predicted tamarisk intermixed with arrowweed in the western portion in the marsh, cattail and bulrush on the edges of water bodies, and bare ground in the eastern and southern portion of the study area (Figure 6). Submerged aquatic vegetation was modeled in the main marsh area in distinct patches and, perhaps inaccurately, in waterways and small water bodies surrounding the marsh. Phragmites spp. and mesquite were predicted in small sparse patches in few locations which are likely related to the small sample size available for these species. Land cover types that did not have training data (e.g., urban, dead mesquite, etc.) were grouped into the most similar class. 


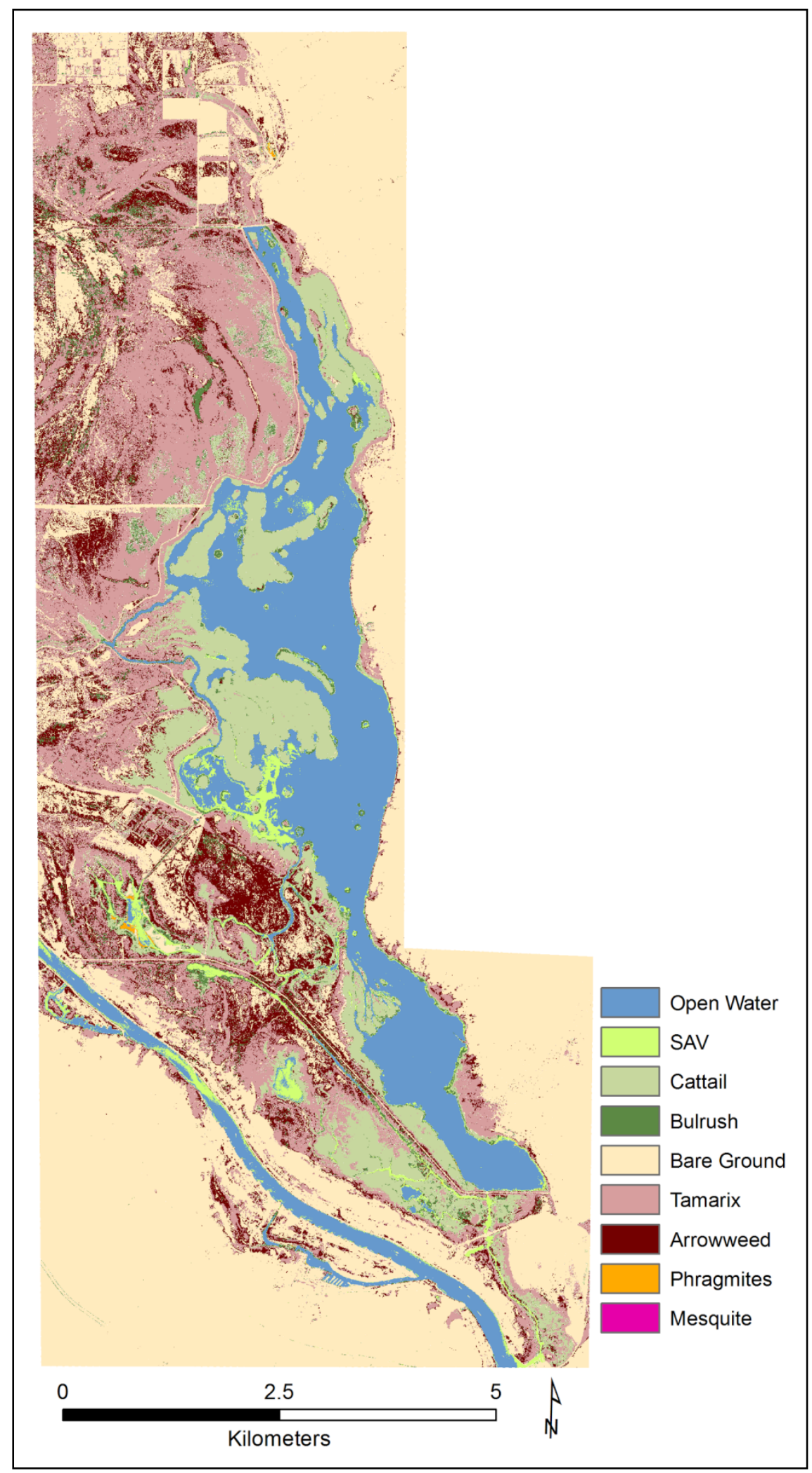

Figure 5. Land cover model results for nine classes across the Topock marsh study are in Havasu National Wildlife Refuge. SAV refers to submerged aquatic vegetation. 
For the land cover model, two different outputs were created (original and smoothed; Figure 7) at two separate extents, resulting in four land cover results layers. The full extent represents the study area shown in red in Figure 2, while the marsh extent is a clipped boundary surrounding the aquatic environment of the marsh shown in green in Figure 2. The smoothed output provides a more general prediction of land cover across the study area.

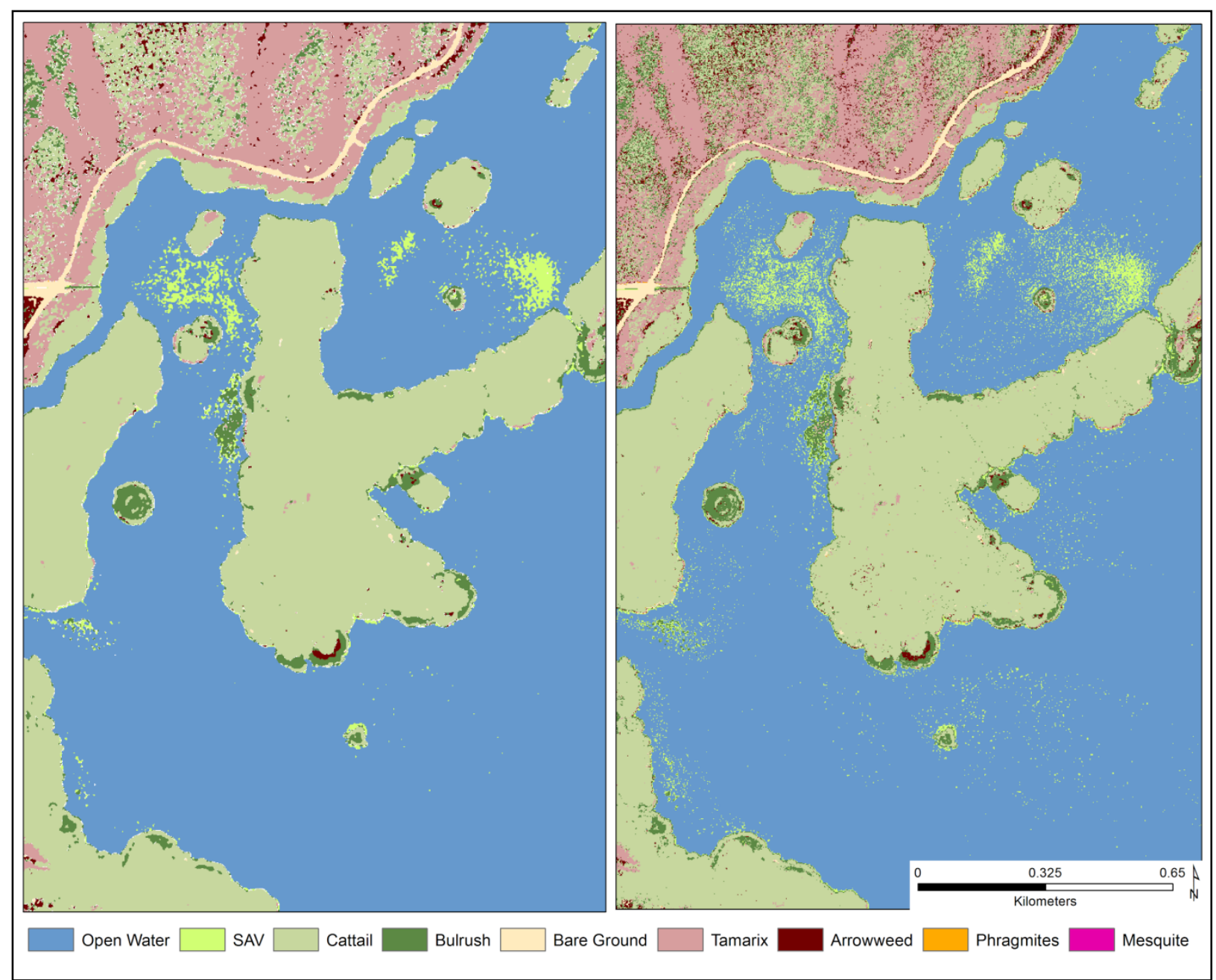

Figure 6. Example of smoothed model results (left) compared with original results (right) for the land cover classification model. SAV refers to submerged aquatic vegetation.

The marsh extent was created to more accurately quantify submerged aquatic vegetation area as it removes many of the submerged aquatic vegetation misclassifications outside of the aquatic area. The areal calculation for each land cover type for each of the four results is shown in Table 4 . 
Table 4. Area $\left(\mathrm{km}^{2}\right)$ from the land cover model of each land cover type for two extents with original and smoothed data. SAV refers to submerged aquatic vegetation.

\begin{tabular}{lccccc}
\hline \multirow{2}{*}{ Land Cover Type } & \multicolumn{2}{c}{ Full extent area $\left.\mathbf{( k m}^{\mathbf{2}}\right)$} & & \multicolumn{2}{c}{ Marsh extent area $\left.\mathbf{( k m}^{\mathbf{2}}\right)$} \\
\cline { 2 - 3 } & Original & Smoothed & & Original & Smoothed \\
\hline \hline Open Water & 10.19 & 10.3 & & 8.85 & 8.94 \\
SAV & 1.48 & 1.31 & & 0.75 & 0.63 \\
Cattail & 7.52 & 7.14 & & 4.43 & 4.43 \\
Bulrush & 2.92 & 1.89 & & 0.64 & 0.51 \\
Bare Ground & 30.92 & 31.1 & & 2.81 & 2.83 \\
Tamarisk & 13.42 & 14.11 & & 1.38 & 1.44 \\
Arrowweed & 8.97 & 8.09 & & 0.67 & 0.53 \\
Phragmites spp. & 0.1 & 0.04 & & 0.02 & 0 \\
Mesquite & 0.03 & 0 & & 0 & 0 \\
\hline
\end{tabular}

Tamarisk

Each of the four tamarisk distribution models performed well, and the best performing model from each sensor was determined based on a review of all accuracy metrics and a thorough visual assessment of the model outputs. Random forests was the top-performing model for both Landsat 8 and WorldView-2, with classification accuracies over 94 and 91 percent, respectively — in addition to high AUC values (see Table 5 for full list of statistical evaluation metrics).

Table 5. Statistical evaluation metrics for both random forests models, including percent correctly classified, sensitivity, specificity, area under the receiver-operating characteristic curve (AUC), and true skill statistic (TSS).

\begin{tabular}{lcc}
\hline \multicolumn{1}{c}{ Evaluation metric } & Landsat & WorldView-2 \\
\hline \hline Percent Correctly Classified & $\mathbf{8}$ & $94 \%$ \\
Sensitivity & 0.89 & $91 \%$ \\
Specificity & 0.96 & 0.75 \\
AUC & 0.97 & 0.89 \\
TSS & 0.85 & 0.72 \\
\hline
\end{tabular}




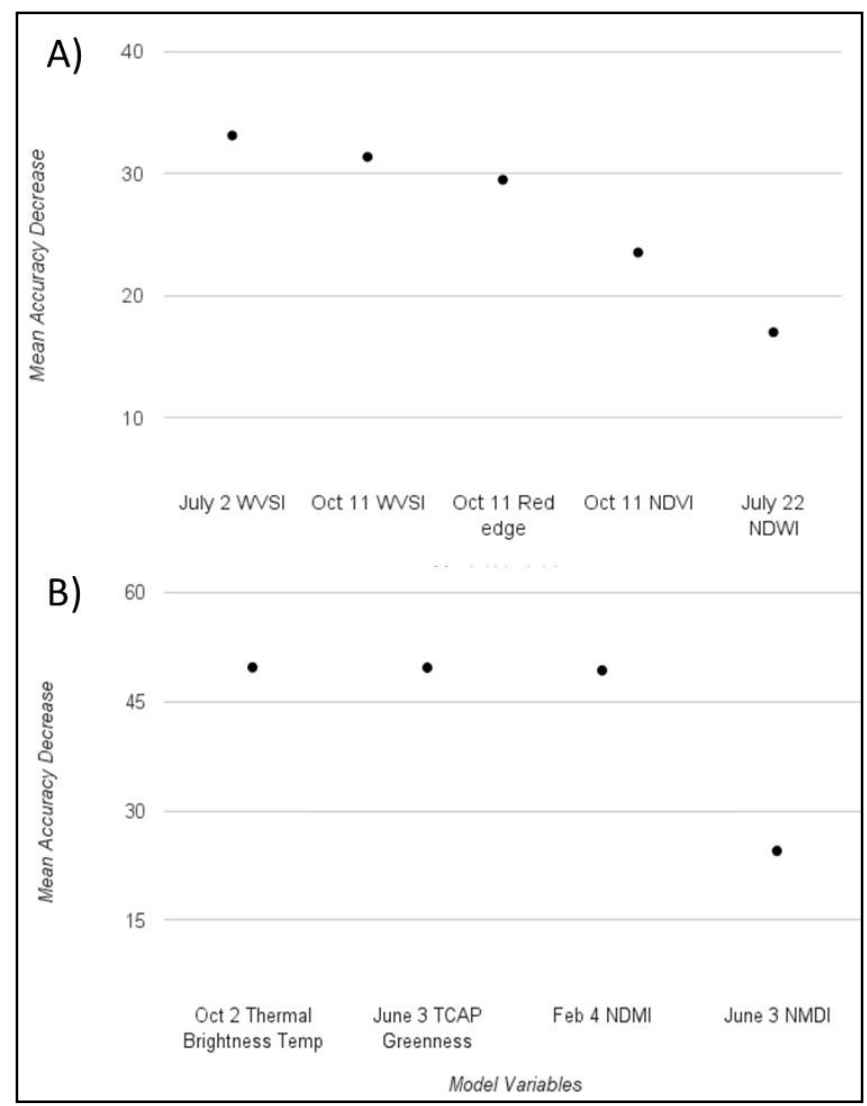

Figure 7. Relative Performance of predictors used in the A) WV-2 RF model and the B) LS8 RF model.
A mixture of variables encompassing multiple months were important for each model. These included February and June NDMI for the Landsat 8 model, and October and July WVSI, July NDWI, and October NDVI for the WorldView-2 model. This suggests the models were able to use tamarisk's phenological characteristics to distinguishing it from similar vegetation, and shows the importance of including multi-date imagery. Interestingly, the band unique to each sensor, Thermal 1 (i.e., Brightness Temperature) for Landsat 8, and Red Edge for WorldView-2, were the most important variables for their respective models.

Visual examination reveals that the model outputs from each sensor are in agreement regarding the general distribution pattern of tamarisk across the study site (Figure 9). Closer inspection reveals that while Landsat 8 clearly identified thick-canopied tamarisk monocultures, WV-2 captured the more nuanced patch dynamics of tamarisk. This is likely a product of the high spatial resolution of the WV-2 imagery and its Red Edge band helping the model distinguish tamarisk from other woody shrubs and trees that often grow in close proximity (i.e., mesquite). 


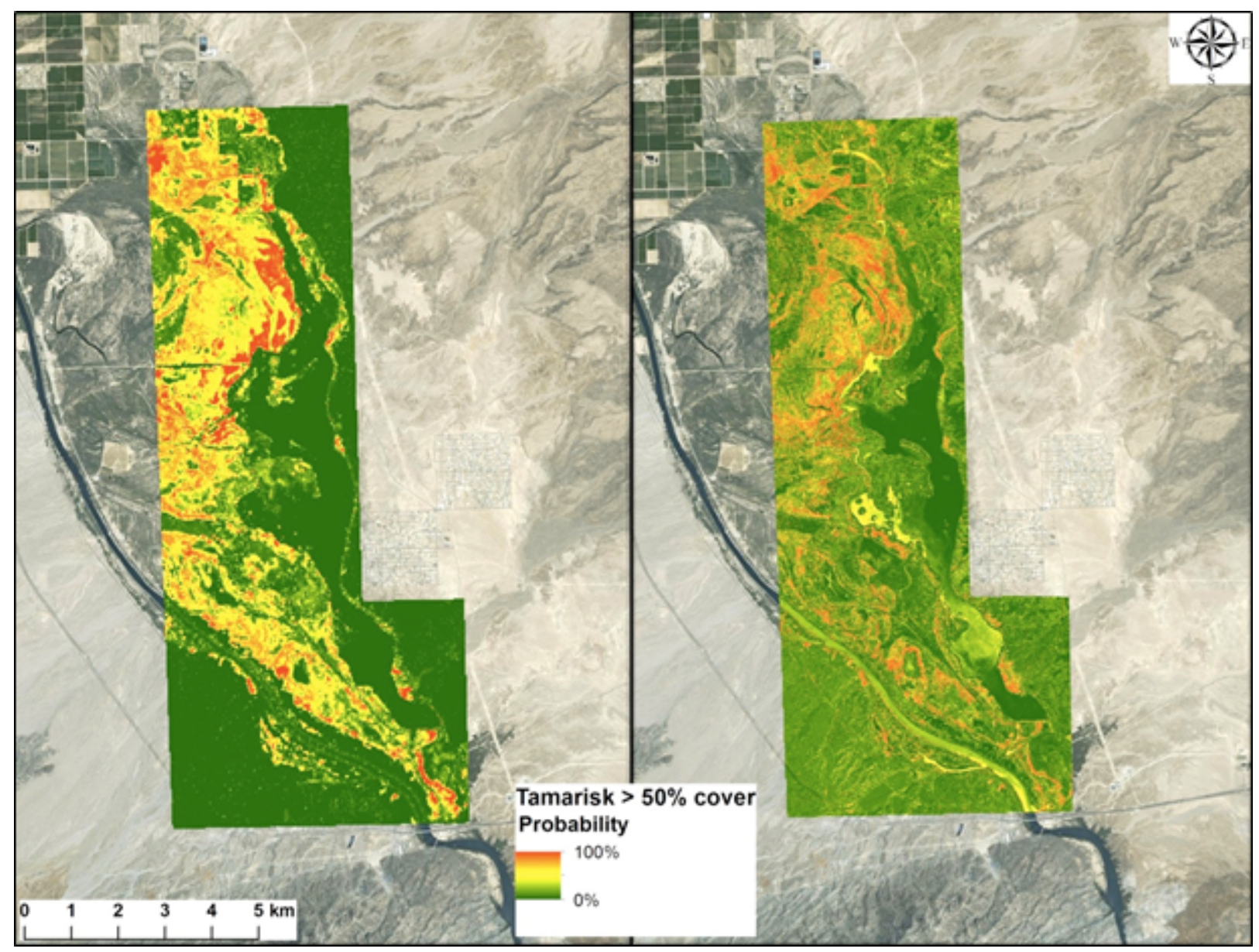

Figure 8. Random forests model results within Topock Marsh for Landsat 8 (left) and WorldView-2 (right). The continuous raster map shows the probability of $>50 \%$ tamarisk canopy cover in each cell.

\section{Discussion}

\section{Land cover}

We developed the first high resolution land cover map of nine classes of interest for Topock Marsh in Havasu National Wildlife Refuge. While the land cover model contained minimal misclassification errors, the model captures overall vegetation distribution trends across the refuge and performed better in areas that were sufficiently covered by the training data. For example, the model appeared to be more accurate along the marsh edge for species that had larger sample sizes (e.g., cattails, bulrush, submerged aquatic vegetation) while areas that were further away from the marsh edge and had few sample sizes appeared to be less accurate (e.g., mesquite).

As previously stated, the land cover map is a model and does not necessarily represent actual conditions observed on the ground in some places. Given this, we suggest the land cover map be used by refuge managers as a general reference for dominant vegetation and habitat types at a given location. While area calculation for the land cover classes can be generated from the land cover map, these too should be interpreted as an approximation of what actually occurs on the ground. These approximations, however, can be very useful for developing management plans. For example, our results can be used to 
calculate the approximate area of critical habitat for a species of interest or estimate the area of infestation of an invasive species such as tamarisk or arrowweed. Additional consideration concerning where on the refuge the model performs better and what land cover classes were more accurate in the final model is also important when interpreting the land cover model results Furthermore, these results can be combined with a suite of other products including temporal water level across the marsh and seasonal wildlife habitat requirements to provide a decision support system for land managers at the refuge.

For future land cover classification projects, the model results could be improved in a number of ways. Arguably the most important factor in producing high accuracy results is the quality of the training data set. Training data for a species distribution model require a large number of points of homogeneous land cover to ensure discrete spectral signatures for the species of interest. Collecting additional field points, especially for land cover classes that had relatively small sample sizes, could improve model results. Further, the dataset should cover the range of environments in which the species may occur. Many of the points for this project were not suitable for modeling purposes as a large number of the points were collected specifically to represent species boundary locations. These points were not used for the model and the remaining training data may not have adequately represented the spectral and spatial variability of each species. The number of presence points required to represent a given species varies depending on the size and diversity of a study area, but it is typically suggested to have several hundred to thousands of points per species or land cover. Given that our training set had limited training points for some land cover classes (Table 1), the potential exists for inaccuracies and misclassifications. Classes such as Phragmites spp. and mesquite had very few training points and should not be expected to be as accurate as other classes that were sampled more thoroughly.

As with any modeling analysis, there are caveats that should be considered. For the land cover results, modeling continuous land cover requires that all land cover types be represented by the training data. Since every location (pixel) in the study area must be classified as a land cover type represented by the training data, misclassification can occur if a given land cover is not represented or underrepresented in the training data. For instance, dead mesquite trees that appear in the middle of the marsh did not have any observation points, meaning these features were classified to the most similar class, in this case, submerged aquatic vegetation. While we attempted to adjust for this specific misclassification by performing a smoothing on the final model, there are still some dead mesquite misclassifications and likely other misclassifications due to species under-representations within the training set. In addition, while the random forests method is generally accepted as a strong classification tool, it is often useful to compare multiple model algorithms to compare model differences and select the output that performs the best. Other classification methods that could be considered for this analysis are support vector machine (SVM) learning algorithms, Classification and Regression Trees (CART), or maximum likelihood.

\section{Tamarisk}

Effective and efficient management of invasive species requires accurate distribution maps. We produced baseline maps of tamarisk in the refuge at two spatial scales. These will facilitate planning of both targeted and regional mitigation efforts, as well as enable researchers to predict the plant's spread 
or recession based on potential changes in climate and water level in the marsh. For example, the refuge land managers could use our maps of tamarisk distribution to estimate the cost of treatment applications such as aerial spraying or burning.

To provide end users at the refuge a tool for guiding future monitoring efforts, we compared Landsat 8 and WorldView-2 to distinguish the costs and benefits that each have to offer (Table 6).

Landsat 8 is a desirable tool for land managers for a number of reasons. It is freely available with global coverage, compared to approximately $\$ 20 / \mathrm{km}$ for $\mathrm{WV}-2$. The historical record of Landsat data is available from 1972 - present, compared to 2009 -present for WV-2, which makes Landsat very useful for managers interested in monitoring natural resource conditions over time (i.e., understanding establishment and succession of invasive plants).

Table 6. Decision matrix for comparing the utility of Landsat 8 and WorldView-2

\begin{tabular}{lll}
\hline Cost & \multicolumn{1}{c}{ Landsat 8 } & \multicolumn{1}{c}{ WorldView-2 } \\
Historical Availability & $1972-$ present (Landsat 1-7) & $\sim \$ 20 / \mathrm{km} 2$ \\
& Largely pre-processed by USGS and & $\begin{array}{l}\text { Requires time, commercial, } \\
\text { software, technical skill }\end{array}$ \\
Data Processing & NASA & $2.5 \mathrm{~m}$ \\
Spatial Resolution & $30 \mathrm{~m}$ & $\begin{array}{l}\text { 8-band multispectral Unique } \\
\text { band: red edge }\end{array}$ \\
Spectral Resolution & 8 -band multispectral + 2 Thermal \\
Revisit Time & Unique band: thermal Infrared & Ad-hoc \\
\hline
\end{tabular}

WV-2 has significantly higher resolution than Landsat (2.5 meter compared to 30 meter) and the additional Red Edge band in WV-2 multispectral imagery may be able to improve discrimination of patch dynamics and hard-to-detect plants such as emergent grasses or aquatic vegetation. With regard to revisit time, Landsat 8 provides images on a consistent 16-day basis while WV-2 imagery is collected ad hoc. It is clear that each data source offers its own constraints and opportunities, all of which should be taken into consideration when designing plans for monitoring and mitigation.

Additional insights can be gained by comparing the predicted distribution of tamarisk of the tamarisk-only model with those of the land cover model. While the maps show general agreement, the tamarisk-only model offers a more conservative and nuanced depiction of tamarisk extent than the land cover model. Probability maps of percent cover provide considerably more information to the user than binary tamarisk presence/absence distinction. This speaks to the importance of tailoring the modeling approach to the needs of the end-user. When the focus is targeting mitigation sites for an invasive species, one-class probability mapping may be the most appropriate method, as it requires fewer data points and provides a manager with a range of confidence with which to base their decisions ( $\mathrm{Li}$ and 
Guo 2010). However, if general inventory of the area's main land cover classes is desired, a thematic land cover approach is the more efficient procedure and offers clear, interpretable results.

In conclusion, thematic maps serve as a critical tool for land managers to inform management decisions. We provide the first high-resolution land cover map while also evaluating multiple data sources when modeling the distribution of invasive tamarisk for Topock Marsh in Havasu National Wildlife Refuge. These products offer an inventory of land cover classes, a detailed distribution map of tamarisk at two spatial resolutions and a practical comparison and evaluation of spatial data sources that were used for this project to assist in the decision for future spatial analyses. While these results can and should be improved upon, they offer a valuable spatial and quantitative description for Topock Marsh in Havasu National Wildlife Refuge.

\section{Acknowledgments}

We would like to thank the U.S. Geological Survey and the Fort Collins Science Center for supporting this project and providing technical assistance and state of the art modeling facilities in the Resource for Advanced Modeling (RAM) room. We are also grateful to Leanne Hanson, Chris Holmquist-Johnson, and Joan Daniels for sharing their data and their logistical support while in the field. This project was also supported by the NASA DEVLOP program and we received excellent contribution from the team members of the Arizona Ecological Forecasting team including Brian Woodward, Peter Gibbons, Matthew Luizza and Melissa Haeffner. In addition, we would like to thank Eric Wahlig for field data collection support. Lastly, we are appreciative to the Havasu National Wildlife Refuge staff for their expertise and logistical support.

\section{References Cited}

Allouche, O., Tsoar, A., \& Kadmon, R. (2006). Assessing the accuracy of species distribution models: prevalence, kappa and the true skill statistic (TSS). Journal of applied ecology, 43(6), 1223-1232.

Alatorre, L. C., Sánchez-Andrés, R., Cirujano, S., Beguería, S., \& Sánchez-Carrillo, S. (2011). Identification of mangrove areas by remote sensing: The ROC curve technique applied to the northwestern Mexico coastal zone using Landsat imagery. Remote Sensing, 3(8), 1568-1583.

Baig, M. H. A., Zhang, L., Shuai, T., \& Tong, Q. (2014). Derivation of a tasselled cap transformation based on Landsat 8 at-satellite reflectance. Remote Sensing Letters, 5(5), 423-431.

Breiman, L. (2001). Random forests. Machine learning, 45(1), 5-32.

CGG (2015). Worldview-2 Specifications. Accessed May 29. 2015. Retreived from: http://www.cgg.com/default.aspx?cid=7466\&lang=1

Di Tomaso, J. M. (1998). Impact, biology, and ecology of saltcedar (Tamarix spp.) in the southwestern United States. Weed technology, 326-336.

Dormann, C.F., Elith, J., Bacher, S., Buchmann, C., Carl, G., Carré, G., Marquéz, J.R.G., Gruber, B., Lafourcade, B., Leitão, P.J., Münkemüller, T., McClean, C., Osborne, P.E., Reineking, B., Schröder, B., Skidmore, A.K., Zurell, D., Lautenbach, S. (2013). Collinearity: a review of methods to deal with it and a simulation study evaluating their performance. Ecography, 36(1), 27-46. 
Evangelista, P. H., Stohlgren, T. J., Morisette, J. T., \& Kumar, S. (2009). Mapping invasive tamarisk (Tamarix): a comparison of single-scene and time-series analyses of remotely sensed data. Remote Sensing, 1(3), 519-533.

Hassan, Q. K., Bourque, C. P., Meng, F. R., \& Richards, W. (2007). Spatial mapping of growing degree days: an application of MODIS-based surface temperatures and enhanced vegetation index. Journal of Applied Remote Sensing, 1(1), 013511-013511.

Hansen, M. C., \& Loveland, T. R. (2012). A review of large area monitoring of land cover change using Landsat data. Remote sensing of Environment, 122, 66-74.

HNWR, (2015) Havasu National Wildlife Refuge Website - Wildlife \& Habitat (2015). Accessed May 29, 2015. Retreived from: http://www.fws.gov/refuge/Havasu/wildlife and habitat/index.html

Huete, A. R. (1988). A soil-adjusted vegetation index (SAVI). Remote sensing of environment, 25(3), 295-309.

Immitzer, M., Atzberger, C., \& Koukal, T. (2012). Tree species classification with random forest using very high spatial resolution 8-band WorldView-2 satellite data. Remote Sensing, 4(9), 2661-2693.

Li, W., \& Guo, Q. (2010). A maximum entropy approach to one-class classification of remote sensing imagery. International Journal of Remote Sensing, 31(8), 2227-2235.

Lowe, S., Browne, M., Boudjelas, S., \& De Poorter, M. (2000). 100 of the world's worst invasive alien species: a selection from the global invasive species database (p. 12). Auckland, New Zealand: Invasive Species Specialist Group.

Marshall, V., Lewis, M., \& Ostendorf, B. (2012). Do Additional Bands (Coastal, Nir-2, Red-Edge and Yellow) in WorldView-2 Multispectral Imagery Improve Discrimination of an Invasive Tussock, Buffel Grass (Cenchrus ciliaris). Proceedings of the International Archives of the Photogrammetry, Remote Sensing and Spatial Information Sciences, 39, B8.

McFeeters, S. K. (1996). The use of the Normalized Difference Water Index (NDWI) in the delineation of open water features. International journal of remote sensing, 17(7), 1425-1432.

Morisette, J. T., Jarnevich, C. S., Holcombe, T. R., Talbert, C. B., Ignizio, D., Talbert, M. K., Silva, C., Koop, D., Swanson, A., \& Nicholas E. Young, N. E. (2013). VisTrails SAHM: visualization and workflow management for species habitat modeling. Ecography, 36(2), 129-135.

Dennison, P. E., \& Meng, R. (2015). Spectroscopic Analysis of Green, Desiccated and Dead Tamarisk Canopies. Photogrammetric Engineering \& Remote Sensing, 81(3), 199-207.

Pal, M. (2005). Random forest classifier for remote sensing classification. International Journal of Remote Sensing, 26(1), 217-222.

Peterson, A.T., Soberon J., Pearson, R.G., Anderson, R.P.,Martinez-Meyer, E., Nakamura, M. \& Araujo, M.B. (2011). Ecological Niches and Geographic Distributions. Princeton University Press, Princeton, N.J.

Pimentel, D. (2002). Introduction: non-native species in the world. In: Pimentel D (Ed). Biological invasions: economic and environmental costs of alien plant, animal, and microbe species. New York, NY: CRC Press. 
Rodriguez-Galiano, V. F., Ghimire, B., Rogan, J., Chica-Olmo, M., \& Rigol-Sanchez, J. P. (2012). An assessment of the effectiveness of a random forest classifier for land-cover classification. ISPRS Journal of Photogrammetry and Remote Sensing, 67, 93-104.

Sankey, T., Dickson, B., Sesnie, S., Wang, O., Olsson, A., \& Zachmann, L. (2014). WorldView-2 High Spatial Resolution Improves Desert Invasive Plant Detection. Photogrammetric Engineering \& Remote Sensing, 80(9), 885-893.

Shafroth, P. B., Cleverly, J. R., Dudley, T. L., Taylor, J. P., Riper III, C. V., Weeks, E. P., \& Stuart, J. N. (2005). Control of Tamarix in the western United States: implications for water salvage, wildlife use, and riparian restoration. Environmental Management, 35(3), 231-246.

Sher, A. \& M.F. Quigley (Eds.) (2013). Tamarix: A Case Study of Ecological Change in the American West. Oxford: Oxford University Press.

Stohlgren, T., Schnase, J., Morisette, J., Most, N., Sheffner, E., Hutchinson, C., Drake, S., Van Leeuwen, W., \& Kaupp, V. (2005). Invasive Species Forecasting System: A Decision Support Tool for the U.S. Geological Survey: FY 2005 Benchmarking Report (1.6).

Talbert, C. \& Talbert M. (2012). User documentation for the Software for Assisted Habitat Modeling (SAHM) package in VisTrails. Fort Collins, CO: USGS Fort Collins Science Center. 69 p. Accessed May 29, 2015. Retrieved from: https:/www.fort.usgs.gov/products/23399/.

Tucker, C. J. (1979). Red and photographic infrared linear combinations for monitoring vegetation. Remote sensing of Environment, 8(2), 127-150.

Wang, L., \& Qu, J. J. (2007). NMDI: A normalized multi-band drought index for monitoring soil and vegetation moisture with satellite remote sensing.Geophysical Research Letters, 34(20).

Wilson, E. H., \& Sader, S. A. (2002). Detection of forest harvest type using multiple dates of Landsat TM imagery. Remote Sensing of Environment, 80(3), 385-396.

Wolf, A. (2010, December). Using WorldView 2 Vis-NIR MSI imagery to support land mapping and feature extraction using normalized difference index ratios. In Proc. SPIE (Vol. 8390).

$\mathrm{Xu}, \mathrm{H}$. (2006). Modification of normalised difference water index (NDWI) to enhance open water features in remotely sensed imagery. International Journal of Remote Sensing, 27(14), 3025-3033.

York, P., Evangelista, P., Kumar, S., Graham, J., Flather, C., \& Stohlgren, T. (2011). A habitat overlap analysis derived from maxent for tamarisk and the south-western willow flycatcher. Frontiers of Earth Science, 5(2), 120-129. 


\section{Appendix}

Appendix 1. Spectral indices considered for model development and their citation in the literature

\begin{tabular}{ll}
\hline \multicolumn{1}{c}{ Spectral Index } & \multicolumn{1}{c}{ Citation } \\
\hline \hline Normalized Difference Vegetation Index (NDVI) & Tucker 1979 \\
Soil Adjusted Vegetation Index (SAVI) & Huete 1988 \\
Enhanced Vegetation Index (EVI) & Hassan et al. 2007 \\
Normalized Multi-band Drought Index (NMDI) & Wang 2007 \\
Normalized Moisture Index (NDMI) & Wilson and Sader 2002 \\
Normalized Difference Water Index (NDWI) & McFeeters 1996 \\
Modified Normalized Difference Water Index (MNDWI) & Xu 2006 \\
Tasseled Cap Brightness, Greenness, Wetness & Baig et al. 2014 \\
Thermal Infrared Band 1 - Brightness Temperature & ENVI 5.1/USGS \\
\hline
\end{tabular}


ISSN 2331-1258 (online)

http://dx.doi.org/10.3133/ofr20161065 